INTERNATIONAL SERIES OF MONOGRAPHS ON

PURE AND APPLIED BIOLOGY

MODERN TRENDS IN

PHYSIOLOGICAL SCIENCES 



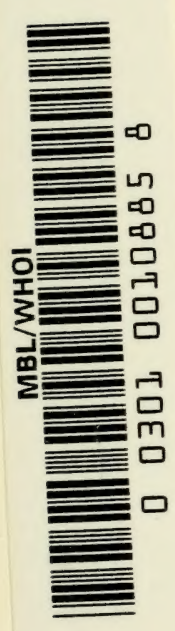



INTERNATIONAL SERIES OF MONOGRAPHS ON PURE AND APPLIED BIOLOGY

Division: MODERN TRENDS IN PHYSIOLOGICAL SCIENCES

General Editors: P. Alexander and Z. M. Bace

\author{
VOLUMe 6 \\ ASPECTS OF \\ THE ORIGIN OF LIFE
}


OTHER TITLES IN THE PURE AND APPLIED BIOLOGY SERIES

Zoology Division

Vol. I. RAVEN-An Outline of Developmental Physiology

Vol. 2. RAVEN-Morphogenesis: The Analysis of Molluscan Development

Vol. 3. SAVORY-Instinctive Living

Vol. 4. KERKUT-Implications of Evolution

Vol. 5. JENKIN-Animal Hormones

Vol. 6. FLORKIN (Ed.)-Aspects of the Origin of Life

BIOCHEMISTRY Division

Vol. I. PITT-RIVERS and TATA-The Thyroid Hormones

Botany Division

Vol. I. BOR-Grasses of Burma, Ceylon, India and Pakistan

Vol. 2. TURRILL (Ed) - Vistas in Botany

Vol. 3. SCHULTES-Orchids of Trinidad and Tobago

Modern Trends in Physiological Sciences Division

Vol. I. FLORKIN-Unity and Diversity in Biochemistry

Vol. 2. BRACHET - The Biochemistry of Development

Vol. 3. GEREBTZOFF-Cholinesterases

Vol. 4. BROUHA-Physiology in Industry 


\title{
ASPECTS OF
}

\section{THE ORIGIN OF LIFE}

\author{
EDITED BY \\ M. FLORKIN \\ PRESIDENT OF THE \\ INTERNATIONAL UNION OF \\ BIOCHEMISTRY
}

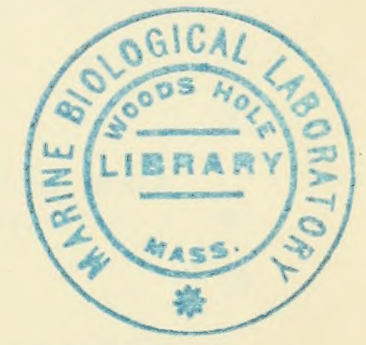

PERGAMON PRESS

NEW YORK · OXFORD - LONDON - PARIS

1960 
PERGAMON PRESS INC.

122 East 55th Street, New York 22, N.Y.

P.O. Box No. 47715, Los Angeles, California

PERGAMON PRESS LTD.

Headington Hill Hall, Oxford 4 E 5 Fitzroy Square, London $W .1$

PERGAMON PRESS, S.A.R.L.

24 Rue des Écoles, Paris Ve

PERGAMON PRESS G.M.b.H.

Kaiserstrasse 75, Frankfurt am Main

\author{
(C) $\mathbf{1 9 6 0}$ \\ Pergamon Press Ltd.
}

The articles here published have been selected from the Proceedings of the Symposium on the Origin of Life on the Earth held in Moscow and sponsored by the U.S.S.R. Academy of Sciences, edited by A. I. Oparin, A. G. Pasynskii, A. E. Braunshtein and T. E. Pavlovskaya, published as Vol. I in the International Union of Biochemistry Symposium Series, Pergamon Press, 1959.

Library of Congress Card No. 60-13823

PRINTED IN GREAT BRITAIN BY ADLARD AND SON LIMITED LONDON AND DORKING 


\section{Contents}

Introduction ... by MARCEL FLORKIN

Some considerations on the primaeval state of the Earth ... by v. G. FESENKOV

Primitive planetary atmospheres and the origin of life ... by H. C. UREY 8

The origin of the biosphere ... by A. P. VINOGRADOV 15

The problem of stages in biopoesis ... by J. D. BERNAL

The formation of the Earth from cold material and the problem of the formation of the simplest organic substances ... by B. Y. LEVIN

Chemical diversity and the origins of life ... by N. W. PIRIE

The geological conditions for the appearance of life on the Earth, and the problems of petroleum genesis ... by P. N. KROPOTKIN

The role of dissymetry in the origin of living material ... by A. P. TERENT'EV and E. I. KLABUNOVSKII

Formation of organic compounds on the primitive Earth ... by s. L. MILLER

The original formation of amino acids under the action of ultraviolet rays and electric discharges ... by T. E. PAVLOVSKAYA and A. G. PAYSINSKII

Absolute asymmetric synthesis and asymmetric catalysis ... by E. I. KLABUNOVSKIǏ

On the origin of the fore-protein ... by s. AKABORI

Evolution of enzymes and the photosynthetic apparatus ... by M. CALVIN

The nature of the forces operating in the process of the duplication of molecules in living organisms ... by L. PAULING

The occurrence of amino acids in nature ... by R. L. M. SYNGE

A chemical theory of spontaneous generation ... by s. w. Fox

The scale of structural units in biopoesis ... by J. D. BERNAL

Biochemical processes in the simplest structures ... by A. I. OPARIN

Protein complexes as biochemically active systems ... by G. A. DEBORIN

The relation between primitive and present-day photobiological processes ... by C. REID 



\section{Introduction}

WHEN, during the nineteenth century, men of science discussed the origin of life, as they have done extensively, they were concerned with the supposed formation of infusoria and other micro-organisms from particles of organic matter. In the frame of the current philosophy of the age, it was common creed to accept the occurrence of such an event, as, in the current philosophy of the sixteenth century, it appeared obvious that the animal spirits of a dirty shirt could produce a litter of mice. It appeared as such due to the fact that the complexities of the embryogeny of a mouse were still unknown. This was no longer the case during the nineteenth century when such notions were considered as being pure fallacy. As their extreme biochemical complexities were still unknown, nothing prevented believing that simple micro-organisms such as bacteria could not be formed by the simple aggregation of particles or organic matter, and furthermore, this was proved by experiments. Bad experiments, as was shown by Theodor Schwann and by Louis Pasteur. Life on our earth is made of cells, modified cells of products of cell activity. Cell structure, biochemistry and physiology are today the focus of attention of biologists and the main subject of their research. We have learned that cells differentiate in the course of the development of a multicellular organism. We recognize, by the comparative study of cells and of organisms, that there are primitive aspects and more differentiated aspects of cell structure and of cell chemistry. Comparative biochemistry brings to light a number of evolutionary aspects of the biochemistry of cells and organisms. This knowledge leads us to believe that if we could follow the course of time backwards, we would find primitive cells, and before them, some kinds of cell precursors. As we know that the continuity of life and the transmission of characters, as well as the possibility for these characters to change, is insured by a code of hereditary transmission of a chemical message, we are inclined to believe that this code, represented by macromolecules of nucleic acids, is a very ancient feature of life. But to imagine in what form of cell or precellular structure it first appeared, or even if it has first appeared in the free stage, belongs to the realm of mere speculation.

To stay on firmer ground, we can start from the other end of the chain of events, i.e. go from molecules to primitive cells. Until Oparin published his epoch-making booklet in 1923, it was a common belief that organic substances were the products of living organisms. With the notion of a panglobal soup made of a solution of organic and inorganic substances, the problem of the origin of life brought a new and powerful appeal to biological thought and experimentation. Whether a large number of metabolic systems and the corresponding enzymes became widely distributed in a metabolizing soup, or if these inventions took place locally in discrete organisms, remain a field for speculation. With more probable data on the situation reigning on the primitive earth, it again 
becomes possible to experiment along different possible lines of prebiological and chemical evolution.

The series of fascinating essays gathered in this book provide a wealth of ideas, data, and experiments on which to build a number of possible schemes leading to organic molecules and from these to discrete organisms, from which the first cells may have derived later.

The chemical evolution of the surface of the primitive earth, and particularly its organic chemical aspects, is clearly the main point of interest in our contemporary attitude towards the problem of the origination of terrestrial life. The interest in chemical evolution is made more pregnant by the possibility of knowing before long how chemical evolution is at present leading its course of events in media not fundamentally different from the conditions which probably reigned on the earth at periods anterior to the dawn of life. If mankind is cautious enough not to modify the surface of the planets of the solar system by thoughtless explosions or contaminations of any kind, a new field of dynamic organic chemistry may be opened soon, and we may be able to study unsuspected metabolic cycles, the nature of which may bring in fresh ideas for the reconstitution of the possible ways of the chemical evolution of the Earth's surface before the origination of life in a reducing atmosphere. The hope of finding some forms of primitive life in these sterile worlds, deprived of oxygen, appears remote, but in our present ignorance great surprises may emerge from the study of samples of the surface of the planets, soon to be taken off by man. We are entering an age in which the study of chemical evolution and even of the origin of life may take the form not only of speculations based on induction and experimentation, but also of a science based on actual observation.

MARCEL FLORKIN 


\title{
Some Considerations on the Primaeval State of the Earth
}

\author{
V. G. FESENKOV
}

Institute of Astrophysics, the Academy of Sciences Kazakh SSR, Alma-Ata, U.S.S.R.

THE SOLUTron of many problems of geology, geochemistry, biology, and particularly the basic problem of the origin and development of life, requires a knowledge of the conditions that characterized the physical state of the Earth during the earliest periods following its formation. To describe these conditions in the light of a definite cosmogonic hypothesis would be misleading, since the problem of cosmogony cannot be as yet considered as fully solved. On the contrary, the solution of this problem should follow from a consideration of all relevant facts that are capable of receiving, as far as possible, a unique interpretation.

From a consideration of such facts one may draw certain conclusions relating to the process of formation and development of the Earth.

The first conclusion is that during its formation the Earth lost a considerable part of its initial mass. It may be assumed that the Earth of to-day is but a nucleus of the primary protoplanetary condensation that consists of the heavier elements and their oxygen compounds [I]. This conclusion is supported by the fact that the elements most frequently met with in the Universe, in the stars and in the sun, and which for this reason should also be abundant in the primaeval medium that gave birth to the planets, are nearly totally absent in the presentday atmosphere of the Earth. Conspicuous is the negligible quantity of the inert gases (including xenon and crypton) in our atmosphere, whereas their abundance in the universe is many times greater [2].

The question may arise as to the process that could promote the escape of the primordial atmosphere of the Earth, including even such heavy gases as krypton and xenon. It is quite evident that if each gas escaped individually in accordance with its atomic weight, these very abundant heavy gases would have remained on the Earth in practically their original abundance. It must therefore be concluded that this process of dissipation is determined chiefly by the most abundant and the lightest element, namely by hydrogen which constituted the greater part of the primitive Earth's mass. As hydrogen escapes into space it takes with it all the insignificant impurities, excessively high temperatures not being required for this purpose. If we assume that the initial abundance of hydrogen corresponded, to a certain extent, to its abundance in the Universe, the inevitable conclusion is that there remains from the primitive Earth only a small percentage of its original mass. A further proof of the primitive Earth's losing a considerable portion of its mass is the very fact of the existence of the Moon. There can be no doubt that the Earth-Moon system occupies a special place in our solar 
system. At present, the rotational moment of the Moon in its orbital motion is nearly $75 \%$ of the total rotational moment of the whole system. This indicates the importance of the role of the Moon in the dynamics of the Earth-Moon system. Nothing resembling this can be found in the systems of the other planets. For example, if we calculate the total rotational moment of Jupiter from the internal distribution of densities and the known period of rotation, and if we compare it with the sum of rotational moments of all of Jupiter's satellites, we shall find that the latter does not exceed $1.5 \%$ of that of the planet. The very great importance of the orbital rotational moment of the Moon in the case of the Earth is cogent proof that the Earth, in contrast to the other planets of the solar system, originated as a double planet and therefore the process of its formation should be very similar to the process of formation of double stars in general.

A binary star is formed from two closely situated centres of condensation in one and the same primary gaseous-dust nebula whose total rotational moment, as is usually the case, is too large for a single stable nucleus to develop. For this reason the rotational moment must necessarily be distributed between two, or, in some cases, among even a larger number of individual condensations.

A similar assumption should be made with respect to the Earth. Thus, the presence of our satellite signifies that by coming into existence the Moon took upon itself the greater part of the total rotational moment of the whole primary system, thus giving stability to the Earth. Without this the protoplanet of the Earth would never have been able to solidify as a single body.

However, the subsequent evolution of the Earth-Moon system evidently proceeded in the direction of a sharp reduction of its reserve of rotational moment, since at present it is already possible to add to the Earth the total rotational moment connected with the orbital movement of the Moon without disturbing the stability of the Earth. Indeed, the rotation period of the Earth would then reach 4.4 hours whereas approximately $I \cdot 3$ hours is sufficient to disrupt the stability. However, a decrease in the rotational moment can take place only in the case of a decrease in the mass.

To sum up, the conclusion may be drawn on the basis of the above-considered facts that during its formation the Earth lost a substantial part of the original mass. This explains the discrepancy between the Earth and the Sun in the abundance of various elements in them despite the fact that both bodies must have come from one and the same medium. Hence, the conclusion may be drawn that the Earth's first atmosphere was entirely lost and that the present-day gaseous shell is a secondary phenomenon.

The chief factors responsible for this loss of mass of the protoplanet are its temperature and initial mass. This immediately becomes clear if we compare the different planets. In the biggest planet, Jupiter, with its mass 318 times that of the Earth, the atmosphere is composed of $80 \%$ of hydrogen, $15 \%$ of helium and approximately $5 \%$ of the other heavy gases [3], thus bearing the closest resemblance to the Sun. In the atmosphere of Uranus, hydrogen is second to helium in abundance; in the surface layers of the Earth it occupies the eighth to the tenth place, but is still present in sufficient quantities to form oceanic waters; 
and, finally, on Mars, whose mass is one order less than that of the Earth, the content of hydrogen is so small that this planet has no water and in all probability never had any appreciable quantities of it (at the present time an equivalent layer of water on the surface and in the atmosphere of Mars is equal to approximately $0.1 \mathrm{~mm})$.

In this connection, of special interest is the phenomenon of vulcanism connected with the generation of water vapours on the Moon, a body with a mass two orders less than that of the Earth. At the present time, the mechanism of lunar formative processes is attributed by certain authors [4, 5] (Baldwin, Urey, and others) solely to external forces, namely the falling of meteorites and asteroids up to hundreds of kilometres in diameter. However, most if not all geologists and others attribute this origin to internal forces, that is tectonic and vulcanic processes [6]. Without entering into a discussion of this problem, we may at least point out that there exist on the Moon a large number of formations and peculiarities of relief which could in no way originate from falling meteorites. Such are the lunar domes noted in certain numbers by P. Puiseux [7] when compiling the lunar atlas of the Paris Observatory some fifty years ago, and more recently by Wilkens \& Moore; the table mountain Margentin; the polygonal forms on the Moon that are especially developed near the north pole (in the district of Mare Frigoris) and represent hexagons of vertical walls placed directly on the surface of the Moon; the systematic distribution of small craters, especially those located along the ridges of huge circular mountains; the existence of close chains of tiny craters situated mostly on rills or clefts in the lunar soil (the well known hill of Hyginus near the centre of the lunar discs strewn with twenty-three small craters); the tendency of the large craters to form twins; the general conformity between the structure of the craters or the circular mountains and the tectonic peculiarities of the surrounding territory, the orientation of gorges, and the like; (one of the best known of such faulted formations and one oriented parallel to the general direction of the gorges in the region of Ptolemy is a vertical wall situated to the northeast of Arzahel; ) the existence of bright haloes around some of the smaller craters, especially those situated in clefts and whose origin is apparently due to various gases escaping from the interior of the Moon. One of the most convincing proofs in favour of earlier vulcanism is the existence of orifices at the summits of the central cones of craters which were recently discovered in considerable number by Wilkens \& Moore using the 33-in. refractor of the Meudon Observatory [8].

All these peculiarities of lunar forms cannot be brought into agreement with the metcorite hypothesis but are in natural accordance with the conception of their tectonic origin.

On 3 November 1958 N. A. Kozyrev, of the Pulkowa Observatory, U.S.S.R., observed the eruption on the Moon produced by the central mountain of Alphonsus nearly in the centre of the lunar disc. This eruption was followed by emission of carbon compounds registered spectroscopically.

If it is recognized (and this follows from the above-mentioned facts) that the Moon is capable of exhibiting vulcanism and tectonic phenomena of internal forces associated with the escaping of gases, including water vapours, which 
must have been widespread chiefly in the distant past, it is all the more reasonable that similar phenomena should have occurred on planets with a greater mass, such as Mars and the Earth. As observations show [9], an atmosphere on the Moon should be non-existent due to the very small force of gravity on its surface and to the comparatively high temperature, which exceeds $100{ }^{\circ} \mathrm{C}$ at the centre of the lunar disc during full Moon. On Mars water vapour may easily escape into interplanetary space at a temperature of approximately $200^{\circ} \mathrm{C}$ (according to Spitzer). This temperature might easily have been attained in the past during the first stages of the existence of this planet. On the Earth, water vapour escaped only during the period of dissipation of the mass of the original protoplanet, but later eruptions from the interior were totally retained because of various tectonic processes. The production of water vapour presupposes a considerable temperature in the interior of the Earth, and this requires an explanation.

In this connection, it is essential to dwell on the problem of the early thermal history of the Earth. Speaking generally, one should presuppose the existence of four different sources of heat during the formation of our planet: the conversion of potential energy into kinetic energy, in other words, the release of the energy of condensation as is the case in the gravitational compression of any gaseous-dust nebula; the origin of different mineral compounds, for example olivine and others, that is the transition of the chemically comparatively simple protoplanetary medium into complex compounds, all of which take place chiefly in conditions where oxygen is insufficient. These geochemical reactions should, in the main, also be of the exothermic type. Then there develop processes of a more protracted character, those that take place throughout the whole existence of the planet, namely radioactive heating that depends essentially on the distribution of radioactive substances within the mass of the Earth, and the redistribution of the internal masses of the planet according to molecular weight. Both processes depend on the intensity of the first two. If even during the very first stage of its existence the planetary mass reaches a sufficiently high temperature, then, owing to the convective currents that arise, radioactive substances are quite rapidly transported to the surface layers, in which case radioactive heating is confined essentially to these surface layers and does not in general attain any great magnitude. If, however, the planetary mass remained in the cold state from the very beginning, the distribution of radioactivity may be considered as being even throughout its whole mass in the course of the greater part of all past history, in which case radioactive heating might be very considerable though not capable of causing the Earth to become liquid. The detailed calculations of the radioactive heating were made by E. A. Lyubimova, J. A. Jacobs, and others for different models of the Earth [9, IO, II]. To avoid these uncertainties in our discussion of the early thermal history of the Earth, we must consider the most indicative facts as a whole. As may be supposed, of greatest importance in this respect are the data of seismology and terrestrial magnetism, according to which the central core of the Earth (at least in its external part) is in a liquid state and does not transmit transverse waves. Consequently, the temperature of the central parts of the Earth should be at least several thousand degrees. The 
sharp jump in density when passing to the crust indicates apparently that the core of the Earth consists chiefly of iron and nickel [II].

A fact pointing to the thermal state of the surface layers of the Earth is that the continents are composed chiefly of granite, which consists of three basic minerals: quartz, felspar and mica. It is generally recognized that granite must have formed through the cooling of hot magma at a temperature not less than $1000^{\circ} \mathrm{C}$. The continental granite massif has been growing in volume and area since the very earliest stages of the development of the Earth [12].

The dynamics of continent formation is far from clear, but in general it should have consisted in the escape of huge quantities of molten silicate from the interior of the Earth, which was accompanied by the development of platforms, a gradual diminution of geosynclines, which was a certain irreversible and gradually relaxing process.

This process was also accompanied by a gradual decrease in the intensity of volcanic activity. A. P. Pavlov [13] has given us a very vivid picture of how enormous basaltic fields occupying many millions of square kilometres on the Yenisei, the Tungusk, in Greenland, India, the United States and in other parts of the world were formed in the past as a result of volcanic activity.

At the present time, the only active zones of vulcanism left are those in the Kamchatka region and the Kurile islands, and also in the Mediterranean. This process of the extrusion of masses of silicate to the surface, the process of formation of a sialitic Earth crust through gradual differentiation, was inevitably accompanied by the production of water vapour that fed the oceans. And this is not all. It may, apparently, be considered that the water of the oceans of today must have come from the interior of the Earth chiefly during the cooling period there. According to Grayton [14] the water vapour content in erupted magma of volcanoes may reach $10 \%$ in weight. Moreover, Geranson has shown that the granite magma under pressures that correspond to a depth of 10 to $20 \mathrm{~km}$ is capable of retaining huge quantities of water in solution that make up as much as $10 \%$ of the total weight. The ability to hold water falls with the pressure, and the water escapes in the form of vapour. Consequently, any extrusion of sialitic material to the surface must inevitably lead to the escape of enormous quantities of water that remains on the quickly cooling Earth and fills the depression between the slightly raised continents. If we consider for a moment that the average depth of the oceans spread evenly over the whole surface of the Earth amounts to approximately $3-4 \mathrm{~km}$, then all that is required for an explanation of the production of this quantity of water from the interior of the Earth is an analogous extrusion of material within the limits of a thin 20-30-km layer, which exactly corresponds to the external thickness of the Earth's crust.

All these geological facts are in good agreement with the theory of $\mathrm{H}$. Jeffreys [15] who postulates that the Earth was originally in a gaseous state, but that in roughly 5000 years it could be reduced to a liquid state due to convection currents. And the total energy of condensation to the present radius would be I0,000 $\mathrm{cal} / \mathrm{g}$. Later, when our planet passed to the solid state, the cooling time was considerably extended until the temperature of the surface at last 
reached $300^{\circ}$ from absolute zero. According to Goldschmidt [i6], the atoms of uranium and thorium cannot (due to their excessive volume) enter into any silicate lattice in the process of crystallization. Therefore, when the deeper parts of the Earth began to solidify, these atoms must have gradually been pushed to the outside and enriched the external layers. In the same way, Holmes [17] assumed that volatile material, extruded from the Earth's interior during cooling, also takes with it radioactive matter. Hence it follows that the radioactive layer during the very first stages of the solidified Earth was extremely thin, and the degree of radioactivity fell sharply with the depth. Thus, radioactivity could never have played a marked role in the thermal history of the Earth.

The formation of the Earth as a heated cosmic body leads inevitably to the loss of enormous quantities of the original gascous elements, and all the more so of the entire primordial atmosphere.

The water of the oceans of to-day must have escaped from the Earth's interior during its cooling stage. The same must be said of the atmosphere which was also formed of gases that accompanied tectonic and volcanic processes. To a great extent, this was water vapour, carbon dioxide, methane, sulphides and also nitrogen, which even to-day is found escaping in certain localitics.

It is known that oxygen in the free state cannot escape from the interior of the Earth. However, a certain quantity of this gas can form gradually by decomposition of water vapour under the action of electric discharges and in the upper layers of the atmosphere due to hard wavelengths of solar radiation. In the lower layers, this gas can exist only in negligible quantities.

The juvenile water that made up the primaeval waters of the oceans was poorly provided with various mineral salts. Its enrichment with the most diverse elements took place gradually as a result of an irreversible process, an example of which is the water cycle in nature, the constant erosion of the continents by rivers which carry their sediment back to the sea. To a certain extent, a similar process of erosion might take place also at the bottom of the ocean due to the peculiar interaction with the continents, all this leading to the formation of deep, submarine canyons in places that never reached sea level.

Resulting from the processes of this so-called geological preparation there was gradually formed a water medium enriched with all possible elements that were in a state of easy migration with respect to each other. A medium of this kind can promote the generation of life. Without such a medium organic life could not have arisen.

Thus, in order that life should appear there must be not only a sufficient amount of solar radiation, a water medium, but also an abundance of all possible elements capable of forming all possible compounds. An essential condition for this is that the surface of the planet must be only partially covered by continents and partially by oceans and that here the waters of the oceans might in the course of thousands of millions of years enrich themselves with the products of erosion of the continents. The medium required for the beginning of organic life could not have formed on a planet like Mars which has never had any open basins of water. 


\section{REFERENCES}

I. G. KUIPER, F. R. astr. Soc. Can., 50, 158, 1956.

2. H. BRown, Rare gases and the formation of the Earth's atmosphere; In The Atmospheres of the Earth and Planets (Ed. by G. KuIPER). Univ. Chicago Press, 1947.

3. V. G. Fesenkov \& A. G. Masevich, Astr. Zh. S.S.S.R., 28, 317, I95I.

4. K. B. BaLDWIN, The Face of the Moon. Chicago, I949.

5. H. UreY, The Planets, their Origin and Development. Yale Univ. Press, New Haven, 1954.

6. J. SPURR, Geology Applied to Selenology. Science Press, Lancaster, 1945.

7. P. Puiseux, La terre et la lune. Gauthier-Villars, Paris, I908.

8. H. Wilkens \& P. MOORE, The Moon. London, 1955.

9. J. A. JACOBS \& D. W. Allan, Nature, Lond., I77, I55, 1956.

Iо. E. A. Lyubimova, Dokl. Akad. Nauk S.S.S.R., 107, 55, I956.

E. A. Lyubimova, Izv. Akad. Nauk S.S.S.R., Ser. Geophys., No. 5, 416, 1955.

I 1. E. ÖPIK, Irish astr. $\mathcal{F} .3$, No. 7, I955.

12. V. A. Obruchev, The Principles of Geology. Akad. Nauk S.S.S.R., Moscow, 1956. O. Fr. Tuttle, Sci. Amer., 192, 77, 1955.

P. N. KRopotkin, Priroda, Leningr., No. 4, 3I, 1956.

13. A. P. Pavlov, Volcanoes, Earthquakes, Seas, Rivers. Moscow, I948.

I4. L. K. Grayton, Conjectures regarding volcanic heat. Amer. F. Sci., 243-A, I945.

15. H. Jefrereys, The Earth. Cambridge Univ. Press, 1952.

I6. V. GoldSCHMidx, Naturwissenschaften, 18, 999, I930.

I7. E. Holmes, Geol. Mag., 2, 322, I915. 


\title{
Primitive Planetary Atmospheres and the Origin of Life
}

\author{
HAROLD C. UREY \\ University of Chicago, Urbana, Illinois
}

HALDANE [I] pointed out that life probably originated under anaerobic conditions. He argued that the fermentative metabolic processes of living organisms of widely different structure are very similar while the oxidative reactions are very different, thus indicating that the anaerobic metabolism is the most primitive. He suggested that the source of energy for the metabolism was metastable molecules produced by ultraviolet light from the sun. Oparin [2] in an interesting book comes to very similar conclusions. He has discussed in some detail the possible ways by which organic substances of inorganic origin may combine to produce the most primitive organisms. These arguments as well as others by Pirie [3] and Bernal [4] seem to me to be more conclusive evidence for the primitive conditions on the Earth than any that can be drawn from geochemical and cosmochemical studies. However, studies of the latter kind confirm the biochemical conclusions.

The most remarkable feature of the Earth's atmosphere is its content of elementary oxygen, and it is the only planet on which free oxygen has been detected. It has been recognized, ever since Jeans derived formulae for the escape of gases from atmospheres, that hydrogen would escape more readily than other gases and that this must result in an increased state of oxidation of the atmosphere and perhaps in the presence of free oxygen $[5,6]$. To-day we have much more information in regard to the Earth's atmosphere than previously and hence are in a better position to discuss its probable history. From the ages of the meteorites as determined from the lead isotopic abundances and from the ${ }^{87} \mathrm{Rb}-{ }^{87} \mathrm{Sr}$ and ${ }^{40} \mathrm{~K}-40 \mathrm{~A}$ dating methods, we know that some very involved physical and chemical processes took place $4.5 \times 10^{9}$ years ago. Presumably this occurred at the time the solar system originated and we can take this as the age of the system. Also, we now know more about the temperature distribution and convection in the terrestrial atmosphere and hence we are able to supplement the theory of Jeans for the escape of atmospheres. These studies make possible a better estimate of the history of planetary atmospheres generally.

\section{HISTORY OF THE EARTH'S ATMOSPHERE}

We do not know the temperature at which the Earth's surface was formed, but it can be stated firmly that the only feasible source of heat for producing a high-temperature primitive earth was its own gravitational energy of accumulation [7]. If it accumulated so rapidly that this energy could not be radiated into space, it could have originated in a melted condition. However, in view of 
our present great difficulty in understanding how a planet could accumulate without retaining certain gaseous constituents, e.g. krypton and xenon, it seems most likely that the accumulation process required tens or hundreds of millions of years and hence that the general temperature of the earth during its formation was low. (The writer no longer accepts Kuiper's proto-planetary model, at least for the terrestrial planets [8], and in fact always had great difficulty in fitting the great amount of chemical evidence into that theory.) The arrival of objects containing metallic iron and water on the earth's surface would result in the production of hydrogen gas, from the reaction $\mathrm{Fe}+\mathrm{H}_{2} \mathrm{O}=\mathrm{FeO}+\mathrm{H}_{2}$, which is strongly displaced to the right at high temperatures. At low temperatures reactions to form methane from carbon and hydrogen, and ammonia from nitrogen and hydrogen should occur and these substances should have been present temporarily at least*.

Thus a reducing atmosphere must surely have existed for a short period of time at least.

The escape of gases from planetary atmospheres is determined at the escape layer by the formula of Jeans,

$$
L_{i}=M_{c} c_{i} \sqrt{\frac{R T_{c}}{2 \pi \mu_{i}}}\left(\mathrm{I}+x_{i}\right) \mathrm{e}^{-x_{i}}, x_{i}=\frac{G M \mu_{i}}{R T_{c} a_{c}}
$$

In this formula, $L_{i}$ is the rate of escape of molecules of the $i$ th kind in molecules per sec and $\mathrm{cm}^{2}, M_{c}$ is the number of molecules per $\mathrm{cm}^{3}$ at the escape layer, $c_{i}$ is the fraction of these molecules at the escape layer which are of the $i$ th kind, $\mu_{i}$ is the molecular weight of the escaping molecule, $T_{c}$ is the temperature at the escape layer, $a_{c}$ is the radius of the planet at the escape layer, $M$ is the mass of the planet, and $G$ the gravitational constant. The quantities in this formula can be estimated approximately with the exception of $c_{i}$ and this depends particularly on the mixing in the atmosphere. Convection must stop at a high level where diffusional separation becomes high. This level is estimated to be at about $160 \mathrm{~km}$ above the Earth's surface and the rate of escape may be limited by diffusion to the escape layer which for the Earth is some $300-500 \mathrm{~km}$ above the Earth's surface. Also, condensible substances such as water will be kept below the tropopause at $8-17 \mathrm{~km}$ above the Earth's surface. Finally, condensible substances may be decomposed by ultraviolet light into noncondensible substances which can then escape through a low temperature layer to the higher atmosphere. In a recent paper, the writer [Io] has reviewed this problem for the Earth, Venus and Mars. The escape of planetary atmospheres when these factors are considered is a very complicated problem. The results will be briefly summarized here.

At the present time escape of hydrogen from the Earth is limited by condensation of water at about $187^{\circ} \mathrm{K}$ at the tropical tropopause and by diffusion from the $160 \mathrm{~km}$ level to the escape layer, the temperature of which must be high, i.e. some $2000-4000{ }^{\circ} \mathrm{K}$. The calculated rate of escape is $10^{7}$ atoms $/ \mathrm{cm}^{2} / \mathrm{sec}$, though this is uncertain by an order of magnitude probably. The escape rate

* When these arguments were advanced some years ago [9] the brilliant work of Miller had not been done and hence modifications of the discussion are necessary. 
corresponds to the decomposition of $20 \mathrm{~g}$ of water per $\mathrm{cm}^{2}$ during $4.5 \times 10^{9}$ years. This would not account for the elementary oxygen of the Earth's atmosphere, but the calculated loss may be in error sufficiently to make agreement possible, as has often been done in the past. However, hydrogen, methane, ammonia, carbon monoxide and hydrogen sulphide escape from the interior of the Earth in unknown amounts. These are oxidized and this can occur without decrease in atmospheric oxygen only by the escape of hydrogen from the Earth. Also, unknown amounts of ferrous iron of the Earth's crust have been oxidized to ferric iron. In order to have oxidized the carbon, sulphur, nitrogen and ferrous iron observed in the crust of the Earth, water to the extent of about 10\% of the oceans must have been decomposed and the hydrogen lost from the Earth. We do not know how extensive the loss of hydrogen has been, but it seems most likely that the rate of loss has been much greater for much of geologic time than the calculated rate given above.

For the purposes of the calculation of the rate of loss of hydrogen mentioned above, the concentration of hydrogen as water or molecular hydrogen above the tropopause was taken as $2 \mathrm{ppm}$. Light of the Schumann region cannot penetrate to the tropopause and below because molecular oxygen absorbs in this region. In the absence of molecular oxygen only carbon dioxide will absorb in this region and this gas is removed in a high degree from the Earth's atmosphere by reaction with silicate rocks ([9], p. I48 ff.). Hence, at the present time, water below the tropopause is not decomposed photochemically and hence excess amounts of hydrogen do not escape above the tropopause and thus to the escape layer and away from the Earth. However, before oxygen appeared in the atmosphere this must have occurred and hence far more hydrogen escaped to the high atmosphere and the rate of escape from the Earth was far greater than it is now. Thus there are good reasons to suppose that the rate of escape during the early history of the Earth was very large.

We outline the history of the atmosphere approximately as follows. Molecular hydrogen escaped so rapidly that this occurred essentially during the period of accumulation of the Earth. Methane and ammonia were decomposed rapidly, but carbon compounds soluble in water were formed which dissolved rapidly in the oceans. Some volatile hydrogen compounds, e.g. $\mathrm{CH}_{4}, \mathrm{C}_{2} \mathrm{H}_{2}$ etc., remained in the atmosphere and were decomposed by light and the hydrogen escaped. If these were absent, water below the tropopause was decomposed and the hydrogen escaped. When carbon dioxide appeared, it reacted with the silicate rocks to form limestone. Only when oxygen appeared did the rapid escape of hydrogen cease due to the absorption of the Schumann region by molecular oxygen and the present low rate of escape begin. There is no difficulty in understanding some very large rate of escape in the past and a very small rate at the present time.

When did free oxygen first appear in the Earth's atmosphere? An attempt was made to answer this question some years ago [9]. Unfortunately, no additional evidence has come to light during the past years. (I) Thode, MacNamara \& Fleming [II] have observed that ${ }^{34} \mathrm{~S}$ is concentrated in sulphates relative to the sulphides and they present evidence that this began some $10^{9}$ years ago. This may mark the time at which free oxygen first appeared in the atmosphere. 
(2) The enormous iron deposit of the pre-Cambrian some $2 \times 10^{9}$ years ago may mark the time of transition from a reducing to an oxidizing atmosphere, as MacGregor [12] suggested.

Attempts have been made in the writer's laboratories to find primitive sources of hydrogen and to determine the relative abundance of deuterium in such hydrogen. It was thought that fractionation of the hydrogen isotopes during escape would occur and hence that primitive hydrogen would have less deuterium than the hydrogen of the present oceans and that the difference in deuterium content would give an indication of the total loss of hydrogen. No conclusive decision in regard to this question has been deduced.

\section{THE ATMOSPHERE OF VENUS}

The atmosphere of Venus contains large amounts of carbon dioxide above the cloud layer estimated by Herzberg [I3] as some $10^{5} \mathrm{~cm}$ atmospheres. No water or oxygen has been detected. Some evidence has been found by Kozyrev [14] for the presence of nitrogen and carbon monoxide.

Recent data of Pettit \& Nicholson [15] on the intensity of light reflected and absorbed in the $8-14 \mathrm{~cm}$ region indicate that the temperatures of the light and dark hemispheres are $233^{\circ} \mathrm{K}$ and $238^{\circ} \mathrm{K}$ respectively. Adel [16] has given reasons for believing that this radiation comes partly at least from higher transitions of the $\mathrm{CO}_{2}$ molecule and since this radiation is absorbed by great thicknesses of this gas, the radiation in this region probably originates fairly high in the atmosphere and not at the cloud level. From the distribution of intensity in the P \& R branches of the 7820 and $8689 \AA$ bands of $\mathrm{CO}_{2}$ Chamberlain \& Kuiper [17] estimate a temperature of $285^{\circ} \mathrm{K}$. Their measurements refer to regions well away from the mid solar point. Since these bands are partly absorbed by the atmosphere the temperature must be some average for all the gas above the clouds at the positions investigated. Mayer, Stoanaker \& McCollough [I8] have reported a temperature greater than $350^{\circ} \mathrm{K}$ by observations on the $3.15 \mathrm{~cm}$ radiation. Possibly this radiation comes from the surface of the planet, though this point is uncertain.

From the standpoint of the question as to whether life exists on the planet, the problem of the presence of water on the planet is of paramount importance for no life as we know it exists in the absence of condensed water, and though many terrestrial plants grow in very dry places and conserve their liquid water, it is very difficult to believe that life could have evolved in the absence of copious amounts of liquid water.

The planet is covered with clouds of a slightly yellow colour which show marked absorption in the blue and near ultraviolet [I4]. These clouds clear slightly and permanent surface markings have been observed by Danjon [19] and Dollfus [20]. If conditions were similar to those of the Earth, nearly all carbon dioxide would have reacted with the silicate rocks and form limestone, dolomite and sand [9]. Whipple \& Menzel [2I] suggest that the planet is completely covered by oceans so that no effective contact between rocks and carbon dioxide exists. Urey assumed that no water existed and hence erosion was ineffective in making contact between carbon dioxide and the rocks. Danjon's and Dollfus' observations 
require that some permanent surface features exist. These might be continents awash with the oceans so that erosion is not effective. Or, water clouds may exist in the high atmosphere but no liquid water is now present in its surface.

It has been suggested that the clouds are due to dust, but in this case the dust must be remarkably white. No abundant white solids are present on the Earth and no method for their production on Venus has been suggested. Moreover, the partial clearing indicates the presence of phenomena such as rain or evaporation. Dust clouds would indicate the presence of strong convection and of very small particles. Settling of dust during a short period of time would be impossible under these conditions.

Water and carbon dioxide appear to be the only stable substances likely to be present on a planet having an oxidation state such as that of Venus. Lyot [22] observed the polarization of the light from the clouds and found it to be very similar to that produced by small droplets of water. Altogether it seems most likely that the clouds are due to water, as Menzel and Whipple have argued, but it is not certain that the surface is covered with oceans.

Since Venus is nearer the sun and had a smaller mass, the escape of hydrogen from its surface should be greater than that from the Earth on the basis of Jeans' formula. However, the escape of hydrogen from the Earth is limited by condensation of water at the tropopause and the diffusion of hydrogen in the high atmosphere and not by the conditions imposed by Jeans' escape equation. We can make only very uncertain estimates in regard to detailed structure of the atmosphere of Venus. Since the planet probably rotates only once in its year, a rising current at the mid solar point probably exists similar to the rising current at the Earth's equator. For purposes of approximate calculation we estimate this temperature as $225^{\circ} \mathrm{K}$ as compared with $187^{\circ} \mathrm{K}$ for the temperature of the Earth's equatorial tropopause. If the atmosphere of Venus above this point is saturated with water at this temperature, the concentration of hydrogen above the tropopause will be about 145 times as great as that above the Earth and, other conditions being similar, the rate of loss of hydrogen will be about $\mathrm{I} .45 \times 10^{9}$ atoms $/ \mathrm{sec} / \mathrm{cm}^{2}$. This is equivalent to $3000 \mathrm{~g}$ of water $/ \mathrm{cm}^{2}$ during $4.5 \times 10^{9}$ years. This would be sufficient to oxidize $1000 \mathrm{~g}$ of $\mathrm{carbon} / \mathrm{cm}^{2}$ from the zero oxidation state to carbon dioxide. This estimate has no great certainty at all.

The decomposition of water below the tropopause cannot occur because of the absorption of light in the Schumann region by carbon dioxide. This absorption will be substantially complete if $100 \mathrm{~cm}$ atmospheres of carbon dioxide is present above the tropopause. Thus, the history of the atmospheres of Venus and the Earth must have been different because the carbon dioxide remains in the atmosphere of Venus and not in that of the Earth. As soon as $100 \mathrm{~cm}$ atmospheres of carbon dioxide remained above the tropopause of Venus the rapid loss of hydrogen ceased, but in the case of the Earth this occurred only when some $2 \mathrm{~cm}$ atmospheres of oxygen gas appeared above its tropopause. Hence, the oxidation of the Earth has probably progressed to a much more advanced stage than did that of Venus. The general course of chemical change should have been similar to that outlined for the Earth. 
There is no certain evidence that life exists on Venus. The conditions most likely to prevent life are (I) the absence of water and (2) prohibitively high temperatures on its surface. So far as we know the conditions on that planet do not exclude its existence.

\section{THE ATMOSPHERE OF MARS}

The only constituent of the atmosphere of Mars that has been definitely identified is carbon dioxide. From Kuiper's [23] observations on the intensities of absorption of the $\mathrm{I} \cdot 6$ band in the Martian and terrestrial atmospheres, Grandjean \& Goody [24] estimate that the $\mathrm{CO}_{2}$ content of the Martian atmosphere per $\mathrm{cm}^{2}$ is thirteen times that of the earth. The remainder of the atmosphere is probably nitrogen with some admixture of radiogenic argon. The total amount of atmosphere is about $230 \mathrm{~g} / \mathrm{cm}^{2}$ according to the measurements of Dollfus [25].

Very small amounts of water are present on Mars. The polarization of the polar caps is similar to that of ice at liquid-air temperatures [25] and Kuiper [23] reports that the reflection spectrum of the caps is similar to that of frost at low temperatures. Also, the morning haze is probably water. Dunham [26] estimated the water as less than $5 \mathrm{~cm}$ atmospheres. Oxygen has not been detected.

The maximum equatorial daytime temperature is reported to be as high as $30{ }^{\circ} \mathrm{C}$ but the night temperature falls to $-70^{\circ} \mathrm{C}$. It is evident that there is no liquid water on the planet at the present time.

The escape of gases from Mars presents quite different problems from those met in the cases of the Earth and Venus, because the mass of the planet is so very much smaller. Hydrogen will escape readily from the planet if the temperature of the high atmosphere is only moderate. The interesting question is whether oxygen will escape also. A recent study by Urey [10] in which condensation at the equatorial tropopause and diffusion in the high atmosphere are considered comes to the following conclusions. If the temperature of the high atmosphere, i.e. the escape layer, is at $2000{ }^{\circ} \mathrm{K}$ oxygen will escape from the planet at appreciable rates and the net effect is the removal of water. (A temperature of $2000^{\circ} \mathrm{K}$ for the high atmosphere of Mars is not unreasonable in view of the indications that high temperatures exist in the high terrestrial atmosphere.) Water remains near the surface but carbon dioxide is transported by oxygen to the high atmosphere. Photochemical decomposition gives atomic oxygen and carbon monoxide. The latter reacts with water at low levels to produce carbon dioxide and hydrogen. Both the oxygen and hydrogen escape. On the other hand nitrogen will not be lost at catastrophic rates because it is not appreciably dissociated at the escape layer and remains mostly as molecular nitrogen, whereas oxygen is mostly dissociated. Thus very large amounts of water may have been present in the past. If life is present on Mars, such oceans must have existed in the past and only the escape of oxygen and hydrogen from the planet could have removed large quantities of water from the planet.

If large amounts of water were present on Mars in the past, a more extensive cloud layer must have been present, the albedo was higher and glaciers must have covered the poles and most of the surface. These glaciers must have trans- 
ported glacial drift toward the equator. Since much of the surface was covered with ice, carbon dioxide could not have reacted with the surface rocks and must have remained in the atmosphere. Hence, high concentrations of carbon dioxide would have reached the high atmosphere and the escape of atomic oxygen must have been very rapid. When most of the water was lost, the carbon dioxide could have reacted with the rocks and disappeared and the present situation with little water and carbon dioxide would have developed.

The evidence in regard to the development of the Martian atmosphere does not preclude the existence of life on the planet providing oxygen in large amounts has escaped from the planet. It is likely that this is the case. The general chemical development should have been similar to that occurring on the Earth during its early history.

\section{CONCLUSION}

It is probable that the three planets, Venus, Earth and Mars, all originated with substantial amounts of water on their surfaces. The estimated temperatures are such as not to be prohibitive for the evolution and maintenance of life.

This paper is a brief summary of certain parts of a much more detailed survey of the problem of atmospheres which will appear in the Handbuch der Physik, where detailed arguments for many points mentioned will be given and where more detailed references will appear.

\section{REFERENCES}

I. J. B. S. HALDANE, The Origin of Life. Rationalist Annual, 1929.

2. A. I. Oparin, The Origin of Life. Macmillan, New York, 1938.

3. N. W. PIRIE, Nerw Biol., 16, 4I, I954.

4. J. D. Bernal, The Physical Basis of Life. Routledge \& Kegan Paul, London, I95r.

5. S. ARrHeNIUS, Ann. Nat.-(u.Kultur)phil., 9, 22, 1910.

6. J. H. J. Poole, Sci. Proc. R. Dublin Soc., 22, 345, I94I.

7, 8. H. C. UREY, Chapter in Physics and Chemistry of the Earth, Vol. 2. Pergamon Press, London, 1956.

9. H. C. UreY, The Planets. Yale Univ. Press, 1952.

IO. H. C. UREY, Handbuch der Physik. In the press.

i1. H. G. Thode, J. MacNamara \& W. H. Fleming, Geochim. et cosmoch. Acta, 3, 235, 1953.

12. A. MACGREgor, S. Afr. F. Sci., 24, I55, I927.

13. G. Herzberg, Atmospheres of the Earth and Planets (Ed. by G. P. KuIPer). Univ. of Chicago Press, I949.

14. N. A. Kozyrev, Publ. Crimean astrophys. Obs., 12, I69, I954.

I5. E. Pettit \& S. B. Nicholson, Publ. astr. Soc. Pacif., 67, 293, 1955.

16. A. ADEL, Astrophys. F., 93, 397, I941.

17. J. W. Chamberlain \& G. P. KUIPER, Astrophys. F., 124, 399, 1956.

I8. C. H. Mayer, R. M. Stoanaker \& T. P. MCCollough. As reported in Sky \& Telesc., 15, 435, I956.

I9. A. Danjon, Astronomie, 57, 16r, 1943.

20. A. Dollfus, Mém. Soc. Sci. Liége, $4^{e}$ série, 18, 14I, 1956.

2. F. H. Whipple \& D. H. Menzel, Publ. astr. Soc. Pacif., 67, I6I, 955.

22. B. Lyot, Ann. Obs. Paris (Meudon), 8, 1929.

23. G. P. Kuiper, Atmospheres of the Earth and Planets (Ed. by G. P. KuIPER). Univ. of Chicago Press, 2nd ed., I952.

24. J. GrandjeAn \& R. M. Goody, Astrophys. F., I21, 548, 1955.

25. A. Dollfus, C. R. Acad. Sci., Paris, 233, 467, 1066, 1951.

26. T. Dunham, Atmospheres of the Earth and Planets (Ed. by G. P. KuIPER). Univ. of Chicago Press, I949. 


\title{
The Origin of the Biosphere
}

\author{
A. P. VINOGRADOV \\ V.I. Vernadskii Institute of Geochemistry and Analytical Chemistry of \\ the Academy of Sciences of the U.S.S.R., Moscow
}

IN REVIEWING this little-studied question, I have naturally tried to assemble the best-authenticated data. However, as there are not many such, I have tried to fill the gaps by means of scientific reasoning. I know that I shall often repeat what has been said by others before me.

As I was not able to give a direct or unequivocal answer to the question of when and under what conditions the biosphere came into being, I was obliged to follow the whole course of geochemical events on the Earth before I could convince myself that I had found out the place and time of its appearance.

The fundamental propositions concerning the biosphere were, undoubtedly, established by E. Süss. He introduced into science the concept of the biosphere as an envelope of the Earth comprised of living things. V. I. Vernadskiir, with his characteristic deep insight, showed the full significance of this envelope in regard to the geochemical processes of the Earth. He said that 'from the geological and geochemical point of view the problem is not that of the synthesis of an individual organism, but that of the emergence of the biosphere.' Nearly a hundred years earlier the happy thought occurred to Daubrée that there is a similarity between the composition of meteorites and that of the layers of the Earth. This idea was, scientifically, extremely fruitful. Bowen, Daly, Goldschmidt, Urey, O. Y. Shmidt and many others followed it up. I am in complete agreement with this point of view. Thanks to isotopic analyses of lead and other researches using radioactivity it has been possible to establish that the age of the substance of which the Earth is composed and that of the substance of meteorites is very similar, namely about $5 \times 10^{9}$ years [20].

\section{THE CRUST OF THE EARTH AT PRESENT}

The crust of the Earth as we know it consists of basaltic and granitic shells overlaid by a covering of sedimentary deposits. The crust of the Earth is classified both according to its chemical composition and to its seismic properties. The superficial part is separated from the rock of the mantle by the Mohorovičic discontinuity, which lies at a depth of about $40 \mathrm{~km}$ beneath the continents. Lower down there lie the ultrabasic rocks which are even poorer in $\mathrm{SiO}_{2}$ and richer in $\mathrm{Mg}$ and $\mathrm{Fe}$. Of these ultrabasic formations, some, the dunites, sometimes emerge on to the surface of the Earth, filling up cracks and deep fractures of its crust.

The basaltic shell covers the whole of the globe. The granitic shell covers about half the Earth's surface and is most highly developed on the continents. It is absent from the floor of the Pacific Ocean. Borings made on the Pacific atolls 
(Marshall Islands and others) have not shown any granite, the bore passing straight into a basic olivine rock. The floors of the Atlantic and Indian Oceans (except in their deep rifts) seem to have a granitic layer. The basaltic layer in the beds of the oceans seems to be at least IO-I5 km thick. There is, thus, no gradual transition between the oceanic and continental parts of the crust of the Earth.

The view was put forward a long time ago that there was a certain uniformity of composition of the shells of the Earth-the granitic, the basaltic and any other-throughout its whole extent.

Undoubtedly the structure of the crust of the Earth, its thickness and composition, give an indication of the way in which it could have been formed. The formation of the crust of the Earth is related to the differentiation of the substances of the Earth when hot.

\section{THE HEAT OF THE EARTH}

The course of the thermal balance of the Earth over $5 \times 10^{9}$ years is a very complicated problem. It is generally considered that there were two possible sources of the heat of the Earth. (I) That it was the result of the radioactive decay of $U$, Th and ${ }^{40} \mathrm{~K}$ and (2) that it was caused by the energy liberated as a result of the compression of the Earth. Even as concerns radiogenic heat there has been no agreement among scientists during recent years, mainly owing to the absence of sufficiently accurate data concerning the amounts of $\mathrm{U}, \mathrm{Th}$ and $\mathrm{K}$ in meteorites and in the depths of the Earth, and to the inaccuracy of determinations of the constants of decay. If we assume that, at the present, the mean content of radioactive substances in the silicate phase of the Earth is the same as that of the stony meteorites or chondrites, i.e. $U \sim 3 \times 10^{-6} \%$, $\mathrm{Th} \sim \mathrm{I} \times \mathrm{IO}^{-5} \%$ and $\mathrm{K} \sim 8.5 \times 10^{-2 \%} \%$, then elementary calculations will show that $5 \times 10^{9}$ years ago the radiogenic heat was enough to melt the material of which the Earth is composed. I must add, though, that the mean values assumed for the content of $\mathrm{U}$, Th and $\mathrm{K}$ in meteorites are minimum ones.*

There is even more room for doubt in the second question, namely, the extent to which the mean values of the content of radioactive elements in chondrites is a permissible means of calculating the thermal effect on the Earth. Unfortunately, however, we have no other means of doing so. Even in the case of dunites, those ultrabasic rocks of the mantle of the Earth which sometimes reach its surface, we have no reliable data as to their content of $U$, Th and $K$ or other elements, let alone mean values. I must point out that the obtaining of such data is quite a difficult task. Our comparative estimate of the contents of $\mathrm{U}, \mathrm{Th}, \mathrm{K}$ and a number of other elements in chondrites and dunites indicates that the latter contain considerably less of radioactive and some other elements than do the stony meteorites or chondrites. As we shall see later, there is, from our standpoint, an explanation for this. We can also agree that the singularly good and definite determinations of $\mathrm{K}$ in dunites carried out by Holyk and Ahrens are correct. They give extremely low values for the $\mathrm{K}$ content of dunites, namely $\sim \mathrm{I} \times 10^{-3} \%$.

* Even when analysing the same stony meteorites different workers have made estimates of $U$ content ranging between $3 \times 10^{-6}$ and $3 \times 10^{-5} \%[8,14,17]$. 
In a few words, if we assume that the crust of the Earth was formed as a slag from the mantle of the Earth and that, overall, it removed into itself from the mantle from $\frac{1}{3}$ to $\frac{1}{2}$ of all the radioactive elements of the Earth, then the analogy between the chondrites, so far as concerns their $\mathrm{U}, \mathrm{Th}$ and $\mathrm{K}$ contents, and the mean composition of the silicate phase of the Earth at least, is unshakeable at present. Nor do the data which Birch has just obtained, showing an identical heat flow per unit area of surface of the continents and ocean beds, contradict this view $[I, 3]$.

The role of gravitational heat, particularly in the earliest phases of the development of the Earth, is not clear.

However, by far the most important event in the history of the development of the thermal balance of our planet was the formation of the crust of the Earth with its alteration of the distribution of radioactive and other elements and of heat within the terrestrial globe, and its disturbance of thermal equilibrium.

\section{THE FORMATION OF THE CRUST OF THE EARTH}

The interdependence of the formation of the crust of the Earth, the hydrosphere and the atmosphere is widely accepted and would appear to be an incontestable truth.

TABLE I

Possible modes of formation of the crust of the Earth

From the hot material of the protoplanet

Differentiation of substances into phases at temperatures above $2000^{\circ} \mathrm{A}$. Loss of light gases $\left(\mathrm{H}_{2}, \mathrm{He}\right)$. Formation of the permanent nucleus of the Earth.

Formation of the thick crust of the Earth (during $10^{6}-10^{7}$ years) and possibilities of differentiation of basaltic and granitic layers.

Absence of volcanism.

Primary density of the atmosphere containing $\mathrm{H}_{2} \mathrm{O}, \mathrm{CO}_{2}, \mathrm{H}_{2}$ etc. and also inert gases in cosmic abundance.

Cooling of the surface of the Earth. Great weathering processes. Condensation of all the water to form the primary 'acid' ocean. Formation of continents. Formation of the secondary oxygencontaining atmosphere as we know it today (by precipitation of $\mathrm{CaCO}_{3}$ and by photosynthesis).
From the cold material of the Earth

Cold, solid heterogeneous material (Fe and silicates) losing chemically inert and volatile compounds.

Absence of gas pressure.

Heating with the formation of a thin, growing crust of the Earth by melting out. (Temp. $\left.1000^{\circ} \mathrm{A}\right)$.*

Growth of the Fe-nucleus of the earth.

Earthly and later underwater volcanism. Degassing. Formation of the primitive atmosphere (without inert gases), vapours, $\mathrm{H}_{2} \mathrm{O}, \mathrm{CO}_{2}, \mathrm{HF}$ etc.

Cooling of the significant surface of the Earth. Weathering. Water condensation. Formation of the ocean. Formation of continents with ancient nuclei of formations which developed as a result of plutonic activity (granitic envelope).

Contemporary, secondary, oxygen-containing atmosphere resulting from precipitation of $\mathrm{CaCO}_{3}$ and photosynthesis.

* The presence of $\mathrm{H}_{2} \mathrm{O}, \mathrm{CO}_{2}, \mathrm{HF}$ etc. may have lowered the temperature. 
The available data as to the amounts of $\mathrm{H}_{2} \mathrm{O}, \mathrm{CO}_{2}, \mathrm{HF}, \mathrm{HCl}, \mathrm{S}, \mathrm{HBO}_{3}$ and a number of other elements or compounds in the crust of the Earth, have led to the unanimous opinion that they cannot be products of rock weathering of the crust of the Earth. Some other source must be found.

If we leave aside details of minor importance we may take it that two different sets of ideas prevail as to how the crust of the Earth and oceans and the atmosphere could have been formed. The first is that the crust of the Earth was formed during the primary process of differentiation of the substance of the Earth from the hot material of the protoplanet. The second is that they were formed from the cold material of the earth by melting. They are directly opposed.

I have presented these two sets of ideas in the form of comparative tables (Table I). I do not pretend that I have been perfectly objective in constructing them. It seemed to me that, on both schemes, the formation of the crust of the Earth should show some sort of logic.

\section{THE 'HOT' THEORY OF THE FORMATION OF THE CRUST OF THE EARTH}

If we assume that the crust of the Earth was formed from hot material of the protoplanet, the phenomena which are most difficult to explain are (I) the absence from the Earth of all inert cosmic gases while $\mathrm{H}_{2} \mathrm{O}, \mathrm{CO}_{2}$ and other light, volatile chemical compounds were retained; (2) the absence of a thick crust of the Earth and (3) the appearance of intense volcanic activity, especially at the beginning of the geological history of the Earth.

On the stars and the nebular aggregations of matter in space there is a very considerable amount of the heavy inert gases $\mathrm{Ne}, \mathrm{A}, \mathrm{Kr}$, Xe. For example, the amount of $\mathrm{Ne}$ and $\mathrm{A}$ is of the same order as that of $\mathrm{O}_{2}$. In our atmosphere, on the other hand, the concentration of the light and heavy inert gases is negligibly small and constitutes some thousandths or tens of thousandths of their relative concentration in the universe as a whole. The inert gases which are found to the greatest extent in the atmosphere of the Earth, viz. ${ }^{40} \mathrm{~A}$ and ${ }^{4} \mathrm{He}$ are of secondary origin, arising from the radioactive decay of ${ }^{40} \mathrm{~K}$ and $\mathrm{U}$ and $\mathrm{Th}$ either by the spontaneous fission of $U$ and $T h$, or as a result of secondary nuclear reactions occurring on a modest scale on the Earth. The isotopic composition of these inert gases in the atmosphere of the Earth is different from the isotopic composition of the stars and cloud-like aggregates. If we do not make the assumption that these inert gases were absent from the protoplanetary cloud, then it is hard, on the basis of the 'hot' theory of the formation of the Earth, to explain why $\mathrm{N}_{2}, \mathrm{CO}_{2}, \mathrm{H}_{2} \mathrm{O}$, and other gases and vapours were retained on the surface of the Earth while the heavier $\mathrm{Ne}, \mathrm{A}, \mathrm{Kr}$ and $\mathrm{Xe}$ disappeared.

Now for a few words about the thickness of the crust of the Earth. If the siliceous material of the Earth became differentiated at a high temperature, there must have occurred a complete and far-reaching melting out heating those parts of it which fuse most difficultly. Calculations and actual fusion of the ultrabasic rocks (dunites) have shown that, in them, this process is not finished. From the relevant data it might be expected that from a substance having a composition 
similar to that of stony meteorites some amount of a lighter fraction could be melted out. In fact, the thickness of the crust of the Earth is extremely small, about $\mathbf{I} /$ roo of that of the mantle. This question, however, requires separate discussion. We will leave it on one side for the moment. Finally, we will consider the reasons for the intense volcanic activity which occurred at the beginning of the formation of the crust of the Earth. The fact that this phenomenon took place in the remote past is beyond question and is geologically well documented. It is enough to point out that, at present, there are more than 500 active volcanoes on the Earth. Naturally, the mechanism of volcanic activity cannot be considered apart from the mechanism of the differentiation of the Earth into layers. According to the views of the very high-standing specialists who have concerned themselves with this question from the point of view of the 'hot' theory, such as Chamberlin, Buddington, Bullen, Jeffreys and others, the crust of the Earth was formed during a, geologically speaking, very short period of about $10^{6}$ $10^{7}$ years. Further thermodynamic changes tended towards the loss of heat and the cooling of both the Earth as a whole and its crust. During this process the liquid magma retained the cosmic gases and vapours which had been in equilibrium with it at the temperature of solidification, and became solid. By far the greater part of the gases and vapours of volatile substances were present, according to this hypothesis, at the periphery of the planet, forming its primary heavy atmosphere which, only later, came down to the cooling surface of the Earth. Naturally, the question arises as to why, at that time, the process of formation of the solid crust of the Earth should have been accompanied by volcanic activity which continued, though less strongly, throughout the whole later history of the Earth. To explain this effect one would have to postulate, not a fall but a rise of temperature within the Earth, or else to admit that there was a secondary melting of the substance of the Earth, a fresh rise of temperature within the planet. According to the 'hot' theory, however, such a supposition is manifestly absurd.

\section{THE HYPOTHESIS OF THE MELTING OUT OF THE CRUST FROM A COLD EARTH}

The hypothesis that the crust of the Earth was formed from cold material involves difficulties of its own. The solid, cold, heterogeneous material of which the planet was formed did not retain any gases or other compounds which were not chemically bound in it. This helpful concept first occurred to H. Brown [2]. This plausible assumption provides a general answer to the question of the reasons why all the inert gases in the Earth fall far short of their cosmic abundance.

When the Earth reached a certain size there took place an adiabatic process in which its substance became heated owing to the accumulation of radiogenic heat generated by the radioactive breakdown of $\mathrm{U}$, Th and $\mathrm{K}$, and perhaps also, to some extent, owing to gravitational compression. Under the influence of this heat the substance of the Earth differentiated and the light and low-melting fractions separated outwards to the surface. It is very hard to explain this process in physico-chemical terms. I will therefore allow myself a digression which seems to be suggestive. I drew attention to the fact that the chemical composi- 
tion of stony meteorites or chondrites differs considerably from that of the ultrabasic formations within the Earth, exemplified by dunites, in having a high content of chemical elements which would appear to be easily mobile in molten silicates (Table 2).

TABLE 2

The contents of some chemical elements in chondrites, dunites, basalts and granites $(\% \%)$

\begin{tabular}{|c|c|c|c|c|c|}
\hline Element & $\begin{array}{c}\text { Silicate } \\
\text { phase of } \\
\text { meteorites }\end{array}$ & Dunites & Basalts & Granitics & $\begin{array}{c}\text { Depth } \\
\text { of core } \\
\text { drawn } \\
\text { upon } \\
(\mathrm{km})\end{array}$ \\
\hline $\mathrm{Li}$ & $2.7 \times 10^{-4}$ & $3 \times 10^{-5}$ & $I \cdot 5 \times 10^{-3}$ & $7 \times 10^{-3}$ & $\sim 600$ \\
\hline $\mathrm{Na}$ & 0.67 & 0.23 & I. 94 & $2 \cdot 77$ & $\sim 300$ \\
\hline $\mathrm{K}$ & $8.5 \times 10^{-2}$ & $\mathrm{I} \times 10^{-3}$ & 0.83 & 3.34 & $\sim_{1000}$ \\
\hline $\mathrm{Rb}$ & $8 \times 10^{-4}$ & $2 \times 10^{-4}$ & $4.5 \times 10^{-3}$ & $4 \times 10^{-2}$ & $\sim_{1000}$ \\
\hline $\mathrm{Sr}$ & $I \times 10^{-3}$ & $2 \times 10^{-4}$ & $4.4 \times 10^{-2}$ & $3 \times 10^{-2}$ & $\sim_{1500}$ \\
\hline Al & $\mathrm{I} \cdot 74$ & 0.44 & $8 \cdot 76$ & $7 \cdot 70$ & $\sim 400$ \\
\hline $\mathrm{U}$ & $3 \times 10^{-6}$ & $\left(I \cdot 1 O^{-6}\right)$ & $8 \times 10^{-5}$ & $3.5 \times 10^{-4}$ & $\sim_{1500}$ \\
\hline $\mathrm{Ti}$ & $1 \times 10^{-1}$ & $6 \cdot 10^{-2}$ & $9 \times 10^{-1}$ & $2.3 \times 10^{-1}$ & $\sim 500$ \\
\hline
\end{tabular}

Consider what happens when you heat a bar made of the material of a stony meteorite towards its melting point in such a way that only a very narrow zone of it is actually melted and that you then move the source of heat gradually along the whole length of the bar. This can be repeated many times. You will then have a liquid fraction which will travel repeatedly through the bar of chondrite being so treated. As a result of this zone melting you will get, collected at one end of the bar, those substances which lower the temperature of crystallization, while at the other end there will be those which raise the temperature of crystallization of the silicate melt. I have carried out this experiment with chondrite and convinced myself that there actually does occur a process of enrichment in a definite direction (the direction, as it were, of driving out of alkalis and other elements). This method will obviously permit us, in future, to obtain a large number of relevant quantitative data. It seems to me that it also provides us with the possibility of giving an experimental explanation of the mechanism of the differentiation of the substance of the Earth. These experiments have enabled me, though only speculatively, to take a first step and to suggest that the dunites forming the mantle of the Earth are the residues left by melting out the terrestrial material which had a composition similar to that of the chondrites. If this is true, an estimation of the amount of the casily transferred elements in dunites, the crust of the Earth and chondrites should give us a measure of the thickness of the mantle of the Earth which was involved in the formation of its crust (Table 2). As yet we have no accurate extraction coefficients for the behaviour of each element mentioned in the Table. However, if we use for our calculation the figures for chondrites as representing the original composition and those for dunites as representing the 
residues and consider the accumulation in the crust of the Earth (granites and basalts separately) of such elements as the alkali metals, U, Th and other elements, then we find that the thickness of the mantle of the Earth involved for this purpose will be hundreds of kilometres, in some cases more than a thousand*. It follows from this that in order to achieve a considerable concentration of many of the chemical elements in the rocks of the crust of the Earth a very great thickness of the mantle would have to have been involved. This makes it obvious why the crust of the Earth is so thin.

If we assume that the crust of the Earth has been growing at a steady rate for $5 \times 10^{9}$ years, then its thickness has increased by $\mathrm{I} \times 10^{-3} \mathrm{~cm} /$ year. If it has been growing for $5 \times 10^{6}$ years it has grown $\mathrm{I} \mathrm{cm}$ thicker each year, and only if the process was completed within $5 \times 10^{2}$ years would the rate of growth have been $10 \mathrm{~m} /$ year.

\section{THE PRIMARY ATMOSPHERE}

From what has just been said it may be seen that I support the hypothesis of the heating of the cold substance of the Earth and of the formation of the primary atmosphere as a result of the liberation, during the melting of the material of the Earth, of volatile compounds which had been chemically bound to it until that time.

The composition of the volcanic gases of the present day gives a general indication of the nature of this primary atmosphere. The main bulk of it consisted of $\mathrm{H}_{2} \mathrm{O}$, next in amount come $\mathrm{CO}_{2}, \mathrm{CO}, \mathrm{HCl}, \mathrm{HF}, \mathrm{H}_{2} \mathrm{~S}, \mathrm{~N}_{2}, \mathrm{NH}_{4} \mathrm{Cl}$ and maybe $\mathrm{CH}_{4}$. No great concentration of inert gases has been observed. The high concentrations of ${ }^{40} \mathrm{~A}$ which are sometimes observed in volcanic gases, like the relatively high concentration of it in the atmosphere, is mainly to be attributed to the radioactive decay of ${ }^{40} \mathrm{~K} \rightarrow{ }^{40} \mathrm{~A}$. The time which would have been required for the accumulation in this way of the amount of ${ }^{40} \mathrm{~A}$ which is now present in the atmosphere if it arose from the amount of formations exposed to superficial weathering would seem to be about $5 \times 10^{9}$ years, i.e. it corresponds to the age of the Earth as estimated by the lead isotope method. $f$

The amount of ${ }^{4} \mathrm{He}$, another inert gas which is present in the atmosphere and which seems to be a product of the radioactive decay of $U$ and $T h$, is less than would be expected from the available data as to the amounts of $U$ and $T h$ in the crust of the Earth. This indicates that $\mathrm{He}$, and, of course, $\mathrm{H}$ which is still lighter, are continually leaving the Earth. The loss of $\mathrm{H}$ by this means is greater than that of $\mathrm{D}$. The idea which we have accepted about the formation of the primary atmosphere does not account for the preservation of gaseous $\mathrm{N}_{2} \cdot \mathrm{N}_{2}$ is present in volcanic gases but its source is unknown. It is very likely that $\mathrm{N}_{2}$ was present in the form of compounds, the general view being that these were nitrides of $\mathrm{Fe}, \mathrm{Ti}$ and other metals or ammonium salts. The nitride $\mathrm{Fe}_{5} \mathrm{~N}_{2}$ has been found as an efflorescence on the lavas of Etna and Vesuvius, while osbornite,

* In making this calculation I have assumed that the basalts are $20 \mathrm{~km}$ thick and that the average thickness of the granites over the whole surface of the Earth is $10 \mathrm{~km} \mathrm{[2I]}$.

$\uparrow$ I shall deal in detail with the isotopic composition of the gases of the atmosphere in another place $[24,13]$. 
TiN, has once been observed in the form of very small crystals in the Bustee meteorite. The great rarity of these compounds does not exclude the possibility that they might have been, in part at least, the sources of $\mathrm{N}_{2}$. On reacting with water they yield $\mathrm{NH}_{4}{ }^{+}$. The process of emission of $\mathrm{NH}_{4} \mathrm{Cl}$ and other ammonium compounds by volcanoes, and especially fumaroles, seems to be of greater extent. It is sufficient to recall, as an example, the exhalations of Tuscany. In the loose rocks of Kamchatka, a very long way from any volcanoes, we have found that $10^{-2}-10^{-3} \%$ of $\mathrm{NH}_{4} \mathrm{Cl}$ is constantly present. In determining gases in rocks Rayleigh [Io] has shown that nitrogen may be present in them in a combined state. According to recent determinations on igneous rocks, their nitrogen content is about $0.00 \mathrm{I} \mathrm{cc} / \mathrm{g}$ of rock. That of stony meteorites is about 0.0008 $\mathrm{cc} / \mathrm{g}$ while it is interesting to record that the amount in dunites is minimal, i.e. about $0.0004 \mathrm{cc} / \mathrm{g}$. Is the $\mathrm{NH}_{4} \mathrm{Cl}$ of volcanoes, then, a juvenile product, or is it synthesized on the incandescent lava from the $\mathrm{N}_{2}$ of the air ? We have tried to synthesize $\mathrm{NH}_{4} \mathrm{Cl}$ on incandescent lava from $\mathrm{H}_{2}$ and $\mathrm{N}_{2}$ but the synthesis only occurs in the absence of atmospheric $\mathrm{O}_{2}$. All this together drives one to the conclusion that the $\mathrm{NH}_{4} \mathrm{Cl}$ of volcanoes is a juvenile product and that the $\mathrm{N}_{2}$ of the atmosphere was formed by outgassing of the Earth. It is relevant to mention that the ratios ${ }^{14} \mathrm{~N} /{ }^{15} \mathrm{~N}$ in the rocks and in the atmosphere are almost the same. The primary atmosphere, like the primary ocean, contained $\mathrm{NH}_{4}{ }^{+}$ions which were not of biogenic origin.

As concerns the question of $\mathrm{CH}_{4}$ in the primary atmosphere, it must be pointed out that the amount present in volcanic gases is extremely small and it may be supposed that this methane always arises from the reaction of carbon, dispersed in the rocks, with hydrogen, $\mathrm{C}+2 \mathrm{H}_{2} \rightarrow \mathrm{CH}_{4}$, or in accordance with the reactions $\mathrm{CO}+3 \mathrm{H}_{2} \rightarrow \mathrm{CH}_{4}+\mathrm{H}_{2} \mathrm{O}$ or $\mathrm{CO}_{2}+{ }_{4} \mathrm{H}_{2} \rightarrow \mathrm{CH}_{4}+2 \mathrm{H}_{2} \mathrm{O}$ on the incandescent lava. In any case Poole [9] has retracted his concept of a primary methane-containing atmosphere.

Finally, we must consider sulphur and its compounds in the primary atmosphere. In volcanic gases sulphur is found in the form of $\mathrm{H}_{2} \mathrm{~S}$ and $\mathrm{S}$ and is later converted to $\mathrm{SO}_{2}$ and oxidized further. The bulk of the sulphur is, however, fixed in the form of sulphides of iron and other heavy metals below the surface of the Earth. It has been suggested that the $S$ of volcanoes is of secondary origin, that is to say, it is derived from sedimentary formations, e.g. marine sulphates. One may convince oneself beyond question that the sulphur of volcanoes is juvenile in nature. It is accompanied by selenium. More important, however, is the fact that the ratio ${ }^{34} \mathrm{~S} /{ }^{32} \mathrm{~S}$ in volcanic sulphur is markedly different from that in sulphates and corresponds with the isotopic composition of the $S$ in stony and iron meteorites [23, 24].

A very rough calculation shows that the amount of gas produced on the surface of the Earth must have emanated from the whole thickness of the mantle of the Earth. The outgassing of the Earth did not proceed at a constant rate but its intensity was probably determined by the general tectonic rhythm of the Earth. The bulk of it was ejected at the beginning of the geological history of the Earth. However, a dense, heavy atmosphere was not formed. Rubey [12] has suggested provisionally that the primary atmosphere contained about $\mathrm{I} \%$ of $\mathrm{CO}_{2}$ (instead 
of the 30 atmospheres of $\mathrm{CO}_{2}$ required by the 'hot' theory). One may well add that, inasmuch as there is not firm basis for this view, the interesting problem of the kinetics of the formation of the shells of the Earth is still awaiting investigation.

\section{THE PRIMARY OCEAN}

The sources of the more important anions (carbonate, fluoride, chloride, sulphate, borate, etc.) present in the waters of the oceans, like that of the water itself, were the products of outgassing of the internal rocks of the mantle of the Earth, while the sources of the more important cations ( $\mathrm{Na}, \mathrm{K}, \mathrm{Mg}, \mathrm{Ca}, \mathrm{Sr}$, etc.) were the weathered products of the rocky formations of the surface of the Earth. The main supply of gases was maintained by volcanic and intrusive activity and they also emerged along with lava. Clearly, the heating of the surface of the Earth and the large amount of gases in the atmosphere entailed by it must, at some time, having reached a maximum. This was followed by slow cooling of the surface of the Earth and condensation of the products of outgassing. These events, it can only be supposed, must have occurred during the first hundreds of millions of years of the life of the planet. There is, however, no factual basis for this figure.

The processes of thickening of the crust of the Earth, increase in the amount of $\mathrm{CO}_{2}$ and other gases in the atmosphere and increase in volume of the oceans, occurred synchronously. They first reached a maximal rate of development, later declined and are not yet complete.

Acid vapours were neutralized by the rocks. The gases of the atmosphere were in equilibrium with the waters of the oceans and, in particular, $\mathrm{HF}, \mathrm{HCl}$ and other acids were quickly removed from the atmosphere. As concerns $\mathrm{CO}_{2}$, the more of it there was in the air the more $\mathrm{CaCO}_{3}$ was dissolved in the water and the formation of calcareous deposits was generally impossible under these conditions [18]. The composition of the gases emanating from the interior of the Earth has probably changed very little. The chemical composition of the oceans has, therefore, not been submitted to any abrupt changes in regard to the salts present. These changes very quickly became as insignificant as the changes which we may observe in the other shells of the Earth (basaltic and granitic). A more significant alteration in the composition of the salts of the oceans occurred in many places when deposits of $\mathrm{CaCO}_{3}$ or dolomite were laid down. What were the reasons for the deposition of $\mathrm{CaCO}_{3}$ ? Essentially they were two: (I) The dissociation of $\mathrm{Ca}\left(\mathrm{HCO}_{3}\right)_{2}$ by the evaporation of the water in shallow seas and (2) The biological fixation of $\mathrm{CO}_{2}$ in the skeletons of organisms $\left(\mathrm{CaCO}_{3}\right)$ and by photosynthesis.

The evaporation from shallow waters occurred on the greatest scale at the time when the epeirogenic, or shallow continental seas were formed. These seas, as we shall see later, became important at the time of the appearance of the broad platforms of the continents, i.e. about $2.5 \times 10^{9}$ years ago or somewhat earlier. In fact, we find that the percentage of carbonates in the deposits of these platforms where there were shallow seas is 50 as compared with $15 \%$ which is the average for all the sedimentary formations of the Earth [I9] 
As part of the overall change in the composition of the ocean we must also take into account the appearance of a considerable amount of $\mathrm{SO}_{4}{ }^{-}$in the water. In the primary atmosphere sulphur was present, for the greater part, as $\mathrm{H}_{2} \mathrm{~S}$ or $\mathrm{S}$ and, although these could have been oxidized photochemically on the surface of the Earth in the presence of water, the process of oxidation probably did not take place to any great extent until a considerable amount of $\mathrm{O}_{2}$ had appeared.

The most ancient and the primary ocean seems to be the depression in the Pacific ocean, the bed of which is not covered by the granitic envelope. The beds of the Atlantic and Indian oceans are covered by the granitic shell (except, possibly, in their deepest parts) and, in the opinion of most geologists, they were formed in the palaeozoic, or perhaps even the mesozoic, age owing to the subsidence of the crust of the Earth and the consequent submergence of the granitic shell beneath the waters.

\section{INDICATIONS OF THE EARLY BIOSPHERE}

Among these indications may be considered the skeletons of organisms, imprints and other morphological structures preserved in the geological formations, biogenic rocks themselves and, finally, the character of the weathering of rocks and their composition. As we can see from Fig. I, none of these indications very rapidly disappear in time.

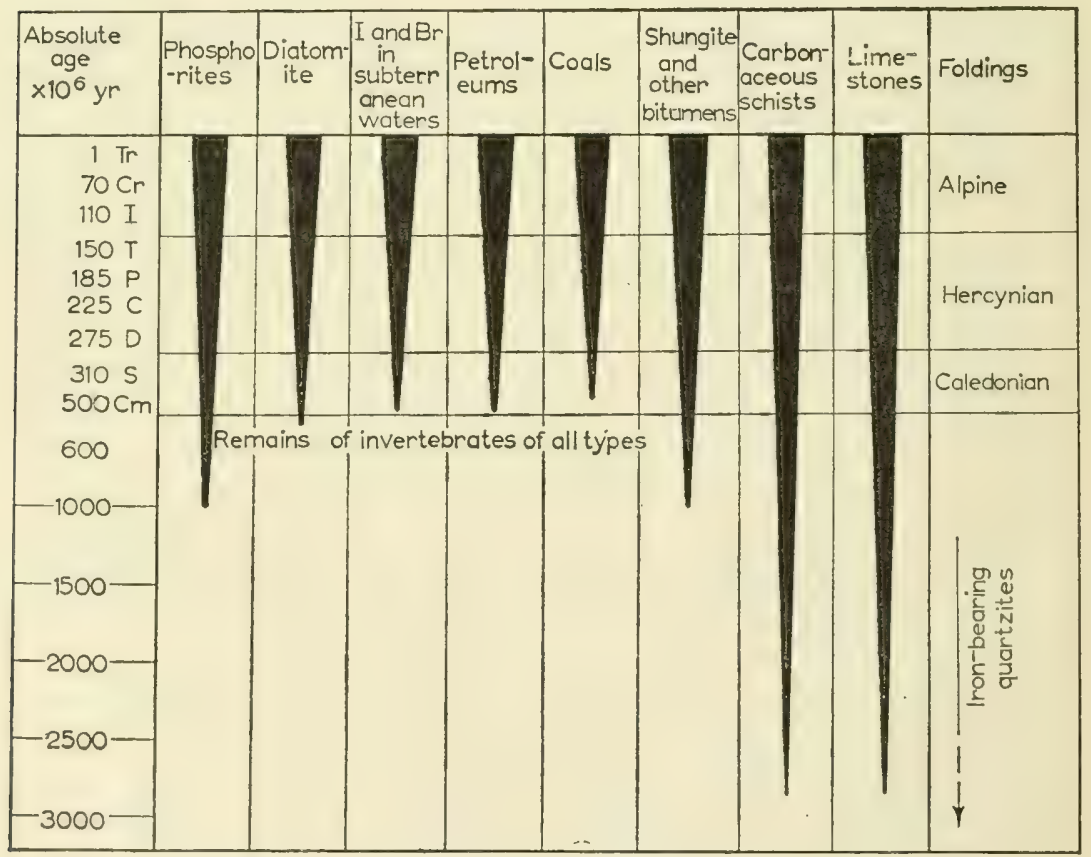

FIG. I. Diagram showing conservation of the different biogenic formations through the ages. 


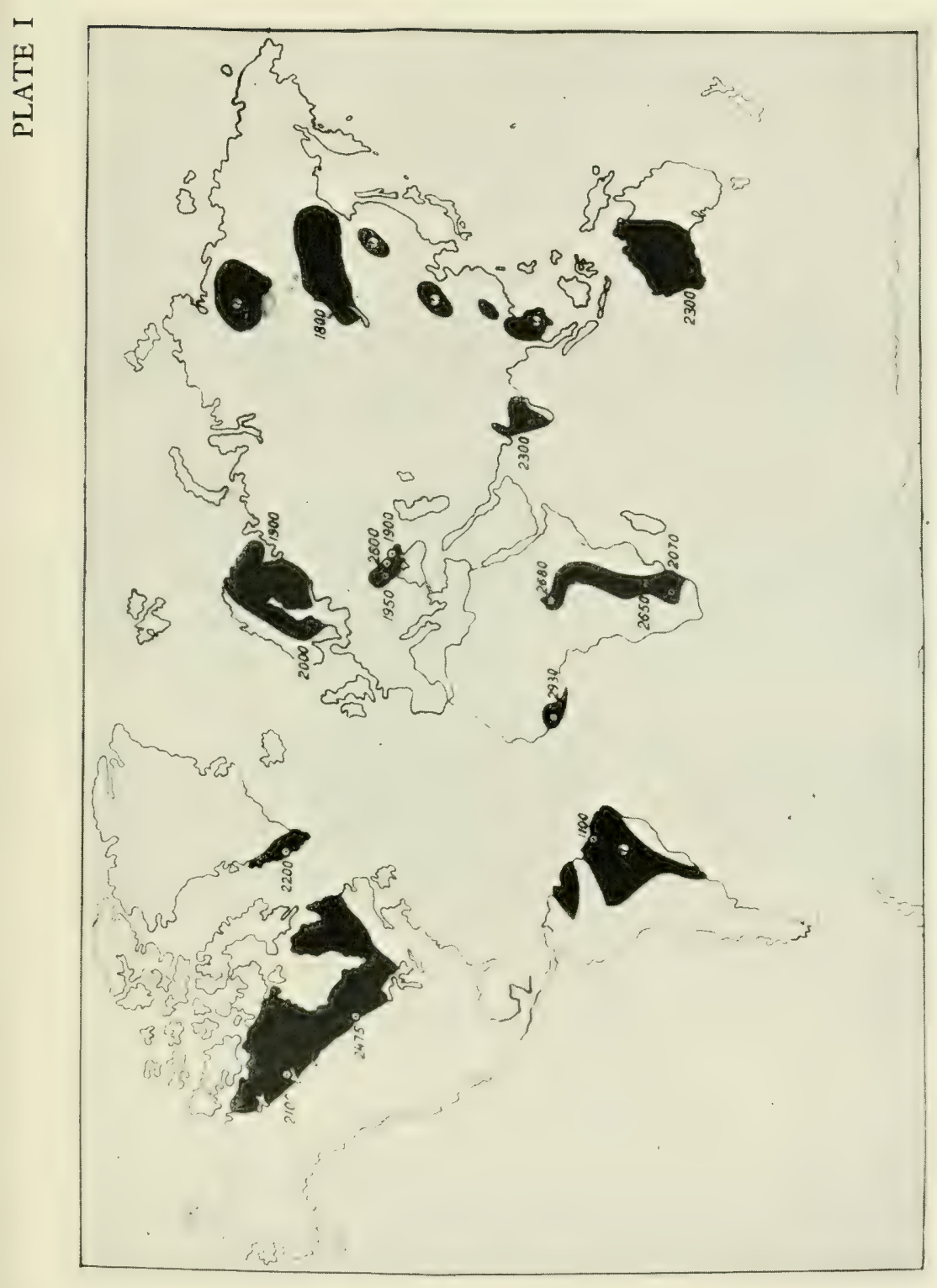

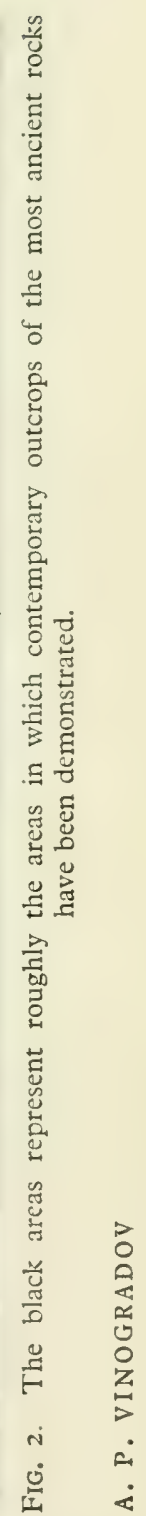



The evolution of the ancient crust of the Earth $3 \times 10^{9}$ years ago and earlier was characterized by intensive tectonic and volcanic activity such as has not taken place since. The whole world comprised a single geosynclinal area. Limitless fields of effusive material and enormous streams of lava built up the basaltic shell of the Earth. Tremendous weathering processes involving the destruction of the erupted materials gave rise to mighty deposits, mainly of clastic material, which, as it were, acted in some places as a filter for the hot gases and magma rising from the depths of the Earth. In addition, the intrusive activity became even stronger at that time. Enormous masses of so-called anatectic granitic batholiths are scattered through these extremely ancient sedimentary strata. Granitic material penetrates so profusely through these ancient sedimentary formations of gneiss that it is hard to define the boundary between the true granite and the host rocks. Thus the early Archaean granites, which are characterized by a high content of potassium felspar, arose from the earliest sedimentary deposits by their becoming molten again under the influence of heat and emanations. Eighty per cent of all granites arose in the Archaean. The growth of the granitic shell, showing an extraordinarily vast scale, was virtually finished by the end of the Archaean or beginning of the Proterozoic, i.e. about I.5 or maybe $2 \times 10^{9}$ years ago.

With the further development of intrusive activity in the crust of the Earth, small islands of solid land appeared in the upsurge of the Archaean surface of the Earth. These constituted ancient nuclei of geological formations which can be shown by methods of dating based on radioactivity to be $2-2.5 \times 10^{9}$ years old or more. These nuclei of continents are known to occur on almost all the main land masses of the present day. These nuclei of continents have, as their foundations, the earliest effusive formations (see Fig. 2).

A turning point occurred in the history of the surface of the Earth when more stable and undisturbed areas first came into being in its geosynclinal surface. These gradually extended to form platforms.

A particularly marked contraction of the geosynclinals and intensive growth of the platforms may be noted at the very end of the Archaean or beginning of the Proterozoic, i.e. about $1 \cdot 5-2 \times 10^{9}$ years ago. The crust of the Earth entered into a new stage of development with the contraction of the geosynclinals and the growth of the platforms with their sedimentary coverings. The biosphere and organic beings are closely associated with sedimentary formations. The earliest sedimentary formations were now laid down on the basis of the persistent nuclei of ancient rocks. The schists of the Keewatin formations of the American continent are estimated to be more than $2.5 \times 10^{9}$ years old. Schists of the same type, found in Kambove in West Africa are credited with an age of more than $2.2 \times 10^{9}$ years. The Svinion gneisses of Karelia are thought to be more than $2.1 \times 10^{9}$ years old. The Saxagan gneisses of the Ukraine are over $2 \times 10^{9}$ years old. The Shamva granites of Africa are $2.8 \times 10^{9}$ years old and so on $[7,22]$. In these, and even in more recent formations of the end of the Archaean and beginning of the Proterozoic, one may find most suggestive evidence for the presence of an oxygen-containing atmosphere in the Archaean in the form of sedimentary iron ores, iron-containing quartzites (the so-called jaspilites) con3 
taining haematite and magnetite, which is a product of its metamorphosis; that is to say, they contain oxidized iron. We may mention the iron-containing quartzites of Krivol Rog, of the Kursk magnetic anomaly, of Canada, Sweden (Kiruna and other places), Africa and other places. When studying the breccia of Suodeniemi in comparison with the primaeval formation of Finland (age $2 \times 10^{9}$ years), Rankama [II] did not find any excess of $\mathrm{Fe}^{\mathrm{III}}$ in the breccia. Geijer [4] denied this and found haematite in the breccias. These ores of the Archaean and Proterozoic are many times greater in amount than all the iron ores of later dates. About the same age is assigned to the universal appearance of calcareous rocks in the form of marbles and crystalline dolomites. These crystalline carbonates originally formed part of the composition of conglomerates and breccias. They were gradually transformed, especially during the Proterozoic, into enormous strata on the platforms. In parallel with this, traces of the most ancient organisms have been found in the Proterozoic and lower down in the Archaean limestones etc. The first such find was that of the well known Collenia walcotta, an alga from the limestone bed of the Grand Canyon, from the Grenville limestones of the Great Lakes which are about $1 \cdot 5 \times 10^{9}$ years old. Grant and his fellow-workers described an organic structure, similar to Collenia in the Huron formations which are of about the same age. In the Lower Huron sediments of Minnesota, Grüner found the alga Inactis. In the Jatulian formations of Karelia (about $1 \cdot 6 \times \mathrm{ro}^{9}$ years old) Carelozoon jatulica has been described. Tyler and Barghoorn found the remains of blue-green algae and flagellates in the formations of the Canadian shield (the formations are about $2 \times 10^{9}$ years old). MacGregor found traces of algae in the limestones of Rhodesia, the age of which is estimated at about $2.7 \times 10^{9}$ years. Other similar finds have been made. Thus we have direct evidence that at least as long as about $2 \times 10^{9}$ years ago $\mathrm{O}_{2}$ was present in the atmosphere. In as much as the primary atmosphere contained $\mathrm{H}_{2} \mathrm{O}$ and $\mathrm{CO}_{2}$ and other oxygen-containing compounds there is absolutely no reason to suppose that some part, at least, of the $\mathrm{O}_{2}$ in the Archaean atmosphere was of abiogenic origin, being formed by photochemical dissociation of these compounds in the upper layers of the atmosphere. This process is very slow and the intense volcanic activity did not permit the accumulation of $\mathrm{O}_{2}$ in the primary atmosphere. Moreover, the absence of $\mathrm{O}_{2}$ did not prevent the development of anerobic life. Even if there were no ozone screen, which is supposed to have shielded the organisms from the harmful effects of ultraviolet irradiation, the waters of the seas, even when quite shallow, would have provided an excellent screen.

Carbonaceous schists and graphite are associated with all these finds. Shungite is also found at the time of the transition from the Archaean to the Proterozoic ages $\left(\mathrm{I} \cdot 6 \times 10^{9}\right.$ years ago).

Although Thode et al. [15] thought, on the basis of determination of the ratio ${ }^{32} S /{ }^{34} \mathrm{~S}$ in sulphides of sedimentary origin, that the earliest limit for life is somewhere about $700-800$ million years ago, we have proved experimentally that this is not true, by determining the isotopic composition of the $S$ in similar sulphides. From this we see that, as I have already said, there is a more or less determinate limit somewhere between $2.5 \times 10^{9}$ and $2.0 \times 10^{9}$ years ago and the correct figure is probably nearer to the longer than to the shorter period. 
At this time, not only do the morphological signs of organisms disappear, but even the sedimentary deposits themselves have vanished owing to assimilation. As a result of this the physical and chemical aspects of our investigations assume particular importance.

\section{CONCLUSIONS}

If we can observe signs of a biosphere in geological strata dating from more than $2 \times 10^{9}$ years ago, then, naturally, the origins of the biosphere must have been earlier than this. In considering what conditions were peculiar to these

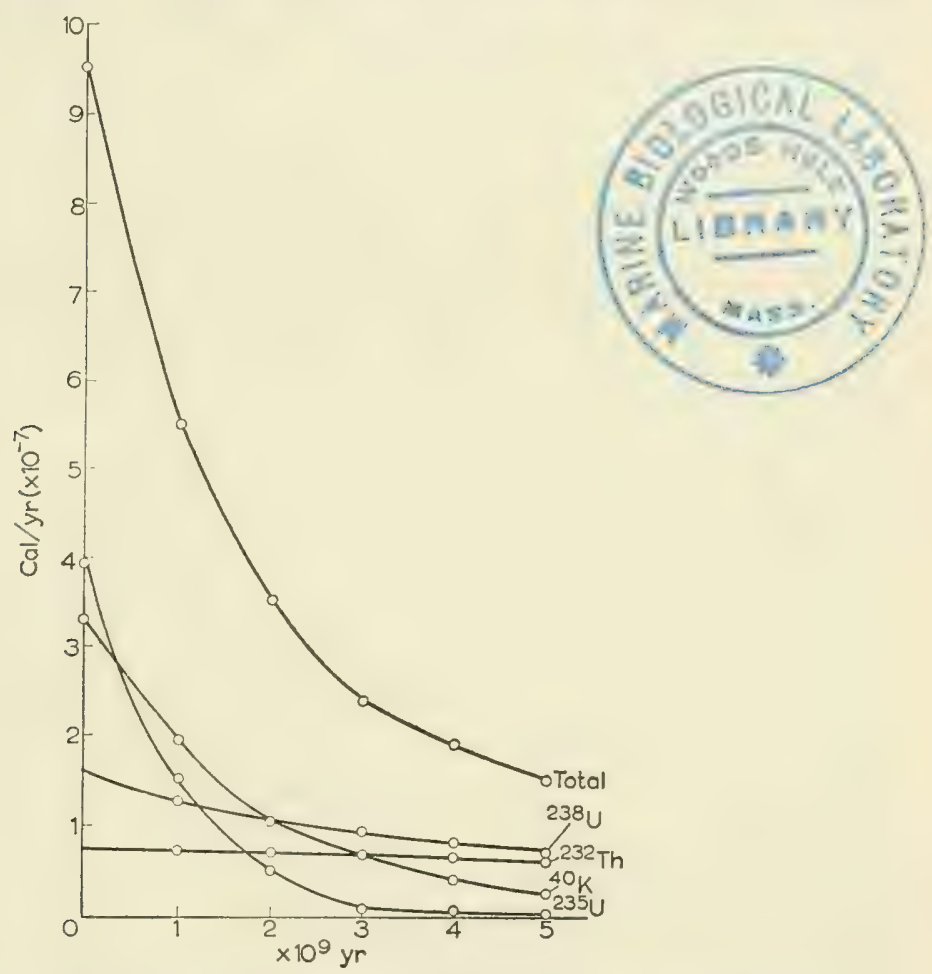

FIG. 3. Radiogenic heat formed in the Earth by U, Th and ${ }^{40} \mathrm{~K}$ separately and together plotted against time.

times and are not now present, we may also mention some, of which, perhaps, I have not spoken in sufficient detail. It is impossible to make any, even remotely plausible hypothesis as to the amount of change which has taken place in, for example, the intensity of ultraviolet or cosmic radiation, etc. It may be that the most important factor limiting the development of living things was the temperature of the rocks, waters and gases on the surface of the Earth. From the graph shown in Fig. 3 it may be seen that, as early as $3 \times 10^{9}$ years after the origin of the Earth, the total heat derived from the decomposition of radioactive elements had begun to abate at a less catastrophic rate than it had done previously. From that time until the present it diminished by less than a factor of 2 . The 
same tendency is found, to a certain extent, in the temperature of the surface of the Earth. I would suggest that the peculiarity of the time when the Archaean biosphere came into existence was just this considerable amount of heat at the surface of the Earth. It manifested itself in numerous volcanic and post-volcanic phenomena in the form of hot gases, hot springs and so forth. This could have led to intensive catalytic synthesis of numerous organic substances on the surface of the Earth from $\mathrm{CO}_{2}, \mathrm{CO}, \mathrm{H}_{2} \mathrm{~S}, \mathrm{~S}, \mathrm{NH}_{4}, \mathrm{CH}_{4}, \mathrm{HCl}, \mathrm{HF}$ and other compounds on a scale which has been unparalleled since that time. From the time of the inception of the biosphere to the Cambrian period, in the strata of which palacontologists have found highly organized organisms including all forms of invertebrate animals, at least $1 \cdot 5-2 \cdot 0 \times 10^{9}$ years must have elapsed. In the course of this time there must obviously have developed all sorts of methods of oxidation of $\mathrm{H}_{2} \mathrm{~S}$ and other analogous processes and, later, the dehydrogenation of $\mathrm{H}_{2} \mathrm{O}$ by means of chloroplasts as well as other reactions. Any conceivable process of photodissociation of $\mathrm{H}_{2} \mathrm{O}$ would have taken $10^{8}$ years to form the oxygen of the atmosphere. The photosynthetic $\mathrm{O}_{2}$ in the atmosphere is produced during 5000 years, forming a sound basis for the development of aerobic life. Many other geochemical cycles of elements and molecules in which organisms were an essential link were also set up and consolidated. Thus, the phosphates of the bones later provided a basis for the development of the neuromuscular tissue in vertebrates. Many other molecules were drawn into these cycles and became involved in the evolution of organisms. $\mathrm{CaCO}_{3}, \mathrm{CaHPO}_{2}$, chitin, cellulose, porphyrins and many other, even more complicated compounds were among them. This, however, is a long way outside the province of the geochemical history of the biosphere.

Thus, we may conclude that the mechanism by which the light basaltic formations were melted out from the whole thickness of the mantle of the Earth under the influence of radiogenic heat, was associated with the outgassing of $\mathrm{H}_{2} \mathrm{O}, \mathrm{CO}_{2}$ and other gases and vapours on to the surface of the Earth. This determined the composition of the primary Archaean atmosphere and ocean. In the course of time the composition of the salts of the ocean and that of the atmosphere may have undergone some change owing to the irregular accession of vapours and gases to the surface of the Earth. The Archaean atmosphere contained, among other vapours and gases, $\mathrm{NH}_{4} \mathrm{Cl}, \mathrm{H}_{2} \mathrm{~S}$ and $\mathrm{S}$ of abiogenic origin and, possibly also $\mathrm{CH}_{4}$ and some $\mathrm{O}_{2}$, which provided the necessary conditions for the catalytic synthesis of complicated organic compounds if the temperature was raised. The last marked changes in the composition of the oceans and atmosphere took place between $3 \times 10^{9}$ and $2 \times 10^{9}$ years ago when the temperature of the surface of the Earth became much what it now is. The ancient nuclei of the continents persisted and provide evidence of magmatic phenomena which took place in the remote past, being locally completed $3 \times 10^{9}$ years ago. We have no reason to exclude the possibility of the existence of anaerobic forms of life at that time. At the same time as, or slightly later than the alteration in the geosynclinal condition of the surface of the Earth there appeared the first platform-like structures which were submerged in the shallow seas. These seas were associated with the intensive precipitation of $\mathrm{CaCO}_{3}$ and the 
removal of $\mathrm{CO}_{2}$ from the atmosphere. The even more powerful process of photosynthetic formation of free cxygen made its appearance. It is just at this time that one can also observe traces of plants and other organisms, as well as oxidized iron ores which provide direct evidence of an oxygenous atmosphere. Associated with the formation of an oxygen-containing atmosphere, there was intensive oxidation of $\mathrm{H}_{2} \mathrm{~S}$ and $\mathrm{S}$ and an increase in the amount of sulphates in the oceans, as well as oxidation of $\mathrm{NH}_{4}$ and an increase in the amount of $\mathrm{N}_{2}$ in the atmosphere. During the later periods of the Proterozoic and in the Cambrian, there occurred no noteworthy change in the composition of the oceans or atmosphere.

Having been brought into existence by the whole course of geological history, the biosphere made its appearance when the Earth was between two and three thousand million years old.

\section{REFERENCES}

I. F. BIRCH, Geophysics, 19, 645, I954.

2. H. Brown, Rare gases and the formation of the Earth's atmosphere. In The Atmospheres of the Earth and Planets (Ed. by G. P. KUIPER), 1947.

3. E. C. Bullard, Proc. Roy. Soc. A, 222, 408, 1954.

4. P. GeIJER, Geochim. et cosinoch. Acta, 10, 304, I956.

5. V. M. Goldschmid, Geochemistry (Ed. by Alex. Muir). Clarendon Press, Oxford, I954.

6. B. GUTENBERG, Internal Constitution of the Earth, I95 I.

7. A. Holmes \& Lucien Cahen, Colon. Geol. Min. Resour., p. 3, I954.

8. E. A. Lyubimova, On thermal régime of the Earth. Trud. geofiz. Inst., Mosk., No. 26, p. 39, I955.

9. J. H. J. Poole, Proc. R. Dubl. Soc. Sci., 25, n.s. 20I, I95I.

IO. RAYLEIGH (LORD), Nature, Lond., I4I, 970, 1938.

II. K. Rankama, Spec. Pap. geol. Soc. Amer., No. 62, 650, 1955.

I2. W. W. RuBey, Bull. geol. Soc. Amer., 62, IIII, 195 I.

I3. H. A. Shil libeer \& R. D. Russell, Geochim. et cosmoch. Acta (8), 2, I6, 1955.

I4. L. B. Surchter, Bull. geol. Soc. Amer., 52 (4), I94I.

15. H. G. Thode, J. Macnamara \& W. H. Fleming, Geochim. et cosmoch. Acta, 3, 235, 1953.

I6. H. C. UrEY, The planets. Yale Univ. Press, New Haven, I952.

I7. H. C. Urey, Proc. nat. Acad. Sci., Wash., 4I, 3, I955.

I8. A. P. Vinogradov, Dokl. Akad. Nauk S.S.S.R., 27, No. 3, 1940.

I9. A. P. Vinogradov, A. B. Ronov \& V. M. Ratynskir, Evolution of the chemical composition of carbonaceus rocks, Soveshchaniya po osadochnym poradom, I, 104, 1952.

20. A. P Vinogradov, I. Zadorozhnyĭ \& S. I. ZyKov, Dokl. Akad. Nauk S.S.S.R., 35 , No. 5, I107, 1952.

21. A. P. Vinogradov, Geokhimiya, No. I, I956.

22. A. P. Vinogradov, Geokhimiya, No. 5, p. 3, 1956.

23. A. P. VINOGRAdov, $S^{32} / S^{34}$ Isotopic composition of meteorites and of the Earth, Radioisotopes in Scientific Research (Proc. Int. Conf. held in Paris, 1957), Pergamon Press, 1958.

24. A. P. Vinogradov, The isotopic composition of rocks of the Earth and of meteorites, Radioisotopes in Scientific Research (Proc. Int. Conf. held in Paris, 1957), Pergamon Press, 1958. 


\title{
The Problem of Stages in Biopoesis
}

\author{
J. D. BERNAL \\ Birkbeck College, University of London, England
}

As THE very calling of this Symposium indicates, the question of the origin of life can only be investigated by a combined effort in which experts in many fields co-operate. Every solution put forward by an individual, however wellread or brilliant, is bound to be a partial one and open to criticism because of its reliance on ideas or supposed facts drawn from regions of knowledge with which that individual is not directly acquainted. These failings can in the course of time be removed by mutual criticism, but the process is very slow and one of our hopes is that the present Congress will act like a catalyst and speed it up. However, with multiplicity of counsel there is another danger arising from different scientific formation of the participants and different ideas of the nature of the problem to be solved. By dealing separately with different aspects of the Origin of Life their sequence and inter-relatedness may be overlooked. It is on this last point that I would like, in this paper, to put forward some suggestions as to the general pattern of the Origin of Life, and in particular to try to block out some formal account of the stages in which it may be deemed, provisionally, to have taken place, in order to focus attention on the problems that may occur at each stage. I am not suggesting that my pattern is the correct one or that it may not require drastic modification, but I do urge that it is better in such a Congress to have before it some pattern than none. At any rate it has helped me to construct one, and my ideas may be useful even if they only provoke contradiction.

In general the pattern I propose is one of stages of increasing inner complexity, following one another in order of time, each one including in itself structures and processes evolved at the lower levels. The division into stages is not in my opinion an arbitrary one. Although the evolution of life was continuous, for no stage could have been completely static, it cannot have been uniform. Discontinuities which occurred at later stages of organic evolution, such as the emergence of air-breathing forms, are likely to have been paralleled at the earlier biochemical stages at such jumps as the genesis of sugars, nucleic acids and fats. One of our major problems is to establish the correct order of the steps inferred from existing metabolism as well as the postulating and checking of other steps which have been subsequently effaced by the success of more efficient biochemical mechanisms.

Before considering these transitions in detail I would like to recall certain general principles which may serve to guide the lines of speculation without themselves furnishing decisive arguments for or against any particular solution. The first of these is the principle of Lyell which tells us to search in the present world for processes which may have occurred in the past. In its particular 
application to the origin of life, it is to search in the inorganic world for the origin of the processes, as well as the materials, of the organic world. This implies more than the condition that the process of the organic world must not be contrary to chemical laws or Henderson's principle of the fitness of the environment. It requires, in addition, that just as the elements used in building up living structures are a selection from those found in the inorganic atmosphere, hydrosphere, and lithosphere, so also are the basic reactions of oxidationreduction, hydrolysis-condensation likely to have an unbroken continuity with those occurring on the surface of the Earth. It is, indeed, a fact of observation that some soluble simple ions like those of potassium and magnesium and the labile atoms of sulphur, phosphorus and iron, which undergo the greatest transformations in the mineral world, have a key importance in biochemistry, while the stable atoms, such as silicon, aluminium, or sodium, which constitute a far larger part of the Earth's crust, are either absent or play a subsidiary role.

The one limitation to our study of biopoesis or life-making is that it is a special and not a general problem. We are limited, and necessarily so in the first place, to the origin of the one form of life that we can observe now on this Earth. There may have been other radically incompatible forms on this Earth at earlier times and these or others we succeed in making artificially. Where life exists on other planets it is most likely that it will be radically incompatible with ours, though we may suspect that it will show striking parallels, biochemically as well as structurally. However, pending the advent of practical biopoesis or trips in space to acquire the basis of comparative biopoesis, we must restrict ourselves to tracing the genealogical tree of life as we know it right back to its origin or origins, for they may be multiple, in the inorganic world. The biochemical genealogy of the terrestrial life, though uniquely determined working backwards, is by no means unique working forwards. This is what makes the biochemical approach to biopoesis more likely to give results than the purely geochemical, except at the very outset. Starting from any initial inorganic origins there are too many possible lines to be followed up. At a number of occasions in biopoesis there must have been alternative arrangements with little to choose between them-even trivial ones such as right- or left-hand configurations of molecules. There may well be potential biochemical cycles that would have solved the problems of the formation of life and reproduction of organism as well as, and even better than, those actually evolved. But biochemical evolution differs from that of organisms in that variant forms, if not actually incorporated in the common biochemical pattern, became absolutely extinct. There is only one dominant chemical pattern of life. If more than one exist the others must be obscure, as are some of the red algae, and unnecessary to the survival of the dominant. It is as if in the subsequent evolution of species only man and a few of his pets were to survive.

One of the major reasons for assuming that, in tracing the origin of life on this planet, we are dealing with a very particular form and have not exhausted the biochemical potentialities of life, is the extreme chemical and structural conservatism or inertia of once established patterns of structure or activities. At and above the level of the protozoa there is no essential change in structure 
and metabolism of the nucleated cell. A common pattern underlies all modifications. Not only was life on this Earth one at that level, but also it has not divided into branches ever since. It cannot be just because all living organisms are part of the food chains of others that they are biochemically compatible. For green plants that do not depend on complex molecules made by other organisms it would be a great biological advantage to be inedible and resistant to fungal and bacterial decay. Yet no plant has achieved this isolation from the rest of the living world. It is precisely because of this biochemical and structural inertia, that we have some reasonable hope of being able to trace back origins by the comparative methods used by Darwin and his followers for gross morphological features in the latter stages of evolution. We may expect patterns of reactions as well as structures to accumulate with modifications and subsequent fusion into more complicated ones and so on until and beyond those found in living things today. The unravelling of protein structure, discussed in my later paper, has shown evidence of several stages of such reduplications and complications or foldings in the most literal sense. Formally the chemical evolutionary process may be likened to the evolution of a drainage for newly emerged lands. Comparatively trivial variations may determine the location of bends but once the main pattern is cut it deepens and fixes itself only to be changed by the effects of its own actions. A too successful utilization of some component can, as Horowitz [13] has pointed out, lead to the holding up of some activity and the employment of an alternative source. An increase of efficiency in another part may render certain earlier steps unnecessary, but in the main the original pattern will be preserved. We should, as time goes on, be able to trace it even more accurately.

We may define life, for the sake of this discussion only, as the embodiment within a certain volume of self-maintaining chemical processes. Our central problem is not here to explain how such a system works but how it can establish itself starting from available inorganic materials and subsequently reproduce and evolve de novo. This can be divided into four inter-related but distinct problems:

(I) the problem of the external source of free energy to keep the system going;

(2) the problem of the facilitation of the energy interchanges within the system, where an isothermal condition implies some catalysis;

(3) the problems of the means of holding the system together and in the more complicated cases, such as bacterial and nucleated cells, of how all parts of the organism can maintain their individuality while being in constant chemical relation with each other;

(4) the problems of reproduction with its almost, but never quite exact, duplication of organisms as shown in evolving species, pose the further problem of the normal transference, with occasional modification, of specific guiding patterns.

All these problems are being discussed in various sections of this Symposium. I list them here simply to provide a general background for a tentative establishment of stages in biopoesis. Although they overlap, the four conditions for life listed above form a natural order. The energy source must come first, there must be some reactions or mere coherence would not imply life and there can be no reproduction without something to reproduce. An analysis of biopoesis can be 
made in accordance with these major conditions by considering first the cssential reactions on an atomic or micromolecular scale in their thermodynamic and kinetic aspects; next the sequence of structures starting from atoms and building up to polymers of colloidal dimensions; and finally the way the mutual arrangements of these impose a pattern of linked reactions which can be reproduced.

On the first steps of emergence of simple organic molecules in the hydrosphere there is still no agreement, but as this question will be largely debated here I will not pursue it at any length. All I would like to say is that following Lyell's principle it seems preferable to start by supposing substances and reactions that still occur even though now modified by the action of life. It is not strictly necessary to postulate the character of the original atmosphcre of the Earth because of the continual contributions which must have occurred from volcanic sources. The character of these seems largely independent of organic sources and to consist mainly of steam, carbon dioxide, ammonia, and hydrogen sulphide. With regard to the supply of carbon dioxide I suspect it is derived from lower layers of the crust where it may exist in the high pressure form of orthocarbonate in such a mineral as fayalite $\mathrm{Fe}_{2}(\mathrm{C}, \mathrm{Si}) \mathrm{O}_{4}$. Ammonia is already known to exist as ammonium felspar $\left\{\mathrm{K},\left(\mathrm{Ni}_{4}\right)\right\} \quad \mathrm{AlSi}_{3} \mathrm{O}_{8}$. Both $\mathrm{CO}_{2}$ and $\mathrm{NH}_{3}$ in the form of $\mathrm{NH}_{4} \mathrm{Cl}$ are known to be liberated in volcanic gases, fumaroles etc. Probably a far larger amount reaches the hydrosphere through the weathering of carbonateor ammonia-containing igneous rocks. The weathering of roo $\mathrm{km}$ of igneous rock already largely depleted of ammonia would provide all the nitrogen at present in the atmosphere.

The question as to whether primary or secondary inorganic hydrocarbons were ever found in the primitive atmosphere is still an open one. They are hardly ever detected in volcanic gases and their presence in carbonaceous meteorites in my opinion points to the origin of these meteorites in a region further from the sun than the Earth. In any case oxidation of methane at the top of the atmosphere would relatively soon reproduce the condition in which carbon dioxide would be the chief carbon compound in the atmosphere.

It has been argued that $\mathrm{CO}_{2}$, the most oxidized form of carbon, is most unlikely in the primitive atmosphere. If it was all derived from the oxidation of the postulated earlier $\mathrm{CH}_{4}$ I would agree for, in that case, intermediates in the forms of alcohols and carboxy acids would first have been formed. The situation would be different if atmospheric $\mathrm{CO}_{2}$ is a product of the lithosphere as the existence, admittedly rare, of carbonates of deep origin would seem to indicate. In any case if $\mathrm{CO}_{2}$ was not a precursor of life it must have been one of its earliest products, as witnessed by the universal presence of limestone even in the early pre-Cambrian rocks. Perhaps a study of carbon isotopes, in carbonatites and limestones of various ages would resolve this problem.

The major exergonic reactions occurring in the primitive hydrosphere would be

$$
\begin{aligned}
2 \mathrm{NH}_{3} & \rightarrow \mathrm{N}_{2}+3 \mathrm{H}_{2} \text { or } \mathrm{N}_{2}+2 \mathrm{H}_{2}+2 \mathrm{H} \text { etc. } \\
8 \mathrm{SH}_{2} & \rightarrow \mathrm{S}_{8}+8 \mathrm{H}_{2}
\end{aligned}
$$

both of which, in the absence of free oxygen, would yield molecular hydrogen 
which would diffuse out of the atmosphere. Nitrogen would steadily be built up in the atmosphere and elementary sulphur or iron sulphide would be deposited. The other main oxidizing reaction is strongly endergonic

$$
2 \mathrm{H}_{2} \mathrm{O} \rightarrow \mathrm{O}_{2}+2 \mathrm{H}_{2} \text { or } \mathrm{O}_{2}+4 \mathrm{H} \text { etc. }
$$

but the energy to effect it can be provided by short-wave radiation at the top of the atmosphere. The concentration of molecular oxygen would tend to rise until it sufficed to oxidize the hydrogen emitted by the dehydrogenation of $\mathrm{NH}_{3}$ and $\mathrm{SH}_{2}$ and also the ferrous iron derived from weathering of rocks. Free energy available for biochemical reactions may also have been available from this source. What this equilibrium concentration of oxygen would be is still a moot point but it would seem on biochemical evidence alone that oxidation reactions, though now furnishing most of metabolic free energy, are not primitive. In any case the high concentration of atmospheric oxygen now observed in the atmosphere is now derived from photosynthesis, the mechanism of which, at least using visible sunlight, seems to have a fairly elaborate biochemical history. The type of endergonic reaction which could lead to organic compounds is, however, now part of the photosynthetic cycle of reactions.

$$
\begin{aligned}
\mathrm{CO}_{2}+2 \mathrm{H} & \rightarrow \mathrm{HCOOH} \text { formic acid } \\
\text { or } \mathrm{CO}_{2}+4 \mathrm{H} & \rightarrow \mathrm{H}_{2} \mathrm{CO} \quad \text { formaldehyde }+\mathrm{H}_{2} \mathrm{O}
\end{aligned}
$$

None of the actual reactions which occurred in the primitive ocean are likely to be as simple as those indicated above. More probable variants and intermediates will certainly be discussed at this Symposium. I only cite them to show firstly that the major features of current metabolism were already present in the primitive hydrosphere and secondly that the actual basic compounds which make up living organisms can be most easily envisaged as constructed mainly of carbon dioxide and ammonia by not implausible processes which do not involve unsupported hypotheses about the constitution of the primitive atmosphere. They are moreover thermodynamically sound even without the assumption of the utilization of free energy derived from the sun. The free energy supplied on this hypothesis would be simply due to the greater reduction potential of the surface lithosphere with respect to an atmosphere from which hydrogen can escape.

Life, geologically speaking, consists of the interference with secondary lithosphere-atmosphere reactions so as to produce a small but ever-renewed stock of organic molecules.

One of the major tasks of biopoesis is to establish the nature and the order of formation of the simpler molecular species out of which the more complex compounds and polymers now found in living organisms were derived. I have no competence in this field, but to complete the picture, I am indicating on the diagram, Fig. I, the kind of molecular genealogical table that needs to be drawn up. Both the lines of derivation and the order need to be examined. Indeed this table is less a statement of probabilities than a setting of problems which may be solved ultimately by a critical use of present-day biosynthetic changes (for it does not follow that the present derivations were the same at the outset) and a 
series of tentative pictures of biopoesis. Particularly important is the problem of the origin of the sugars, whether anteriorly or posteriorly, as I have imagined, to that of the amino acids. Another associated problem is the stage at which photosynthesis and oxidation enter the picture. I have tentatively put it after the appearance of the porphyrins.

I am inclined now, especially after looking at the results of the synthetic experiments of Miller, Terenin, Pavlovskaya and Pasynskil, to think that sugar production must have come rather earlier in biopoesis. Our preoccupation with proteins, quite rightly as the essential biochemical molecule most difficult to synthesize, has led us to pay particular attention to amino acid synthesis.

However, in the actual synthesis non-nitrogenous substances, mostly vegetable acids, were in fact the main products. Although in these experiments no sugars were produced, this may have been due to the absence of suitable inorganic catalysts.

As important, but much more characteristic of living systems than the molecules they contain, is the mode in which the chemical reactions between them are carried out. This mode we now observe in living organisms is that of reactions arranged in cycles and operated by means of specific enzymes. This cannot have been the original mechanism, if for no more compelling reason than that the enzymes themselves are produced by the system and are particularly complex bodies even for the simplest reactions. The problem here is to trace the evolution of such facilitating agents for increasing efficiency and speed of action in relation to the kind of substances available at the corresponding stage of molecular evolution. We have to examine the possible nature of proto-enzymes and protoco-enzymes. The relation between the reactions and the facilitators is a complementary one. Suitable enzymes must exist at every stage for all the essential reactions at that stage. However, a newly evolved or modified enzyme may in turn modify the reaction or produce new molecules. To some extent every enzyme system will select its own substrates and thus, by reciprocal interaction, biochemical evolution will advance. The modal elements of all organic and biochemical reactions are extremely simple, they all involve the juxtaposition of two particular atoms at hardly more than the sum of their atomic distances apart, the making or breaking of a bond and usually the insertion or removal of a proton. To secure any reaction at all the two components must be present in the appropriate quantum state; to secure that the reaction is only of one kind the molecules of the reagents must come together in the same configuration; to secure rapid reaction that configuration must be easily made and broken. The actions can be direct or mediated by other molecules with reactive groups of which sulphydryl, phosphate and iron ions are the commonest both in the inorganic and biochemical world.

The efficiency of the primary inorganic catalysts was probably extremely low, but this was of little importance as there could have been at the start no competition. Increase in efficiency and speed of reaction must have run in parallel with increasing complexity and size of structure. Two factors intervene in this evolutionary process: greater specificity of the reaction, implying the production of more stable attachment bases suitable for one particular reaction; and greater 
efficiency of the reaction, implying an adjusted set of quantum states for the more active agent in the transformation, and minimizing the activation energy. These functions we know today as those of enzyme and co-enzyme respectively. The first of these are now provided by the proteins, the second by nucleotides, flavones and some transition-metal compounds. It is most significant that, while the enzymes are so far innumerable, each responsible for one or two reactions only, the co-enzymes are few and each can function in many different reactions. Specificity in quantum level of the active partner would seem to be less important than specificity in spatial configuration in the passive partner.

The prevalence of nucleotides among co-enzymes is particularly noteworthy. The active group here is the terminal phosphate which can add one or two further phosphate groups that are easily detachable by a process of energy exchange, long known to biochemists as the energy-rich phosphate bond. In existing life and probably in life as far back as we can trace it the sugar-purine complex has been attached to the phosphate group. But this probably indicates a limiting stage of efficient modification of quantum levels. At an earlier stage, before sugars or purines had been synthesized, the basic phosphate-hydrogen exchange mechanisms had probably been active first as oligo- or poly-metaphosphate and then with phosphate linked with some simple carbon-nitrogen derivative such as cyanate. Indeed, as Lipmann claims [14], carbamyl phosphate $\left(\mathrm{OC} \cdot \mathrm{NH}_{2} \cdot \mathrm{OPO}_{3}\right)$ derived from the cyanate and phosphate ions can reasonably be regarded as the first living molecule, or at least as the first step in the evolution of biochemistry.

The association of phosphate with the fixing of carbon dioxide may be related to the basic anabolic process, the formation of amino acids and sugars at first in the triose glyceraldehyde form. The energy required for this came in the first place from dehydrogenation reactions, but at some stage it came to be derived from sunlight by photochemical reactions. The present highly efficient mechanism of photosynthesis is too complicated to have been an early one, but its place may have been filled first by some other and less efficient organo-metallic light trap, perhaps a clathrate compound of iron. The origin of the first effective photosynthesis, and with it the first production of molecular oxygen and its concentration in the atmosphere, may also be linked with that of the bulk production of pentose and hexose sugars. The earlier this occurred in biopoesis the earlier can have been the origin of the new omnipresent nucleosides.

Papers presented at the Symposiurn, notably those of Calvin, Krasnovskir, Reid and Sorokin, have enlightened me on the evolution of photosynthesis by emphasizing the separation of at least three factors existing in the photosynthesis of green plants: carbon dioxide fixation, light energy utilization, and oxygen production. These may well have originated separately. Carbon dioxide fixation using some other source of free energy I had already postulated as preceding photosynthesis. However, I had not considered the intermediate stage, which I now feel fits much better into the picture of photosynthetic decomposition, of $\mathrm{SH}$ groups giving molecular sulphur as now carried out by the sulphur bacteria.

This would have had the first effect of photosynthesis in biopoesis in providing a secure source of organic materials, perhaps even too much in the absence of 
oxidation mechanisms, leading to a hydrogen shortage which was only relieved by the evolution of a means of extracting it from water with an improved chlorophyll photocatalyst. Only after this stage had been reached and oxygen began to accumulate in the atmosphere did its pressure rise sufficiently to initiate the more complicated oxidative processes supplementing those of fermentation. Some oxidations of the sulphide to sulphur type may have preceded this stage, but the energy gain would have been much lower. In the overall picture of the evolution of the chemistry of life what we notice is not so much an improvement in the total energy changes-except in so far as solar energy is used-but rather in the effecting of a speedier turnover, in increase in power of assimilation or energy production.

With the other element in catalysis, the specific fixed base, similar considerations apply. It is clear that the present profusion of protein enzymes cannot have been primitive. A major problem is the discovery of what preceded them in this role. The degree of polymerization of amino acids and the complexity of their sequences which would be required before a protein could function as an enzyme is very great. Protein enzymes must therefore have come relatively late in biopoesis. What preceded them? Even simpler amino acid polymers cannot have been primitive and it would appear that the choice lies between postulating an inorganic crystal-clay or quartz as the primary catalyst or assuming that in the early stages there was no heterocatalysis and that reactions proceeded through the diffusion of active radicals as Pringle [I] has proposed.

The discussion of the first stages of biopoesis, the formation of what Pirie [2] has called probiotic soups, involves not only the chemical problems of the formation of the particular organic molecules they contained and of the reaction chains that link them, but also the physico-chemical problem of how these molecular concentrations were built up and maintained. It is conceivable, though I think unlikely, that no such stage of solution of monomers or oligomers such as amino acids, simple peptides, or sugar molecules, ever existed and the formation of such molecules went pari passu with their polymerization. If, however, free molecules ever existed or even more so, if there was a stage where these were the only molecules there were, the problem of how their diffusion was restricted is a real one that bears closely on the locus of the origin of life. All conditions counter-indicate the primary synthesis of anything but the very simple molecules, of say three to six atoms, in large volumes of water where the dilution is so great that the probability of chance encounters leading to more complex compounds would be negligible. The possibilities of small volumes of water such as occur in drying pools are rather greater as far as concentration go, but not the maintenance and propagation of the resulting substances and reactions, for the chances of drying up or washing out would be too great.

What is required is a medium free from turbulence and under constant conditions for long periods in which the diffusion of small molecules, though never stopped, would be so restricted that considerable concentrations could be built up and maintained. Such conditions are only likely to be found on an azoic Earth-in mud beds; under water; on dry land; or alternatively wet and dry as in tidal estuaries. From the purely physical point of view it is unimportant 
whether this layer is referred to as clay [3], or soil [4] or even the steady concentration gradient [I] for this could only be maintained in a medium weighed down by solids and the only solid that stays put under water is clay. It is a separate question to ask whether the small first-formed molecules were actually absorbed on the mineral particles or merely lay in their interstices and still another whether these particles also assisted in catalysing reactions between organic molecules. I suspect that such catalysis did occur on particles of montmorillonite, quartz and iron hydroxide, but this can only be proved by experiment. The argument that such structures or even their elements such as silicon or aluminium are not found extensively in living systems to-day is beside the point. There was no need for primitive life to synthesize crystals of materials that were amply available in its environment and when substitutes in the form of polymerized organic enzymes were formed there was no need to retain the original minerals.

As long as only small molecules formed from the condensation of carbon dioxide and ammonia were available, nothing in the nature of a separate organism was possible, only patches of fairly constant composition in which metabolism was maintained for various periods and which were more like cold flames than organisms as we know them. All such sub vital units would be broadly similar but not identical, and would have indefinite and shifting boundaries and could in general merge and fuse with one another. Where two were incompatible, one or both would be destroyed; where compatible, their range of biochemical activities would be increased by fusion. In the long run this would lead by a kind of natural selection to improved performance and uniformity within the areas in which interchange could take place, which may over extensive mud flats have been many square miles in extent.

The first crucial step which enabled life to get beyond this stage and to emancipate itself from mineral support was the production of polymers. These must not be imagined to have had in the first place the perfection of those we know in living things. The active polymers, the proteins and nucleic acids, are characterized by high degree of specific order in the arrangements of their various monomers. The passive polymers silk fibroin or cellulose seem to be simple regular polymers of a better quality than those produced artificially by most radical-activated polymerization processes.

It is not to be expected that the first natural polymers would have such a high degree of regularity or specificity. This, however, would not be required in the first place simply to provide the colloidal properties necessary to permit the existence of globules or proto-cells independent of mineral support and, owing to their lightness, able to float away and be distributed over larger areas. These proto-cells, which lacked membranes, would be formed by the loose coherence of neutral hydrated particles of dimensions of the order of I50-300 $\AA$. Owing to long-range ionic forces, whose precise mechanism has not yet been explained, such particles cohere in quite dilute solutions. They form, as Barbu \& Joly [5] have shown, coacervate drops when they are approximately spherical and tactoids or spindle-shaped drops when the particles are markedly elongated or flattened. The spontaneous formation of such coacervate drops, varying in size 
from sub-microscopic to a few millimetres, offers considerable justification for the hypothesis of Oparin [6] that the formation of coacervates formed one stage in the development of life. They would appear as a natural consequence of the formation of even irregular and polydisperse polymer molecules of protein. In so far as each coacervate drop contained most or all of the reactants and enzymes necessary for mutually supporting chemical reactions and could carry them out in the dilute medium from which it was precipitated, it qualifies as a self-subsisting system. However, as it was indefinitely divisible or miscible with other drops and possessed no mechanism for ensuring its reproduction it hardly qualifies as an organism and might well, following Pirie [2], be termed an eobiont.

If the physical consequences of polymerization made possible the existence of long-lived independent aggregates, its chemical consequences can have given rise to a more advanced characteristic of life, the regularization and fixing of reaction chains in the eobiont. Here evidence is accumulating that the key role was played by the polynucleotides or nucleic acids or perhaps by their possible precursors the polymetaphosphates or organo phosphates-phosphate groups linked by some polyalcohol, possibly as simple as glycerol and phosphoglyceraldehyde. The essential feature of any such system of linking is that the energytransferring power of the phosphate group is not lost. As Bresler [ 15 ] has shown, nucleic acid can be diphosphatized reversibly just as can a single nucleotide. At the same time a new formal element is introduced when two different nucleotides or proto-nucleotides are coupled-the possibility of a topochemical reaction specifically dependent on the order of linking of the nucleotides. This is the germ of the evolution of order and reproducibility in living systems. The degree of reproducible order we see now is very great; it cannot have been so at the outset. But further elucidation of the reciprocal relations of synthesis between proteins and nucleic acids should help to show how such a high degree of order could be built up step by step, from lower degrees.

Polymers, and especially ordered polymers, can acquire another form of regularity over and above that of the sequence of their monomers. According to the geometrical and chemical character of the identical repeating unit and its various residues, the polymer chain assumes one or many configurations determined sterically and through internal hydrogen bonding. In this way discrete spirals such as the Pauling [7] $a$-helix of fibrous proteins can be built up as well as the more complex two- or three-strand twining of deoxyribose nucleic acid (DNA) and collagen. Further coiled-coiling or folding can lead to discrete quasispherical molecules like those of the globular proteins with their potential enzyme activities. These in turn can become reduplicated and aggregated to form larger molecules and intracellular structures in a way discussed in more detail in my second paper. Here it is is sufficient to recall that the small globular proteins can aggregate almost as do separate atoms with different valencies. Univalent associations lead to doubled molecules as in the haemoglobins, bivalent association to chains and rings as in insulin, tervalent association to sheets or basket-like forms as found in viruses, multivalent association to clumps such as occur in haemocyanin. The associations can be of various degrees of stability, dependent on the nature of the surrounding medium, or they can become vir- 
tually permanent by the formation of covalent links, as in the production of fibrinogen. The most important is the so-called globular fibrous ( $g \rightleftharpoons \mathrm{f}$ ) transformation by which small protein molecules can be rapidly and reversibly aggregated into fibres, a phenomenon most carefully studied in the case of insulin. Such transformations seem to play a considerable part in intracellular mechanics, notably in the formation and disappearance of the mitotic spindle (tactoid).

The achievement of higher degrees of regular configuration must have depended to a certain extent on geometrical accidents, that is, it was a secondary consequence of a polymerization process involving primarily only the individual in the chain. For steric reasons any polynucleotide would tend to adopt a quasi-spiral structure with the flat purine and pyrimidine groups piled on top of each other, but nothing in the monorners could have preconditioned the possibility of the snug fitting of two identical polymers into a double spiral. Indeed out of many possible nucleosides produced by variations in their biosynthesis, those containing desoxyribose may have been selected on account of the close fitting and consequently low energy of their association in pairs. How important is this low energy is shown by the work of Rich [8] in which two complementary synthetic polyribose nucleotides, one with purine and the other with pyrimidine groups, each separately irregularly coiled, came together in vitro out of the quasi-infinity of possible configurations into a close double spiral similar to that of natural DNA. The stability and specificity of this fit we may well imagine led, though possibly somewhat late in biopoesis, to its use as the chief carrier of specificity in sexual reproduction.

The complementary, but not symmetrical, relation of proteins and nucleic acids probably belongs to this stage of biopoesis. A particular nucleic acid can promote the synthesis of one specific protein molecule, as is shown in the behaviour in vivo of viruses of both ribonucleic acid (RNA) and DNA type, and as Straub [9] has shown also in the production of the enzyme amylase in vitro using liver nucleic acid. On the other hand a specific protein enzyme can promote the syntheses of many if not all nucleic acids, as has been shown by Ochoa [10]. Which particular nucleic acid is formed may depend on the nature of the nucleic acid model already present. The story is only beginning to be unfolded and we shall no doubt hear more about it at this Symposium; however, enough seems to be established already to mark out the first appearance of the nucleic acidprotein, mutual synthesis relation as a decisive stage in biopoesis. Subsequent stages would involve the coming together of a set of different systems of this character to provide a comprehensive self-regenerating metabolic system.

The association of protein and nucleic acid also provides a new type of physical body in which a core of nucleic acid or nucleoprotein is surrounded by a shell of protein molecule synthesized by the core itself. This was first described for the plant (RNA) viruses by Franklin [II] and Caspar [I2] and probably also holds for the RNA-containing microsomes in the cytoplasm. Though it has not been so convincingly demonstrated, it also holds for the DNA-containing chromatin bodies in bacteria and for the chromosomes in higher organisms. It does not follow, however, that the actual production of protein or nucleic acids occurs in these bodics in the condition in which these have been observed. Rather 
then would it seem to mark a resting stage of a process which in full activity does not, and perhaps could not, occur in such an enclosed state. This we cannot know until their mechanism of reproduction has been observed.

However that may be, these small bodies $100-300 \AA$ in dimensions appear as the simplest macromolecular sub-units or organelles which form the population of cells or existing organisms. It would seem not unreasonable to imagine that they antedate cells themselves and may have first appeared as inhabitants of either the diffuse pools of metabolizing material or the coacervate drops already described. The protein-covered resting stage that we observe to-day in viruses may indeed in the first place have served to protect them when the rest of the system dried up. However, neither the nucleoprotein organelles nor the viruses can be considered as organisms in the full sense, or even by themselves as proto-organisms, because of their extremely limited and specialized metabolisms.

More elaborate organelles such as plastids, mitochondria and Golgi bodies, as well as some DNA viruses, possess another element which seems to mark them off as later in biopoesis. This is the presence of membranes, seeming to consist of phospholipid, usually appearing in double or multiple layers containing hydrocarbon chains of 16-20 atoms long. The present biosynthesis of lipids is much too complicated for it to have been their original synthesis.

Nevertheless they probably originated, then as now, from a condensation of two-carbon acids which in turn may be derived from sugars. I am still inclined to put their first appearance as somewhat late, but convincing evidence for this is lacking and this gap in our knowledge seriously hinders the building of a consistent scheme of biopoesis.

Because a hydrocarbon chain of more than a few atoms is hydrophobic, with the first synthesis of lipids there appears a foreign element in an aggregate of water-soluble molecules. Such lipid molecules are driven together to form micelles which if they are long and uniform take the shape of bimolecular ribbons or sheets. Though such micelles are not polymers in the chemical sense of being held together by covalent links, they play the same role in two dimensions as linear polymers do in one, though they are far more easily disaggregated and reaggregated. The function of lipid sheets in cells seems to be twofold: first as divisions between parts of a cell ; and second as the basis of attachment of other molecules, either active enzymes as lipoproteins or passive lipid-based protein membranes. This first function is an intrinsic consequence of the packing of long-chain hydrophobic molecules. Such sheets will automatically set themselves across concentration gradients and make it possible by closing up to maintain vesicles with a different chemical composition from their surroundings. The membrane-limited drop differs from the coacervate drop in holding up the diffusion of molecules and thus allows for much more intra-organismal specialization.

Double lipid membranes, such as those of soap bubble but with the hydrophilic side out, are intrinsically stable. They have been demonstrated in the electron microscope round such elementary structures as animal (DNA) viruses and bacteriophages and, although its structure seems more complicated, the cell 
nuclear membrane is also double. The association with DNA in all these cases may be significant, indicating the relatively later arrival of this form of nucleic acid. The disappearance of the nuclear membrane at the outset of mitosis may also be significant as a reversion to an earlier state of affairs. That most DNAcontaining structures are found within such membranes may also be an indication of the relative lateness of DNA over RNA in biopoesis.

One consequence of closed vesicles whose membranes offer a differential resistance to the diffusion of molecules of different size or character is the appearance of osmotic pressure and the need to equalize it by ionic mechanisms or periodic expulsions of liquid to secure any permanence for the enclosed system. The simple membrane-covered drop has a minimum surface for its volume. Where active molecules, such as enzymes, are attached to it greater effective surface can be obtained by pushing in the surface to form invaginations or cisternae leading to the kind of complexity found in mitochondria, plastids, Golgi apparatus, or endoplastic reticulum. At some such degree of complexity and interdependence of biochemically specialized parts we approach the first possibility of a self-subsistent enclosed cell, an organism rather than an organelle. How far the evolution was one single process, and how far it represents a fusion of partially competent but chemically interdependent sub-organisms still remains as a major problem in biopoesis. I am inclined to favour the latter alternative and even to postulate something like an organization of this fusion through the dominance of the more reliably self-reproducing DNA-protein mechanism. It would seem from the study of plant viruses that RNA-protein reproduction, precise as it is, can oniy take place in the presence of DNA and we as yet know of no independent organisms which only contain RNA.

It is perhaps best to leave the problem of physico-chemical biopoesis at this point and refer the study of further development to the older established disciplines of morphological evolution. Even the development of the nucleated cell of the protozoa and all higher organisms does not seem to depend on any radically new biochemical factor. The specialization of parts of cells and ultimately of whole cells for secretory, muscular, receptor or neural functions, seems to have been achieved by the setting apart and modifying of the chemical and structural elements already present in the generalized cell.

The general picture of biopoesis described above seems to fall into seven distinguishable stages set out in Table I. This provisional division is based essentially on the degree of coherence and organisation of the effective sub-vital or vital unit. In the first stage there is no degree of coherence. The whole or part of the hydrosphere-oceans or lakes-is the seat of the essential micromolecular prevital process. In the second stage further biochemical evolution occurs in concentrations determined by more or less fixed mineral aggregates forming extensive sub-vital units. In the third stage, thanks to polymerization, coacervate drops are formed liberating life from mineral dependence and constituting separate but indefinitely divisible and fusible eobionts. The fourth stage, which I admit is more hypothetical than the others, is that of nucleoprotein organelles similar to the viruses incapable of independent metabolism but set apart from the remainder of the uniform protobiont. The fifth and later stages 
are characterized by the presence of lipoprotein membranes giving rise to other types of organelles-mitochondria, plastids etc. The sixth stage envisages the formation of a membrane-enclosed cell, the first organism of the type of the present day bacteria. The seventh stage is that of the appearance of the nucleated cell of the protozoa, which is the basis of all the later evolution of species both plant and animal.

In the other columns of the Table I have put down hypothetical sequences of biochemical evolution running in parallel with the structural evolution outlined above which is shown in more detail in Fig. $x$. Here there is, on account of the greater complexity, no such clear sequence. The evolution of the main metabolites-amino acids, sugars, fats, enzyme systems, proteins and co-enzyme systems, nucleotides-must have proceeded in close interaction with each other but the pattern is still difficult to unravel. Nor are the correlations with the stages in the evolution of structure by any means as yet verifiable. Indeed some of the correlations suggested have been inserted only to provide the elements of a plausible detailed account. For instance, the origin of pentose sugars has been referred to the third or eobiont stage while that of the nucleic acids only occurs in the fourth stage. Good arguments could be adduced for referring them indeed to the second and third stages but that of the sugars must in all cases precede the nucleoside of which it is part. A similar doubt affects the position in the sequence of photosynthesis, which by providing abundant new energy must have led to a great break-out of vital evolution. It may, however, as I have earlier maintained, have occurred in a more primitive form from the very beginning, using ultraviolet light in the first place. I have abandoned this view because I now think that the essential anabolic step-the reduction of carbon dioxide to carbohydrate-can have been effected in the dark with hydrogen and free energy supplied by the oxidation of ammonia to nitrogen.

I realize that this is still a most debatable point, but the picture of an enlarged table in which every alternative suggestion finds some place is one I could not contemplate at this stage, though it might be well worth while to appoint a committee to draw one up as a provisional working hypothesis after this Symposium. The major problems of biopoesis, as I have seen them, are difficult enough to solve and no doubt others have found or will find many more before a generally accepted scheme can be drawn up. However, I list nine of them here in what I think may have been chronological order, and it is to be hoped that some of them will receive elucidation in the course of our present discussions.

I. What was the constitution of the original atmosphere? Was it oxidative or reductive in character? Did the carbon dioxide come from the lithosphere or from oxidation of hydrocarbons?

2. What was the nature of the first simple organic compounds? Had they a carbohydrate or amino character? Or were both formed simultaneously?

3. At what stages were triose and cyclic (pentose) sugars formed? At what stages were pyrimidines formed? When were purines formed from them?

4. What was the precursor of porphyrins as the molecule trap for photosynthesis? 
5. What was the first coherent metabolism of the sub-vital (mineral supported ?) indefinite areas?

6. What polymerized compounds stabilized the eobionts (coacervate drops)?

7. What were the first nucleoproteins? Did RNA precede DNA in the biopoesis?

8. What is the origin of long-chain lipids? What was contained in the first lipid-covered vesicles (organelles)?

9. What is the history of the nucleated cell?

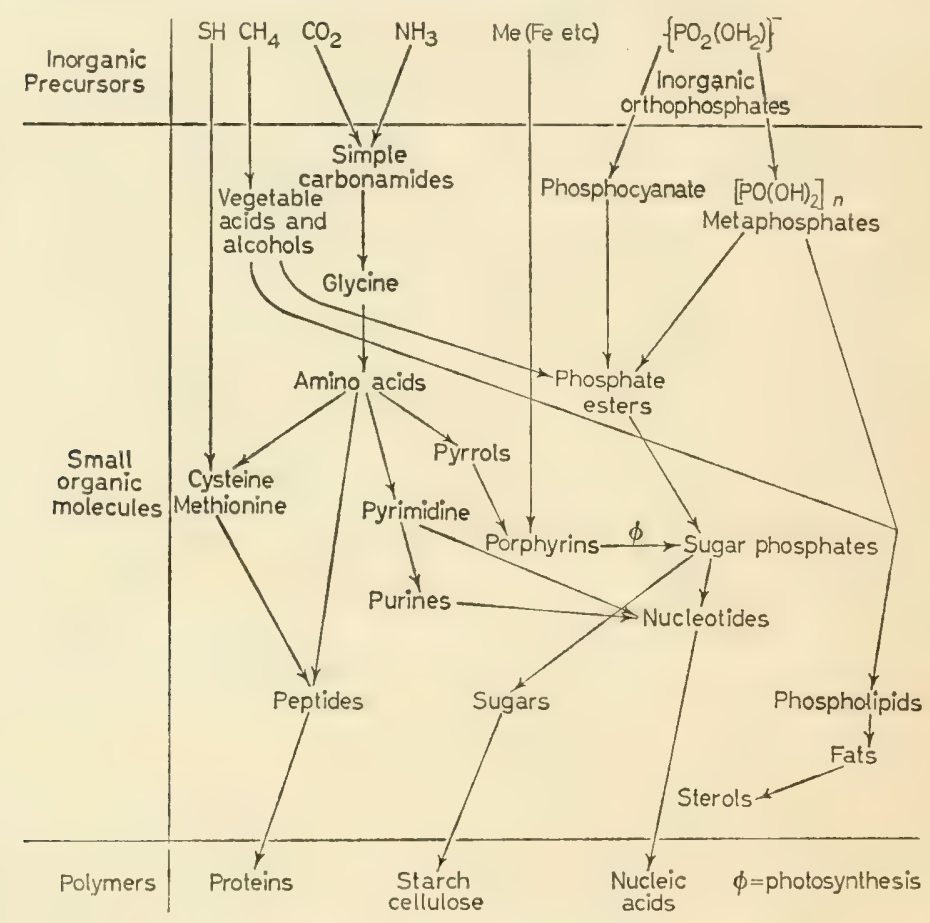

FIG. I. Scheme of organic molecular evolution

Of these questions $1,2,3,4,5$, and 7 form a sequence in biochemical history to which I have suggested answers in Fig. I. Questions 6, 8, and 9 form a sequence in the history of intracellular structure. The relation of the two sequences need not however be as indicated here or in Table $\mathrm{I}$.

To conclude, the purpose of this paper has been throughout not one of providing solutions to the problems of biopoesis but rather of formulating these problems themselves and putting them in some framework of order. The two chief tasks in the elaboration by many workers of a complete scheme of biopoesis are first the establishment of more or less plausible connected areas of development, those for instance of the origins of proteins or of photosynthesis, and secondly the reasonable linking of these areas of knowledge into a coherent whole. The first of these tasks has been much advanced in recent years, as witness the many valuable contributions to this Symposium, but the second is only just 
TABLE I. - Stages in biopoesis

\begin{tabular}{|c|c|c|c|c|c|c|c|c|c|c|c|c|c|c|}
\hline \multirow[b]{3}{*}{ I } & \multirow{3}{*}{$\frac{\text { Stage }}{\text { Production and concen- }} \begin{array}{l}\text { tration of simple mole- } \\
\text { cules }\end{array}$} & \multicolumn{5}{|c|}{ Main new constituents } & \multirow[b]{2}{*}{$\begin{array}{l}\text { Primary free- } \\
\text { energy source }\end{array}$} & \multicolumn{4}{|c|}{ Developments in Biosphere } & \multirow[b]{2}{*}{$\begin{array}{l}\text { Catalyst or } \\
\text { enzymes }\end{array}$} & \multirow[b]{2}{*}{$\begin{array}{l}\text { Coherence } \\
\text { mechanism }\end{array}$} & \multirow[b]{2}{*}{$\begin{array}{l}\text { Reproduction } \\
\text { mechanism }\end{array}$} \\
\hline & & $\begin{array}{l}\text { Surf: } \\
\text { Litho }\end{array}$ & $\begin{array}{l}\text { face of } \\
\text { osphere }\end{array}$ & Hydross & spphere & Atmosphere & & Free-energy sink & $\begin{array}{l}\text { Leading types } \\
\text { of metabolism }\end{array}$ & $\begin{array}{c}\text { Main } \\
\text { metabolites }\end{array}$ & Coenzymes & & & \\
\hline & & $\begin{array}{l}\mathrm{SiO}_{2} \\
\mathrm{AlSiO} \mathrm{OH}) \\
\mathrm{F}(\mathrm{OH})_{2} \\
\mathrm{CaCO}_{3}\end{array}$ & $\begin{array}{l}\text { Sand } \\
\text { Clay } \\
\text { Precipitated } \\
\quad \text { limestone }\end{array}$ & $\left.\begin{array}{l}\mathrm{NH}_{4} \mathrm{HCO}_{3} \\
\mathrm{H}_{2} \mathrm{~S} \\
\mathrm{NaCl} \\
\mathrm{KCl} \\
\mathrm{KH}_{2} \mathrm{PO}_{4}\end{array}\right\}$ & \} $\begin{array}{l}\text { Low } \\
\text { concentra- } \\
\text { tions }\end{array}$ & $\left.\begin{array}{l}\left.\mathrm{CO}_{2} \text { (or } \mathrm{CH}_{4}\right) \\
\mathrm{N}_{2} \\
\mathrm{NH}_{3} \\
\mathrm{H}_{2} \mathrm{~S} \\
\mathrm{H}_{2} \mathrm{O}\end{array}\right\}$ Very little & $\begin{aligned} & 2 \mathrm{NH}_{3} \rightarrow \mathrm{N}_{8}+3 \mathrm{H}_{3} \\
& \mathrm{~N}_{2}+2 \mathrm{H}_{2}+2 \mathrm{H} \\
& 8 \mathrm{SH}_{2} \rightarrow \mathrm{S}_{8}+8 \mathrm{H}_{2}\end{aligned}$ & $\begin{array}{l}\mathrm{CO}_{2}+4 \mathrm{H}=\mathrm{H}_{2} \mathrm{CO}+\mathrm{H}_{2} \mathrm{O} \\
\text { Fixation of } \mathrm{CO}_{2}\end{array}$ & $\begin{array}{l}\mathrm{CO}_{2}, \mathrm{NH}_{3} \\
\text { condensation }\end{array}$ & $\begin{array}{c}\mathrm{NH}_{4}^{+} \\
\mathrm{CO}_{2}(\mathrm{OH})^{-} \\
\mathrm{CO}_{2} \mathrm{NH}_{2} \\
\mathrm{HS}^{-}\end{array}$ & $\begin{array}{l}\mathrm{PO}_{2}(\mathrm{OH})_{2} \\
\left\{\mathrm{PO}(\mathrm{OH})_{2}\right\}_{n} \\
\text { Polymetaphos- } \\
\text { phoric acid }\end{array}$ & $\mathrm{SiO}_{3}$ ? & $\begin{array}{l}\text { Non-turbulent areas } \\
\text { Sea bottoms } \\
\text { Sand banks }\end{array}$ & None \\
\hline 2 & $\begin{array}{l}\text { Dehydrogenation and } \\
\text { condensation. SUB- } \\
\text { VITAL AREAS }\end{array}$ & Same with $\mathrm{E}$ & & $\left.\begin{array}{l}\mathrm{NH}_{4} \mathrm{HCO}_{3} \\
\mathrm{H}_{2} \mathrm{~S} \\
\mathrm{KCl} \\
\mathrm{NaCl}\end{array}\right\}$ & $\begin{array}{c}\text { Decreasing } \\
\text { concentra- } \\
\text { tion } \\
\text { Increasing } \\
\text { concentration }\end{array}$ & $\begin{array}{l}\text { Increasing } \mathrm{N}_{2} \\
\mathrm{Deccreasing} \mathrm{CO}_{2} \\
\mathrm{CH}_{4}, \mathrm{NH}_{3} \text { and } \mathrm{SH}_{2} \\
\text { disappear }\end{array}$ & Short-wave sunlight ? & The same & Dehydrogenation & $\begin{array}{l}\text { Amino acids } \\
\text { Trioses }\end{array}$ & $\mathrm{NH}_{2} \mathrm{CO} \mathrm{PO}_{2}(\mathrm{OH})$ & $\begin{array}{l}\text { Clay } \\
\text { Iron hydroxides }\end{array}$ & Adsorption on clay & $\begin{array}{l}\text { Continuity of sub- } \\
\text { vital areas }\end{array}$ \\
\hline 3 & $\begin{array}{l}\text { Polymerization and co- } \\
\text { acervate formation } \\
\text { EOBIONTS }\end{array}$ & $\begin{array}{l}\text { Organically } \\
\text { FeO(OH) } \\
\text { and } \mathrm{CaCO}_{3}\end{array}$ & formed & $\begin{array}{l}\mathrm{K} \text { ions and in } \\
\text { ions decrea }\end{array}$ & $\begin{array}{l}\text { norganic } \mathrm{PO}_{4} \\
\text { easing }\end{array}$ & $\begin{array}{l}\text { Very low concentration of } \\
\mathrm{CO}_{2}\end{array}$ & $\begin{array}{l}\text { Visible sunlight } \\
\text { Metal clathrate photo- } \\
\text { synthesis? }\end{array}$ & $\begin{array}{l}\text { Primitive photosynthesis } \\
2 \mathrm{H}_{2} \mathrm{~S} \rightarrow 4 \mathrm{H}+\mathrm{S}_{2}\end{array}$ & $\begin{array}{l}\text { Anaerobic fermen- } \\
\text { tation }\end{array}$ & $\begin{array}{l}\text { Peptides } \\
\text { Pyrimidines } \\
\text { Purines } \\
\text { Pentoses }\end{array}$ & $\begin{array}{l}\text { Proto nucleotides } \\
\text { Flavones }\end{array}$ & $\begin{array}{l}\text { Peptide proto- } \\
\text { enzymes }\end{array}$ & $\begin{array}{l}\text { Coacervate drops of } \\
\text { large peptide mole- } \\
\text { cules }\end{array}$ & $\begin{array}{l}\text { Simple division } \\
\text { Evolution and re- } \\
\text { production not } \\
\text { distinct }\end{array}$ \\
\hline 4 & $\begin{array}{l}\text { Nucleoprotein organ- } \\
\text { elles }\end{array}$ & $\begin{array}{l}\text { Organically } \\
\text { celerated }\end{array}$ & $\begin{array}{l}\text { formed ac- } \\
\text { weathering }\end{array}$ & $\begin{array}{l}\text { Composition } \\
\text { ing to pres } \\
\mathrm{NaCl} \\
\end{array}$ & $\begin{array}{l}\text { approximat- } \\
\text { esent but less }\end{array}$ & Rapidly increasing $\mathrm{O}_{2}$ & $\begin{array}{l}\text { Activated porphyrin } \\
\text { PHOTOSYNTHESIS }\end{array}$ & $\begin{array}{l}2 \mathrm{H}_{2} \mathrm{O} \rightarrow 4 \mathrm{H}+\mathrm{O}_{2} \\
\text { Photosymthesis liberation of } \\
\text { oxygen }\end{array}$ & $\begin{array}{l}\text { Formation and fer- } \\
\text { mentation of } \\
\text { carbohydrates }\end{array}$ & $\begin{array}{l}\text { Proteins } \\
\text { Nucleic acids } \\
\text { Starch }\end{array}$ & $\begin{array}{l}\text { ATP } \\
\text { RNA }\end{array}$ & Protein enzymes & $\begin{array}{l}\text { Protein-covered organ- } \\
\text { elles in coacervates }\end{array}$ & $\begin{array}{l}\text { Precise copying of } \\
\text { nucleo-proreins }\end{array}$ \\
\hline 5 & $\begin{array}{l}\text { Lipid-covered organ- } \\
\text { elles }\end{array}$ & The same & & $\begin{array}{l}\text { The same wit } \\
\mathrm{NaCl}\end{array}$ & ith increasing & $\begin{array}{l}\text { Atmosphere approximat- } \\
\text { ing to present compo- } \\
\text { sition }\end{array}$ & $\begin{array}{l}\text { Lipid plastids with } \\
\text { chlorophyll for photo- } \\
\text { thesis }\end{array}$ & $\begin{array}{c}(n+\mathrm{I}) \mathrm{CH}_{3} \mathrm{COOH} \rightarrow \\
\mathrm{CH}_{3}\left(\mathrm{C}_{2} \mathrm{H}_{4}\right)_{n} \mathrm{COOH} \\
\text { Lipid formation }\end{array}$ & $\begin{array}{l}\text { Oxidation of carbo- } \\
\text { hydrates }\end{array}$ & $\begin{array}{l}\text { Lipids } \\
\text { Sterols }\end{array}$ & DNA & The same & $\begin{array}{c}\text { Lipid-covered vesicles, } \\
\text { spherical and laminar }\end{array}$ & The same \\
\hline 6 & $\begin{array}{l}\text { Membrane-enclosed cells. } \\
\text { Protobacteris } \\
\text { ORGANISMS } \\
\end{array}$ & $\begin{array}{c}\text { Organic so } \\
\text { areas }\end{array}$ & oils on land & $" \quad "$ & & The same & $\begin{array}{l}\text { Oxidation of } \mathrm{S} \text { and } \mathrm{Fe} \\
\text { with atmospheric oxy- } \\
\text { gen }\end{array}$ & $\begin{array}{l}\text { Maintenance of ionic con- } \\
\text { centrations }\end{array}$ & - & Cellulose & The same & $"$, & $\begin{array}{l}\text { Lipid-based } \\
\text { cell membrane }\end{array}$ & $\begin{array}{l}\text { Fission and conju- } \\
\text { gation of nucleo- } \\
\text { proteins }\end{array}$ \\
\hline 7 & $\begin{array}{l}\text { Nucleated cells } \\
\text { PROTOZOA }\end{array}$ & $\begin{array}{l}\text { Trapped or } \\
\text { in sedimer } \\
\text { Oil }\end{array}$ & $\begin{array}{l}\text { rganic matter } \\
\text { :nts }\end{array}$ & $" \quad "$ & & $" \quad "$ & $\begin{array}{l}\text { Separation of photosyn- } \\
\text { theric plants from } \\
\text { organiphagic animals }\end{array}$ & - & - & $\begin{array}{l}\text { Fibrous protein } \\
\text { Myosin } \\
\text { Collagen }\end{array}$ & & $"$, & $\begin{array}{l}\text { Nuclear membrane } \\
\text { Protein-covered cell } \\
\text { wall }\end{array}$ & $\begin{array}{l}\text { Mitosis and sexual } \\
\text { reproduction }\end{array}$ \\
\hline
\end{tabular}



beginning and I hope that the suggestions I have made here may do something to rouse interest in it.

\section{REFERENCES}

I. J. W. S. Pringle, Nerw Biol., 16, 54, 1954.

2. N. W. PIRIE, Nerw Biol., 16, 4I, 1954 .

3. J. D. Bernal, Proc. phys. Soc. Lond., 52, 537, 1949.

4. J. B. S. Haldane, New Biol., 16, r2, 1954.

5. E. Barbu \& M. Joly, Discuss. Faraday Soc., 13, 77, I953.

6. A. Oparin, Proiskhozhdenie zhisny. Moscow, 1924.

7. L. Pauling, Proc. nat. Acad. Sci., Wash., 37, 205, 195 I.

8. J. Rich, f. Amer. chem. Soc., 78, 3548, 1956.

9. F. B. Straub, Acta physiol. hung., 10, 137, 1956.

10. S. ОсноA, Science, 122, 907, 1955.

II. R. Franklin, Nature, Lond., I77, 928, 1956.

12. D. L. D. CASPaR, Nature, Lond., 177, 475, 1956.

13. N. H. Horowitz, Proc. nat. Acad. Sci., Wash., 3I, I53, 1945.

I4. M. E. Jones, L. Spector \& F. Lipmann, f. Ainer. chem. Soc., 77, 819, 1955.

I5. S. E. BRESLER (private communication).

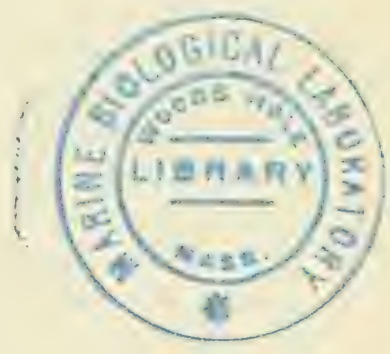




\title{
The Formation of the Earth from Cold Material and the Problem of the Formation of the Simplest Organic Substances
}

\author{
B. YU. LEVIN \\ O. Shmidt Institute of Geophysics \\ of the Academy of Sciences of the U.S.S.R., \\ Moscow
}

ONE ASPECT of the problem of the origin of life may be formulated as the following question: How, and under what conditions did the abiogenic synthesis of organic compounds take place and lead to the appearance on our Earth of organisms, which later became the major synthesizers of these compounds? To obtain an answer to this question it is necessary to survey the history of the whole substance of our planet, as this history determines how far abiogenic synthesis could proceed and what was the state of the Earth at the time when life came into being.

I. Let us begin with the question of the time and place of the original formation of the organic compounds which is most closely asssociated with the question of the formation of the Earth. For a long time there prevailed, among those who studied the formation of planets, hypotheses according to which the Earth and other planets were formed from aggregations of incandescent gaseous material. At temperatures of several thousands of degrees $\mathrm{C}$ organic compounds cannot exist. These hypotheses therefore led to the assumption that organic compounds were only formed after the formation and sufficient cooling of the Earth.

At present there prevails, among students of the origin of planets, a different opinion as to the 'original' state of the planetary material. Almost all contemporary hypotheses concerning the origin of the planets regard them as having been formed from a cold cloud of gas and dust which at one time encircled the Sun. In such a cloud the simplest organic compounds must have been present, just as they are present elsewhere in the interstellar gases.

However, the unanimity with which those who study the origin of the planets agree about the 'original' state of the planetary material does not mean that the authors of theories about this subject are unanimous in their ideas about its further evolution, the actual process of formation of planets. In particular, and this is very important in connection with the problem we are considering, different workers have different views as to the later thermal history of the original material of dust and gas. Thus Kuiper $[1,2]$ considers that very massive protoplanets composed of dust and gas must have been formed within the cloud of dust and gas. He claims that their compression, in the course of their trans- 
formation into the planets of the present, was accompanied by strong heating on account of the gravitational energy thus released. A similar idea is now advocated by V. G. Fesenkov $[3,4]^{*}$. If this idea of Fesenkov were correct it would mean that the simplest organic compounds which existed in the preplanetary cloud must have disintegrated during the hot stage and only after the Earth had become sufficiently cool could their formation begin again. In this case the compounds which existed in the cloud cease to interest us and the problem of the original formation of the simplest organic compounds is exactly the same as it was at the time when the hypotheses of Jeans and his associates prevailed.

The other extreme case, in which there is supposed to be minimal heating of the Earth during the process of its formation, is that envisaged in the theory of O. Yu. Shmidt [6-8]. According to this theory the Earth was formed by the gradual accumulation of dust particles of the protoplanetary cloud taking place at low temperatures. An essential intermediate stage in this process was the formation of a multitude of bodies of the size of asteroids. The collision of these bodies naturally led to heating, but this was localized. As well as the nonvolatile stony materials which constituted the main part of the mass of the Earth, there must have entered into it various gases, both in the sorbed state and in the form of frozen bodies formed in cold parts of the cloud far away from the Sun and entering the zone where the Earth was being formed. In this way organic compounds existing in the preplanetary cloud could perfectly well enter the Earth and be present throughout the whole depth of its substance. Contemporary organic substances on the Earth are, if one may put it so, the direct descendants of the organic compounds of the protoplanetary cloud.

The ideas of Urey [9-I4] are, to some extent, intermediate between those of Fesenkov and Shmidt. According to Urey, the main process consisted in the accumulation of cold solid particles, but he considers that, at some stage, there was strong superficial heating of the asteroid-like bodies. We shall return later to the question as to why Urey needed to postulate this heating. In the meanwhile it is important for us to note that, according to Urey, the composition of the internal parts of the asteroidal bodies remained unchanged during heating. According to Urey, therefore, as well as to Shmidt, organic compounds from the preplanetary cloud must have entered into the composition of the Earth.

Without entering into detailed criticism of Kuiper's and Fesenkov's hypothesis from the astronomical point of view we will only point out the implausibility and baselessness of their supposition that, when gravitational instability developed within the preplanetary cloud and it began to disintegrate into separate aggregates, there was formed just one protoplanet for each planet. In fact, gravitational instability must have led to the development of many aggregates (protoplanets),

* Recently, in a book written in collaboration with A. I. Oparin [5], V. G. Fesenkov has expressed ideas which are essentially similar to those of $O$. Shmidt. In particular, he considered that the Earth was formed by gradual growth and that, in the first place, it was relatively cold. Nevertheless, he postulated a large original mass, 'the proto-Earth', with a high hydrogen content. This involved an internal inconsistency. In the address which he presented to the present symposium, V. G. Fesenkov has reverted to his earlier views which are similar to those of Kuiper. 
the later fate of which must, on account of their collision with one another, have been far more involved and complicated than that indicated by Kuiper.

A more important criticism of Kuiper's and Fesenkov's hypotheses for us to-day is based, not on astronomical, but on physical and chemical considerations. Data as to the chemical composition of the Earth and meteorites contradict the idea that the Earth was formed from a hot, massive protoplanet [9-I7]. We must emphasize that the contradiction only becomes manifest when one considers all the mutual implications of the chemical data. There is some chemical evidence which does not contradict the idea that the Earth was formed by such a process as Kuiper and Fesenkov postulate. This is the part of the evidence which has been surveyed in the works of, for instance, Eucken and Latimer, who therefore arrived at a wrong conclusion [12]. Furthermore, I. S. Shklovskii [18, I9] had shown that the process of thermal dissipation of gaseous aggregates takes place extremely slowly. It would be impossible, within the period allowed by cosmogonic theory, for the protoplanet to have got rid, by this means, of the tremendous amount of hydrogen which supposedly entered into its composition.

Thus, Kuiper's hypothesis is open to most serious objections of an astronomical, physical and chemical nature. Objections of almost the same kind could be made to the views of V. G. Fesenkov. The replacement of the idea of the separation of hot gaseous bodies from the Sun, by the idea of their formation from a cold cloud of gas and dust was unsuccessful.

I am glad to notice that A. P. Vinogradov who, some years ago, subscribed to the view of the formation of the Earth from hot material, now supports the idea that it was formed from cold material, as may be seen from his paper (p. 23).

2. Inasmuch as I am taking part in the working out of O. Shmidt's theory, it seems to me that this is the theory which gives the clearest and most logical explanation of the essential features of the planetary system, both astronomical and chemical. It must, however, be mentioned that Urey's theory, to which I shall refer later, agrees, in many respects, with that of Shmidt. This agreement, which is increasing as both the theories are further developed, is very significant for two reasons. In the first place, Urey developed his theory independently of Shmidt. In the second, Urey was, primarily, basing himself only on chemical data and only secondarily on astronomical evidence, while the development of Shmidt's theory began (1943-44) with the explanation of the fundamental astronomical characteristics of the planetary system and only later (1949-50) embraced the chemical aspects. It must be added that Urey, being a chemist, made a detailed and penetrating analysis of the chemical evidence.

The process of evolution of the protoplanetary cloud and the formation of the planets as envisaged by Shmidt's theory, may be conventionally divided into two stages. The first comprises the formation of numerous bodies with diameters of several hundreds of kilometres (we shall call these bodies of an asteroidal type or simply asteroidal bodies). The dust component of the cloud must have settled comparatively quickly into its central plane, i.e. it became collected into a very flat disc. The breakdown of this disc into separate aggregates owing to the onset of gravitational instability would seem to have been the chief way in which the asteroidal bodies were formed. If the properties of the dust 
particles were such that they stuck together when they hit one another, then the formation of asteroidal bodies may have happened in this way too.

Owing to the opacity of the disc of dust, its outer zone was extremely cold (at a temperature of about $3^{\circ} \mathrm{K}$ ) and even volatile compounds condensed there. Only a small inner zone was heated by the Sun and there only solid particles and bodies made of compounds of high melting point could exist [20, 2I]. Thus, there developed a markedly zonal differentiation in the abundance and composition of solid material, in particular, of the asteroidal bodies which had accumulated by the end of this first stage.

The second stage of evolution, which began even before completion of the first, consisted in the formation of planets from the swarm of asteroidal bodies (and also from the fragments which were formed when they collided). The original circular orbits of these bodies gradually became elliptical owing to their gravitational attraction and this provided a wide 'feeding zone' for each planet. The natural averaging out of the pecularities of movement of the separate bodies, which occurred when they amalgamated, led to the orbits of the planets being almost circular. Zonal differences in the characteristics and composition of solid matter caused, as we have said, by differences in temperature, are now reflected in differences in mass and composition between the two groups of planets, those belonging to the same group as the Earth and the giant planets.

According to this concept, the planets of the same group as the Earth, and also the Moon, should be of essentially the same composition. We have no direct evidence of the composition of these bodies and are therefore obliged to judge their composition by their mean densities, in the case of the Earth $5.5 \mathrm{~g} / \mathrm{cm}^{3}$, in that of the Moon $3.3 \mathrm{~g} / \mathrm{cm}^{3}$. It would seem that, to solve the problem, it is necessary to adopt one view or another as to the nature of the dense core of the Earth.

For more than a century it was held that the core of the Earth consisted of nickel-iron. At present, however, most geophysicists believe that the core of the Earth may be explained by a discontinuity in the increase in density owing to the effects of high pressure. This idea was first put forward in a general form by V. N. Lodochnikov [22]. In 1948 the English physicist Ramsey [23-24] developed the same hypothesis independently and it soon obtained recognition. Working on the basis of the Lodochnikov-Ramsey hypothesis, it may be shown that the Earth, Venus, Mars and the Moon are of the same composition and only Mercury is made of denser material. This is obviously due to specially strong heating by the Sun's radiation of those parts of the preplanetary cloud from which Mercury was formed [17, 25-28].

Urey supports the earlier hypothesis, that the core of the Earth is largely made of iron. In this case the differences in density between the planets belonging to the same group as the Earth have to be interpreted as being a result of their differing contents of metallic iron. This leads one to look for processes which might have led to variation in the iron : silicate ratio. Superficial heating of the asteroidal bodies so that some of the silicates were vaporized without changing the internal composition seems to Urey [12, I3] the most likely, although the astronomical and physical aspects of this process remain extremely obscure [29]. 
However, as we have already said, Urey insists that the internal parts of the asteroidal bodies did not undergo any change. They should therefore bring into the composition of the Earth all those organic compounds from the protoplanetary cloud which had been incorporated in them when they accumulated at low temperatures.

Thus we see that, according to the theories of both Shmidt and Urey the simplest organic compounds must have entered into the composition of the Earth even during the process of its formation. The English astrophysicist Hoyle, who also believes that the Earth accumulated from solid particles, assigns to the organic compounds derived from the protoplanetary cloud, the determining role in the origin of life and the formation of petroleum beds [30].

Let us see what evidence astronomy provides about these simplest organic compounds.

3. Spectroscopic observations have shown that the simplest organic compounds exist both within our planetary system and far beyond its bounds. For example, it has been established that the gas-dust medium which occupies the whole of interstellar space contains molecules of $\mathrm{CH}$ and $\mathrm{CN}$. These molecules and also molecules of $\mathrm{C}_{2}$ are present in the atmospheres of relatively cold stars.

The giant planets, Jupiter, Saturn, Uranus and Neptune, contain large amounts of methane $\left(\mathrm{CH}_{4}\right)$ and ammonia $\left(\mathrm{NH}_{3}\right)$ which are undoubtedly of abiogenic origin.

Spectroscopic observations have revealed the presence of molecules of $\mathrm{C}_{2}$, $\mathrm{C}_{3}, \mathrm{CN}, \mathrm{CH}, \mathrm{OH}, \mathrm{CO}$ and $\mathrm{N}_{2}$ in the heads and tails of comets. Until recently it was believed that these chemically unstable radicals made their appearance as a result of the photodissociation of chemically stable parent molecules which were given off as vapours (desorbed) from the nuclei of the comets. It was supposed that $\mathrm{CH}_{4}, \mathrm{NH}_{3}, \mathrm{CO}_{2}$ and $\mathrm{H}_{2} \mathrm{O}$ acted as such parent molecules. Recently, however, Donn \& Urey [3I] basing themselves on the laboratory experiments which have been carried out during recent years by various workers, have put forward the hypothesis that frozen, unsaturated radicals are present in the nuclei of comets.

Turning to the planets belonging to the same group as the Earth we must note that $\mathrm{CO}_{2}$ is present in the atmospheres of Venus and Mars. The amount of $\mathrm{CO}_{2}$ present on Venus is equivalent to a layer $\mathrm{I} \mathrm{km}$ thick (at normal temperature and pressure) and that on Mars to one $440 \mathrm{~cm}$ thick, i.e. twice as thick as that on the Earth.

Among the bodies formed in the inner zone of the planetary system must be included the meteorites which fall on the Earth. In the regions of the planetary system which are far from the Sun there are probably meteorites made of the 'ices' of various gases, i.e. bodies related to the nuclei of comets. However, the metcoric bodies which move through the same region as the Earth, that is, those near to the Sun, are composed of materials of high melting point, silicates and nickel-iron. Among the gases which are present in a sorbed form in all meteorites, without exception, are organic compounds. The gases given off by meteorites when they are heated contain $\mathrm{CO}_{2}, \mathrm{CO}, \mathrm{CH}_{4}, \mathrm{H}_{2}, \mathrm{~N}_{2}, \mathrm{H}_{2} \mathrm{~S}$ and $\mathrm{SO}_{2}$. The Presence of hydrocarbons on some meteorites has been wcll known for a long 
time. It was just this fact which served as a basis for N. V. Sokolov when, in 1890, he put forward the hypothesis that organic substances entered into the composition of the Earth at the time of its formation [3I $a$ ].

Extremely interesting evidence about the organic compounds of the planetary system is provided by the study of one type of meteorites, namely the carbonaceous chondrites. They are called carbonaceous because they contain amorphous carbon, and possibly also graphite, as well as various hydrocarbons. Some years ago Mueller [32] undertook a study of such compounds in one such meteorite in the British Museum. This work is so far the most comprehensive.

The British Museum contains specimens from all the 20 carbonaceous chondrites which are known from all over the world. It has been shown that nineteen of these give no fluorescence with ultraviolet rays. This indicates the absence of free hydrocarbons having a $\mathrm{H} / \mathrm{C}$ ratio greater than I.4.

The hydrocarbons contained in the Cold Bokevelt meteorite have been submitted to detailed analysis. Extraction with numerous solvents (methyl alcohol, ethyl alcohol, chloroform, benzene) applied in various orders has shown the extracted material to amount to $I \cdot I \%$, the greatest part being extracted with ethyl alcohol and benzene. The extracted material after deduction of ash $(\mathrm{I} 8 \%$ ) and crystals of sulphur (II-I2\%) had the following composition: C, $24.26 ; \mathrm{H}, 8.12 ; \mathrm{N}, 4.00 ; \mathrm{S}, 8.78 ; \mathrm{Cl}, 5.89 ; \mathrm{O}$ etc., $48.95 \%$.

The presence of chlorine in organic compounds is of particular interest since halogens are absent from terrestrial bitumens.

A study of thermal breakdown at temperatures up to $350{ }^{\circ} \mathrm{C}$ showed that the substances extracted lost $55 \%$ of their weight while the powdered meteorite lost only $8.85 \%$ (mainly due to the loss of combined water which is present in all carbonaceous chondrites).

By comparing the carbon compounds present in the Cold Bokevelt meteorite with the bituminous substances found in terrestrial sedimentary deposits, Mueller noticed the following two important differences. In the first place, on heating the meteorite lost water, but it did not give off liquid hydrocarbons. In the second place, terrestrial carbonaceous substances are not, as a rule, extracted by solvents. The first of these assertions requires confirmation as Boato [33] found that, on heating powdered specimens of some carbonaceous chondrites. to $250-300^{\circ} \mathrm{C}$, oily sublimates made their appearance in a number of cases. Nevertheless, there is a difference between the carbonaceous compounds in meteorites and the terrestrial bituminous substances, and, in particular, the abiogenic origin of the meteoritic compounds is not open to the least doubt. Terrestrial minerals of biological origin always give optical rotation while the extracts of meteorites studied by Mueller were optically inactive. He therefore made special mention of a fallacy which is often met with in popular literature, namely that the presence of organic compounds in meteorites may be interpreted as indicating the presence of life on those bodies from which they originated. Mueller believes that the meteoritic organic material consists of com plicated organic acids which arose abiogenically by a process of polymerization in a gaseous medium containing nitrogen, chlorine and sulphur. Judging from the difficulty of dissolving silicates, this material envelopes the stony particles. 
Unfortunately we lack any more accurate data about the composition of meteoritic organic material. One can only add that the composition of these carbonaceous compounds must reflect the equilibrium between carbon on the one hand and hydrogen, oxygen, nitrogen and sulphur on the other, which was established at the time when the substance of the meteorite attained its highest temperature.

While studying the isotopic composition of the carbon and hydrogen from twelve carbonaceous meteorites, Boato [33] found a notable difference between the different meteorites and, in some cases, between different parts of the same meteorite. This is due to a process of fractionation or to chemical reactions taking place at different stages of the formation of the meteorites and the whole planetary system. Data as to the isotopic composition of the carbon and hydrogen will be very valuable in later investigations of these processes and, in particular for a study of the original organic compounds.

4. Let us come back, at last, to our own Earth. As we have already said, various gases and vapours, as well as organic compounds, must have entered into the composition of the whole thickness of the substance of the Earth during its formation. During the gradual heating of the interior of the Earth owing to the accumulation of heat generated by the decay of radioactive elements, gases and vapours began to seep towards the surface and were given off, forming the atmosphere and hydrosphere [15]. This same process of internal heating led to the gradual development of the crust of the Earth starting about 3000 million years ago when the temperature became high enough for the partial melting of silicates. We must note that A. P. Vinogradov (p. 23) makes a great mistake in assuming that the temperature of the superficial layers of the Earth changed according to a curve corresponding approximately with that for the amount of heat generated, and that at some time it was high. The mean temperature of the surface of the Earth was always low and was always determined by the heat reaching it from the Sun. The temperature of the interior, however, had in general risen throughout the long history of the Earth.

At present all astronomers, geologists, geophysicists and geochemists are agreed that the contemporary atmosphere and hydrosphere of the Earth are not the residues of some very extensive primary atmosphere, but are of 'secondary' origin, i.e. they have arisen owing to the gradual giving off of gases and vapours from the interior [34-39 and Sokolov, p. 54]. Among other evidence indicating that the hydrosphere and atmosphere arose in this way, an important piece is that concerning the absence of any great fluctuations in the $\mathrm{CO}_{2}$ content of the atmosphere during the course of the whole of geological history. As the amount of carbon laid down in carbonaceous deposits increased in the course of time, there must have been a continual accession of $\mathrm{CO}_{2}$ to the atmosphere.

The emergence of gases and vapours from the interior into the atmosphereduring volcanic eruptions, through gas springs and by the general 'breathing' of the planet-continued until the present, though, unfortunately to what extent these gases and vapours are juvenile and to what extent they are taking part in cycles involving only the outer layers of the Earth we do not know. Thus, for example, we cannot tell what part of the methane which is present in the atmosphere or that which is given off by sources of natural gas, is of abiogenic origin. 
The presence of such abiogenic, cosmic methane, though perhaps only in the distant past, perhaps in the first stages of the emission of gases from the interior of the Earth, may be inferred from its presence on the other planets, in meteorites and from what are now known to be the essential features of the process of formation of the Earth. From the fact that methane is present in eruptive formations it also follows that abiogenic methane must, up till now, have been given off from the interior to a greater or lesser extent.

It is hard to estimate the overall quantity of hydrocarbons and abiogenic organic compounds in general which was present in the whole volume of the Earth in the past and the quantity it now contains. It is, however, clear, from the evidence adduced already, that this quantity may be very large. This circumstance is one of the incentives to a search for ways in which petroleum could have been formed abiogenically. The main stimulus to such a search is the fact that analysis of geological data concerning the conditions under which petroleum has been laid down and concerning the distribution of natural gases in the Earth suggests that petroleums are of purely abiogenic origin [4O, 4I].

The ironic way in which Hoyle [30] referred to the organic theory of the formation of petroleum and the absence from his book of serious discussion of the possibility of its inorganic origin evoked a protest from Link, the president of the American Association of Petroleum Geologists [42]. That there is a serious basis for working out a non-organic theory of the formation of petroleum is evident from, for example, the fact that that eminent specialist on the question of the formation of petroleum, Prof. V. D. Porfir'ev has changed his earlier opinion and now embraces the non-organic theory [43]. At the same time we must draw attention to the perfectly correct appeal by Link for a reconciliation between the views of representatives of related scientific disciplines.

As Mueller pointed out, even before the formation of meteorites, that is to say, in the very earliest stages of the evolution of the dust-gas cloud, hydrocarbons could polymerize, forming the hydrocarbon compounds which are present now in the carbonaceous chondrites. Thus, it was not only methane, but also these more complicated compounds which entered into the composition of the Earth from the very beginning. Such of these compounds as are not now present in the interior of the Earth probably broke down long ago into simpler ones owing to the high temperatures which now prevail there. However, such of them as managed to move outwards towards the surface while the temperature was still moderate could have undergone further complication and polymerization during their journey towards the surface.

Finally, when they emerged on to the surface of the Earth they were exposed to new possibilities. According to Süss, the photodissociation of methane in the presence of water vapour indicates a possible mode of synthesis of the most diverse organic substances. Evaluation of these complicated questions of organic chemistry is outside the sphere of competence of astronomers and geophysicists. Chemists must play the main part here.

Nevertheless, the evidence of contemporary astronomy and geophysics leads to two conclusions which seem to me important for the problem of the origin of life. In the first place, organic compounds of varying degrees of complexity 
existed in the preplanetary material and, with it, entered into the composition of the Earth through its whole depth. In the second place, the emission of gases and vapours from the interior, leading to the formation of the hydrosphere and atmosphere, was accompanied by the carrying out of organic compounds which underwent further changes in the course of it.

Such then, is the astronomical and geophysical background which must be borne in mind when considering the problem of the origin of life on the Earth.

\section{REFERENCES}

I. G. P. KUIPER, Astrophys. F., 109, 308, 1949.

2. G. P. KuIPER, in Astrophysics (Ed. by J. A. HYNEK). McGraw-Hill, New York, I95 I

3. V. G. FESENKov, Sovremennye predstavleniya o proiskhozhdenii nebesnykh tel. Akad. Nauk S.S.S.R., Moscow, 1953.

4. V. G. FESENKOV, p. 9.

5. A. I. Oparin \& V. G. FeSENKov, Zhizni vo vseleno'. Izd. Akad. Nauk S.S.S.R., Moscow, 1956.

6. O. Yu. Shmidt, Dokl. Akad. Nauk S.S.S.R., 45, 245, 1944.

7. O. Yu. Shmidt, Chetyre lektsii o teorii proiskhozhdeniya Zemli. 3rd ed., Moscow, 1958.

8. O. J. Shmidt, Mem. Soc. Sci. Liège (Liège symposium, 1954), 15, 638, 1955.

9. H. C. UREY, Geochim. et cosmoch. Acta, I, 209, I95I.

IO. H. C. UREY, The Planets. Yale Univ. Press, 1952.

II. H. C. UREY, XIIIth Int. Congr. pure appl. Chem., 1953, p. 188, Uppsala, 1954.

I2. H. C. UrEY, Astrophys. F. Suppl., I, I47, I954.

13. H. C. UREY, Chapter Io in Nuclear Geology (Ed. by H. FAUL). John Wiley, New York, p. 355, 1954.

I4. H. C. UREY, Astrophys. F., 124, 623, 1956.

15. B. YU. Levin, Priroda, Leningr. xo, 3, I949.

I6. B. Yu. Levin, Izv. Akad. Nauk S.S.S.R., Ser. Geofiz., 4, 289, I953.

17. B. YU. LeVIN, Trudy geofizich. Instituta Akad. Nauk S.S.S.R., 26 (I53), II, 38, I955.

I8. I. S. SHKLovskil, Dokl. Akad. Nauk S.S.S.R., 76, I93, I95I.

I9. I. S. SHKLovskiľ, Astr. zhur., 28, 234, I95I.

20. L. E. GuREvich \& A. I. Lebedinskiř, Dokl. Akad. Nauk S.S.S.R., 74, 905, 1950.

2i. L. E. Gurevich \& A. I. Lebedinskiľ, Izv. Akad. Nauk S.S.S.R., Ser. Fiz., I4, $790,1950$.

22. V. N. Lodochnikov, Zap. Min. Obshchestva, 2 Ser., 64, 207, 1939.

23. W. H. Ramsey, Mon. Not. R. Astr. Soc., 108, 406, 1948.

24. W. H. Ramsey, Mon. Not. R. Astr. Soc., Geophys. suppl., 5, 409, I949.

25. K. E. Bullen, Nature, Lond., I70, 363, 1952.

26. K. E. Bullen, Seismology. Methuen, London, I954.

27. K. E. Bullen, Ann. Géophys., II, 53, 1955.

28. S. V. KozlovsKaya, Dokl. Akad. Nauk S.S.S.R., 92, 903, 1953.

29. B. J. Levin, Mem. Soc. Sci. Liège (Liège symposium, 1956), 18, I86, I957.

30. F. HoYle, Frontiers of Astronomy. London, I955.

31. B. DONN \& H. C. UREY, Astrophys. F., 123, 339, 1956.

31a. N. V. Sokolov, Byull. Mosk. O-va Ispyt. Prirody, 3, 720, 1890.

32. G. MUEller, Geochim. et cosmoch. Acta, 4, I, I953.

33. G. BoAto, Geochim. et cosmoch. Acta, 6, 209, I954.

34. G. P. KuIPER, Astrophys. F., 100, 378, 1944.

35. H. Brown, in The Atmospheres of the Earth and Planets (Ed. by G. P. KuiPER). Univ. Chicago Press, 1949.

36. R. T. Chamberlin, ibid.

37. J. L. Kulp, Bull. geol. Soc. Amer., 62, 326, 1951.

38. W. W. RuBEY, Bull. geol. Soc. Amer., 62, 326, I951.

39. B. MASON, Principles of geochemistry, N.Y. - London, 1952.

40. P. N. Kropotkin, Sov. Geol., Moscow, 47, 104, 1955.

4r. P. N. KRopotkin, P. 84.

42. T. A. Link, Bull. Amer. Ass. Petrol. geol., 41, 1387, 1957.

43. V. D. PORFIR'Ev, Tezisy dokladov na yubileìnoi nauchno-tekhnich. konfer. L'vovskogo Politekhn. Inst., I957. 


\title{
Chemical Diversity and the Origins of Life
}

\author{
N. W. PIRIE \\ Rothamsted Experimental Station, Harpenden, Great Britain
}

CONTEMPORARY discussions about the origin of life start with the simplifying assumption that no occult phenomena are involved and no forces or principles operated to bring life into being in the past that do not operate now. This assumption is sometimes called the 'uniformitarian' principle. The chemistry and physics with which biology is and has been concerned is the ordinary chemistry and physics of the period at issue but we know very little even of the chemistry and physics of to-day and the little we know is not necessarily the most relevant part. Furthermore, Haldane argues $[I, 2]$ that chemistry and physics may have been significantly different in the Pre-Cambrian. That would complicate detailed interpretation but would not affect the principle.

This basic assumption has been made by most scientists and philosophers who have considered the problem. They have not disagreed about whether life could originate from non-living matter but only about how often it did so. The 2500 year history of this dispute has often been surveyed (e.g. Huxley, Tyndall, Oparin). On the one side we have such men as Redi, Spallanzani, Pasteur and Tyndall who regarded the event as so infrequent that it could be disregarded in the course of ordinary work; on the other such men as van Helmont, Needham, Pouchet and Bastian who looked on it as an easy and regular transition. Although the dispute did not always proceed along strictly objective lines it was extremely valuable both in integrating knowledge and in uncovering new phenomena. In this respect it contrasts with the idea that 'Life' is something quite different from anything else and that it either comes to us from space or is the consequence of special activity by a deity or demiurge. Though sterile, this conclusion has been common among physicists and engineers and has been come to by a few biologists such as Linnaeus and Wallace.

The 'uniformitarian' principle takes us to the limit of simplicity. Before we can frame a theory of the origin of life we should know the nature of the environment in which it originated and we should know, or be able to define, the criteria by which we would define or recognize it. Unfortunately we know neither. During the nineteenth century it was generally assumed that Earth had cooled from an incandescent mass so that if any form of life had been carried over from an earlier phase in its history it must have been carried by silicates or some such thermostable material. The discovery of radioactivity made the idea tenable that Earth originated by the accretion of cold interstellar detritus and so made the old 'cosmozoic' idea a little more attractive. But this idea merely moves our problem to a different environment [3] and does nothing to solve it. At present there are advocates for both a hot and a cold origin of Earth so that it would seem wise not to make our theory of the origin of life depend exclusively on either. 
On the conventional theory that Earth was originally incandescent with approximately its present mass, the oceans can only have formed after there was a solid crust and its components come from those parts of the total mass that later came near enough to the surface to be washed. Similarly the atmosphere consists of those original volatile components that were heavy enough to be retained by gravitation, together with subsequent exhalations. On the accretional theory, on the other hand, it is probable that a much larger proportion of the whole mass was exposed to liquid water during the process of condensation. It is already difficult, on the conventional theory, to account for the low salt content of the ocean; present-day rivers would bring down that amount in a fraction of the time for which the ocean is thought to have existed. On the accretional theory, the problem of what materials were initially present in solution is raised in an even more acute form and a recognition of this may keep us from being dogmatic about the composition of the pools that first formed on Earth.

It is unlikely, on either theory, that the probiotic atmosphere contained $\mathrm{O}_{2}$ because of the immense preponderance of $\mathrm{Fe}^{++}$over $\mathrm{Fe}^{+++}$in rock. $\mathrm{O}_{2}$ is now produced by photosynthesis at such a rate that each molecule of it in the atmosphere has a 'half-life' of only a few thousand years before returning to $\mathrm{CO}_{2}$ or $\mathrm{H}_{2} \mathrm{O}$. It is tempting to assume that $\mathrm{O}_{2}$ had this origin initially but that assumption cannot account for the immense deposits of sedimentary $\mathrm{Fe}^{+++}$and sulphate. If, as seems certain, these are made by atmospheric oxidation of $\mathrm{Fe}^{++}$and $\mathrm{S}$ or $\mathrm{H}_{2} \mathrm{~S}$, it is hard to see where all the $\mathrm{C}$ or other reducing material that is simultaneously produced during photosynthesis has gone to. As Herbert Spencer first pointed out, the $\mathrm{C}$ in shale, coal and oil is approximately equivalent to the $\mathrm{O}_{2}$ in the atmosphere now. A probiotic origin for $\mathrm{O}_{2}$ must be sought and one is readily available in photolysis of $\mathrm{H}_{2} \mathrm{O}$ in the upper atmosphere followed by loss of $\mathrm{H}_{2}$ into space. The atmosphere is a system through which the $\mathrm{CO}_{2}$ now present in limestone and dolomite, and the $\mathrm{O}_{2}$ now present in sulphates or instrumental in making $\mathrm{Fe}^{+++}$, has flowed. The quantities present in, or represented by, these 'fossil' forms of $\mathrm{CO}_{2}$ and $\mathrm{O}_{2}$ are very much greater than the quantities in the atmosphere or ocean now. This, taken in conjunction with the fact that rates of production and sequestration are uncertain by factors of at least Io, makes it legitimate to conclude that dogmatism about the composition of the atmosphere at any stage in Earth history before perhaps the Jurassic is out of place. Very large amounts of $\mathrm{O}_{2}$ and $\mathrm{CO}_{2}$ have passed through it and the concentration of either at any phase of history is still a matter of assumption. If a certain type of atmosphere is necessary for a certain type of biopoesis (see p. 78 , footnote) it is reasonable to postulate that atmosphere for argument but it is not reasonable, on existing information, to try to exclude some other type of atmosphere or mode of biopoesis. The fact that amino acids and related substances are made when electrical discharges pass through a mixture of $\mathrm{CH}_{4}, \mathrm{NH}_{3}, \mathrm{H}_{2} \mathrm{O}$ and $\mathrm{H}_{2}$ [4] is sometimes quoted as evidence that that was the composition of the probiotic atmosphere. This would be logical only if it were demonstrated that similar substances are not formed in other gas mixtures and if we know that these substances were the substrate from which the first life grew. There are geo- 
chemical reasons [5] for thinking that the probiotic atmosphere was mainly $\mathrm{CO}_{2}$ and $\mathrm{N}_{2}$.

As knowledge grows the range of possible compositions for Earth's surface will be narrowed. It could be argued that discussions about biopoesis might well wait till this narrowing had taken place. There are two important reasons for disagreeing with this idea. The urge to solve the problem of the origin of life is an important stimulus for the accumulation of evidence about the original environment. Reciprocally, if biochemical research could define unequivocally the necessary qualities and composition of an original organism, or eobiont*, this would define the conditions in at least part of the primitive environment. It would be analogous to the use of the morphology of fossils to define whether the region in which they lived was dry land, marsh or water.

There are many difficulties here. I have already argued [7] that, even with existing organisms and systems a rigid division into the living and the nonliving is not possible. Every criterion that has been suggested will both exclude something that, for aesthetic reasons, we wish to call living and include something that we do not. Something more satisfactory could be achieved by saying that a living organism had to show some arbitrary number out of a group of qualities but in practice this would be almost as clumsy as a catalogue of the things we intend to call living and it would operate particularly badly among the simpler systems where the issue becomes of most interest. It seems better to recognize that life is not a definable quality but a statement of our attitude of mind towards a system. This makes life a fallible guide through geochemistry.

Even if it is not possible to say that a system with certain activities is alive it may yet be possible to say that certain chemical substances or processes are peculiar to life and essential for it. A cursory study of present-day organisms shows many uniformities in their use of proteins, fats, carbohydrates, phosphoric esters etc. At one time particular attention was attached to the proteins, now there is a tendency to use the phosphoric esters as the fundamental criterion of life. It is of course perfectly legitimate to say that you do not propose to call any system alive unless it contains protein. That establishes a simple linguistic rule and it is essentially what Engels did in his celebrated dictum. But it is not a very useful point to make because not all systems containing protein or phosphoric esters are alive and to say that whatever else a system may be doing, it cannot be called alive if it does not contain the chosen substance, seems to be as arbitrary as the erection of a colour bar among people.

All present-day forms of life that have been examined contain protein. The number examined is only a small proportion of the whole but protein-based mechanisms seem to be so efficient that it is likely that most or even all the other forms of life also use proteins now. If this turns out to be so it will have no more relevance for a discussion about the origins of life than the now almost universal use of paper has for the origin of writing or the use of matches for the original making of fire. The first metal frying pan was probably made of gold because that metal was available and usable though later ousted. The point is worth

* I have proposed elsewhere [6] the words biopoesis and eobiont for the origination of life and for the first organisms originated and argued the advantages of the new words. 
labouring because very many people have written as if the problem of the origin of life was the same as the problem of the spontaneous synthesis of proteins and some, having realized that the latter involves difficulties, have concluded that God or some similar agency must be involved.

Proteins, so far as we know, are mainly useful to an organism because they are enzymes that catalyse metabolic actions very efficiently. But there are innumerable non-protein catalysts of similar actions. Oxidations can be catalysed by many metals and by thiourea, some of the rare earth elements are esterases and so on. An organism using such systems might be sluggish but it would be conceivable. If Corycium is indeed the fossil of an organism it was enigmatic in more ways than the paleontologists have thought of and probably organized its metabolism with the help of molecules that would not fit neatly into our systems of classification. Proteins, built economically out of about twenty-five amino acids, are probably a late development selected from a more chaotic group of primitive chemical experiments. Evolution operates to give us morphological structures that are relatively simple and efficient without being by any means the only possible structures; it is only reasonable to conclude that it also operated on chemical structure to make the efficient enzymes with which we are familiar.

The evidence for evolution, and the Linnaean system of classification, both make it appear that the number of species in existence at any time has been getting larger. Projecting this principle back it seems reasonable to think that all sprang from one or a few common ancestors [8]. This is logical enough but it is illogical to think that this ancestor was the original organism. It seems much more probable that this, the beginning of morphological complexity, was nearly the limit of biochemical complexity. With this idea in mind we may consider some aspects of biochemical complexity to see what hints they give us about the mechanisms that may have been made use of initially, and about the manner in which selection may have operated on them.

The origins of life were probably local phenomena. It is an illusion to think that rare events necessarily happen and prosper to an extent proportional to the amount of material to which they could happen. Thus, although human genius may arise unrecognized with a predictable frequency, it has flourished and become effective most often in specialized and often small communities. Similarly, Vavilov showed that new plant species often arise in the isolated and slightly adverse environments at the edge of the main areas of growth. I am therefore perfectly willing to postulate an effective environment less extensive than the whole probiotic hydrosphere. At different stages in Earth's history either the whole environment of parts of it probably ranged from being alkaline with $\mathrm{NH}_{3}$ to acid because of the oxidation of $\mathrm{S}$ and $\mathrm{H}_{2} \mathrm{~S}$. Two thousand million years of leaching, precipitation and rearrangement have considerably diminished the complexity of the mineral surfaces at which relevant actions may have gone on so that, besides the elements commonly present in large bodies of water now, it is reasonable to think about actions involving such elements as $\mathrm{V}, \mathrm{Ba}, \mathrm{Cr}, \mathrm{Se}$, Ge, etc., either in solution or, as Goldschmidt [9] suggested, at the reactive edges of crystals.

Oil and bitumen regularly contain vanadium: this suggests that it was once 
used commonly as it is still used by some tunicates. It is interesting that it is the primitive species of tunicate that have blood corpuscles containing large amounts of $\mathrm{V}$ and also normal, or stronger, $\mathrm{H}_{2} \mathrm{SO}_{4}$. An existence that depends on a strongly acid solution of an element as rare as $\mathrm{V}$ is obviously both hazardous and precarious so that more highly evolved species, able to do the same job with a commoner element, such as iron, have an advantage. Dependence on the use of $\mathrm{V}$ in quantity seems to have been disappearing and we see now only the last remnant of it. But selection does not operate in the same way against the use of traces of $\mathrm{V}$ and, in traces, the element is present in many organisms. It is essential for some moulds and algae [10] and probably for other plants as well. Much the same can be said for aluminium. It is essential for the growth of some plants and is widely distributed, particularly in the more primitive types such as tea [II] and lycopodium. It is not so easy here as with $\mathrm{V}$ to see what kind of reaction may be involved. In many species there is barium in the choroid and chromium in the blood corpuscles but there is no evidence whether these occurrences are the relics of ancient metabolic paths or the beginnings of new ones.

Selenium is widely distributed in rocks so that dependence on it would rarely be a serious disadvantage and yet it is seldom used and is poisonous to most species. A few plants however grow better in the presence of Se and it is built into their proteins in place of sulphur so that the protein is poisonous to animals. The phenomenon, if not the interpretation, was known to Marco Polo and a close study of it would be most illuminating.

The relationship between $S$ and Se leads naturally to a consideration of the possibility of a similar relationship between carbon and germanium. There is no evidence that $\mathrm{Ge}$ is essential for any present-day organism but the Hartley coal seam in Northumberland is rich in it and it is present in workable amounts in many other coal seams. This could be the result of adsorption of Ge by coal or its precursors but it is just as likely that coal-forming organisms used Ge. If they did, some may do so still, and a search might be rewarding both biochemically and commercially. The presence in fossils of some other elements, for example caesium, thallium and titanium suggests a biological role for them also, but secondary specific absorption, during the process of fossilization, confuses the interpretation of all evidence of this type. Argument about these elements may seem to be too nebulous to merit serious attention. There are two reasons for setting it out; it is important to keep all the possibilities to some extent in mind, and until the possible significance of this type of evidence is appreciated not much effort is likely to be put into finding or co-ordinating the facts.

Halogen metabolism offers some other hints about the early course of evolution. Halide ions have probably been available ever since liquid water formed, there may have been free chlorine, and chlorinated hydrocarbons are present in bitumens both of terrestrial and meteoric [12] origin. The ability to handle the halogen-to-carbon bond may therefore have been useful to an eobiont. Sponges still make extensive use of bromine compounds, so do the various species of mollusc that make Tyrian purple; there is at least one group of plants, Dichapetalum, that makes fluoroacetic acid and several of the moulds make a range of chlorine compounds. But the vertebrates have nearly given up this type 
of metabolic expertise. Not completely however; we still use iodine in the thyroid and normal life depends on this otherwise exceptional synthesis. There is no reason to think that this use of iodine is new; it is found in present-day amphibia and fish and may well be ancient. I suggest that it is a relic of an initially more catholic approach to metabolism and that evolution has not eliminated it because there are few regions where the amount of iodine in rock is so small as to make this dependence a disadvantage. The only logical alternative is to look on the thyroid as the remains of a commensal sponge that lodged in the gill arches of a primitive vertebrate giving rise ultimately to symbiosis as intimate and essential as that in the lichens.

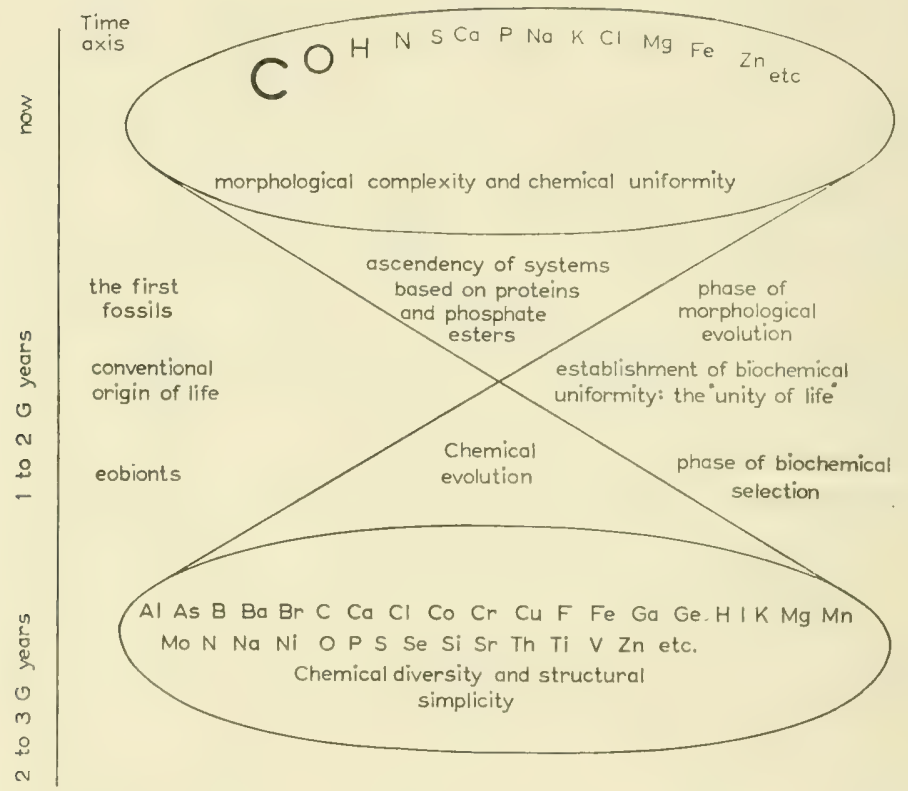

FIG. I. At each level of time the width of the cone represents the number of ways in which living or lifelike systems worked. The size of the atomic symbol is an indication of the contribution that element may have made to the process at the time.

The evidence that much of evolution is accompanied by the selective loss rather than gain in capacity was marshalled by Lwoff [13]. This leads to the conclusion that present-day organisms are descended from one or a few superorganisms with more extensive capacities than those now found. It is necessary to conclude that these super-organisms were far removed from eobionts and were perhaps built up by symbiosis among several of them. The same type of selection that Lwoff has called attention to probably then operated so that the final organism would be derived as much by discarding or minimizing capacities as by acquiring new ones. The metabolic processes used by present-day organisms were probably present in some of the early forms of life but there is no reason 
to think that they were all present, that they were present in all forms, or that when present they were quantitatively important. Life now is the result of two quite independent processes; the random appearance of capacities in small atypical regions, and the integration of these capacities into a mechanism adapted to survival in the environment that exists more generally. The former may have been concerned predominantly with reactions that are now unusual but they are the processes that should be taken as the origins of life. This point of view is roughly illustrated in the diagram (Fig. I). Two cones are set apex to apex and the number of processes used by all the forms of life at any time is indicated by the width of the cone at that time. The broad base thus shows the original biochemical complexity, the broad top the present morphological complexity, and the narrow middle is the conventional 'origin of life'.

At each stage of science there has been a tendency to associate life with a recently discovered type of phenomenon. At one time it was magnetism. Then Pasteur overstressed the relevance of optical activity* and pointed out the analogy with crystallization. Proteins and adenosine triphosphate have had their turn and now there is a tendency to overstress isotopic fractionation. Living systems, like all other systems with a series of stages of adsorption, diffusion, or phase equilibrium, may differentiate between isotopes. They pack the regions of separation into smaller compass than an isotope separation factory but they only perform the same fractionation that a long enough column of suitable mineral adsorbent would. An unusually high ratio of ${ }^{12} \mathrm{C}$ to ${ }^{13} \mathrm{C}$ in a structure is prima facie evidence that $\mathrm{C}$ was once part of an organism, but other systems can fractionate $\mathrm{C}$ isotopes and living systems do not at all times fractionate them in the same way [14]. The Universe contains a vast range of processes and types of compound. It is probable that none of these appear exclusively in living systems but it is equally probable that many more have appeared or still appear in them than is generally assumed.

The argument has been presented here in terms of the elements because they make it easy to put diversity on to a quantitative basis. Somewhat similar conclusions can be drawn from other aspects of chemistry. The more primitive animal species have the most complex fats [15], this may be a consequence of their failure to fractionate food fats [16, I7] but that in itself is cvidence of versatility. Some insects use substances such as formic acid and the oxides of nitrogen that seem to fall outside the range of normal biochemistry and they may well have been doing this for $100,000,000$ years. The simpler organisms such as moulds and bacteria handle a more diverse group of metabolites and make a more diverse group of excretory products than any other organisms but there is no evidence about the antiquity of the species. In summary: the development of morphological complexity has been associated with some biochemical simplification, in the process many originally vital activities have probably been lost and the relative importance of others has probably altered. This Symposium will have demonstrated that there is no basis for dogmatism about the processes involved in the origins of life; my contention is that there is not yet even a basis

\footnotetext{
* This point has been elaborated elsewhere (N. W. PIRIE, Trans. Bose Res. Inst., 22, III, I958).
} 
for dogmatism about the materials undergoing these processes. A quotation from Louis MacNeice may serve as a summary:

World is suddener than we fancy it.

World is crazier and more of it than we think, Incorrigibly plural.

\section{REFERENCES}

I. J. B. S. HALDANE, Nature, Lond., 153, 555, 1944.

2. J. B. S. HaldaNe, New Biol., I6, I2, I954.

3. N. W. PIRIE, Modern Quarterly, 3, NS 82, 1948.

4. S. L. Miller, Science, II7, 528, 1953.

5. W. W. Rubey, Spec. Pap. geol. Soc. Amer., 62, 63I, I955.

6. N. W. PIRIE, Discovery, I4, 238, I953.

7. N. W. PIRIE, Perspectives in Biochemistry. Cambridge Univ. Press, 1937.

8. N. W. PIRIE, New Biol., 16, 4I, 1954.

9. V. M. GoldsChMidt, Nerw Biol., I2, 97, 1952.

IO. D. I. ARNON \& G. WESSEL, Nature, Lond., 172, I039, I953.

I I. E. M. Chenery, Plant \& Soil, 6, I74, 1955.

I2. G. Mueller, Geochim. et cosmoch. Acta, 4, I, I953.

13. A. Lworf, L'évolution physiologique: études des pertes des fonctions chez les microorganismes. Paris, I943.

I4. H. Craig, Science, II9, I4I, I954.

I5. T. P. Hilditch \& J. A. Lovern, Nature, Lond., 137, 478, 1936.

I6. F. B. SHORLAND, Nature, Lond., 170, 924, 1952.

I7. T. P. Hilditch, Nature, Lond., 170, 925, 1952. 


\title{
The Geological Conditions for the Appearance of Life on the Earth, and the Problems of Petroleum Genesis
}

\author{
P. N. KROPOTKIN
}

Geological Institute, U.S.S.R. Academy of Sciences

THE GEOLOGICAL CONDITIONS AT THE SURFACE OF THE EARTH IN THE EARLY STAGES OF ITS DEVELOPMENT AND THE PROBLEM OF THE ORIGIN OF LIFE

ALL THE modern investigations on the origin of life lead to the conclusion that the source of the primary, most primitive forms of life on the Earth was abiogenic organic compounds of the complex hydrocarbon type [I-4].

Among the organic material widely distributed in the Earth's crust that could be considered as a source of the primary forms of life, is petroleum or complex hydrocarbons, similar to it in composition.

Most investigators assume that the Earth's atmosphere originally had no oxygen. Free oxygen appeared later, as a result of the life activity of plants [5]. Evidently, reducing chemical conditions were predominant in the atmosphere at that time. Besides a certain amount of methane, there were probably carbon dioxide, nitrogen, and aqueous vapour in the atmosphere, similar in composition to the present atmosphere of Venus. (It consists of $\mathrm{CO}, \mathrm{N}_{2}$ according to Kozyrev, and $\mathrm{H}_{2} \mathrm{O}$-according to Lyot, and judging by the reflection of the sun's rays, penetrating the cloud layer of this planet to the reflective surface, which is most probably an ocean surface.) The important, and perhaps even predominant, rôle of carbon dioxide in the atmosphere's composition at the early stages of the Earth's development has been shown by the numerous calculations, made by different authors, of the amount of $\mathrm{CO}_{2}$, which is equivalent to the total amount of carbon in mineral coal and in the diffused carbonaceous matter buried in sedimentary rocks.

Developing in such conditions at the surface of dry land or water basins, the primary living organisms evidently could neither make use of solar energy (not yet having acquired chlorophyll) nor of the energy which under present conditions is freed through oxidation of organic compounds in the atmosphere or in water containing molecular oxygen (for instance, in processes of putrefaction). It would appear that chemical processes, at that time, were of the type now effected by anaerobic bacteria.

Two types of exothermic reaction accompanied by the emission may be con- 
sidered as a prototype of the processes on the basis of which the vital activity of the primary organisms could have taken place:

$$
\begin{aligned}
& \text { I. } \mathrm{C}_{n} \mathrm{H}_{m}=a\left(\mathrm{H}_{n^{\prime}}, \mathrm{C}_{m^{\prime}}\right)+\mathrm{CH}_{4} \uparrow \text {, with } n^{\prime}=\frac{n-\mathrm{I}}{a}, m^{\prime}=\frac{m-4}{a} \\
& \text { 2. } \mathrm{SO}_{4}^{\prime \prime}+2 \mathrm{C}+2 \mathrm{H}_{2} \mathrm{O}=2 \mathrm{HCO}_{3}^{\prime}+\mathrm{H}_{2} \mathrm{~S} \uparrow
\end{aligned}
$$

The first type of reaction is carried on by anaerobic bacteria during the decomposition of organic matter in water basins in conditions of a reducing chemical medium, methane $\left(\mathrm{CH}_{4}\right)$ being formed at the expense of more complex organic compounds.

The second type of reaction, i.e. desulphatization, is brought about by desulphurizing petroleum bacteria in the presence of petroleum and water containing $\mathrm{SO}_{4}^{\prime \prime}$ ions. Petroleum bacteria, discovered by T. L. Ginzburg-Karagicheva in the petroleum of the Apsheron Peninsula, and by Bastin in the Pennsylvania oil (U.S.A.), are found in wells from 750 to 2760 metres deep. They breed most abundantly near the under interface, where the petroleum comes in contact with the waters underlying it, these waters usually being of the sulphate-chloride type. It is known that the sulphates in these waters are of inorganic origin and are derived partly from the salt residue in the marine sedimentary strata, and partly, possibly, from mineralized waters of more abyssal genesis. The course of both mentioned reactions from left to right is favoured by the fact that the gaseous products $\left(\mathrm{CH}_{4}, \mathrm{H}_{2} \mathrm{~S}\right)$ gradually rise.

Similar conditions, in principle, could have arisen in the Archaean era the surface of lagoons or other water basins, if they were covered with a film of oil. It should be noted that the oxidation of oil, which now rapidly leads to the formation of resin, polymerization of bitumens, and to the transformation of petroleum into asphalt, at that time did not as yet take place because of the lack of oxygen. Consequently, conditions favourable for the reduction of sulphates in sea or lake waters, with petroleum present, could have been maintained for a considerable time.

\section{THE PRESENT STATE OF RESEARCH ON THE INORGANIC ORIGIN OF PETROLEUM}

The pattern of the origin and development of life, outlined above, could only be considered sufficiently if the sources of the large quantities of petroleum or abiogenic hydrocarbons, similar to oil in chemical composition, were known. The origin of petroleum has been debated for Ioo years and is one of geology's most controversial problems. The hypothesis of inorganic origin of petroleum was highly popular in the second half of the nineteenth century, when it was developed by D. I. Mendeleev, M. Berthelot, H. Moissan, E. Coste, and others. But later, it seemed to have been completely abandoned. This was especially so during the I920's and 30's, when there appeared the investigations of C. D. White, P. D. Trask, and others in the U.S.A., of I. M. Gubkin, G. L. Stadnikov, and A. D. Arkhangelskir in the U.S.S.R., and so on [6].

But geologists have lately again become interested in the inorganic hypothesis. This interest was roused owing to the fact that explorations in any well-studied 
petroleum- and gas-bearing district have shown, first of all, that the petroleumand gas-bearing sources descend vertically to great depths, down to the folded basement, consisting of metamorphic or igneous rocks, and, secondly, that in an overwhelming number of cases, the distribution of petroleum is not connected with the distribution (in area) of sedimentary formations rich in organic matter (such, for instance, as coal and bituminous shales).

That the problem is of great importance is shown by the fact that in 1954 it was discussed at the Lvov conference dedicated to the problems of the origin and migration of oil where two reports in favour of the inorganic origin hypothesis were submitted [7-9, II, I5]. Earlier still, in I95 I, N. A. Kudryavtsev had criticized the organic theory and put forward serious arguments in favour of the inorganic origin of petroleum [IO, II]. In the United States, the inorganic (cosmic) hypothesis was supported by Macdermott [12]. Moreover, such well known specialists as Van Tuyl \& Parker and Van Orstrand [I3, I4] also pointed out some facts confirming this theory.

At the same time, the ideas connected with the organic hypothesis were developing in such a way, that they began to contradict one another (the hypotheses of V. A. Sokolov, V. A. Uspenskiir, and others), none of them being universally accepted. In our mind, these contradictions are not accidental and reveal a profound crisis, or an impasse, into which the organic theory has come.

\section{SPACE DISTRIBUTION OF OIL AND GAS DEPOSITS} AND THEIR RELATION TO THE TECTONIC STRUCTURE

Oil fields are usually found in the regions which possess natural gas deposits (methane, with a certain amount of ethane and heavier hydrocarbons), sometimes in mixed oil and gas deposits, forming together definite oil and gas provinces (petroliferous provinces). Geological investigation of these districts shows that both their general outline and the location of separate deposits of petroleum and gas occurring in the above-mentioned provinces, are determined not by the presence or absence of sedimentary rocks rich in biogenic organic substances (for instance, coal, carbonaceous and bituminous shales), but by purely tectonic factors, i.e. by dislocations of the strata in the Earth's crust. Frequently, the localization of oil is determined by deep faults, cutting both the sedimentary cover and the crystalline basement under it, consisting of granite and gneiss. Such are the petroleum fields of Egypt along the faults of the Earth's crust bordering the Red Sea graben, the large gas fields of eastern Brazil, and the oil appearing in the Lake Baikal graben in Siberia and in the Lake Albert graben in Africa. The connection with the deep faults and flexures of the crystalline basement is manifested, although in a somewhat masked form, in the location of many oil and gas fields on tectonic platforms, for instance, the Volga River fields, connected with the flexure of the Zhiguly Hills, in Eldorado field (Kansas, U.S.A.) and others. (See Fig. I); [I5-I7]. This connection with the tectonic disturbances indicates the compliance of the oil and gas deposits to the zones where, owing to faults, flexures and tension of Earth's crust, the basement becomes more penetrable to fluids rising from the depths of the Earth. 
'The absence of any connection between the localization of petroleum and the distribution of biogenic organic substances is evidenced by the fact that the coal basins and large deposits of bituminous rocks of the combustible shale type (Scotland, Tasmania, Sweden, Estonia, and others) are, in the overwhelming majority of cases, not oil-bearing districts of industrial importance. And if in some of such districts, like the Urals and Pennsylvania, petroleum is met, its distribution in the vertical direction is traced much lower than the layers rich in organic substances, and, consequently, must have another source.

\section{THE VERTICAL RANGE \\ OF HYDROCARBON MIGRATION}

The vertical distribution of petroleum and gas also indicates a much wider range of hydrocarbon migration than accepted in different variations of the
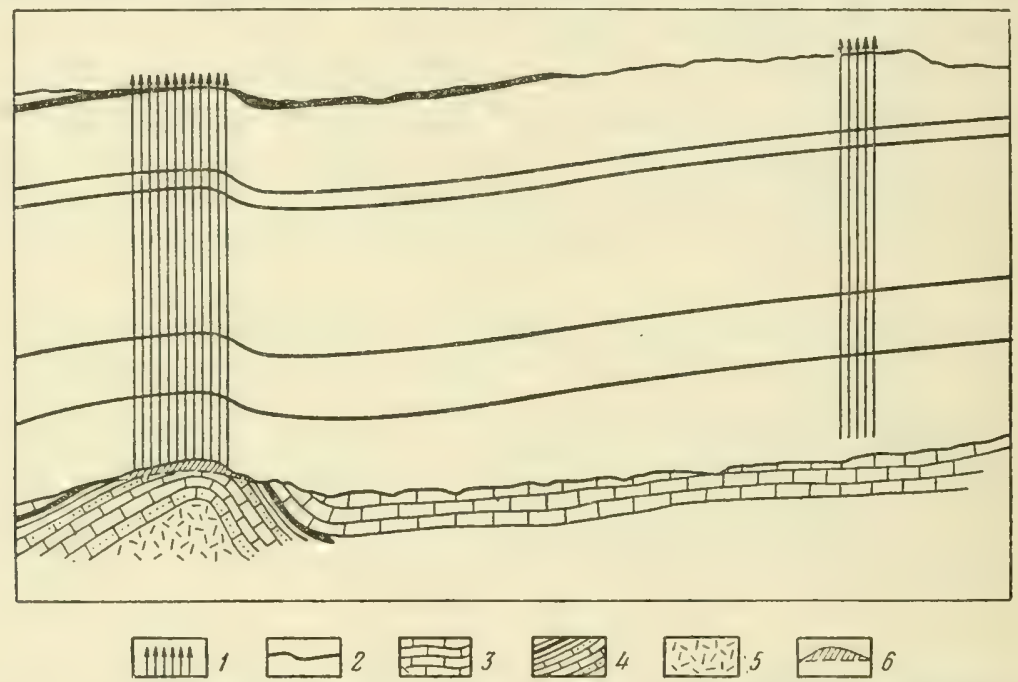

FIG. I. An example of the connections between oil deposits and dislocations of the basement and sedimentary cover of the tectonic platform: oil field of El Dorado, Kansas, U.S.A.

Vertical section: the vertical scale is considerably more than the horizontal (cited by Moore from Ver Viebe, I950). 1-drill holes; 2-Pennsylvanian rocks $\left(\mathrm{C}_{3}\right)$; 3-Mississippian sediments (limestone $\left.\mathrm{C}_{1}\right)$; 4-Ordovician sediments (S); 5 -granites of the pre-Cambrian crystalline basement; 6 -Stapleton oil zone in the lower Palaeozoic rocks.

organic theory. The secondary nature of oil pools usually does not raise any doubt.

I. O. Brod pointed out that 'if we are to understand as primary deposits those which originated in situ, then we must state that such deposits do not exist at all' [I8]. Obvious structural geological and lithological evidence is always found to show that these hydrocarbons came to the reservoir rocks not only after the formation of the rocks bearing them, but after the rocks have undergone the action of tectonic forces (fractured, flexed and folded). Asphalts and asphaltites 


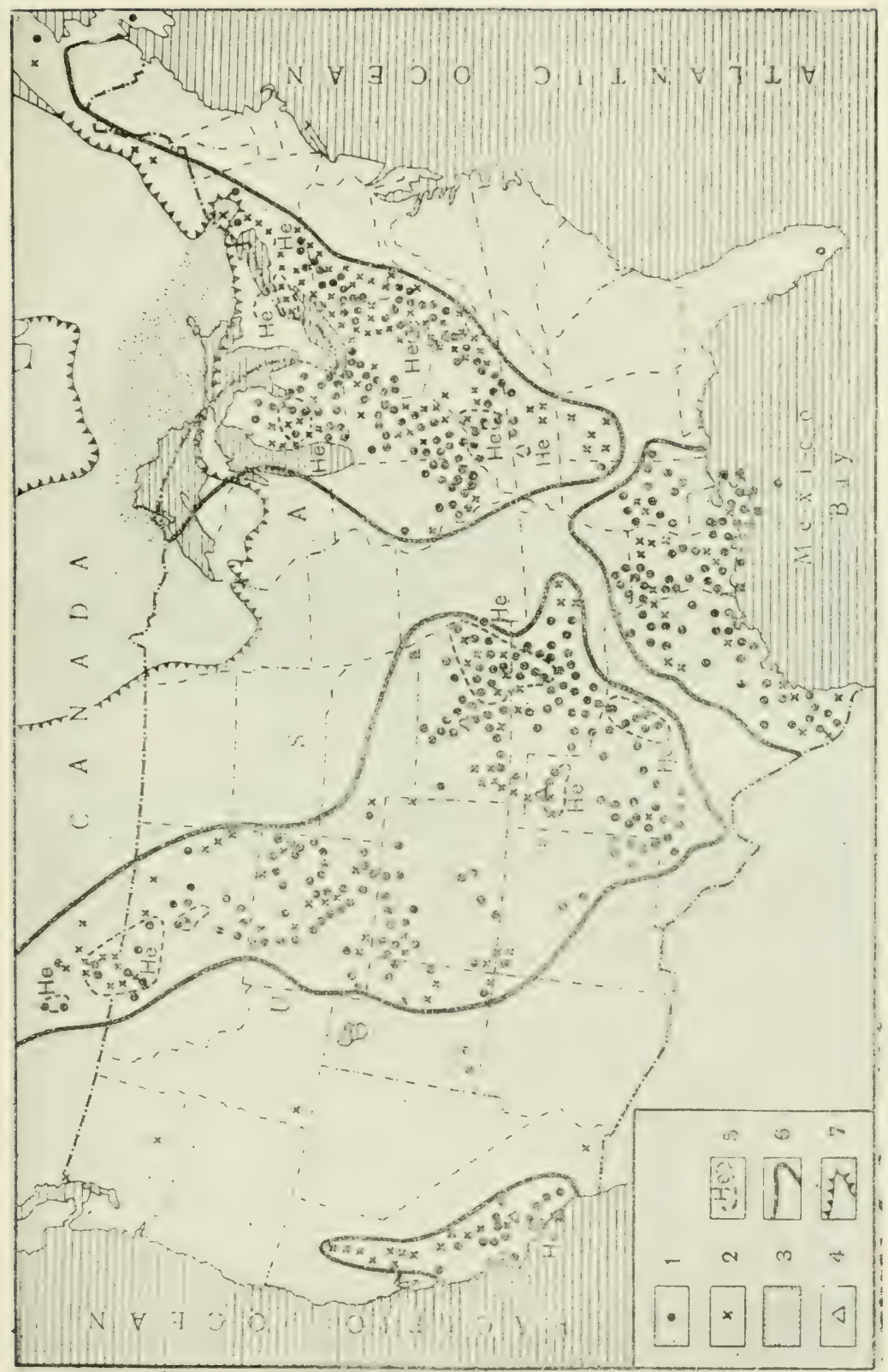

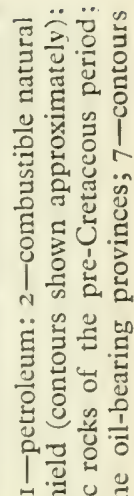

- $\frac{3}{\infty}$

로 폴 눙

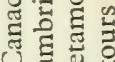

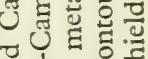

ह ํㅣㄴ छ क

㶽。.

ผे छี

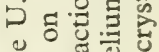
छ 进

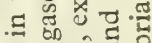
के हा है है है 吅 폴 可 $\vec{E} \Xi \Xi$ 를 음 돌

घี. है है क 윯 ¿ 出㗁豆

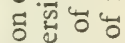

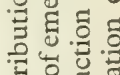
苟范 的出 寻范 (i

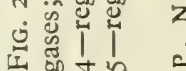



often lie in veins, which prove the vertical migration of hydrocarbons of the deep oil type (Sadki deposits, Buguruslan district, and some pyrobitumen dikes on pre-Cambrian crystalline shields).

The vertical distribution of petroleum does not show any connection with the distribution of organic matter in the Earth's crust layers. The achievements in the technique of prospect drilling to a depth of $4.8 \mathrm{~km}$ in the U.S.S.R. and $6.3 \mathrm{~km}$ in the U.S.A., have furnished much new data on the extent of the vertical migration of hydrocarbons. It turned out that petroleum and gas are met in large quantities below the layers rich in organic matter (for instance, the dark clays of the Maikop series in the Caucasus), which only recently were considered the mother formations (i.e. primary source rocks) of oil. With the increase of drilling depth, in oil districts all over the world are discovered new oil-bearing horizons in rocks having satisfactory porosity, down to the base of the nonmetamorphized sedimentary cover.

The early Palaeozoic sedimentary rocks (Cambrian, Ordovician) at the base of the sedimentary layers are oil bearing in the Mid-Continent, Appalachian, and so-called Permian Basin of western Texas on the North American platform, in Wyoming, U.S.A., on the Chinese platform, and in the southern Siberian platform. The Devonian series, comprising the lower part of the sedimentary cover, are oil-bearing in the Timan and Volga-Urals provinces on the Russian platform.

If the igneous and metamorphic rocks of the folding basement are sufficiently crushed by faults and cracks and may serve as oil collectors, these rocks sometimes contain commercial reserves of oil (Kansas, the Edison oil field and others in California; Mara-La Paz field in Venezuela) [19]. Traces of petroleum have been met in fractured granites or gneisses of the pre-Cambrian basement in Wyoming, on the shores of Lake Baikal and the Red Sea, and in the pre-Cambrian Ural-Volga oil-bearing districts (Shugurovo, Vyatskaya Polyana) [II, 20]. In some Volga districts the impregnation of oil bitumens has been discovered in cores of granite-gneissic rocks of the pre-Cambrian crystalline basement extracted from boring wells. Bores in the metamorphic shales of the folding basement in Timan have revealed oil and combustible gas to a depth of $400 \mathrm{~m}$ below the roof (upper surface) of basement [2I].

In the part of the Canadian pre-Cambrian shield bordering on the Michigan and Appalachian petroleum- and gas-bearing provinces, combustible gases appear directly from the pre-Cambrian granite-gneiss basement (the region of the Lakes Superior and Huron, the Edwards Mine in the Adirondack pre-Cambrian uplift). At Fort William, for instance, combustible gas was obtained by drilling in the pre-Cambrian basement at a depth of $335-400 \mathrm{~m}$ below its surface [22].

Combustible gas comes from a considerable depth from the pre-Cambrian rock of the Baltic (Fennoskandian) shield (Kola Peninsula, some Swedish mines) and Australia (methane gases at the Kalgoorlie Mines; gases containing $70 \%$ of hydrogen and $7 \%$ of methane from a depth of $260 \mathrm{~m}$ on the York Peninsula) [23]. This list is enough to convince us that the sources of petroleum and gas are deep down in the pre-Cambrian basement, corresponding to what the geo- 
physicists call the granite layer of the Earth's crust. The presence of free hydrogen and methane in volcanic gases, and the discovery of liquid hydrocarbons and solid paraffins in the basalt lava of Mt. Etna and in products of volcanic eruptions on the Island of Java indicate that hydrocarbons are met in the magma of the basic (basaltic) and ultra-basic (peridotitic) composition, forming in still deeper layers of the Earth. Stony meteorites, which are considered as analogues of the Sima layer ultra-basic rocks, contain gases with $4 \cdot 2 \%$ of $\mathrm{CH}_{4}$ and $17 \cdot 6 \%$ of $\mathrm{H}_{2}$. In the carbonaceous varieties of stony meteorites, paraffin matter is found, composed of carbon (80-84.9\%) and hydrogen (15-20\%). Some meteorites have the specific odour of heavy remains of crude oil [24-27].

Thus, various facts indicate that the vertical range of migration of hydrocarbons is very great. Not only methane, but more complex hydrocarbons too can rise to the upper layers of the Earth's crust from the crystalline basement and the deeper subcrustal layers of the solid mantle of the Earth, formed of ultrabasic material. The peculiar gas deposits of so-called condensate pools, found during the last decades at the deepest levels of oil deposits $(2.8$ to $4 \mathrm{~km}$ deep), may be samples of these deep fluids. A condensation of such fluids at a decreasing pressure produces liquid methane, oil and combustible gases.

\section{THE GEOCHEMICAL ASSOCIATES OF PETROLEUM:} METHANE, HYDROGEN, NITROGEN, AND HELIUM

Gaseous hydrocarbons, free hydrogen, nitrogen, and helium, i.e. gases the deep origin of which becomes more and more evident (Fig. 2), are the characteristic geochemical associates of petroleum. The gas pressure at the deep horizons is so great (combustible gases up to $880 \mathrm{~atm}$, nitrogen up to $20 \mathrm{~atm}$ and more) that it cannot be explained by biochemical processes or by the capture of atmospheric gases. The high pressure of subterranean gases shows that they come from the depths. V. I. Vernadskiǐ, who long ago considered the Earth as a cold and solid cosmic body with scatterings of separate nidi of magmatic melts, was the first to note the grandiose scale at which the deep juvenile gases (nitrogen, methane, and others) discharge. Their ascent from the depths of the Earth's crust he figuratively called 'the breathing of the Earth'. V. I. Vernadskir also noted the connection of these gases with faults, stressing that all the large helium pools (Amarillo, Texas, and others) were connected with the outflows of 'tectonic gas streams: nitrogen, methane-nitrogen gases, and methane' [28]. In some methane-nitrogen gas streams the concentrations of helium exceed by several thousand times those of helium in the atmosphere. The source of this helium is the crystalline basement, where it gradually accumulates, due to the decay of radioactive elements. 'Nitrogen', V. I. Vernadskii pointed out, 'unlike oxygen, constantly enters the Earth's atmosphere from the deep sections of the Earth's crust ... In many places, gas streams are known to consist of almost pure nitrogen, always containing noble gases. Besides these emissions, nitrogen in the shape of unnoticeable emanation, undoubtedly, continuously penetrates everywhere into the Earth's crust, and into the biosphere' ([28] p. 226). He ascribed the same deep origin to free hydrogen, which now, thanks to improved 
methods of analysis, is constantly being found in small amounts (sometimes to $10 \%$ ) in combustible gases $[29,30]$. 'By no means always',-wrote V. I. Vernadskii,, 'are hydrocarbons connected with life. There exists methane, which rises from the deeper sections of the Earth's crust... It is in regard to methane, in particular, that the exclusive connection with life is doubtful, since this light gas has properties similar to those of hydrogen. Its known syntheses in the laboratory are extraordinarily varied and often independent of organic compounds. There must be analogous processes in magmas'. ([3I], p. I33).

Lately, thanks to the investigations carried on by V. A. Sokolov, the magnitude of incessant addition of methane from the depths of the Earth into the atmosphere has become known. V. A. Sokolov has estimated the annual addition of methane to the atmosphere from oil and gas deposits and volcanoes to be about I00 million tons [32]. Even if we were to take a figure ten times less, it would appear that, during a very short geological period of 100,000 years, the atmosphere has received an amount of hydrocarbons many times more than the known and estimated oil resources on the Earth. In this aspect, the accumulation of oil appears to be a secondary resulting effect of the grandiose process of ascension of gaseous hydrocarbons, together with other gases, from the depths of the Earth.

\section{THE THERMAL CONDITIONS FOR THE FORMATION OF OIL AND THE CHANGE IN ITS COMPOSITION IN THE EARTH'S CRUST}

Thus, the tectonic regularities of oil and gas distribution (in area) in the Earth's crust, the wide vertical range of hydrocarbon migration, and, finally, the geochemical association of petroleum with gaseous hydrocarbons, hydrogen, nitrogen and helium, throw light on the origin of oil and gas. The hydrocarbons rising up out of the depths of the Earth are of a primary inorganic origin. Together with methane, the hydrocarbon stream contains heavier, compositionally more complex hydrocarbons which are detained in the porous rock of the sedimentary cover, accumulating in the form of the peculiar gas mixture of the so-called condensate pools (see above) and in the form of methane petroleum, i.e., petroleum composed almost exclusively of saturated hydrocarbons. Judging by the physical-chemical equilibrium of hydrocarbons studied by S. P. Obryadchikov and A. V. Frost, methane petroleum forms at a temperature of $200-350^{\circ}$ $[33,34]$. The further change in the composition of petroleum in the Earth's crust consists chiefly in the differentiation of hydrocarbons and removal of the lightest fractions, which are the richest in hydrogen; correspondingly, the petroleum is enriched with naphthenes, isoparaffins, and heavy components. Together with the differentiation, a certain oxidation of the petroleum takes place (the appearance of naphthene acids, bases, resin), and also its sulphuration in connection with the life activity of bacteria and the dissolution in petroleum of the products, mostly of plant origin (such as porphyrins and phytosterol), contained in petroliferous rocks [35]. Porphyrins, to which such great importance was attached by the advocates of the biogenic origin of petroleum, are practically absent in 
some of the clear light oils. Porphyrin enrichment is found especially in the heavy, resinous, and sulphurous oils. According to available data, the same refers to the dissolution in oil of admixture of organic matter of biogenic origin exhibiting optical rotation.

In discussing the deposits of petroleum and combustible gases as the results of ascension of hydrocarbons rising from the deep layers of the Earth's crust, we would like to emphasize that available facts agree with the hypothesis that hydrocarbons are of inorganic origin, though not connected with magma. Disintegrating at high temperatures (especially when there is an acidic, i.e., granite magma, comparatively richer in oxygen) in conditions when methane $\mathrm{CH}_{4}$ can be split off or oxidized, the petroleum hydrocarbons are preserved at a lower temperature, in reducing conditions. This is in harmony with the fact that in regions of the acidic or mediosilicic (andesitic) vulcanism, carbon compounds in gases are represented chiefly by carbon dioxide $\mathrm{CO}_{2}$, and outside these regions by $\mathrm{CH}_{4}$ (the Caucasus, the zones of mud-vulcanism, etc.).

These conclusions about the abyssal but magma-independent origin of petroleum and gas are in agreement with the modern conceptions of deep faults, of the solid state of the Earth's mantle and the formation of the planet from cold cosmic dust and gas (the hypotheses of O. Yu. Shmidt, H. Urey and others [36, 37]). Judging by the relative abundance of hydrocarbons in the cosmos, there was a sufficient amount of these compounds in the original gas-and-dust nebula from which the Earth and other planets of the solar system have arisen. The idea of primary (cosmic) origin of petroleum hydrocarbons was first put forward by V. Sokolov [38].

\section{THE BIOGENIC (ORGANIC) THEORY \\ OF ORIGIN OF PETROLEUM. \\ CHANGES IN THE COMPOSITION OF ORGANIC MATTER IN THE EARTH'S CRUST}

Although the number of facts in favour of the inorganic origin of petroleum increases every year, most specialists still adhere to the biogenic conception of its origin (see, for instance, the review [39]). Different variations of the organic theory can be divided into two groups. One trend proceeds from the idea that petroleum hydrocarbons were formed under the 'least severe' pressure and temperature conditions, i.e. under conditions which exist in sediments immediately after their deposition in a water basin or at the early stages of their genesis $[40,4 \mathrm{I}]$. From this point of view it proves impossible to explain the secondary nature of the petroleum occurrence in most of the petroleum beds, and the absence, outside the oil fields, of any signs of petroleum in sedimentary rocks; in other respects these rocks may have exactly the same lithological composition and geological age as those developed in the oil-field districts, or may even be richer in biogenic organic matter, in comparison with them. Discoveries of oil in the crystalline basement mentioned here also exclude the possibility of the origin of petroleum according to this scheme. 


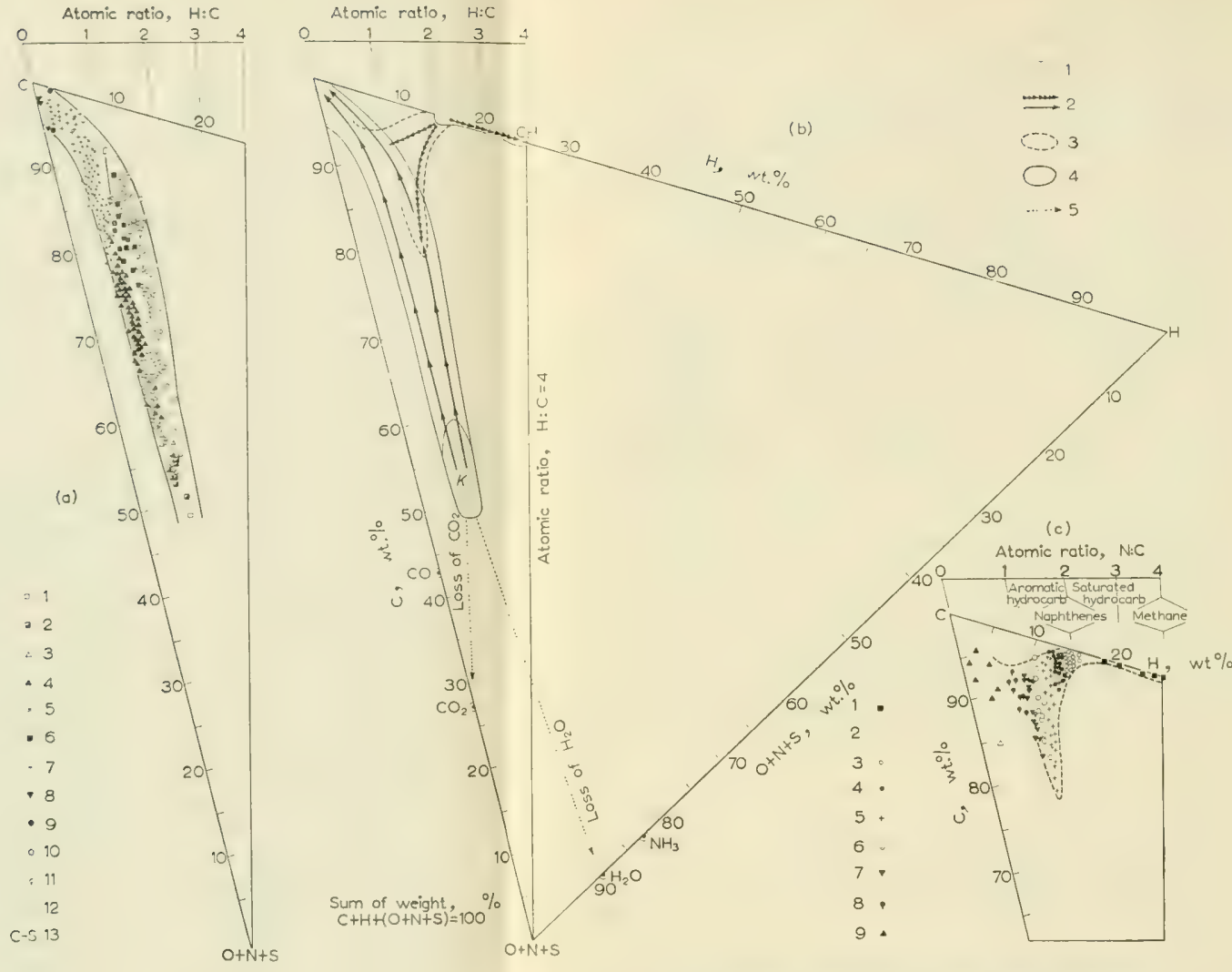

FIG. 3. The chemical composition of fossil organic substances.

(a) Composition of caustobiolites of the coal-sapropelite series: 1-cellulose; 2 -wood; 3-peat; 4-lignites; 5 -coal ; 6 -striped coals and others; 7 -anthracites; 8-bedded graphites; 9 -shungites: 10-sapropel coals; 11 -combustible bituminous shales; 12 -sapropels; 13 -carbonified saproponites.

(b) Demonstrated processes of change of organic substances in the earth crust: 1 -composition of the caustobiolites of the coal sapropelite series $(K)$ and bitumens of the oil series; 2-demonstrated processes of change of organic substances; 3 -composition of gaseous hydrocarbons and bitumens of the oil series; 4 -composition of caustobiolites of the coal-sapropelite series: 5 -Loss of $\mathrm{CO}_{2}, \mathrm{H}_{2} \mathrm{O}$ and others.

(c) Composition of bitumens of the oil series: 1-Average composition of hydrocarbons of combustible gas; 2-average composition of methane oil; 3-normal type oils; 4 -resinous oils; 5 -asphalts and malthas; 6 -gilsonites; 7 -grahamites; 8-impsonites; 9 -anthraxolites.

The sum of three perpendiculars dropped from any point of the diagram to the sides of the equilateral triangle is a constant value; it is $100 \%$ and corresponds to the sum of the contents in weight $(\mathrm{C})+(\mathrm{H})+(\mathrm{O}+\mathrm{N}+\mathrm{S})$ in the composition of the organic substance. The weight percentages of carbon, hydrogen, and the sums of oxygen, nitrogen, and sulphur correspond to each of the three perpendiculars dropped to the sides of the triangle. 
The second trend is represented by the hypothesis held by V. A. Sokolov, V. B. Porfiriev, J. Roberts and others. These authors clearly demonstrate the complete unsoundness of the hypothesis of 'least severe' conditions for the formation of oil as far as hydrocarbon chemistry is concerned. Instead, they offer a scheme for the formation of oil and gas as a result of changes in biogenic organic matter under 'the most severe' conditions, i.e., at temperatures of I50$500^{\circ}$ and at a considerable depth $[42,43]$. But the fact that a number of rich oil deposits have been found in the sedimentary cover of the shields lying on the pre-Cambrian crystalline basement, has proved fatal for all these variations. The thickness of that covering strata often does not exceed $I \cdot 5 \mathrm{~km}$, while the temperature at its base, corresponding to the geothermal gradient of the tectonic platforms, could not rise above $40-60^{\circ}$, i.e. certainly could not reach the limits necessary for the formation of petroleum according to these schemes (the UralVolga region, Kansas and Oklahoma, Egypt). The pre-Cambrian basement itself, with its insignificant graphitized fossils of plant and animal organic matter could not, of course, produce later a noticeable amount of biogenic hydrocarbons when the sedimentary layers had been formed above it.

Examination of a large number of analyses of the chemical composition of bitumens and caustobiolites clearly reveals the rules governing the changes of organic matter in the Earth's crust. The triangular baricentric diagram (Fig. 3) shows two independent centres of primary organic matter. One of these centres corresponds to the compositions of cellulose, wood, peat, and sapropel. The figurative points of the composition of the changed organics of the coal series (lignite and coal, anthracites, and other) and of the sapropelite series (sapropel coals, combustible or bituminous shales, shungites) stretch in a narrow strip from this centre to the pure carbon (graphite). Changes in the organics are bound with losses of carbon dioxide, water, methane, and inevitably lead to their dehydration rather than to hydrogenization. In this case, the ratio of the number of hydrogen atoms to carbon atoms decreases from I.67 to $0.2-0.5$ receding more and more from the high ratio of $\mathrm{H}: \mathrm{C}(\mathrm{I} \cdot 7-2 \cdot \mathrm{I})$ characteristic of petroleum. Another centre, being quite separate, located in the upper part of the diagram, is formed by methane and other combustible gases, a complex mixture of condensate pool hydrocarbons and methane oil. The diagram shows that all the other oil bitumens are formed at the expense of dehydration and oxidation of these compounds, forming naphthene and resin oils, oxyasphalts, and others.

Thus it is clear that changes in biogenic organic matter in the layers of the Earth's crust, chiefly consisting in carbonization and elimination of hydrogen and oxygen, cannot lead to the formation of petroleum from animal and plant organic substances, since petroleum consists of compounds almost completely saturated with hydrogen [44].

According to some conceptions, the source of oil is volatile derivatives, separating when the change in the organic substances takes place, for example, methane, which is formed together with $\mathrm{CO}_{2}, \mathrm{CO}$, and $\mathrm{H}_{2} \mathrm{O}$ during the metamorphism of biogenic organic matter [45]. But as the study of the composition of coal-mine gases shows, these gases, as a rule, do not contain any heavy hydro- 
carbons (ethane, propane, butane, and others), and, therefore, cannot be considered as a primary source of the formation of petroleum.

Thus, the available data reveal the insolvency of different variants of the organic (biogenic) hypothesis, and favour the hypothesis of abyssal inorganic origin of petroleum and gas not connected, however, with magmas.

\section{REFERENCES}

I. A. I. Oparin, The Origin of Life on the Earth. Izd. Akad. Nauk S.S.S.R. Moscow, Leningrad, 2nd ed., I94I.

2. A. I. Oparin, Vop. Filos. No. I, I953.

3. D. V. BelikHov, Zap. Kazan Ped. Inst., Fak. estestv. Nauk, 9, 1950.

4. A. I. OpARIN \& V. G. Fesenkov, Life in the Universe. Izd. Akad. Nauk S.S.S.R., Moscow, 1956.

5. W. Rubey \& K. Rankama, Spec. Pap. geol. Soc. Amer., No. 62, 1955.

6. I. M. Gubkin, Petrolenm Research Science. Gosnauchnotekhneftizdat, Moscow, 1932.

7. N. A. Kudryavtsev, Materials of a Discussion on Problems of the Origin and Migration of Petroleum. Izd. Ukr. Akad. Nauk, Kiev, I955.

8. P. N. Kropotrin, Material of a Discussion on Problems of the Origin and Migration of Petroleum. Izd. Ukr. Akad. Nauk, Kiev, I955.

9. P. N. Kropotkin, Soviet. Geol., Moscow, No. 47, I955.

IO. N. A. Kudryavtsev, Neft. Khoz., No. 9, 195 I.

II. N. A. Kudryavtsev, Izv. Akad. Nauk S.S.S.R., Ser. Geol., No. 4, 1955.

I2. E. MACDERMOTT, Geophysics, 4, I95, 1939.

13. F. M. Van Tuyl \& B. N. Parker, Bull. Amer. Ass. Petrol. Geol., 19, 1547, 1935.

I4. C. E. VAN ORSTRAND, World Oil, 128, I50, 1948.

I5. I. O. Brod \& N. A. Yeremenko, Principles of the Geology of Petroleum and Gas. Izd. MGU, Moscow, I953.

I6. K. L. LANDes, Petroleum Geology. Wiley: Chapman \& Hall; New York: London, I95I.

I7. W. A. Ver VIEBE, North American and Middle East Oil Fields. Wichita, Kansas, 1950.

I8. I. O. Brod, N. A. Yeremenko \& V. A. Klubov, Vestnik Mosk. Univ., xо, I948.

19. R. F. Walters, Bull. Amer. Ass. Petrol. Geol., 37, 201, 953.

20. S. Powers \& F. G. Clapp, Bull. Amer. Ass. Petrol. Geol., 16, No. 8, 1932.

21. A. Y. KREMS, Neft. Khoz., No. I, 1947.

22. F. M. Van TuYl \& B. N. PArker, Col. Sch. Min. Quart., 36, No. 2, I94I.

23. W. G. Woolnough, Bull. Amer. Ass. Petrol. Geol., 18, 226, 549, 1934.

24. R. PRENDEL, Ezhegodn. po geol. miner. Rossii, v. 2, I898.

25. E. Cohen, Meteoritenkunde, Heft I. Stuttgart, I894.

26. G. MUELER, Geochim. et cosmoch. Acta, 4, No. I-2, I953.

27. R. W. Pike, Bull. Amer. Ass. Petrol. Geol., 24, 496, 1940.

28. V. I. VERNADSKIII, The History of the Minerals of the Earth's Crust, vol. I. Leningrad, 1927.

29. I. V. Vysotskiř, Principles of the Geology of Natural Gas. Gostoptekhizdat, Moscow, 1954.

30. L. V. Khmelevskaya, Izv. Akad. Nauk S.S.S.R., Ser. Geol., No. 4, I07, 1947.

3I. V. I. Vernadskil, The History of the Minerals of the Earth's Crust., vol. II, The History of Natural Waters. Part I. Leningrad, 1933.

32. V. A. Sokolov. In a symposium: In Memory of Acad. I. M. Gubkin. Izd. Akad. Nauk S.S.S.R., Moscow, I95I.

33. S. N. Obryadshikov, in The Origin of Petroletm and Natural Gas, a symposium, Moscow, I947.

34. A. V. Frost \& L. K. Osnitskaya, in a symposium: In Memory of Acad. I. M. Gubkin. Izd. Akad. Nauk. S.S.S.R., Moscow, I95 I.

35. O. A. RadChenko \& L. S. Sheshina. Dokl. Akad. Nauk S.S.S.R., 105, I285, 1955.

36. P. N. Kropotkin, Izv. Akad. Nauk S.S.S.R., Ser. Geogr. Geophys., No. I, I950.

37. A. V. Peive, Izv. Akad. Nauk S.S.S.R., Ser. Geol., No. I, 1956.

38. V. Sokolov, Bull. Soc. Nat. Moscou, nouv. sér., 13, 720, 1890. 
39. I. O. Brod \& V. G. Levinson, The Origin of Petroleum and Problem of Petroleum and Gas Accumulation (A Review of Foreign Literature for 1940-1954). Gostoptekhizdat, Moscow, I955.

40. V. A. Uspenskil̆ \& O. A. Radchenko. Izv. Akad. Nauk S.S.S.R., Ser. Geol. No. 6, 121, 1952 .

4I. P. W. Smith, Bull. Amer. Ass. Petrol. Geol., 38, 377, 1954.

42. V. A. Sokolov, Notes on the Petroleum Genesis. Gostoptekhizdat, Moscow, 1948.

43. V. B. Porfiriev \& I. V. Grinberg. Nauch. Zap. Lvov. polytechn. Inst., r6, No. 4., Lvov, 1949.

44. O. A. Radchenko, in a symposium: In Memory of Acad. I. M. Gubkin. Izd. Akad. Nauk S.S.S.R., Moscow, I95I.

45. I. I. Potapov. Neft.Khoz., Azerbaijdszchan, No. 9, I95I. 


\title{
The Role of Dissymmetry in the Origin of Living Material
}

\author{
A. P. TERENT'EV \& E. I. KLABUNOVSKII
}

Moscow State University (M.V. Lomonosov) and Institute of Organic Chemistry of the Academy of Sciences of the U.S.S.R., Moscow

ALmost 100 years ago Pasteur noticed a characteristic peculiarity of the chemical processes of living nature, namely that they are optically selective. Pasteur stated that this was perhaps the only sharp boundary which can be discerned between the chemistry of dead and living nature.

\section{TWO FORMULATIONS OF THE QUESTION}

How did there arise, in living protoplasm as it exists to-day, living enzymic systems, with dissymmetrical molecules subserving the optical selectivity of chemical processes? Many authors hold that the proteins which first came into existence were optically symmetrical and that it was only during the process of evolution that they gradually assumed an optical dissymmetry which was useful in some way, for it is easier to imagine the process of formation of symmetrical proteins than of dissymmetrical ones. This assumes that life can exist without dissymmetry and that symmetrical proteins, being alive, developed dissymmetry, i.e. dissymmetry developed out of symmetry.

Another view is possible and we will try to substantiate it. We will start from the assumption that life cannot and never could exist without molecular dissymmetry. This means that it is necessary to find an answer, based on some experimental evidence, to two main questions:

r. What is the biochemical role of molecular dissymmetry?

2. How could the molecular dissymmetry of the original protoplasm, which led to the development of the living protein-enzymes, have arisen without the intervention of life?

THE ESSENTIAL PROPERTIES

OF OPTICALLY ACTIVE SUBSTANCES:

THE PASTEUR EFFECT

The optical activity of organic substances is only one of the manifestations of molecular and crystalline dissymmetry. Many other manifestations of dissymmetry may be cited: the piezo effect, triboluminescence, polarized fluorescence. Finally, there are known to exist a large number of crystals which are dissymmetrical in form but do not contain centres of dissymmetry. Among these are 
$\mathrm{K}_{2} \mathrm{Cr}_{2} \mathrm{O}_{7}, \mathrm{Cu}_{2} \mathrm{O}, \mathrm{Ba}\left(\mathrm{NO}_{3}\right)_{2}$ and $\mathrm{Pb}\left(\mathrm{NO}_{3}\right)_{2}[\mathrm{r}]$. Antipodes differ from racemates in the form of their crystals, their solubility and their melting points. The presence of several centres of dissymmetry in one structure is the reason for the existence of many diastereoisomers with different physical and chemical properties. It has been shown, c.g. that the polymerization of the amino acid derivatives, (-)-propylene oxide [2] and (-)- $\alpha$-methylbenzyl methacrylate [3] leads to the formation of polymers which differ in their propertics according to whether they were made from a pure antipode or a racemate.

These special properties of optically active compounds provide the necessary conditions for some other factors which are not present in substances with symmetrically constructed molecules. These peculiarities and the behaviour of optically active substances may be termed the 'Pasteur effect' since Pasteur first drew attention to them.

The reasons for this effect are primarily determined by the configurations and conformations of the molecules. When they interact with one another, dissymmetrical molecules form crystalline or colloidal solid bodies with different 'packings' depending on the nature of the dissymmetry. Not surprisingly, the bonds between the molecules, which are responsible for the Pasteur effect, are extremely labile.

There can be no doubt that, in biochemical processes involving complicated molecules with many centres of dissymmetry, the Pasteur effect must be very important. Maybe the first protein manifested the characteristics of life owing to the presence of a definite sequence in the arrangement of residues of dissymmetrical molecules of amino acids.

\section{THE ORIGIN OF DISSYMMETRY IN PRIMAEVAL PROTOPLASM}

Let us try to answer the second question: How could dissymmetry have arisen in the primaeval protoplasm?

Various ways by which optically active substances may be obtained abiogenically are known.

In the first place: the resolution of a racemate by the spontaneous crystallization of one antipode from a solution of the racemate. This method need hardly be taken into account in connection with the complicated substances of colloidal structure which undoubtedly played the essential part in the building up of the primaeval protoplasm.

In the second place: the chemical action of circularly polarized ultraviolet light. By this means Kuhn and other authors have succeeded in bringing about a number of absolute asymmetric syntheses with appreciable optical activity.

In spite of the insignificant predominance of the right circularly polarized component in the scattered light falling on the surface of the Earth, this action must surely have made itself felt during the long years of the evolution of the living world.

We consider that this factor must be taken into account in connection with the problem under discussion and more will be said about this later. 
In the third place: asymmetric catalysis with the help of dissymmetrical crystals of minerals. Schwab and his colleagues were the first (1932-34) to bring about the asymmetric destruction of butan-2-ol using, as catalysts, finely divided metals on crystals of dextro- and laevo-quartz. Later (1950-53) [3] we extended this method considerably, bringing about a number of asymmetric syntheses with different catalysts on quartz crystals under many variable conditions. In addition syntheses were brought about in solution at ordinary temperatures using a layer of alkali on crystalline quartz.

This gives us reason to suppose that, under natural conditions, quite complicated syntheses could have taken place on the surface of dissymmetric crystals of minerals with the formation of optically active compounds of high molecular weight.

The only objection to the supposition that the first dissymmetrical compounds could have arisen in this way is the fact that, in nature, there is no predominance of optically active crystals of one sign. One antipode is always accompanied by an equal amount of the other in the formations in which it occurs as found by G. G. Lemmlein in the case of quartz.

If we assume that the sole causes determining the dissymmetry of the primaeval protoplasm were minerals then, in order to arrive at an explanation for the one-sided dissymmetry of the natural amino acids, we should have to postulate a one-sided dissymmetry of the crystals of geological formations. We have no basis for doing so. Thus, there must be some dissymmetrical, natural factors which would make it possible for one form of complicated organic molecule to come into being and become predominant.

It is possible that these were the right circularly polarized light which, in the view of physicists, is present in the scattered sunlight.

In the coastal zone of the primaeval ocean where life probably arose, amino acids could form complex compounds with iron, copper, vanadium, magnesium and other metals. This led to a considerable, selective absorption of light owing to the circular dichroism of such complexes. The preferential destruction of $\mathrm{D}$-amino acids by light could have led to the development of the $\mathrm{L}$-forms and their products.

In this connection it is possible to approach the problem of the formation of petroleums from a new standpoint. Until now the presence of optically active substances in petroleums has been considered as an incontrovertible proof of their biogenic origin. Nevertheless, petroleum has undoubtedly undergone a number of chemical transformations in the depths of the Earth involving the catalytic activity of various silicates and other formations. Among these there might have been some in which crystals of one particular sign predominated. The optical activity of petroleum might thus have arisen purely abiogenically.

By using the method of asymmetric catalysis it has been possible to discover the dissymmetrical structure of minerals and formations with which the ordinary crystallographic methods have been ineffective. For this the asymmetric synthesis of an organic compound by catalysis based on the mineral under investigation must be realized. The appearance of optical activity in the catalysate serves as indisputable proof of the dissymmetry of the catalyst. 
The experimental evidence concerning the spontaneous resolution of racemates and photochemical asymmetric synthesis will be considered below. The part played by asymmetric catalysis and asymmetric adsorption in producing the dissymmetry of living material will be considered separately.

\section{SELECTIVE SPONTANEOUS CRYSTALLIZATION}

\section{OF ANTIPODES}

The self-propagating separation of enantiomorphs, commonly called spontaneous crystallization, may occur under various conditions: from optically active solvents; by seeding with a crystal of one or other antipode of the same compound or one isomorphous with it; or by spontaneous crystallization.

These cases of selective crystallization are due to differences in the nature of racemates. The spontaneous crystallization of true racemic compounds containing equal amounts of $(+)$ - and (-)-enantiomorphs in the crystal lattice of the molecules is a comparatively rare phenomenon [4].

Crystallization under the influence of isomorphic crystals, or those of one antipode of the crystallizing racemate, is possible when the racemate crystallizes as a conglomerate in which each of the antipodes crystallizes in its own lattice. True spontaneous crystallization occurs when mixed crystals are formed, the antipodes entering into a common lattice in any proportions. In specially favourable cases the crystalline deposit contains a great excess of one antipode [5].

I. Crystallization in an optically active solvent. When crystallizing sodium or ammonium tartrate from a solution of D-glucose, Kipping \& Pope [6] usually obtained an excess of one enantiomorph in the deposit. McKenzie [7] separated out $(+)$-ammonium tartrate by crystallizing ammonium tartrate from a solution of (-)-ammonium malate. Crystallization from a solution of $(+)$-ammonium malate led to the separation of the (-)-tartrate [8].

This case is of great interest as being the first example of the isolation of one antipode of a racemic acid by the action of another optically active acid instead of by a base as ordinarily used.

2. Crystallization initiated by a crystal of one antipode or by an isomorphous crystal. A considerable amount of work has been devoted to the study of the selective crystallization of optical antipodes, or crystalline enantiomorphs, by insertion, into a supersaturated solution, of a crystal of one antipode of the same substance, or some other crystal isomorphous with it.

On the basis of Pasteur's work Gernez [9] proposed a method of isolation of one antipode under the influence of crystals of the $(+)$ - or (-)-antipode [1o]. Kipping \& Pope [II] were inclined to ascribe such separation to the action of seeds of crystallization reaching the solutions in the dust of the air of the laboratory. In fact, when a compound crystallizes as a conglomerate of $(+)$ - and $(-)$ crystals, crystallization with free access of air leads to an equal probability of the separation of either $(+)$ - or $(-)$-isomer.

This is confirmed by the observations of Anderson \& Hill [12] on the crystallization of synthetic atropine sulphate. Read [13] also inclines towards this view. 
Soret [ $\left.\mathrm{I}_{4}\right]$ observed that crystallization of sodium chlorate in the air led to the formation, mainly, of the (-)-enantiomorph while, when the crystallization took place in sealed tubes the $(+)$-form separated in 433 cases, the $(-)$-form in $4 \mathrm{II}$ cases while in 43 cases a mixed form was produced. However, if the necessary precautions are taken, this method gives satisfactory results.

Thus, by priming with crystals of one antipode it has been possible to separate the racemic forms of zinc and ammonium lactates [15], phenylbenzylhydrazone of erythrose [16] and Co- and Cr-oxalatobisethylenedianine [17].

In I934, Calzavara $[18,19]$ took out a patent on the separation into antipodes of racemic adrenaline and other alkaloids. This was the method by which Velluz et al. [20] resolved racemic threo-I- $N$-nitrophenyl-2-aminopropaneI : 3-diol.

The selective crystallization brought about by the introduction into a supersaturated solution of racemate of crystals of one antipode or other crystals isomorphous with it has been studied in detail by Ostromyslenskiî [2I]. It was found that, from a supersaturated solution of sodium ammonium tartrate one antipode would crystallize out in the presence of not only the $(+)$ - or (-)tartrate but also when isomorphous or isodimorphous crystals were added. Thus. the introduction of L-asparagine evoked the crystallization of $(+)$-tartrate. Even such compounds as glycine, which are not composed of dissymmetrical molecules but form enantiomorphic crystals can evoke the crystallization of one isomer from a solution of racemate of asparagine or sodium ammonium tartrate. In the presence of crystals of sodium nitrate one enantiomorph always crystallizes out from aqueous solutions of sodium periodate [22] sodium silicotungstate [23] or guanidine carbonate [24]. Zelinskii [24] achieved the separation of enantiomorphs during the crystallization of dimethyldihydroxyglutaric acid.

Enantiomorphic substances in nature are almost always found in the separate crystalline state, their crystalline racemates are extremely rare. It is thus quite possible that localized asymmetric synthesis could take place on such inorganic and organic dissymmetrical crystals.

3. Spontaneous crystallization. On evaporation, concentrated solutions of acid ammonium malate deposit crystals which show optical acitivity. Van't Hoff \& Dawson [25] showed that these crystals consist of three parts of the $(+)$ - and one part of the (-)-salt. Malic acid may be obtained in an optically active form by the spontaneous crystallization of a salt of composition $\mathrm{C}_{4} \mathrm{H}_{6} \mathrm{O}_{5}, 2 \mathrm{MoO}_{3}, 2 \mathrm{NH}_{3}$ [26].

The spontaneous crystallization of sodium tartrate and sodium ammonium tartrate has been thoroughly studied. Other known cases of spontaneous resolution of racemates concern asparagine [27], methoxy-4-methyldeoxybenzoin [28], dibenzalpentacrythritol [29] and erythritol [30], dilactylamide [31], the lactone of gulonic acid [32], camphoric [33] and glutamic acids [10, 36], complex salts of cobalt and rhodium [34], $\beta$-decalol [35] and isolyydrobenzoin [36].

Neuberg [37] found that, when it has been kept for a long while in a solution of potassium salts, $\beta$-methylvaleric acid deposits crystals of the $(+)$-acid of a high degree of purity. After keeping a solution of methylethylallylphenylammonium iodide in a sealed ampoule for some months, Havinga [38] observed 
that resolution had taken place, the crystals, dissolved in chloroform, had a rotation of $+27^{\circ}$ while that of the mother liquor was $-0.15^{\circ}$.

On crystallization of racemic histidine hydrochloride Duschinsky [39] obtained the (+)-isomer while Vogler \& Kofer [40] were the first to resolve $2: 4$-dioxo3-diethyl-5-methylpiperidine into its antipodes.

Recently, Darmois [4I] has proposed a general method for the resolution of racemic bases, based on the artificial forcing of spontaneous crystallization.

By this method Ferreira [42] made a partial resolution of the racemic alkaloids narcotine and laudanosine which are not soluble in water. He converted them to hydrochlorides and caused pyridine to react slowly with the solution. The resolution of synthetic adrenaline was considerably more successful. After four crystallizations the alkaloid was almost completely resolved [4I].

It is obvious from the material which has been surveyed, that it is essentially compounds of comparatively simple structure which can be submitted to spontaneous separation. Therefore, as has been shown above, it seems hardly likely that the primaeval colloidal organic substances became dissymmetrical in this way. On the contrary, the belief that the only factors playing a part in bringing about the primary asymmetry of the organic world were asymmetric adsorption and catalysis [43] and circularly polarized light, polarized mainly in one direction, meets with no such difficulties and agrees with the experimental evidence [44].

\section{PHOTOCHEMICAL ASYMMETRIC SYNTHESIS}

Interest in the question of the ways in which the primary dissymmetrical substances could have arisen has increased rapidly since the discovery of the optical isomer by reducing phenylglyoxylic acid, by adding bromine to stilbene and esters of fumaric or cinnamic acids [46-49].

Pasteur [45] saw physical processes as the source of the optical activity of the substances important for life.

To test this idea he tried to bring about an absolute asymmetric synthesis by crystallizing the antipodes out of a racemate in powerful magnetic fields or in rapidly rotating tubes.

Under similar conditions attempts have been made to obtain an excess of one optical isomer by reducing phenylglyoxylic acid, by adding bromine to stilbene and esters of fumaric or cinnamic acids [46-49].

Similarly, electrolysis of salts of iron with substituted malonic acids in a magnetic field did not lead to the formation of optically active products [50], although the influence of a magnetic field in orienting crystals of complex salts of cobalt, nickel $[5 \mathrm{r}, 52]$ etc. has been noticed.

The attempts by Ostromyslenskir [53] to find differences in the rates of crystallization of antipodes were unsuccessful. So were those of Rosenthaler [54] to hydrolyse polysaccharides asymmetrically in a magnetic field.

All these unsuccessful attempts were based on the false assumption that a magnetic field, or mechanical movement, were factors of such a nature that their 
involvement in reactions might evoke the formation of optically active compounds. This mistake became obvious after 1894 when P. Curie [55] formulated the requirements which must be fulfilled by a dissymmetrical agent if it is to be able to lead to the formation of asymmetry by influencing reactions; elliptically or circularly polarized light could constitute such an agent.

Another reason for the lack of success in achieving asymmetric syntheses was the choice of agents which had no effect on the reaction in question [56].

Thus, the dissymmetrical agent must not only be able to cvoke dissymmetry but must also be able to initiate the reaction [57].

These two requirements were met in experimental work devoted to the photochemical asymmetric resolution of racemates and the asymmetric synthesis of optically active compounds, when the agent evoking the dissymmetry was circularly polarized light. Both the necessary conditions were satisfactorily fulfilled.

\section{ABSOLUTE ASYMMETRIC SYNTHESIS UNDER THE} INFLUENCE OF CIRCULARLY POLARIZED LIGHT

I. Asymmetric decomposition of racemates. Scattered sunlight, when reflected from the surface of the Earth under the influence of its magnetic field, becomes partly circularly polarized with a slight preponderance of the right-handed component [58-6I]. The suggestion has been made that, owing to the effect of this component being in excess, there occurred, during the course of the long years of evolution of the living world, a regular biosynthesis of optically active organic compounds [62-64].

This hypothesis, which was first put forward by Van't Hoff, seemed very attractive and provided a stimulus for researches into the experimental conditions required for the accomplishment of absolute asymmetric synthesis under the influence of circularly polarized light in which one component preponderated.

The photochemical effect of linearly polarized light on organic compounds was discovered in $184 \mathrm{I}$ but statements about its selective effect on optical antipodes were mistaken [65]. A selective action on antipodes can only be expected from circularly polarized light $[66,67]$.

The first attempts to demonstrate this effect experimentally were unsuccessful [68] and only Cotton [69] succeeded in discovering circular dichroism-different degrees of absorption of circularly polarized light by the optical antipodes of the racemic tartrates of chromium or cobalt-a phenomenon which has been called the Cotton effect [70]. It should be noted that McKenzie [7I] had already tried to carry out the asymmetric decomposition of salts of racemic lactic acid under the influence of circularly polarized light.

After it has been established that optical antipodes have different capacities for the selective absorption of light which is circularly polarized in one direction, many attempts were made to use this dissymmetric factor for the selective decomposition of racemates. 
Thus the photochemical asymmetric decomposition of camphor and lactic acid [72] and the decarboxylation of acids having the formulac<smiles>CCC(C)(C#N)C(=O)O</smiles>

and

were undertaken.<smiles>CC(Cl)(C(=O)O)C(C)(Cl)C(=O)O</smiles>

The negative results of these attempts are explained by the absence of any circular dichroism or any photochemical dissociation in those parts of the absorption spectrum which were being studied. An asymmetric effect may, accordingly, be expected in substances which are highly susceptible to photochemical decomposition taking place under the influence of light with waves of the same length as those which manifest dichroism. Under these conditions selective absorption of one component of circularly polarized light occurs and this should lead to asymmetric synthesis when the reaction proceeds with the activation (or leads to the appearance) of centres of dissymmetry.

In I929, Kuhn \& Braun [74], bearing this in mind, submitted the ethyl ester of a-bromopropionic acid to photochemical decomposition by the action of circularly polarized light.

The major component of the light brought about a greater decomposition of the antipode of the opposite sign. The product contained an excess of the $(+)-$ ester with $\alpha=+0.05^{\circ}$ when right circularly polarized light was used.

A relatively high degree of asymmetric resolution was obtained (rotation, $\alpha=\mathrm{I} \cdot 04^{\circ}$, degree of resolution $0.5 \%$ ) by the use of the dimethylamide of $\alpha$ azidopropionic acid (Kuhn \& Knopf, I930 [75]).

As in the previous case, the right-handed component of the light brought about greater decomposition of the (-)-antipode.

The optical activation $\left(\alpha= \pm 0.2 I^{\circ}\right.$ ) of the nitrosite of humulene ( $\alpha$-caryophyllene [76]) by the action of circularly polarized light was carried out by Mitchell [77]; left-handed light brought about decomposition of the $(+)$ antipode.

Special hopes were entertained of being able to carry out asymmetric photochemical decomposition of the light-sensitive salts of cobalt and rhodium which, in the optically active form, have a high specific rotation [78]. However, only the racemic complex $\mathrm{K}_{3}\left\{\mathrm{Co}\left(\mathrm{C}_{2} \mathrm{O}_{4}\right)_{4}\right\}$ could be optically activated by the selective decomposition, under the influence of right circularly polarized light, of the (-)-antipode [79].

As the cases which have been discussed are not really cases of asymmetric synthesis, but they were the first examples of the photochemical resolution of racemates. 
Far greater theoretical interest attaches to the experiments aimed at carrying out absolute asymmetric syntheses of optically active compounds from substances which had a symmetrical structure. As a result of a reaction of this sort, an asymmetric carbon atom appears in the product and the compound shows optical activity.

2. Photochemical, absolute, asymmetric synthesis. Genuine, absolute, asymmetric synthesis, as distinct from the resolution of racemates, in the course of which new centres of asymmetry came into being, was accomplished very soon after Kuhn's experiments.

The first attempts to carry out photochemical absolute asymmetric syntheses by the bromination of substituted cinnamic acids [80] angelic acid [8I] or by adding $\mathrm{HCN}$ to acetaldehyde [82] were unsuccessful.

Not until I933-34 did Karagunis \& Drikos [83] first bring about an absolute asymmetric synthesis by adding chlorine to a free triarylmethyl radical under the influence of circularly polarized light:

$$
\mathrm{R}_{1} \mathrm{R}_{2} \mathrm{R}_{3} \mathrm{C}-+\frac{1}{2} \mathrm{Cl}_{2} \rightarrow \mathrm{R}_{1} \mathrm{R}_{2} \mathrm{R}_{3} \mathrm{C}-\mathrm{Cl}
$$

During the reaction the magnitude of the rotation passed through a maximum, reaching $0.08^{\circ}$.

In the following year Tenney \& Heggic [84] obtained optically active products under the same conditions, adding bromine to $2: 4: 6$-trinitrostilbene, while Betti \& Lucchi [85] found a small asymmetric effect on chlorinating propylene, butylene and butadiene.

Special interest attaches to the first absolute asymmetric synthesis of a natural compound, carried out in 1945 by Tenney \& Ackerman [86].

At first they obtained an optically active substance, $(+)$-tartaric acid, by the action of circularly polarized light, and it was in the very form in which it occurs in living Nature. The synthesis was completed by the hydroxylation with hydrogen peroxide of diethyl fumarate by illumination with circularly polarized light. The rotation of the product passed through a maximum, reaching $+0.073^{\circ}$ which corresponds to a degree of asymmetric synthesis of $2.5 \%$.

It should be added that ( + )-tartaric acid is obtained by the action of the right-handed component of circularly polarized light and this is the component which is present in slight excess in scattered light on the surface of the Earth as we noted earlier. This fact provides strong support for the hypothesis that the optical asymmetry of the molecular constituents of living organisms was brought into being by the action of circularly polarized light.

\section{A DISSYMMETRIC SEQUENCE AS A FACTOR IN LIFE}

In conclusion we will give some consideration to the significance of those factors which we termed the Pasteur effect.

Recent investigations have shown that polymers and polycondensates in which the molecules are composed of unsymmetrical links of a single type have special properties, different from the properties of irregular polymers. This is caused by the different and closer packing of regular chains [87]. 
The same idea should be applied to enzymic systems with a definite sequence in the arrangement of their links of dissymmetric L-amino acids. This gives rise to a definite, and always uniform, orientation of the molecules taking part. Out of the chaos of different molecules of the surrounding solution, the enzymecatalyst strings together an appropriate molecule in a definite order. Weakly associated with the molecule of the enzyme by the Pasteur effect, the molecular system, which has been built up in this way, is imprinted by the molecule which propagated it, just as a stereotype or a page of text is printed by the matrix of a printing machine.

\section{REFERENCES}

I. V. S. Podisko A. V. Shubnikov, Trudy Instituta Krist., No. II, 212 , 1955.

2. C. C. Price \& M. Osgan, 7. Amer. chem. Soc., 78, 690, 1956.

3. N. BerEDJik, f. Amer. chem. Soc., 78, 2646, 1956.

4. V. Grignard, Traité de Chimie Organique, Vol. I, p. 935, Paris, I935.

5. A. V. INGERSOLL, in Organic reactions, 2, 40I, 1950.

6. F. S. KIPPING \& W. J. POPE, f. chem. Soc., 73, 606, 1898; Z.Kristallogr., 30, 472, I 899

7. A. McKenzie, $\mathcal{F}$. chem. Soc., 107, 440, 1915.

8. A. McKenziE, . chem. Soc., I21, 349, I922; 123, 2875, I923.

9. Gernez, C. R. Acad. Sci., Paris, 63, 843, 1866.

IO. E. Jungfleisch, Bull. Soc. chim. Fr. (2), 4I, 225, r884.

Ir. F. S. Kipping \& W. J. Pope, 7. chem. Soc., 95, 103, 1909.

I2. L. ANDERSON \& D. W. Hill, f. chem. Soc., p. 993, I928.

13. J. READ, Nature, Lond., 17I, 843, 1953.

14. C. SORET, Chem. Zbl. II, 905, I90I; Z.Kristallogr., 34, 630, 1900.

15. T. PURDIE, f. chem. Soc., 63, I I 43, 1893.

16. O. RuFF, Ber. dtsch. chem. Ges., 34, 1362, I901.

17. A. WERNER, Ber. dtsch. chem. Ges., 47, 217I, 1914.

18. E. Calzavara, Chem. Zbl. II, 2134, I934; Fr. Pat.,763374, 23.I., 1933.

I9. A. P. Terent'ev \& V. M. Potapov, Priroda, Leningr., 5, 37, 1955.

20. L. Velluz, G. Ammiard \& R. Joly, Bull. Soc. chim. Fr., 3, 342, 1953; Chem. Abstr., $2470,4216,1956$.

21. I. Ostromyslenskil̆, Ber. dtsch. chem.Ges., 4r, 3035, 1908; C.R. Acad. Sci., Paris, I76, 391, 1923.

22. A. S. EACLE, Chem.Zbl., 649, 1896; Z.Kristallogr., 26, 562, 1896.

23. G. WyroubofF, Chem. Zbl., 2, 90, I898.

24. N. D. Zelinskil̆, Ber. dtsch. chem. Ges., 24, 4006, I89I.

25. J. H. Van'T Hoff \& H. M. Dawson, Ber. dtsch. chem. Ges., 31, 528, I898.

26. G. Wyroubofr, Bull. Soc. chim. Fr. (2), 4I, 212, I884; 45, 52, I886; Liebigs Ann., (6), 9, 22I, I886; Z. phys. Chem., 5, II 8, I890; K. FreUdENBERG, Stereochemie, I, $565,1933$.

27. A. Puitti, C.R. Acad. Sci., Paris, 103, I34, 1886; W. Körner \& A. Menozzi, Ber. disch. chem. Ges., 2I, 87, 1888.

28. M. Bruzau, C.R. Acad. Sci., Paris., 196, 122, 1933.

29. J. BöEsEKEN \& B. FeLIX, Ber. dtsch. chem. Ges., 6I, 787, 1928.

30. M. Godchot \& P. Vieles, Bull. Soc. chim. Fr. (4), 51, 589, 1932.

31. L. Marquenne \& G. Bertrand, C.R. Acad. Sci., Paris, 132, I565, I90I.

32. E. FisCher \& R. CuRTiss, Ber. dtsch. chem. Ges., 25, I025, I892.

33. E. Jungfleisch, C.R. Acad. Sci., Paris, 110, 792, 1890; 108, 982, 1889.

34. F. JAEger, Rec. trav. chim. Pays-Bas, 38, 250, I919; Z. anorg. Chem., 175, 2 I I, 1928.

35. W. HüCKEL \& C. KuHN, Ber. dtsch. chem. Ges., 70, 2479, 1937.

36. E. ErLenmeyer, Ber. dtsch. chem. Ges., 30, I53I, I897; see also f. chem. Soc., p. 9I2, 1927; F. chem. Soc., p. 2305, 1929; Z. angew. Chem., 188, 47, 1930; Z. Kristallogr. 69, 69, 1928.

37. C. NEUBERG, Biokhimiya, 2, 383, I937.

38. E. Havinga, Chem. Weekbl. 38, 642, 1941; Biochem. biophys. Acta, 13, 171, 1954. 
39. R. Duschinsky, F. Soc. chem. Ind., Lond., 53, Io, r934.

40. K. Vogler \& M. Kofler, Helv. chim. acta, 39, I387, I956.

4I. E. Darmois, C. R. Acad. Sci., Paris, 237, I24, 1953.

42. R. C. FerreIRA, Nature, Lond., 171, 39, I953.

43. E. I. Klabunovskil \& V. V. Patrikeev, Priroda, Leningr., 7, 89, I954. Vestnik Moskov. Gosndarst. Univ., 5, 53, 1953.

44. E. I. KlabunovsKill, Origin of Life, p. 158.

45. L. Pasteur, Oeuvres de Pasteur (Ed. par Valléry-Radot), Vol. I, p. 375. Masson et Cie, Paris, 1922.

46. A. P. Terent'ev \& E. I. Klabunovskil̆, Uchennye Zapiski Moskov. Gosudarst. Univ., I5I, I45, I95I.

47. J. P. MATHIEU, La synthèse asymmetrique, Paris, 1934.

48. P. D. Ritchie, Advanc. Enzymol., 7, 65, 1947.

49. P. Guys \& G. Drouginine, f. Chim. Phys., 7, 97, 1909.

50. P. D. Ritchie, Asymmetric Synthesis and Asymmetric Induction. O.U.P., London, 1933.

5I. L. W. Sтоск, Z. phys. Chem., (B), 23, 236, 1923.

52. G. RoAsio, Z. Kristallogr., 59, 88, 1924 .

53. I. OstromysLEnSKIII, Ber. dtsch. chem. Ges., 4r, 3035, I908.

54. J. Rosenthaler, S.B. preuss. Akad. Wiss., $\mathbf{x}, 20$, 1908.

55. P. Curie, f. Phys. Chim. Hist. nat. (III), 3, 403, 1894 .

56. J. MEYER, ChemZtg, I, 4I, 1904 .

57. F. M. JAEGER, Optical activity, p. 76. New York, 1930.

58. Jamin, C. R. Acad. Sci., Paris ,31, 696, 1850.

59. H. Becquerel, C. R. Acad. Sci., Paris, 108, 997, 1899.

60. L. Tenney \& R. Heggie, f. Amer. chem. Soc., 57, I622, 1935.

6I. A. BYK, Ber. dtsch. chem. Ges., 37, 4696, I904; 42, I4I, I909; Arch. Pharm., Berl., 269, 356, I93I; Z. phys. Chem., 49, 641, I904.

62. E. I. Ki.ABunovskiř \& V. V. Patrikeev, Vestnik $M G U(5), 53,1953$.

63. K. D. Todorov, Kristalicheskata antisimmetria $i$ zhivot" $t$ na bel'tsite. State University, Stalin, Bulgaria, I95I. Reviewed by E. I. KLABUNovsKIǏ, Biokhimiya, I9, 638, 1954.

64. A. I. Oparin, Proiskhozhdenie zhizni Zemle. Izd. Akad. Nauk S.S.S.R., Moscow 1957; The Origin of Life on the Earth. Oliver \& Boyd, Edinburgh, 1957.

65. D. J. MACHT \& W. T. ANDERSON, 7. Amer. chem. Soc., 49, 201, 1927.

66. L. Pasteur, Rev. Sci., Paris (III), 7, 3, I884.

67. Sutherland, Phil. Mag., 19, 52, 1841.

68. J. A. Le BeL, Ann. Chim. Phys. (III), 8, 373, r896.

69. A. Cotton, Liebigs Ann., 8, 360, 1896.

70. C.R. Acad. Sci., Paris, 189, 1260, 1929; 7. Chim. phys., 7, 81, 1909; f. chem. Soc., p. $3258,1928$.

7r. A. MCKenZIE, Z. angew. Chem., 45, 59, r932.

72. G. BREDIG, $Z$. angew. chem., 36, 456, I923.

73. F. HeNle \& H. HaAKH, Ber. dtsch. chem. Ges., 4I, 426I, I908; 42, I4I, 1909.

74. W. KuHn \& E. BRAUn, Naturwissenschaften, 17, 227, 1929.

75. W. KuHN \& E. KNOpF, Naturvissenschaften, 18, 183, I930; Z. phys. Chem. (B), 7, 292, I930.

76. G. R. Clemo \& J. O. Harries, Chem. E Ind., p. 50, I95I; f. chem. Soc., p. 665, 1952.

77. S. Mrtchell, f. chem. Soc., p. I829, I930.

78. R. Luther \& A. Nikopulos, Z. phys. Chem., 82, 361, I9I3.

79. R. Tsuchida, F. chem. Soc. Fapan, 59, I339, 1935.

80. J. Freundler, Bull. Soc. Chim. Fr., I, 657, I907.

81. M. Padoa, R. C. Accad. Lincei, 18, 390, 1909.

82. J. PIRAK, Biochem. Z., I30, 76, I922.

83. G. Karagunis \& G. Drikos, Naturwissenschaften, 21, 607, I933; Nature, Lond., 132, 354, 1933; Z. phys. Chem. (B), 26, 428, 1934; Prakt. Akad. Athen, 9, 177, 1934.

84. L. Tenney, D. Heggie \& R. Heggie, f. Amer. chem. Soc., 57, 377, 1935.

85. M. Betti \& E. LuCchi, Chem. Abstr., 7273, 1939.

86. L. Tenney, D. Ackerman \& J. Ackerman, F. Amer. chem. Soc., 67, 486, I945.

87. G. Natta, Chim. nell' Industr., 38, I24, 1956. 


\title{
Formation of Organic Compounds on the Primitive Earth
}

\author{
STANLEY L . MILLER \\ Department of Biochemistry, College of Physicians and Surgeons, \\ Columbia University, U.S.A.
}

ONE OF the most fundamental problems of biology is posed by the question, 'How did life arise on the Earth'. The Theory of Evolution offers an explanation for the development of complex multi-celled living organisms from single-celled organisms, but this theory does not explain the development of the first organism. To assume that life arose from inorganic matter presents overwhelming difficulties. Not only would a self-duplicating organism have to be made from the inorganic matter, but the organism would have to contain the complex apparatus to synthesize all its components and energy requirements from carbon dioxide, water and light.

Oparin [I] in his book The Origin of Life proposed that spontaneous generation of life would be less difficult if the ocean contained a large amount of complex organic compounds similar to those present in living organisms. These compounds would serve both as structural components and as the energy source for the first organisms. Oparin also proposed that the Earth had a reducing atmosphere of methane, ammonia, water and hydrogen in its early stages, and that organic compounds might be formed under these conditions. Bernal [2] has given a similar discussion.

Urey [3, 4] based his arguments for the reducing atmosphere on the thermodynamic properties of the gases in a cosmic dust cloud from which the solar system was formed. The equilibrium constants at $25^{\circ} \mathrm{C}$. for the reactions of the gaseous species are given in Table $\mathrm{I}$.

TABLE I

\begin{tabular}{l|l}
\hline & $K_{25}$ \\
\hline $\mathrm{CO}_{2}+4 \mathrm{H}_{2}=\mathrm{CH}_{4}+2 \mathrm{H}_{2} \mathrm{O}$ & $7 \times 10^{22}$ \\
$\mathrm{CO}+3 \mathrm{H}_{2}=\mathrm{CH}_{4}+\mathrm{H}_{2} \mathrm{O}$ & $3 \times \mathrm{IO}^{26}$ \\
$\mathrm{C}+2 \mathrm{H}_{2}=\mathrm{CH}_{4}$ & $8 \times 10^{5}$ \\
$\mathrm{~N}_{2}+3 \mathrm{H}_{2}=2 \mathrm{NH}_{3}$ & $7 \times 10^{5}$ \\
$\mathrm{H}_{2}+\frac{1}{2} \mathrm{O}_{2}=\mathrm{H}_{2} \mathrm{O}$ & $4 \times 10^{41}$ \\
$\mathrm{~S}+\mathrm{H}_{2}=\mathrm{H}_{2} \mathrm{~S}$ & $6 \times 10^{5}$ \\
\hline
\end{tabular}

These equilibria show that in the presence of hydrogen the carbon will be as methane, the nitrogen as ammonia and the oxygen as water. Urey proposed 
that organic compounds might be synthesized by ultraviolet light and by electric discharges in the proposed reducing atmosphere.

Experimental support for these theories came from studies of the action of electric discharges on these gases [5-7]. The experimental results will be summarized, and some of their implications will be discussed.

As a basis for discussion the following model of the primitive Earth is proposed. The atmosphere was reducing and the oceans covered an appreciable fraction of the surface of the Earth. The temperature is assumed to have been less than $100^{\circ}$. The sources of energy for the production of the initial organic compounds were ultraviolet light, electric discharge and high temperatures (under local conditions such as volcanoes). Although the level of radioactivity was higher than at present, the energy available was still quite small, and there is no evidence that the cosmic ray intensity was ever large enough to compare with the energy from the sun.

The energy from ultraviolet light would probably be greater than that from electric discharges. Because of the difficulties of working with ultraviolet light in the region where the reduced gases would absorb $(<2000 \AA)$, electric discharges were used in the first experiments.

\section{SPARK DISCHARGE-RUN I}

An approximation of the proposed model is shown in Fig. I. The apparatus is made of Pyrex with tungsten electrodes. The water in the small flask is boiled to promote circulation and to bring water to the region of the spark. The products of the discharge are condensed and flow through the U-tube, which prevents circulation in the wrong direction. The non-volatile compounds accumulate in the small flask. The spark discharge is produced by a high frequency Tesla coil having a peak of 60,000 volts.

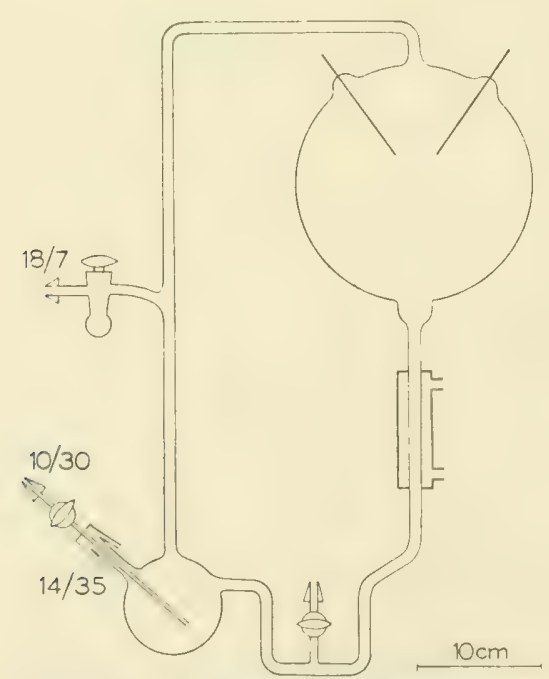

FIG. I. Spark-discharge apparatus 
The pressures of hydrogen, methane, and ammonia were 10,20 and $20 \mathrm{~cm}$ of $\mathrm{Hg}$, respectively. During a run the water was boiled and the spark operated continuously. Colloidal silica, originating from the action of ammonia on glass, formed in the boiling flask during the run together with a yellow polymer. The yellow polymers have a strong ultraviolet absorption but no peaks above $230 \mathrm{~m} \mu$. The non-dialysable compounds were hydrolysed and chromatographed. Only a very small amount of amino acid was present in this fraction.

A red colour was formed with the spark discharge in some of the experiments. The synthesis of the colour seems to depend on the presence of trace metals. The colour is an organic compound and has absorption maxima at 390 and $540 \mathrm{~m} \mu$. It is not a porphyrin.

\section{Analysis of Products}

Analysis of the gases remaining at the end of a run showed carbon monoxide, carbon dioxide and nitrogen present in addition to the initial gases. The organic compounds were separated into acidic, basic, and ampholytic fractions by various ion-exchange resins. The different acids were separated by chromatography on silica [8] and the amino acids by chromatography on Dowex 50 [9]. The compounds were identified by $R_{F}$ values on ion-exchange resins, silica, and on paper. Some of the compounds were further characterized by preparation of derivatives and comparing the melting point and mixed melting point with an authentic sample of the derivative.

TABLE 2

Yields of compounds (moles $\left.\times 10^{5}\right)$

\begin{tabular}{|c|c|c|c|c|c|c|c|c|}
\hline & & & & & & $\begin{array}{l}\text { Spark } \\
\text { Run I }\end{array}$ & $\begin{array}{c}\text { Silent discharge } \\
\text { Run } 3\end{array}$ & $\begin{array}{l}\mathrm{N}_{2} \text { Run } \\
\text { Run } 6\end{array}$ \\
\hline Glycine & . & - & • & - & • & $63(2 \cdot I)^{*}$ & $80(0.45)^{*}$ & $14.2(0.48) *$ \\
\hline Alanine & - & - & - & . & - & 34 & 9 & $I \cdot O$ \\
\hline Sarcosine & . & . & - & - & - & 5 & 86 & $I \cdot 5$ \\
\hline$\beta$-Alanine & $\because$ & $\therefore$ & - & - & - & 15 & 4 & $7 \cdot 0$ \\
\hline$\alpha$-Aminobut & yric as & cid & - & - & - & 5 & I & - \\
\hline$N-M e t h y l a l a$ & nine & . & - & - & - & $\mathbf{I}$ & $12 \cdot 5$ & - \\
\hline Aspartic acid & & - & - & - & - & $0 \cdot 4$ & 0.2 & 0.3 \\
\hline Glutamic aci & & - & - & - & - & 0.6 & 0.5 & 0.5 \\
\hline Iminodiaceti & c acid & & $\therefore$ & - & . & $5 \cdot 5$ & 0.3 & $3 \cdot 9$ \\
\hline Imino-acetic & -propi & ionic : & cid & - & - & $I \cdot 5$ & - & - \\
\hline Formic acid & & - & - & - & - & 233 & I 49 & 135 \\
\hline Acetic acid & $\therefore$ & . & - & . & - & $15 \cdot 2$ & 135 & $4 I$ \\
\hline Propionic aci & & - & - & - & - & $12 \cdot 6$ & I9 & 22 \\
\hline Glycolic acid & & $\cdot$ & • & - & • & 56 & 28 & 32 \\
\hline Lactic acid & - & - & - & - & - & $3 I$ & $4 \cdot 3$ & $I \cdot 5$ \\
\hline$a$-Hydroxyb & utyric & acid & - & - & - & 5 & I & - \\
\hline Succinic acid & & - & - & - & - & $3 \cdot 8$ & - & 2 \\
\hline Urea & - & . & - & - & - & 2 & 一 & 2 \\
\hline Methylurea & - & $\cdot$ & - & - & - & $I \cdot 5$ & - & 0.5 \\
\hline \multicolumn{6}{|c|}{ Sum of yields of compounds listed . } & $15 \%$ & $3 \%$ & $8 \%$ \\
\hline
\end{tabular}

* Percent yield of glycine, based on carbon placed in the apparatus as methane. 
The optical rotation of a sample of alanine was $0.000 \pm 0.003^{\circ}$. If this sample had been either pure enantiomorph, the rotation would have been $0.12^{\circ}$. The yields of compounds from the various runs are shown in Table 2.

\section{Absence of Purines and Pyrimidines}

The mixture of compounds from a run similar to Run I was evaporated to dryness and the whole sample was chromatographed on a column of Dowex 50 $\left(\mathrm{H}^{+}\right)$[10]. The eluent showed no $260 \mathrm{~m} \mu$ absorption maximum where the naturally occurring purines and pyrimidines would have been eluted, and paper chromatography of the evaporated fractions showed no spots with an ultraviolet lamp. It is concluded that the presence of any purine was less than $0.2 \times 10^{-5}$ moles and of any pyrimidine was less than $\mathrm{O} \cdot \mathrm{I} \times \mathrm{IO}^{-5}$ moles.

\section{The Effect of Adding Ferrous Ammonium Sulphate}

Since iron is one of the more abundant elements on the Earth, and would be present as both the metal and ferrous compounds, an experiment was performed to compare the organic compounds synthesized by a spark discharge in the system with and without added ferrous ammonium sulphate. About $16 \%$ of the iron had been oxidized to ferric by the end of the run. The organic compounds were the same as in Run I, and the quantitative values were only slightly different.

\section{THE SILENT DISCHARGE-RUN 3}

An experiment was performed using a silent electrical discharge (ozonizer) instead of a spark. As seen in Table 2, the yields are about one-fourth that of the spark, but the products are similar.

\section{SPARKING A MIXTURE OF METHANE, NITROGEN, WATER AND HYDROGEN-RUN 6}

The equilibrium constant for the reaction $\mathrm{N}_{2}+3 \mathrm{H}_{2}=2 \mathrm{NH}_{3}$ is $7 \times 10^{5}$ atm $^{-2}$, at $25^{\circ}$, which predicts that the nitrogen would remain as ammonia instead of $\mathrm{N}_{2}$ until the partial pressure of hydrogen fell below IO $^{-2}$ atm by escape into outer space. However, the disruptive effect of ultraviolet light and electric discharges might result in a steady-state concentration of ammonia less than the equilibrium value. To see which organic compound would be formed under these conditions, a mixture of methane, nitrogen, hydrogen, and water was sparked. The same products are formed as in Run I, but the yields are somewhat less.

\section{THE MECHANISM OF SYNTHESIS}

There is the question of whether the compounds observed in this system were synthesized by micro-organisms. To check this point, blank runs with the same gases but no spark were made. The amino acid production was less than ro $\mu \mathrm{g}$. There is the possibility that the micro-organisms might synthesize amino acids from some of the products of the discharge. To check this point the apparatus was filled with water and the reduced gases, sealed, autoclaved for 18 hours at $130^{\circ}$, and sparked for one week. The yield of organic compounds was the same 
as in runs without autoclaving. In addition the apparatus was $80-100^{\circ}$ during the run, the alanine was racemic, and the organic compounds do not represent the distribution one would expect if produced by living organisms. For these reasons it is stated with confidence that the organic compounds in the system were synthesized without the aid of micro-organisms.

The next problem in attempting to understand the chemistry of the system is to determine which compounds are formed in the electric discharge and which reactions are taking place in the solution phase of the system. The following alternative hypotheses will be made for the synthesis of the products: (I) Hydrogen cyanide, aldehydes, acrylonitrile, aliphatic nitriles, amines and part of the polymers are synthesized in the electric discharge, and the amino, hydroxy and aliphatic acids are formed by hydrolysis of the respective nitriles in the solution. (2) All the products identified were synthesized in the gas phase from radicals and ions formed in the electric discharge.

In order to determine a few of the direct products of the electric discharge, samples were withdrawn from the U-tube during the course of a run. Hydrogen cyanide was qualitatively detected by the Prussian Blue test and estimated by titration with $\mathrm{AgNO}_{3}$. Formaldehyde was detected qualitatively by chromotropic acid and acetaldehyde by $p$-hydroxydiphenyl [II]. The total aldehydes (and ketones) were estimated with 2:4-dinitrophenylhydrazine [12].

Figure 2 shows the concentrations of ammonia, hydrogen cyanide, and aldehydes in the U-tube and amino acids in the $500 \mathrm{ml}$ flask during the sparking of a mixture of methane, ammonia, water and hydrogen. It is seen that the

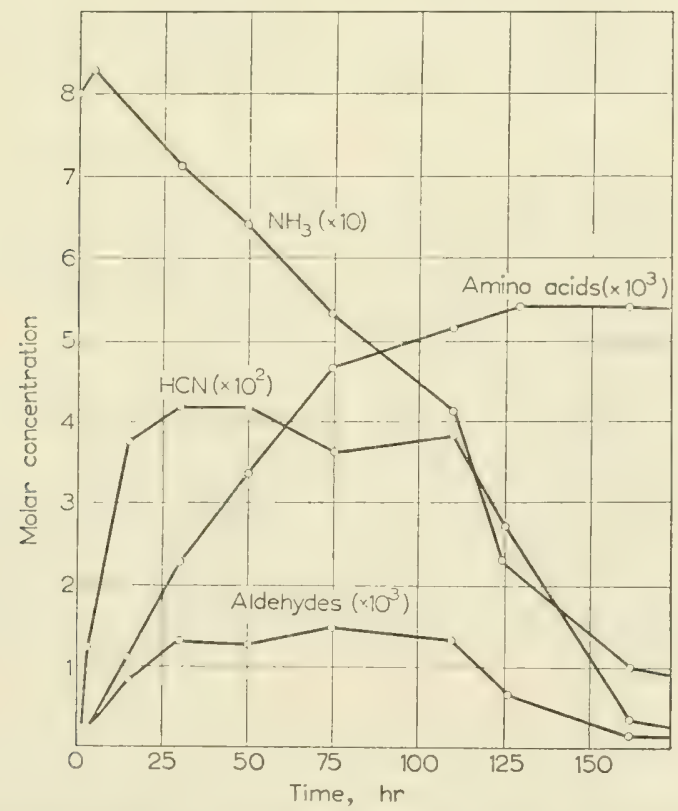

FIG. 2. Concentrations of ammonia, hydrogen cyanide and aldehydes in the U-tube, and amino acids in the $500 \mathrm{ml}$ flask while sparking a mixture of methane, ammonia, water, and hydrogen in the apparatus of Fig. I. 
concentration of ammonia decreased steadily during the run, mostly due to decomposition of the ammonia to hydrogen and nitrogen in the discharge. The hydrogen cyanide concentration rose to $4 \times 10^{-2} \mathrm{M}$, and after 120 hours apparently little more was synthesized in the spark. Thereafter the hydrogen cyanide present was hydrolysed to formic acid or decomposed in the spark. The aldehyde concentration rose to about $10^{-3} \mathrm{M}$ and declined after 120 hours. The concentration of amino acids rose during the run and levelled off after about I40 hours.

Several repetitions of this experiment gave concentrations of these compounds of the same order of magnitude, but the values were not reproducible in detail. Probably the most important variable that could not be controlled was the operation of the spark.

\section{Hydrolysis of Amino- and Hydroxynitriles-Run 4}

Hydrogen cyanide, aldehydes and ammonia are known to react to give aminoand hydroxy-nitriles. There is a question of whether the conditions of this experiment will hydrolyse these nitriles to the corresponding acid. A solution of $63 \mathrm{~m}$-moles $\mathrm{NH}_{3}$ (corresponding to $25 \mathrm{~cm} \mathrm{Hg}$ pressure), $20 \mathrm{~m}$-moles hydrogen cyanide, $6 \cdot$ I m-moles formaldehyde, $3.64 \mathrm{~m}$-moles acetaldehyde and I. I $6 \mathrm{~m}$-moles propionaldehyde (in $325 \mathrm{ml} \mathrm{H}_{2} \mathrm{O}$ ) was boiled in the apparatus for a week. The glycine, glycolic acid, iminodiacetic acid and imino-aceticpropionic acid accounted for $52 \%$ of the formaldehyde; alanine, lactic acid and imino-acetic-propionic acid accounted for $58 \%$ of the acetaldehyde; $\alpha$-amino- $n$-butyric acid and $\alpha$-hydroxybutyric acid accounted for $36 \%$ of the propionaldehyde. This experiment shows that aminonitriles and hydroxynitriles can be hydrolysed in this system, and further that the amino and hydroxy acids are formed in good yield from the aldehyde.

By titrating samples withdrawn from the U-tube for hydrogen cyanide during the course of the run, the rate constant for hydrolysis of hydrogen cyanide to formic acid is estimated to be $0 . \mathrm{I} \mathrm{hr^{-1 }}$. Similarly by determining the amino acid concentration in the $500 \mathrm{ml}$ flask at various times, the rate constant for hydrolysis of the aminonitriles is estimated to be $0.2 \mathrm{hr}^{-1}$.

From these rate data and the concentrations in Fig. 2 the yield of formic acid from hydrolysis of hydrogen cyanide is calculated to be $3.6 \mathrm{~m}$-moles and the yield of amino acids from hydrolysis of the aminonitriles is calculated to be I. $4 \mathrm{~m}$-moles. These values agree within the experimental error with the observed yields of $2.4 \mathrm{~m}$-moles of formic acid and $\mathrm{I} \cdot 2 \mathrm{~m}$-moles of amino acids. Thus in the case of the spark discharge, the rates of hydrolysis under the conditions of the experiment are sufficient to account for the total yields of formic acid and amino acids observed.

\section{The Ratios of Products}

Further evidence that the synthesis of the amino and hydroxy acids is through the corresponding nitrile can be obtained by considering the ratios of products predicted by this mechanism. 
It can be shown [6] that if the reaction of the aldehyde, hydrogen cyanide, and ammonia to form the amino- and hydroxy-nitriles is a rapid and reversible equilibrium and that the hydrolysis is a first-order irreversible reaction, then the ratio of hydroxy acid to amino acid at the end of the run will be

$$
\mathrm{R}_{1}=h_{i} H_{i} / k_{i} K_{i}\left(\mathrm{NH}_{3}\right),
$$

where $H_{i}$ and $K_{i}$ are the equilibrium constants for the formation of the hydroxy and aminonitrile from aldehydes, and $h_{i}$ and $k_{i}$ are the respective rates of hydrolysis. Similarly we have

$$
\begin{aligned}
\mathrm{R}_{2} & =N \text {-methylamino acid/amino acid } \\
& =-m_{i} M_{i}\left(\mathrm{CH}_{3} \mathrm{NH}_{2}\right) / k_{i} K_{i}\left(\mathrm{NH}_{3}\right),
\end{aligned}
$$

where $M_{i}$ and $m_{i}$ are the equilibrium constant and rate constant of hydrolysis of the methylaminonitrile.

$\beta$-Alanine cannot arise from a Strecker synthesis as with the $\alpha$-amino acids. A reasonable mechanism would be from a Michael addition of ammonia to acrylonitrile, acrylamide or acrylic acid. One would expect that hydrogen cyanide and methylamine would also add to give, after hydrolysis, succinic acid and $N$-methyl- $\beta$-alanine. $N$-Methyl- $\beta$-alanine was not detected during the analysis since it does not react with ninhydrin. The rate of formation of the nitrile of $\beta$-alanine and succinonitrile would be

$$
K_{\mathrm{NH}_{3}}\left(\mathrm{NH}_{3}\right)\left(\mathrm{CH}_{2}=\mathrm{CHCN}\right) \text { and } K_{H C N}\left(\mathrm{CN}^{-}\right)\left(\mathrm{CH}_{2}=\mathrm{CHCN}\right) \text {, }
$$

respectively, where the $K$ 's are the rate constants for addition. Assuming that the addition is irreversible and that the nitriles are hydrolysed by the end of the run, then

$$
(\text { Succinic acid }) /(\beta \text {-Alanine })=K_{H C N}\left(\mathrm{CN}^{-}\right) / K_{\mathrm{NH}_{3}}\left(\mathrm{NH}_{3}\right) \text {. }
$$

This treatment is easily generalized to include additions to acrylonitrile and acrylic acid. The ratios of products are given in Table 3.

If the ratio $h H / k K$ does not depend on the aldehyde, then equation I predicts that the ratio of the hydroxy acid to the amino acid should be the same for the different aldehydes in a given run. The agreement is good for the spark discharge and silent discharge except for hydroxybutyric/aminobutyric in the silent discharge. In Run 4 the hydrolysis of the amino- and hydroxy-nitriles was necessarily the mechanism for synthesis of the respective acids. There is less agreement of the ratios than with the electric discharges, but the agreement is within the errors of the experiment.

Similarly the ratios of methylamino acid/amino acid are nearly the same for Run I and 3. The succinic acid/ $\beta$-alanine ratio is the same in Runs $I$ and 6.

The ratios of various products are in qualitative agreement in all cases and in quantitative agreement (within the experimental error) in most of the cases. The similarity of products in Runs I and 4 is striking (except for the expected absence of $\beta$-alanine and succinic acid since no acrylonitrile was added), suggesting that the products were formed by the same mechanism. 
TABLE 3

Ratios of products

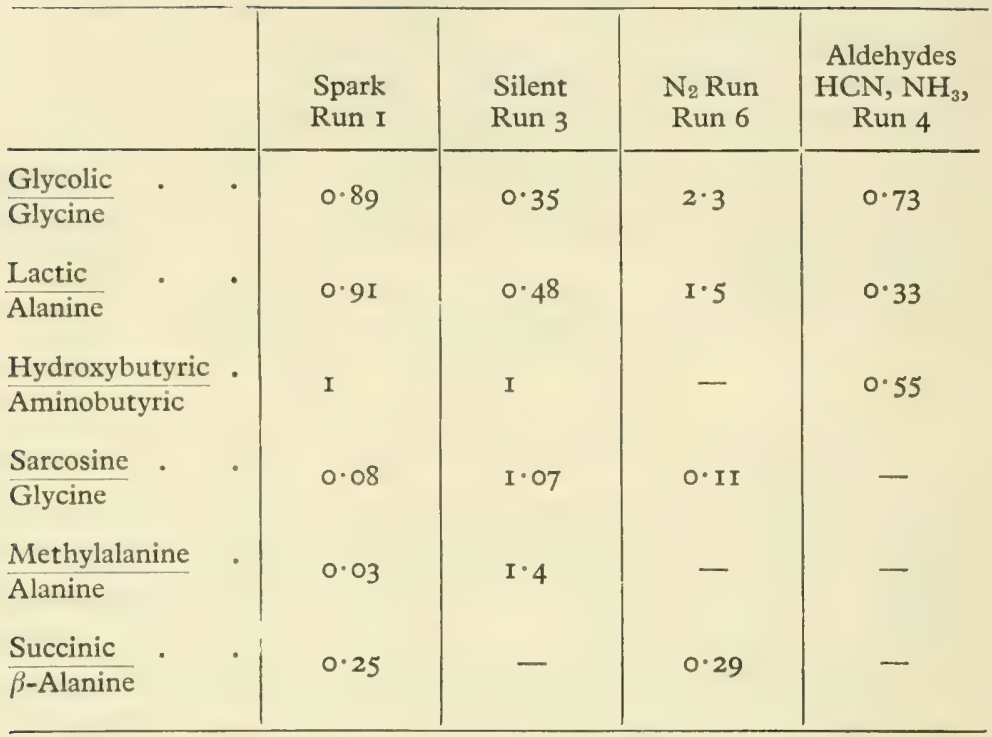

Since the production of aldehydes and hydrogen cyanide is sufficient to account for the observed yield of amino acid, there can be little doubt that most of the amino and hydroxy acids were formed from the nitriles in Run I. However, these experiments do not exclude the possibility that a small percentage of the amino acids was formed directly in the spark, entirely by radical reactions*.

The synthesis of the products expected from acrylonitrile and the agreement of the ratios of these products in the different runs provides strong indirect evidence for the synthesis of $\beta$-alanine and succinic acid by $\beta$-addition, and in turn that acrylonitrile or derivatives were synthesized in the electric discharges.

If cyanate were formed in the electric discharge, then both urea and methylurea could be expected of reaction with ammonia and methylamine (Wöhler synthesis). The direct synthesis of the simple ureas in the electric discharge is also quite reasonable.

\section{DISCUSSION}

Assuming that the Earth initially had a reducing atmosphere, do the experimental results obtained in this very simple system show that amino acids or other organic compounds would be present in the ocean? The experiments on the mechanism of the electric-discharge synthesis of amino acids indicate that a special set of conditions or type of electrical discharge is not required to obtain amino acids. Any process or combination of processes that yielded both alde-

* The hydrogen cyanide concentration in the silent discharge case is too low to account for the yield of amino acids unless the hydrolysis of the nitriles is more rapid than in Run I. Hydrogen peroxide catalysis is a possibility. The ratios of products in the various runs is strong evidence that the products were formed by the same mechanism. 
hydes and hydrogen cyanide would have contributed to the amount of $a$-amino acids in the hydrosphere of the primitive Earth. Therefore, electric discharges are not critical for the synthesis of amino acids, and similar results could be expected from ultraviolet light.

The ultraviolet light emitted by the sun as black-body radiation amounts to $85 \mathrm{cal} \mathrm{cm}^{-2} \mathrm{yr}^{-1}$ for wavelengths less than $2000 \AA$ and $\mathrm{I} \cdot 6 \mathrm{cal} \mathrm{cm}^{-2} \mathrm{yr}^{-1}$ for wavelengths less than I $500 \AA$ [4]. Superimposed on the black-body radiation is a strong Lyman $a$-line at $12 \mathrm{I} 6 \AA$ of $\mathrm{I} \cdot 9 \mathrm{cal} \mathrm{cm}^{-2} \mathrm{yr}^{-1}$ [13]. This line is absorbed by $\mathrm{CH}_{4}, \mathrm{H}_{2} \mathrm{O}, \mathrm{NH}_{3}$ and $\mathrm{CO}$.

Hydrogen atoms from photolysis of $\mathrm{CH}_{4}, \mathrm{NH}_{3}$ and $\mathrm{H}_{2} \mathrm{O}$ would react with $\mathrm{CO}$ to give formaldehyde $\left[\mathrm{I}_{4}, \mathrm{I} 5\right]$. Carbon monoxide activated by wavelengths less than $\mathrm{I} 545 \AA$ reacts with $\mathrm{H}_{2}$ to give formaldehyde and glyoxal [16]. Hydroxyl radicals would react with hydrocarbons to give aldehydes [I7]. If any $\mathrm{O}$ atoms should be formed by photolysis of water or $\mathrm{CO}$, they would react rapidly with $\mathrm{H}_{2}$ to give $\mathrm{H}_{2} \mathrm{O}$ and with hydrocarbons to give aldehydes*.

Active nitrogen, probably $\mathrm{N}$ atoms in the ${ }^{4} \mathrm{~S}$ state $[\mathrm{I} 8, \mathrm{I} 9]$, reacts with methane and other hydrocarbons to give hydrogen cyanide in good yield [20]. Photodissociation of $\mathrm{N}_{2}(>\mathrm{I} 100 \AA)$ or $\mathrm{NH}$ radicals give $\mathrm{N}$ atoms. $\mathrm{NH}$ and $\mathrm{NH}_{2}$ radicals from the photolysis of ammonia might react with hydrocarbons to give hydrogen cyanide, but this has not yet been demonstrated.

The reactions outlined above show that aldehydes and hydrogen cyanide would be produced photochemically, and there probably are other photochemical reactions that would also give these compounds $\uparrow$.

Infra-red radiation by the polyatomic molecules of the reducing atmosphere would probably result in a cool atmosphere and ocean rather than the boiling temperatures used in these experiments or the molten Earth proposed by some workers. However if there were any local areas of high temperature, hydrogen cyanide would be formed [2I], and aldehydes might be synthesized from hydrocarbons and carbon monoxide by reactions analogous to the Fischer-Tropsch or hydroformalation reactions [22].

If the conditions on the Earth were cool, then the hydrolysis of the nitriles would still take place, but more slowly than in these experiments. The Strecker synthesis of amino acids will work at much lower concentrations of aldehyde and hydrogen cyanide than obtained in these experiments. At very low concentrations, however, the Strecker synthesis will not operate. The rate of synthesis of amino acid is given by

$$
-\mathrm{d}(\mathrm{HCN}) / \mathrm{d} t=k K\left(\mathrm{NH}_{3}\right)(\mathrm{RCHO})(\mathrm{HCN})
$$

* If aldehydes were synthesized from the Lyman $\alpha$-radiation with a quantum yield of $\mathrm{I} \cdot \mathrm{O}$, then yield for the Earth would be $2 \cdot 1 \mathrm{O}^{13}$ moles $\mathrm{yr}^{-1}$. If the aldehydes were dissolved in the present oceans this would give a solution of $3 \cdot \mathrm{IO}^{-8} \mathrm{M}$. Of course, the efficiency of the Lyman radiation would not have been $100 \%$, but the oceans would probably have been smaller in volume, and the electric discharges and temperature reactions would contribute to the aldehyde production.

† Jome pretiminarv experiments performed at Brookhaven National Laboratory showed that the $1850 \AA$ mercury line will synthesize amino acids from $\mathrm{CH}_{4}, \mathrm{NH}_{3}$, and $\mathrm{H}$. O. Only $\mathrm{NH}_{3}$ and $\mathrm{H}_{2} \mathrm{O}$ absorb this line but apparently the radical reactions formed the active carbon intermediates. Formaldehyde was detected. The yield of amino acids was very low. 
The $k K(\mathrm{RCHO})$ means the sum of this term over the different aldehydes. The hydrolysis of hydrogen cyanide to formic acid is a competing reaction with the rate

$$
-\mathrm{d}(\mathrm{HCN}) / \mathrm{d} t=r(\mathrm{HCN})
$$

where $r$ is the rate constant for the hydrolysis of hydrogen cyanide. Thus if the concentrations of aldehydes are so low that $k K\left(\mathrm{NH}_{3}\right)(\mathrm{RCHO}) / r \ll \mathrm{I}$, then cyanide will not be available for the Strecker synthesis because of hydrolysis to formic acid. It is necessary to know the values of $K, k, H, h$, and $r$, their $\mathrm{pH}$ and temperature dependence for a quantitative treatment of this problem.

From a qualitative standpoint it can be seen that the Strecker synthesis will operate in very dilute solutions. The $H$ for acetaldehyde at $25^{\circ}$ is $\mathrm{I} \cdot 4 \times \mathrm{IO}^{4}$ [23] and the $K$ is probably greater. The experiments reported here indicate that $h, k$, and $r$ are of the same order of magnitude. Thus the hydrolysis of the nitriles in the hydrosphere is by the same mechanism as in these experiments (probably $\mathrm{OH}^{-}$attack on the carbon of the nitrile) then (RCHO) can be as low as $10^{-4}$ or $1 \mathrm{O}^{-5} \mathrm{M}$ and the Strecker synthesis will still operate. If the value of $k$ relative to $r$ (and $h$ ) is increased by catalytic hydrolysis (e.g., $\mathrm{SH}^{-}, \mathrm{HPO}_{4}^{-}$) then the concentration of aldehydes could be much lower.

The ratio of hydroxy acid to amino acid is given by equation (I). If the concentration of ammonia is very low and ( $\mathrm{RCHO})$ and $(\mathrm{HCN})$ are high enough, then hydroxy acid will be synthesized rather than amino acid or formic acid.

There are competing reactions which the aldehyde can undergo instead of a Strecker synthesis. The aldehydes can be reduced or oxidized, the latter being important if any oxygen were present. The most important competing reaction would be aldol condensations. These condensations would give products that are of biological importance such as trioses, tetroses, pentoses and hexoses. The rate of these condensations relative to the Strecker synthesis would not depend markedly on the concentrations of aldehydes, since the aldol condensations would be second-order reactions. Therefore, the competing reactions of the aldehydes would not predominate at low concentrations.

The composition of the primitive Earth atmosphere has been assumed to be reducing in the above discussion. The general geochemical argument for the reducing atmosphere, advanced by Oparin and Urey, is that the ratio of hydrogen to oxygen in the Universe is about a thousand to one, the Earth being rather anomalous. No one has shown any mechanism which, before the planets were formed, would produce oxygen in the region of the Earth but not in the region beyond Mars. The formation of oxidizing conditions on Mercury, Venus, Earth, and Mars after their formation is explained by the escape of hydrogen from these planets. Their atmospheres are hot enough and their gravitational fields weak enough so that hydrogen can escape into outer space from the atmosphere. The escape of the strong reducing agent $\mathrm{H}_{2}$ results in oxidizing atmosphere. In the region beyond Mars, the planets are at low temperature and have a high gravitational field. These conditions prohibit the escape of hydrogen from their atmospheres, as a result of which they are still reducing.

A second argument for the existence of a reducing atmosphere on the primitive Earth is based on the assumption that for life to arise there must be present 
first a large number of organic compounds similar to those that would make up the first organism. Therefore, if it can be shown that the organic compounds which make up living systems cannot be synthesized under oxidizing conditions, and if it can be shown that these organic componds can be synthesized under reducing conditions, then one conclusion would be that the Earth had a reducing atmosphere in its early stages and that life arose from the sea of organic compounds formed while the Earth had this atmosphere.

From a review of the literature on electric discharges [24] and ultraviolet light [25], from the result of the experiments described in this paper, and from the first part of this discussion, one can see that organic compounds can be easily synthesized under reducing conditions.

There have been many attempts to synthesize organic compounds under oxidizing conditions, usually from casbon dioxide and water, and these attempts have almost always failed. A review of these attempts using ultraviolet light [26] shows that success was claimed by some workers, but when their experiments were repeated in other laboratories or when contaminating reducing agents were removed, no organic compounds were synthesized. The action of electric discharges on carbon dioxide and water has also resulted in failure [27]. Of course, if a strong reducing agent such as $\mathrm{Na}$ or $\mathrm{Mg}$ is used, organic compounds can be formed, but these reducing agents would not be present on the Earth with either a reducing or an oxidizing atmosphere. High-energy radiations on ammonium carbonate solutions might give organic compounds, but the presence of ammonia would imply reducing conditions.

There has been one successful synthesis of organic compounds from carbon dioxide and water using 40 million electron volt helium ions from a 60 -inch cyclotron $[28,29]$. Formic acid was obtained in small yield, and if ferrous ion was added to the solution as a reducing agent then a small yield of formaldehyde was obtained in addition to formic acid. In view of the absence of a strong source of high-energy particles, the small yields, and the very simple organic compounds synthesized, it would seem that instead of showing that organic compounds can be synthesized this experiment can best be interpreted to mean that organic compounds cannot be effectively synthesized under oxidizing conditions.

If any organic compounds should be synthesized under oxidizing conditions, however difficult this may be, then the question of their stability arises. In the presence of molecular oxygen the organic compounds would be oxidized rather rapidly, especially in the presence of light [30]. An important reaction of the oxygen would be the oxidative deamination of the amino acids. This reaction is catalysed by blood charcoal and probably by many iron compounds [3I]. The oxidative deamination is a significant reaction even in the absence of catalysts [32]. Oxygen would also attack aromatic compounds such as the purines and pyrimidines, especially in the presence of light. These arguments make a strong case that free oxygen must have been absent when the organic compounds were formed and also absent during the development of heterotrophic organisms. Shortly after the appearance of oxygen on the Earth the autotrophic organisms would have to develop, for otherwise the nutrients would be rapidly exhausted.

If the Strecker synthesis was the principal synthesis of amino acids on the 
primitive Earth, then ammonia must have been present in the ocean even though $\mathrm{N}_{2}$ could be the principal nitrogen species in the atmosphere*.

This implies that the Earth must have been rather reducing, with a pressure of $\mathrm{H}_{2}$ of at least $\mathrm{IO}^{-4}$ atmospheres, unless one is to assume that the amino acids were formed in limited areas containing reducing conditions.

This argument would not be valid if there are other reasonable syntheses of amino acids. One possibility would be the reductive amination of any a-keto acids present in the ocean, although decarboxylation of the keto acid would be a competing reaction. Another reaction would be synthesis of amino acids from $\alpha$-keto aldehydes and ammonia catalysed by mercaptans [33, 34]. A possible source of the a-keto aldehydes would be from the oxidation of polyhydroxyl compounds obtained from aldehyde condensations. These two syntheses require ammonia, however. It is very difficult to see how an amino group can be synthesized directly from $\mathrm{N}_{2}$ by any reasonable process except under reducing conditions. Reasonable syntheses of amino acids involving hydroxylamine, nitrites or nitrates would require strong reducing agents to convert the nitrogen to an amino group. A direct synthesis of the amino acids in an electric discharge, if possible, would probably require reducing conditions.

On the basis of primarily geochemical arguments Rubey [35] has argued that the primitive Earth had an atmosphere of carbon dioxide, nitrogen, carbon monoxide and water. This atmosphere would come mainly from the interior of the Earth instead of being the residual gases of the cosmic dust cloud. Abelson [36] has examined the action of a spark discharge on this mixture of gases and found that good yields of amino acids could be obtained as long as some hydrogen was present $\dagger$. If no hydrogen was present, then no amino acids were obtained. The amino acid production was more rapid if $\mathrm{CO}_{3}, \mathrm{H}_{2} \mathrm{O}$ and $\mathrm{NH}_{3}$ (instead of $\mathrm{N}_{2}$ ) were used. The mechanism of the reaction was not investigated, but it may well be a Strecker synthesis as in the methane, ammonia and water case.

Because of the presence of hydrogen in the gas mixtures used by Abelson, the mixtures were reducing although not as reducing as the methane, ammonia, water and hydrogen mixture. Therefore, the argument that reducing conditions are necessary to synthesize organic compounds is not altered, but whether the atmosphere was strongly reducing or only weakly reducing cannot be decided on the basis of ability to synthesize organic compounds.

As hydrogen escapes into outer space from a strongly reducing atmosphere, it becomes less reducing and finally becomes oxidizing. Thus the atmosphere proposed by Urey would be converted in the course of time to the atmosphere

* Ammonia is quite soluble in water. The vapour pressure in atmospheres is given by $\mathrm{P}_{\mathrm{NH}_{3}}=\alpha\left[\left(\mathrm{NH}_{4} \mathrm{OH}\right)+\left(\mathrm{NH}_{4}{ }^{+}\right)\right]$, where the concentrations of $\mathrm{NH}_{4} \mathrm{OH}$ and $\mathrm{NH}_{4}$ are in moles/litre. For $25^{\circ} \mathrm{C} a$ is $9.3 \times 10^{-5}$ at $\mathrm{pH}=7 ; 8.8 \times 10^{-4}$ at $\mathrm{pH}=8$, and $6.1 \times 10^{-3}$ at $\mathrm{pH}=9$. Thus unless the temperature of the ocean was rather high (70$\left.100^{\circ}\right)$ most of the ammonia would be in the ocean. The cyanide could be formed from the $\mathrm{N}_{2}$ in the atmosphere (as in Run 6).

$\dagger$ The equilibrium constant for the reaction $\mathrm{CO}_{2}+4 \mathrm{H}_{2}=\mathrm{CH}_{4}+2 \mathrm{H}_{2} \mathrm{O}$ is $7 \times 10^{21}$ at $25^{\circ} \mathrm{C}$, so that the mixture of gases used by Abelson is thermodynamically unstable. Whether this equilibrium would be attained on the Earth is not predicted by thermodynamics, but carbon dioxide in the presence of hydrogen can be reduced to carbon monoxide and methane in electric discharges and probably by ultraviolet light. 
proposed by Rubey. The principal question is the relative length of time that the Earth had these respective atmospheres. This question is not critical to the problem of spontaneous generation since organic compounds can be synthesized in both proposed atmospheres (provided Rubey's contains some hydrogen) and since the organic compounds would be similar in both cases.

\section{REFERENCES}

I. A. I. Oparin, The Origin of Life. Macmillan, New York, I938 (Republished by Dover Publications, 1953); (3rd ed.) The Origin of Life on the Earth. Oliver \& Boyd, Edinburgh, 1957.

2. J. D. Bernal, Proc. phys. Soc. Lond., 62A, 537; 62B, 597, 1949.

3. H. C. UREY, The Planets. Yale Univ. Press, New Haven, I952.

4. H. C. Urey, Proc. nat. Acad. Sci., Wash., 38, 351, 1952.

5. S. L. MILlER, Science, I17, 528, 1953.

6. S. L. Miller, F. Amer. chem. Soc., 77, 235I, I955.

7. S. L. Miller, Biochim. biophys. Acta, 23, 480, 1957.

8. W. A. Bulen, J. E. Varner \& R. C. Burrell, Analyt. Chem., 24, I87, 1952.

9. W. H. Stein \& S. MOore, Cold Spr. Harb. Symp. quant. Biol., I4, 179, 1949.

IO. J. S. WaLl, Analyt. Chem., 25, 950, I953.

II. B. A. Neidig \& W. C. Hess, Analyt. Chem., 24, 1627, I952.

I2. G. R. Lappin \& L. C. Clark, Analyt. Chem., 23, 54I, I95I.

I3. W. A. Rense, Phys. Rev., 91, 299, 1953.

I4. A. Caress \& E. K. Rideal, Proc. Roy. Soc., A, 120, 370, 1928.

I5. H. S. TAYLOR, Trans. Faraday Soc., 21, 560, 1926.

I6. W. Groth, $Z$. phys. Chem., 37B, 315, I937.

I7. N. A. Milas, L. E. Stahl \& B. B. Dayton, F. Amer. chem. Soc., 71, I448, 1949.

18. J. Berkowitz, W. A. Chupka \& G. B. Kistiakowsky, f. chem. Phys., 25, 457, 1956.

I9. D. S. JaCKson \& H. I. Schiff, f. chem. Phys., 23, 2333, I955.

20. C. A. WINKLER \& H. I. SChiff, Disc. Faraday Soc., I4, 63, I953.

21. V. Migrdichian, The Chemistry of Organic Cyanogen Compounds. Reinhold, New York, p. 5, I947.

22. H. H. Storch, E. Golumbic \& R. B. Anderson, The Fischer-Tropsch and Related Syntheses. John Wiley, New York, I95I.

23. W. F. Yates \& R. L. Heider, 7. Amer. chem. Soc., 74, 4153, 1952.

24. G. GlockLeR \& S. C. LIND, Electrochemistry of Gases and other Dielectrics. John Wiley, New York, I939.

25. W. A. Noyes, Jr., \& P. A. Leighton, The Photochemistry of Gases. Reinhold, New York, I94I.

26. E. Rabinowitch, Photosynthesis. Interscience, New York, vol. I, p. 8I, I945.

27. K. A. Wilde, B. T. ZWolinski \& R. B. Parlin, Science, II8, 43, I953.

28. W. M. Garrison, D. C. Morrison, J. G. Hamilton, A. A. Benson \& M. Calvin, Science, I14, 4I6, I95I.

29. W. M. Garrison \& G. K. Rollefson, Disc. Faraday Soc., 12, 155, 1952.

30. C. C. Palit \& N. R. Dhar, 7. phys. Chem., 34, 993, 1930.

3I. O. Warburg, Heavy Metal Prosthetic Groups and Enzyme Action. Oxford Univ. Press, p. 38, 1949.

32. P. H. Abelson, Ann. N.Y. Acad. Sci., 92, 276, 1957.

33. T. Wieland, J. Franz \& G. Pfleiderer, Ber. dtsch. chem. Ges., 88, 64I, 955.

34. T. Wieland \& F. Jaenicke, Ber. dtsch. chem. Ges., 88, 1967, 955.

35. W. W. RuBey, Spec. Pap. geol. Soc. Amer., 62, 631, 1955.

36. P. H. Abelson, Science, 124, 935, 1956. 


\title{
The Original Formation of Amino Acids under the Action of Ultraviolet Rays and Electric Discharges
}

\author{
T. E. PAVLOVSKAYA \&A. G. PASYNSKII
}

A. N. Bakh Institute of Biochemistry of the Academy of Sciences

of the U.S.S.R., Moscow

IN THE history of the formation of organic compounds on the Earth, special significance is attached to the appearance of amino acids, since they are the starting materials for the formation of peptides and protein-like compounds without which life, in its turn, could not have come into being. The original formation of amino acids from simpler compounds required an expenditure of energy to activate the starting molecules. According to Oparin [I] the most significant of the various sources of energy available in the prebiological history of the Earth was ultraviolet irradiation from the Sun, which in regard to the Earth amounted to about $10^{20} \mathrm{kcal} / \mathrm{yr}$, a high proportion of which reached the surface of the Earth at that time. Of lesser importance (probably not more than $0 \cdot I-I \cdot 0 \%$ of this value) were electrical discharges in the atmosphere, though these were also an important factor in activating chemical reactions.

As early as I9I3, Loeb [2] observed the formation of glycine when silent electric discharges were passed through mixtures of carbon monoxide, ammonia (both obtained by the decomposition of formamide) and water vapour. In recent years the formation of amino acids by passing electrical discharges through mixtures of methane, ammonia, hydrogen and water vapour, imitating the possible composition of the primaeval reducing atmosphere of the Earth, has been studied in detail in Miller's [3] interesting work. In his expcriments he obtained glycine, $\alpha$-alanine, $\beta$-alanine, sarcosine, $\alpha$-aminobutyric acid and other compounds.

K. Bahadur [4] has also published some interesting data concerning the production of serine, aspartic acid, valine, lysine and other amino acids by the prolonged action of sunlight on solutions of mixtures of paraformaldehyde, $\mathrm{KNO}_{3}$ and $\mathrm{FeCl}_{3}$.

In the present work, we have studied the action of ultraviolet rays, as an important source of energy under the primaeval conditions of the Earth, on solutions of mixtures of formaldehyde and ammonium chloride or nitrate, and we have demonstrated the formation of amino acids under these conditions. We have also repeated Miller's experiments using gascous mixtures of somewhat different composition. 


\section{THE ACTION OF ULTRAVIOLET RAYS}

The irradiation of the solution was carried out in optical cuvettes through laminae of plane-parallel quartz, using a PRK-2 lamp at $25 \mathrm{~cm}$, the intensity of the irradiation being $2.7 \times 10^{6} \mathrm{erg} / \mathrm{cm}^{2}$ min during 20 hours. In the main experiments we used aqueous solutions containing $2 \cdot 5 \% \mathrm{CH}_{2} \mathrm{O}$ and $\mathrm{I} \cdot 0-\mathrm{I} \cdot 5 \%$ $\mathrm{NH}_{4} \mathrm{NO}_{3}$ or $\mathrm{NH}_{4} \mathrm{Cl}$; the volume irradiated was $20 \mathrm{ml}$. During irradiation the temperature of the solution was about $40-45^{\circ} \mathrm{C}$, in some experiments it was $+\mathrm{I}-+2{ }^{\circ} \mathrm{C}$ (the temperature of melting ice). The $\mathrm{pH}$ of the solution was $\mathrm{x} \cdot 5-2$, or $5-6.2$ when chalk was present. When the irradiation was finished the volatile amines and organic acids were distilled off in a vacuum and the concentrate (e.g. I ml.) was submitted to chromatography on paper (Leningrad slow) using butanol-acetic acid mixtures as solvents. Chromatography was repeated in most experiments to give better separation of the spots. The chromatograms were coloured with ninhydrin and were then fixed with solutions of copper salt; the fixed spots were of the ordinary rosy colour. Identification of the spots was, however, made more difficult by the possible presence of volatile amides and amines in the concentrate [5]. Preliminary extraction of the concentrate with ether in the modified Soxhlet apparatus for 45 hours only led to a weakening of the spots. We therefore compared the extraction of amines with ether, directly with chromatograms through which butanol and acetic acid had flowed for 77 hours (method of repeated chromatography). The dried unsprayed chromatograms were then extracted with ether for 120 and 168 hours after which they were sprayed. As a result of this we manage to bring about the disappearance of a large spot $\left(R_{F} \sim 0.4\right)$, the identification of which with amines was confirmed with control mixtures of amino acids with diethylamine (hydrochloride).

To get rid of amides, acid hydrolysis of the eluate of the spots was carried out by refluxing with $\mathrm{I} 5 \% \mathrm{HCl}$ for 8 hours. The hydrochloric acid was then removed by evaporating six times with water.

Later we adopted another routine for analysing our experimental mixtures. The separation of the amino acids and organic bases was carried out on an ionexchange resin, Amberlite anionite (IRA-400) with strongly basic properties.

Thus, in the beginning, volatile amines were distilled off in vacuo in the presence of barium hydroxide, from the mixtures we obtained, while amides were hydrolysed with $15 \% \mathrm{HCl}$ for 8-10 hours.

To separate the amino acids from non-volatile organic bases the mixture was put through a column of anionite at a rate of $9 \mathrm{ml} / \mathrm{hr}$. The bases passed right through this column, while the amino acids were retained in it. The elution of the amino acids was carried out with about 20 volumes of $\mathrm{M}-\mathrm{HCl}$ which was put through at the same rate as the experimental solution. When the hydrochloric acid had been removed from the eluate, this was concentrated in vacuo. The completeness of the separation of amino acids from organic bases on the column was checked, using artificial mixtures of amines and amides. The concentrate of the eluate was further analysed for its component amino acids by paper chromatography using the following solvents: mixtures of butanol, acetic acid and water $(4: I: 5)$, phenol-water and, for the identification of valine, 
phenylalanine and isoleucine, mixtures of cresol with a phosphate buffer $(0.067$ $\mathrm{M}-\mathrm{KH}_{2} \mathrm{PO}_{4}+0.067 \mathrm{M}-\mathrm{Na}_{2} \mathrm{HPO}_{4}$ (I : I)).

In some experiments supplementary measurements were made on the chromatogram with a microphotometer. Fig. I shows a microphotogram of amino acids synthesized in a mixture of formaldehyde and ammonium nitrate.

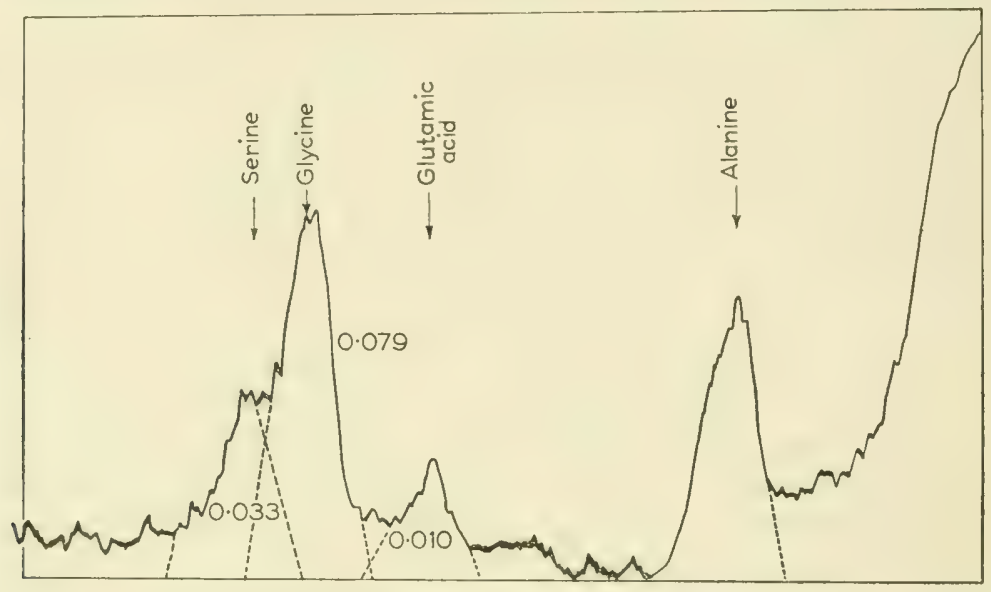

FIG. I. Microphotogram of mixtures of amino acids.

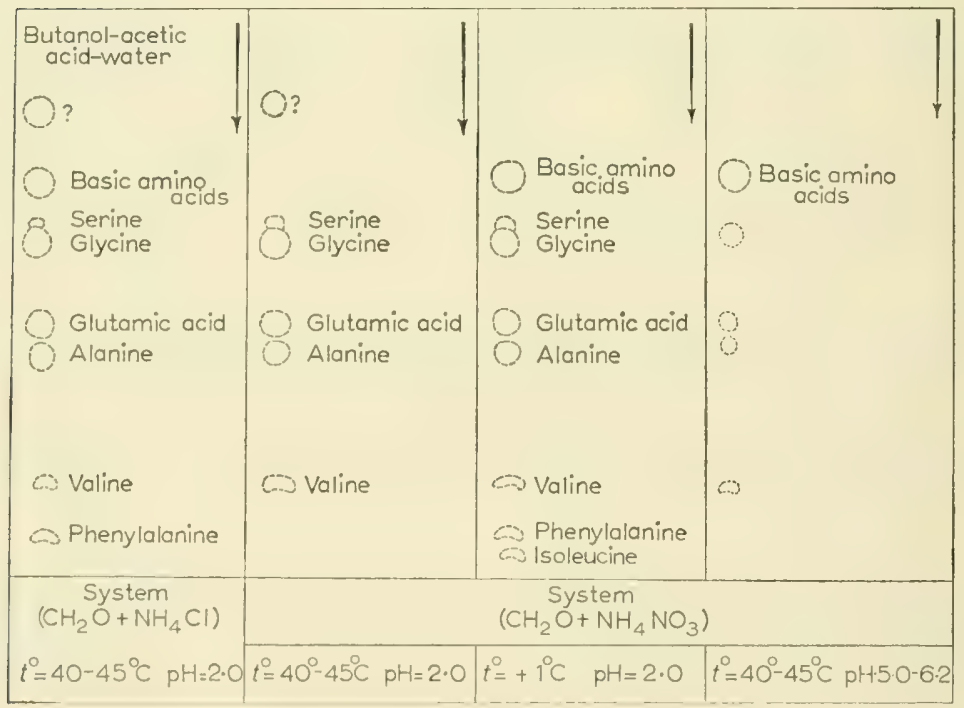

FIG. 2. Chromatograms of amino acids synthesized by the action of ultraviolet rays.

In the formaldehyde-ammonium chloride mixture after irradiation with ultraviolet rays (at a temperature of $40-45^{\circ}$ and $\mathrm{pH} \mathrm{I} \cdot 5-2$ ) it was established that the following amino acids were present: basic amino acids, serine, glycine, glutamic acid, alanine, valine and also phenylalanine (Fig. 2). 
In a solution of formaldehyde and ammonium nitrate treated in the same way, the following were identified: serine, glycine, glutamic acid, alanine and valine (Fig. 2). Lowering of the temperature of the experiment to $\mathrm{I}-2{ }^{\circ} \mathrm{C}$, while keeping all the other conditions unchanged and using ammonium nitrate, led to the formation of isoleucine, phenylalanine and basic amino acids as well as those just listed (Fig. 2).

If the experiments were carried out in the presence of chalk (i.c., at $\mathrm{pH} 5-6 \cdot 2$ ) the basic amino acids predominated while glutamic acid, alanine, valine and phenylalanine were only formed in negligible amounts under these conditions (Fig. 2). The amino-acid content was $\mathrm{IO}^{-4} \mathrm{M}$. In control experiments, in which the mixtures were not irradiated, amino acid spots were not found.

The idea that bacterial contamination might have been a factor in the formation of amino acids is, to our minds, precluded by the conditions under which the experiments were conducted, involving the intensive exposure to ultraviolet irradiation for 20 hours of a solution containing $2.5 \%$ of formaldehyde at a $\mathrm{pH}$ of $\mathrm{I} \cdot 5$ and a temperature of $45^{\circ} \mathrm{C}$. Furthermore, the results of the control experiments (without irradiation) were negative. We checked this by special microbiological experiments in which the experimental solution was cultured on nutrient media: meat-peptone-agar and wort-agar. The absence of growth of colonies after 72 hours demonstrated the complete sterility of the experimental solution.

\section{THE ACTION OF ELECTRIC DISCHARGES}

In the gaseous mixtures (of methane, ammonia, hydrogen and water vapour) studied by Miller, the formation of amino acids was hindered by a deficiency of oxygen and a great excess of hydrogen such as he believed to have been present in the primaeval reducing atmosphere of the Earth. For every molecule of amino acid formed, two atoms of oxygen were needed and these could only be obtained from two molecules of water. At least one atom of nitrogen was also needed and this required a molecule of ammonia. At least two atoms of carbon were also needed and they could only be obtained from two molecules of methane. But even in the mixture $2 \mathrm{H}_{2} \mathrm{O}+\mathrm{NH}_{3}+2 \mathrm{CH}_{4}$ there are $\mathrm{I}_{5}$ atoms of hydrogen of which no more than half are required for the formation of the simplest amino acids (glycine and alanine), while Miller's mixtures contained, in addition, free, and obviously superfluous, hydrogen. When molecules of more complicated amino acids are formed the proportions, as one can easily see, remain unfavourable. For this reason the composition of the gaseous medium used by Miller is unsuited to the formation of amino acids. We arrive at the same conclusion by a thermodynamical calculation in respect of the overall reaction by which alanine, for example, is formed. When they take place under standard conditions there is a great increase in free energy $\left(\Delta Z_{0}\right)$ :

$$
\begin{gathered}
2 \mathrm{H}_{2} \mathrm{O}+{ }_{3} \mathrm{CH}_{4}+\mathrm{NH}_{3} \rightarrow \mathrm{CH}_{3} \cdot \mathrm{CH}\left(\mathrm{NH}_{2}\right) \cdot \mathrm{COOH}+6 \mathrm{H}_{2} \\
\Delta Z_{0}=+62,040 \mathrm{cal} / \mathrm{mole}
\end{gathered}
$$

Naturally, in an electrical discharge the energy of the discharge will cover this increase in $\Delta Z_{0}$, but even when reactions are proceeding in an electrical 
discharge, those which are thermodynamically capable of occurring spontaneously will be favoured. Obviously, more favourable conditions for the reaction will be present in a mixture in which carbon monoxide is exchanged for hydrogen, and this, from geochemical considerations, would appear to have been a possible component of the primaeval atmosphere of the Earth, while not destroying its reducing character. From this point of view the formation of amino acids was facilitated when the atmosphere was depleted of hydrogen and contained a certain amount of $\mathrm{CO}$. In fact, in this case the formation of alanine, for example, could proceed in accordance with the overall equation:

$$
\begin{gathered}
\mathrm{CH}_{4}+2 \mathrm{CO}+\mathrm{NH}_{3} \rightarrow \mathrm{CH}_{3} \cdot \mathrm{CH}\left(\mathrm{NH}_{2}\right) \cdot \mathrm{COOH} \\
\Delta Z_{0}=-5900 \mathrm{cal} / \mathrm{mole}
\end{gathered}
$$

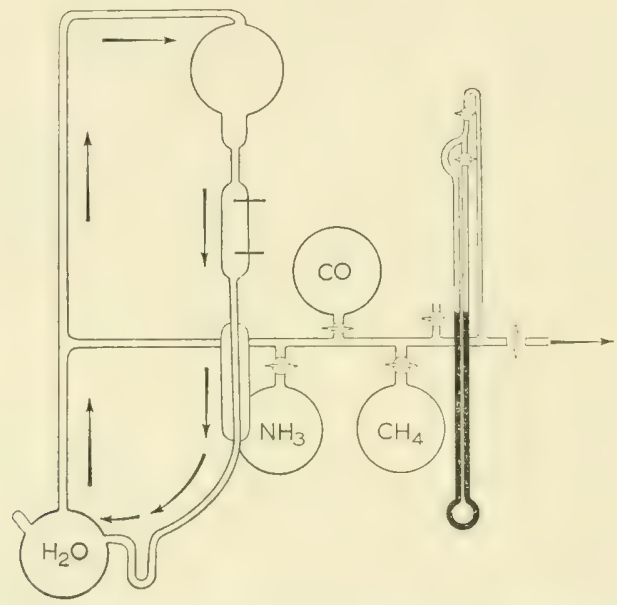

FIG. 3. Diagram of apparatus for the synthesis of amino acids in an electric discharge.

In fact, a certain amount of $\mathrm{CO}$ was formed in Miller's apparatus when electric discharges were passed through mixtures of $\mathrm{CH}_{4}$ and $\mathrm{H}_{2} \mathrm{O}$ (I-10\%), but the alteration in the composition of the starting mixture which this entailed had a somewhat damping effect on the reactions which were going on. We therefore tried Miller's experiments leaving hydrogen out of the mixture altogether and substituting $\mathrm{CO}$.

We carried out our experiments in an apparatus constructed in accordance with Miller's diagram (Fig. 3) [6]. At first we repeated Miller's experiments using a gaseous mixture of the same composition as that which Miller used and we were able fully to confirm his results, obtaining identical two-dimensional chromatograms. To supplement our test of the possibility of bacterial contamination, we carried out experiments lasting 80 hours, which were the same apart from the absence of electrical discharges, and obtained wholly negative results. It is obvious that when water is continually boiling and the gas is circulating in the electrical discharge, bacterial processes can be excluded.

Experiments with mixtures containing $\mathrm{CO}$ were carried out in a spark dis- 
charge (using electrodes in the form of two circular plates inserted into the discharge tube at a distance of $5 \mathrm{~cm}$ from one another) lasting 100 hours at a potential of about $24 \mathrm{kV}$ with a mixture of the following composition:

$$
\mathrm{CH}_{4} \text { and } \mathrm{NH}_{3}-200 \mathrm{~mm} \mathrm{Hg} ; \mathrm{CO}-\mathrm{IOO} \mathrm{mm} \mathrm{Hg}
$$

and water vapour up to atmospheric pressure. At the end of the experiment the solution was analysed in the ordinary way with preliminary vacuum distillation to remove amines and volatile organic acids and the concentrate was chromatographed $[3,6]$. In this way we established (Fig. 4) the presence of a number of

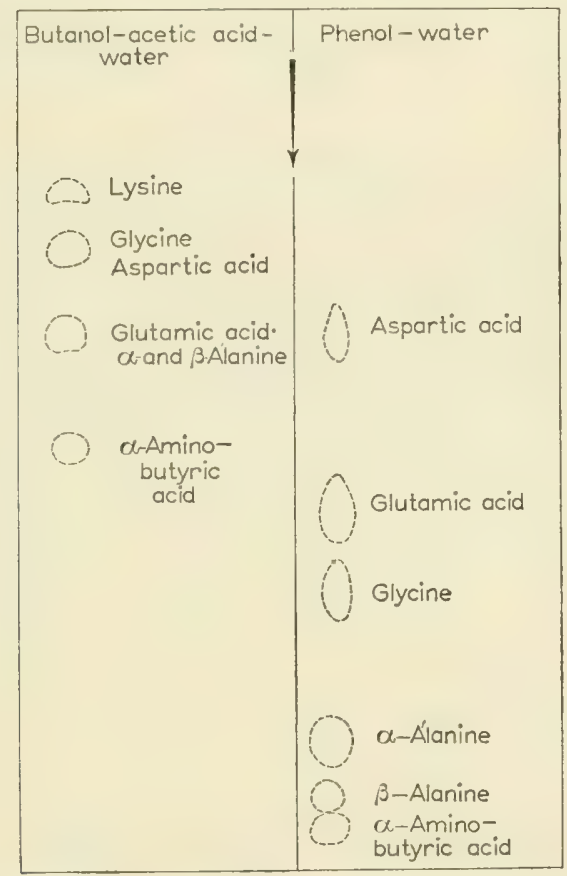

FIG. 4. Chromatograms of amino acids synthesized in an electric discharge.

amino acids: glycine, $\alpha$ - and $\beta$-alanine, $\alpha$-aminobutyric acid and aspartic and glutamic acids. We did not study the mechanism of their formation but it would appear that the formation of cyanhydrins, as postulated by Miller, played an essential part, as HCN was found to be present in the solution after the passage of the discharge. The results of our experiments and theoretical considerations indicate that the presence of free hydrogen in the gaseous mixture is not necessary for the formation of amino acids in an electric discharge. It is possible that, during the evolutionary development of the Earth, more favourable conditions for the formation of amino acids in the atmosphere existed at the stage when a considerable part of its hydrogen had been lost and the atmosphere, while still retaining its reducing character, could have contained a relatively large quantity of CO. Under such conditions amino acids could have been formed, not only in 
electric discharges but also by the action of ultraviolet rays which were a far more powerful source of energy. It would seem that these processes may have some significance even now. We may suggest the possibility of the partial formation of formaldehyde by irradiation of mixtures of $\mathrm{CO}$ and $\mathrm{H}_{2}$ or $\mathrm{CO}_{2}$ and water vapour [5] with ultraviolet light. By means of further reactions of formaldehyde with ammonium salts dissolved in water, in mist particles, raindrops etc in ultraviolet rays, the formation of some amino acids, as demonstrated in our experiments, could occur, together with the formation of many other organic substances $[\mathrm{I}, 5]$.

The authors are deeply grateful to Academician A. I. Oparin for his continued interest in the work and for a number of valuable comments, and to A. I. Grebennikova for help in carrying out some of the experiments.

\section{REFERENCES}

I. A. Oparin, Vozniknovenie zhizm na Zemte (The Origin of Life on the Earth). Izd. Akad. Nauk S.S.S.R., I957.

2. W. LOEB, Ber. dtsch. chem. Ges., 46, 690, I913.

3. S. Miller, F. Amer. chem. Soc., 77, 235I, I955.

4. K. Bahadur, Nature, Lond., I73, I I4I, I954; K. Bakhadur (Bahadur) \& S. RanGANAYAKI, Zhur. obshch. Khim., 25, 1629, I955.

5. E. Orlov, Formal'dehid. Moscow (ONFI), I935; J. Walker, Formaldehyde. New York, 1953.

6. S. MILLER, Science, 117, 528, 1953. 


\title{
Absolute Asymmetric Synthesis and Asymmetric Catalysis
}

\author{
E. I. KLABUNOVSKII
}

Institute of Organic Chemistry of the Academy of Sciences of the U.S.S.R., Moscow

IT Is well known that almost all substances subserving the vital activities of organisms are optically active. In considering the process whereby the first protein bodies came into being, one must, therefore, bear in mind the way in which they became dissymmetrical, this being a necessary stage in the emergence of the functions of living substance. It is clear that, once they had developed, optically active compounds, having a greater free energy than racemates, would quickly become commoner owing to partial asymmetric synthesis or, as they act more effectively as dissymmetric catalysts, they would supplant racemates in all important vital processes. The original optically active substances did not arise by the action of other optically active compounds, but by absolute asymmetric synthesis, owing to the action of dissymmetrical physical factors, namely circularly polarized light and asymmetric adsorption.

A consideration of the experimental evidence set forth below shows convincingly the part played by the factor of dissymmetric adsorption in the production of the first optically active compounds. In view of the theoretical importance of absolute asymmetric synthesis for an understanding of the processes which led to the production of optically active substances without the participation of other optically active organic compounds we must consider both the case of absolute asymmetric synthesis of optically active compounds from substances of symmetrical structure, and examples of the resolution of asymmetrically adsorbed racemates under the influence of the structure of the crystals on which they were adsorbed.

\section{THE RESOLUTION OF RACEMATES BY ASYMMETRIC ADSORPTION}

Long ago, van't Hoff [I] showed the possibility of producing optical activity in racemates by bringing them into contact with optically active substances in the form of solvents, adsorbents etc.

A number of attempts to resolve racemates of mandelic and tartaric acids [2], camphor and camphorsulphonic acid and carvoxime [3] under the influence of optically active fructose, limonene and pinene, were unsuccessful. It was only when the unstable racemate of 2-acetomethylamide-5:4-dimethyldiphenylsul- 
phone was crystallized from a solution of $(+$ )-ethyl tartrate that partial optical activation was observed [4-6].

By an improvement of the method it has been possible to resolve mandelic acid $\left(0.66^{\circ}\right)$ under the action of $(+)$-carvone [7]. A high degree of resolution was achieved by using racemates with surface-active properties, such as camphor, terpineol and pinene, by bubbling their vapours through aqueous solutions of tannin, gelatin and leucine [8].

Better results are obtained if the resolution is carried out, not in the liquid phase, but on the surface of a solid adsorbent.

It is known that diastereoisomers can be separated on optically inactive adsorbents. On aluminium oxide one may separate the (-)-menthyl ester of DL-mandelic acid [9] and the (-)-isopropanolamide of DL-isolysergic acid [10], and $N$-benzoylcycloheptano-2 :3-pyrrolidine, while on glucose one may separate the brucine salt of DL-mandelic acid [II].

Similar behaviour is manifested by the superficial diastereoisomers formed by the interaction of a racemate with a layer of optically active substance carried on an inert adsorbent. Thus carbon, silica gel and aluminium oxide, when carrying a layer of optically active alkaloid, are effective agents for the resolution of mandelic acid [12].

Highly specific adsorbents of this type have recently been made [13].

Curti \& Colombo [14] used silica gel, precipitated in the presence of ( $t)$ camphorsulphonic acid. Using the artificial optically active adsorbent prepared in this way, they succeeded in obtaining a $30 \%$ resolution of camphorsulphonic acid and a 10\% resolution of mandelic acid.

Grubhofer \& Schleith [I5] increased the efficiency of such agents considerably by using an ion-exchange resin, the carboxylic acids of which had been esterified with quinine. The quinine-containing resin (25\% quinine) thus obtained would resolve racemic acids almost completely.

In this latter case, when the optically active agent is chemically associated with the carrier, the mechanism of separation is based on the asymmetric adsorption of the antipodes of the racemate; while in the previous cases, the resolution was produced by selective solution of the antipodes in a layer of optically active compound on an inert adsorbent.

Natural dissymmetric adsorbents have also been studied in connection with the resolution of racemates, for example, wool, silk, polysaccharides, colloidal adsorbents [16] and quartz.

The first attempts to demonstrate the differential adsorption of the antipodes of tropacocaine, atropine and homatropine on the protein of wool or silk were made by Willstätter [I7] in 1904 .

The selective adsorption of antipodes on wool was discovered in the case of racemic azo-dyes but the degree of resolution was insignificant and the findings could not always be repeated (Ingersoll, Adams, Brode, 1922-26 [18]). Slight selectivity is observed when the $(+)$ - and (-)-forms of an acid having the formula

$$
\left(\mathrm{CH}_{3}\right)_{2} \mathrm{~N} \cdot \mathrm{C}_{6} \mathrm{H}_{4} \cdot \mathrm{N}: \mathrm{N} \cdot \mathrm{C}_{6} \mathrm{H}_{4} \cdot \mathrm{CO} \cdot \mathrm{NH} \cdot \mathrm{CH}\left(\mathrm{C}_{6} \mathrm{H}_{5}\right) \cdot \mathrm{COOH}
$$

are adsorbed on serum protein [19], and also when strains are adsorbed on 
histological preparations of tissues, a case in point being the adsorption by malignant tumours of the antipodes of the stain

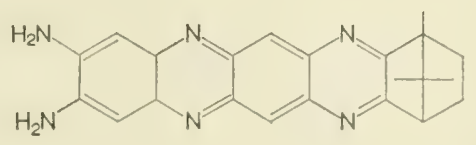

It would seem that only by asymmetric adsorption on a protein, genetically associated with the spiral structure of deoxyribonucleic acids, can one explain the selective sorption of $\mathrm{D}$-alanine by the walls of the blood vessels and many other examples of the appearance of spiral structures in natural compounds of high molecular weight [2I].

The protein of wool is very effective in resolving racemic hydroxy acids. A considerable degree of resolution was achieved by Marthin \& Kuhn [22] by passing a continuous ribbon of wool through a solution of mandelic acid.

Bradley [23], also studying the asymmetric adsorption of mandelic acid and its analogues on wool and casein, concluded that successful resolution was only possible in the case of acids of which one antipode could form a superficial labile salt by reacting with the basic groups of the protein.

For analytical purposes the asymmetric adsorbents lactose, starch and especially the cellulose of paper, have had a great application. By using lactose in Tsvet's chromatographic method a complete separacion of the antipodes of p-phenylenebisiminocamphor was obtained (Henderson \& Rule, I938) [24]. Great efficiency of resolution was seen, both in the case of Tröger's base, containing an asymmetric atom of tervalent nitrogen, and in that of DL-chloramphenicol [25].

A less effective method was adsorption on starch during chromatographic separation of complex, racemic, cobalt compounds [26]. Only in the case of cobalt triethylenediamine did the separation amount to ro-30\%.

The resolution of racemates by paper chromatography has been widely used during the past years. Many attempts [27] to resolve racemic acids and amines on the celluloses of paper and deacetylated chitin [28] have failed to give satisfactory results. Only on paper treated with $(+)$-tartaric or $(+)$-camphorsulphonic acid, at first using optically active solvents, has it been possible to separate the antipodes of $\beta$-hydroxynaphthylbenzylamine [29], phenylalanine [30] and tyrosine3 -sulphonic acid. The separation occurs even without the use of optically active solvents, which is explained by the asymmetric character of the adsorption on the cellulose of the paper [3I].

Many examples of the separation into antipodes of racemic amino acids and sugars are now known and their number is steadily growing [32].

A method for the resolution of racemates of special theoretical interest has recently been published. It is based on the selective spontaneous crystallization of inclusion complexes, formed by the honeycomb-like spiral structure of a complex-former, with insertion, into the spaces thus formed, of molecules of the racemate to be resolved [33].

The adsorbent or complex-former may be optically active, racemic or inactive, 
but it must have a dissymmetric structure. Cases have been described in which all three forms of such complex-formers were used.

For the resolution of esters of hydroxy acids Cramer [33] used a crystalline inclusion complex with cyclodextrin. The resolution amounted to $16 \%$. For the resolution of sec.-butyl bromide, Powell [34] used triorthothymotide, which crystallizes as a racemate without forming enantiomorphic crystals, but which easily gives rise to inclusion complexes.

Schlenk [35] gave an example of the use of an optically inactive adsorbentcrystals of urea-which have a spiral structure, similar to that of quartz, and which easily form inclusion complexes. When racemic 2-chloro-octane is crystallized with urea $95.6 \%$ resolution is achieved.

Quartz occupies an important position in hypotheses concerning the appearance of the first optically active substances, by virtue of its being a dissymmetric adsorbent.

Owing to its dissymmetrical lattice, quartz manifests considerable selectivity in the adsorption of compounds with molecular or crystalline dissymmetry. The selective adsorption on quartz of galactose and arabinose is well known [36]. It is found that there is epitaxy of hemihedral crystals of glycine, alanine and glutamic acid on D- and L-quartz [37].

The selective adsorption of antipodes on quartz for the purpose of resolving racemates does not show a high specificity. Thus, attempts to resolve $p$-phenylenebisiminocamphor have been unsuccessful [24] while the degree of activation of racemic butan-2-ol and the differential adsorptive capacity of D- and L-quartz for (-)-2-methylbutan-I-ol was insignificant [38].

In spite of the low selectivity of the adsorption of antipodes of a number of metallic complexes, this method has had a certain application in the establishment of their structure. A number of cases are known of the selective adsorption of one antipode of a complexes of chromium or cobalt on L-quartz $[39,40]$, as well as the partial resolution of racemic complexes of chromium, cobalt and platinum $[4 \mathrm{I}, 42]$.

Quartz plays an incomparably more important part as a carrier of catalysts, with the help of which one may carry out absolute asymmetric syntheses, thereby imitating enzymic activity.

\section{ASYMMETRIC CATALYSIS}

\section{Enzymes and Chemical Models of Enzymes}

Practically all vitally important processes are brought into being by the influcnce of enzymes-dissymmetric formations-the mechanism of their stereospecific action being, for the most part, still obscure. Therefore, in trying to find out the subtle ways in which these catalysts act, great interest attaches to attempts to produce dissymmetric inorganic and organic catalysts, i.e., chemical models of enzymes. This is valuable, both for the elucidation of the stereospecificity of enzymes, and for an understanding of the mechanism of asymmetric catalysis, which plays a great part in the production and development of dissymmetry in the organic world. 
The multiplet theory of catalysis of A. A. Balandin [42] designates those atoms or groups of atoms in the reacting molecules, which form intermediate adsorption complexes with the catalyst, as the multiplet. The multiplet theory might be applied with advantage to the study of enzymic reactions, in that enzymes are microheterogeneous while, in a number of cases, chemical models of enzymes are also heterogeneous catalysts. Furthermore, it is easy to use the multiplet theory for the classification of reactions catalysed both by enzymes and by models of them.

All reactions of enzymic asymmetric synthesis can be divided into two groups: coupling at $\mathrm{C}=\mathrm{C}$ and $\mathrm{C}=\mathrm{O}$ bonds [43].

Table I shows the enzymes, the starting material and the multiplet index of the reaction.

\section{TABLE I}

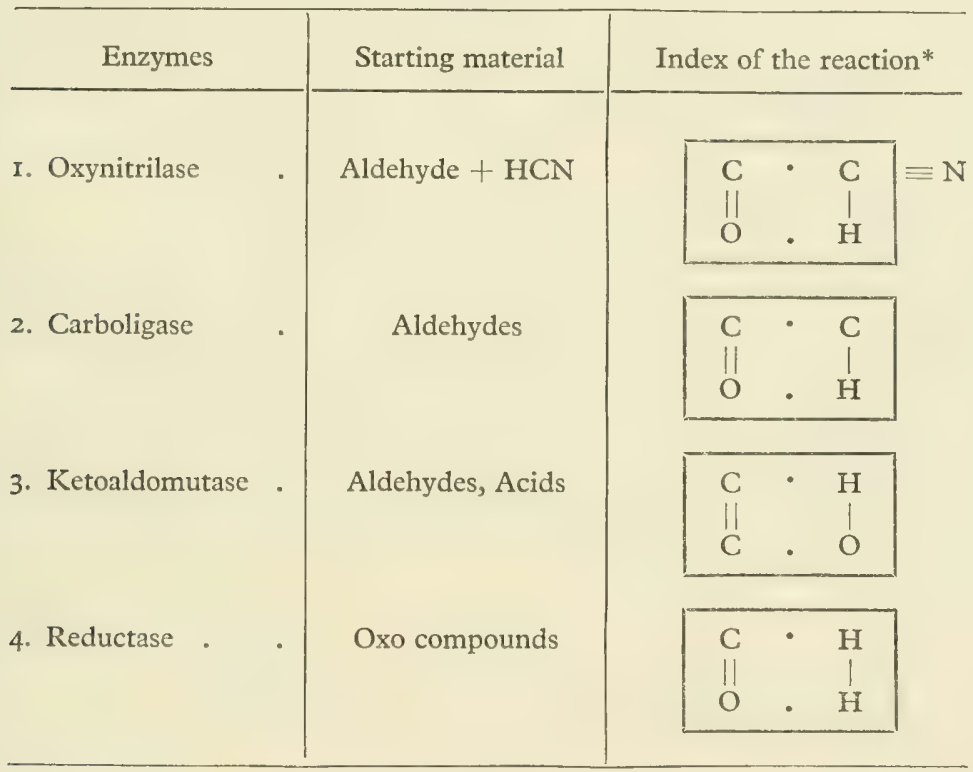

* Points are active centres of catalysts.

Optically active catalysts, even if of comparatively simple structure, exert an asymmetrizing influence on reactions, similar to that of natural enzymes.

At first, attempts were made to use optically active solvents as asymmetric influences on reactions.

It was discovered that the reaction between $\alpha$-phenylethylamine and phenyl isocyanate proceeded asymmetrically in a medium of $(-)-a$-pinene [44] as did Grignard reactions in ( + )-dimethoxybutane [45]. The extent of the asymmetry was, however, small. Only by using optically active substances as catalysts in a particular reaction, as, for example, in the decarboxylation of camphorcarboxylic acid by the action of alkaloids, was any considerable (up to $17 \%$ ) difference found in the rate of decomposition of the antipodes, with the resultant production of optically active camphor. 
The action of the catalyst, in this case, resembles that of carboxylase. The action of alkaloids on the asymmetric reduction of $\beta$-methyl- and $\beta$-( $\alpha$-naphthyl)cinnamic acid in the presence of hydrocinchonine [46] would appear to be analogous, as would their action in the bromination of cinchonine salts of cinnamic acid or glucosamine cinnamate [47].

There is, of course, a catalytic action by alkaloids which is even more like that of enzymes. It is seen in cases when the possibility of the formation of individual chemical compounds is ruled out. There are many such examples [48] of the formation of an excess of one antipode of esters by the catalytic action of brucine or strychnine. They are obtained by acetylation or benzoylation of racemic secondary alcohols or by the esterification of racemic chloranhydrides of acids.

The dehydration of methylphenylcarbinol [49] also belongs to this group of reactions; it occurs in the presence of $2 \%$ camphorsulphonic acid with the formation of the optically active oxide. The asymmetric dehydration of a diphenyldinaphthylallyl alcohol with the formation of a substituted allene [50] has also been reported.

The general nature of the index is such that, in spite of their variety, all these reactions belong to the group of reactions catalysed by esterases.

$(+)$-Camphorsulphonic acid is of special interest, being an asymmetric catalyst which, besides acting as an esterase, can also function asymmetrically as a ketoaldomutase. Asymmetric synthesis in the flavone series can be brought about by the catalytic action of $(+)$-bromocamphorsulphonic acid.

Optically active $4^{\prime}$-methoxy-5:6-benzoflavonone has been obtained by the method of Fujise \& Sasaki [5I]. (+)-7-Hydroxyflavone was obtained from 2 : 4dihydroxychalcone, and $(+)-6: 8$-dimethyl-5:7-diacetoxy-4'-methoxyflavone was obtained from $2^{\prime}: 4^{\prime}: 6^{\prime}$-triacetoxy-3': $3^{\prime}$-dimethyl-4-methoxychalcone.

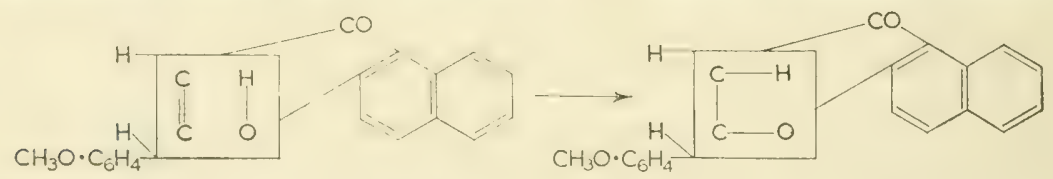

A chemical model of oxynitrilase is provided by the catalytic action of the cinchona alkaloids in the synthesis of the partially optically active nitrile of mandelic acid from benzaldehyde and HCN. This reaction extends to cover other aldehydes, including cinnamic aldehyde, anisic aldehyde, citral, piperonal and acetaldehyde [52].

Prelog \& Wilhelm [53] have made a detailed study of the influence of the structure and of the configuration of the molecules of catalysts (derived from quinine and quinidine) on the efficiency of the asymmetric catalytic synthesis of the nitriles of benzallactic and mandelic acids:

$$
\begin{aligned}
\mathrm{C}_{6} \mathrm{H}_{5} \cdot \mathrm{CH}: \mathrm{CH} \cdot \mathrm{CHO}+\mathrm{HCN} & \rightarrow \mathrm{C}_{6} \mathrm{H}_{5} \cdot \mathrm{CH}: \mathrm{CH} \cdot \mathrm{CH}(\mathrm{OH}) \cdot \mathrm{CN} \\
\mathrm{C}_{6} \mathrm{H}_{5} \cdot \mathrm{CHO}+\mathrm{HCN} & \rightarrow \mathrm{C}_{6} \mathrm{H}_{5} \cdot \mathrm{CH}(\mathrm{OH}) \cdot \mathrm{CN} .
\end{aligned}
$$

A definite relationship has been established between the spatial structure of the catalyst and that of the product. 
Chemical models of enzymes are to be found, not only among microheterogeneous catalysts, but also among heterogeneous ones. The adsorption of the reacting substances on the surface of the catalyst is fundamental to any heterogeneous-catalytic process. It is, therefore, necessary to distinguish between cases in which the catalyst itself is dissymmetrical and those in which the structure of the catalyst is symmetrical but it is carried on a dissymmetrical carrier. It might be expected that, in both cases, asymmetric adsorption would lead to asymmetric catalysis.

When the $\left(\mathrm{C}_{2} \mathrm{H}_{5}\right)_{2} \mathrm{~N}$ group has been introduced into the cellulose of cotton fibres they are transformed into active catalysts which, like the alkaloids, can simulate the asymmetric activity of carboxylase in breaking down camphorcarboxylic acid, and that of oxynitrilase in catalysing the synthesis of the (-)nitrile of mandelic acid. A catalyst of this sort was obtained in 1932 by Bredig \& Gerstner [54]. Although these authors regard the example they give as the first case of heterogeneous asymmetric catalysis, namely that in which the optically selective activity of the catalyst itself is the determining factor rather than that of the carrier, nevertheless, the mechanism of the dissymmetric action of a catalyst of this sort is, in fact, dependent on asymmetric adsorption on the optically active cellulose with ordinary, optically non-specific catalysis.

The mechanism of action is the same in the case of the catalyst palladium on silk fibroin (Akabori [55]) in reactions of asymmetric reduction of $\mathrm{C}=\mathrm{N}$ bonds. In support of this explanation we have the facts of asymmetric adsorption on cellulose, which has had extensive application recently in the chromatographic resolution of racemic amino acids on paper [3I, 32].

Attempts by Ghosh [56] to bring about asymmetric catalysis on asymmetric, dichroic, thin layers of metals (silver, platinum and palladium), which have a high optical rotation, were unsuccessful. We therefore have, for the present, no evidence for the existence of dissymmetric catalysts which are not associated with a dissymmetric carrier.

More successful experiments in the field of the optically selective activity of catalysts have been done with optically non-specific catalysts carried on a dissymmetric carrier.

Schwab and his colleagues [57] used, as their catalyst, copper, platinum or nickel, deposited in a thin layer on optically active crystals of quartz. They achieved optically selective decomposition of racemic butan-2-ol at $400-500{ }^{\circ} \mathrm{C}$. In this reaction the optical antipodes of the racemate are dehydrated at unequal rates and an excess of one optical antipode gradually accumulates in the remaining alcohol:
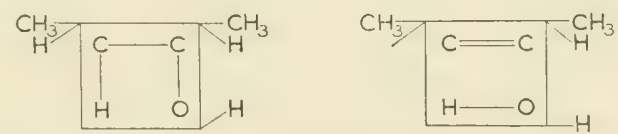

These effects have been successfully reproduced in the dehydration of other alcohols, namely menthol and methylethylbutylcarbinol [58].

Terent'ev \& Klabunovskii [59] have made a detailed study of the dehydration and dehydrogenation of butan-2-ol using various metal-quartz catalysts and 
extended their application to the absolute asymmetric synthesis of $\alpha-\beta$-diphenylpropionic acid by liquid-phase hydrogenation of $\alpha$-phenylcinammic acid, and that of optically active pinane from $a$-pinene.

Ponomarev \& Zelenkova [60] used nickel on quartz for the asymmetric synthesis of a number of derivatives of furane. The reactions occurred under pressure at $120^{\circ} \mathrm{C}$. From I-( $\alpha$-furyl)-propan-3-ol they obtained optically active I-tetrahydrofuryl-propan-3-ol and I : 6-dioxaspiro(4:4)nonane; while from I( $\alpha$-furyl)-butan-3-ol they obtained optically active I-tetrahydrofurylbutan-3-ol and 2-methyl-r : 6-dioxaspiro( $4: 4)$ nonane.

The action of the catalyst in evoking dissymmetry in these cases resembles that of reductase.

Using a catalyst (alkali on quartz) it has been possible to bring about the asymmetric, liquid-phase cyanethylation of 2-methylcyclohexanone. This differs essentially from the reactions previously considered in that it does not require a high temperature but takes place at $20-30{ }^{\circ} \mathrm{C}$, i.e. under the same conditions as enzymic syntheses in nature [6r, 43]:

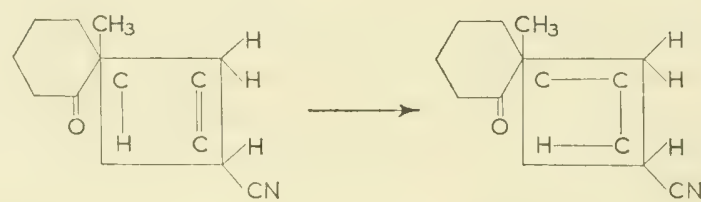

From what has been said it is seen that much material has been collected with reference to the imitation of the asymmetric action of enzymes.

Chemical models of enzymes have an interesting peculiarity: the range of their actions is incomparably greater than that of the enzymes while they are not so stereospecific. If a particular enzyme is capable of carrying out the reactions described under one heading in the index, then the corresponding organic catalyst will be able to bring about reactions of a completely different type with a fair degree of specificity.

Table 2 shows the enzymes, the index of their reactions and their chemical counterparts which have a comparable action.

Clearly, if the model of the enzyme has a relatively simple structure (derivatives of camphor), it will be hard to distinguish the parts of the molecule corresponding with the coenzyme or apoenzyme. Even in the case of the quinine alkaloids it has been possible to show that, for example, in the cyanhydrin synthesis, it is only the C-9 configuration in the molecule which determines the asymmetric synthesis of the oxynitrile [53]. In the case of heterogeneous catalysts it is easier to distinguish the evocation of dissymmetry from the act of catalysis since dissymmetry is evoked by asymmetric adsorption.

The results obtained by the use of catalysts, and, in particular, quartz catalysts, as chemical models of enzymes are of great theoretical interest in that they reveal the possibility of creating a new type of heterogeneous model of enzymes. Furthermore, the bringing about of absolute asymmetric syntheses and asymmetric decomposition of racemates, by the use of metals deposited on optically active 
quartz crystals, enables a new approach to be made to an understanding of the origin of the first asymmetric substances in nature.

TABLE 2

\begin{tabular}{|c|c|c|c|}
\hline Enzyme & Reaction inde & & Chemical model \\
\hline $\begin{array}{c}\text { I. Oxynitrilase } \\
\text { Carboligase : }\end{array}$ & $\begin{array}{lll}\mathrm{C} & \cdot & \mathrm{C} \\
\|_{\mathrm{O}} & \cdot & \text { I } \\
\mathrm{H}\end{array}$ & & $\begin{array}{l}\text { Alkaloids } \\
\text { Ethylamine on } \\
\text { cellulose }\end{array}$ \\
\hline 2. Reductase - & $\begin{array}{lll}\mathrm{C} & \cdot & \mathrm{H} \\
\| & & \mid \\
\mathrm{O} & \cdot & \mathrm{H}\end{array}$ & & Alkaloids \\
\hline 3. Esterase . & $\begin{array}{ccc}\mathrm{O} & \cdot & \mathrm{C} \\
\mid & & \mid \\
\mathrm{H} & \cdot & \mathrm{X}\end{array}$ & $\mathrm{X}=\mathrm{OH}$ or $\mathrm{Cl}$ & $\begin{array}{l}\text { Alkaloids } \\
\text { Camphor deriva- } \\
\text { tives }\end{array}$ \\
\hline 4. Ketoaldomutase . & $\begin{array}{lll}\mathrm{C} & \cdot & \mathrm{H} \\
\| & & ! \\
\mathrm{C} & \cdot & \mathrm{O}\end{array}$ & & $\begin{array}{l}\text { Camphor deriva- } \\
\text { tives } \\
\text { Metal on quartz }\end{array}$ \\
\hline 5. Decarboxylase & $\begin{array}{ll}\mathrm{C} & \cdot \mathrm{H} \\
\mathrm{I} & - \\
\mathrm{C} & -\mathrm{O}\end{array}$ & & $\begin{array}{l}\text { Alkaloids } \\
\text { Ethylamine on } \\
\text { cellulose }\end{array}$ \\
\hline $\begin{array}{l}\text { 6. No analogue. Action } \\
\text { the reverse of that } \\
\text { of glutamino- } \\
\text { dehydrase }\end{array}$ & $\begin{array}{lll}\mathrm{C} & \cdot & \mathrm{H} \\
\| 1 & & \mid \\
\mathrm{N} & \cdot & \mathrm{H} \\
\end{array}$ & & Palladium on silk \\
\hline 7. No analogue & $\begin{array}{lll}\mathrm{C} & - & \mathrm{C} \\
1 & & 1 \\
\mathrm{H} & \cdot & \mathrm{O}\end{array}$ & & $\begin{array}{l}\text { Metals and oxides } \\
\text { on quartz }\end{array}$ \\
\hline 8. No analogue & $\begin{array}{lll}\mathrm{C} & \cdot & \mathrm{H} \\
\| & & \mid \\
\mathrm{C} & \cdot & \mathrm{H}\end{array}$ & & Metals on quartz \\
\hline 9. No analogue & $\begin{array}{lll}\mathrm{C} & \cdot & \mathrm{C} \\
\| & & \mid \\
\mathrm{C} & \cdot & \mathrm{H}\end{array}$ & & Alkali on quartz \\
\hline
\end{tabular}




\section{REFERENCES}

I. J. H. VAN't HoFf, Die Lagerung der Atone in Raume, 3 Aufl. Braunschweig, I9o8.

2. Cf. F. phys. Chem., 20, 412, 1896; F. Amer. chem. Soc., 23, 255, 1900; Ber. dtsch. chem. Ges., 64, 342, I93I.

3. S. Goldschmidt \& H. C. Cooper, Z. phys. Chem., 26, 714, I898.

4. T. S. Patterson \& C. Buchanan, F. chem. Soc., p. 290, 1940.

5. T. S. Patterson \& A. H. Lamberton, F. chem. Soc., p. I453, I937.

6. C. Buchanan \& S. H. Graham, F. chem. Soc., p. 500, I950.

7. E. SCHRÖER, Ber. dtsch. chem. Ges., 65, 966, I932.

8. G. Karagunis \& P. Nikolaidis, Koll. Z., 106, i I2, I944; Z. angew. Chem., 48, 74, 276, I935.

9. M. JAMISON \& E. TURNER, F. chem. Soc., p. 6 I I, I942.

IO. A. Stoll \& A. Hoffmann, Hoppe-Seyl. Z., 251, 155, 1938.

I I. V. Prelog \& V. Geyer, Helv. chim. Acta, 28, 576, i945; L. Zechmeister, Ann. N.Y. Acad. Sci., 49, 220, I948. H. B. Hass, T. DE VRIES \& H. H. JAFFE, $\mathcal{F}$. Amer. chem. Soc., 65, I486, I943.

12. H. Fischgold \& K. AmmoN, Biochem. Z., 234, 39, I93I.

13. R. G. Haldeman \& P. H. Emmett, f. phys. Chem., 59, 1039, I955.

i4. R. Curti \& U. Colombo, F. Amer. chem. Soc., 74, 396i, i952; A. P. Terent'ev \& V. M. Potapov, Priroda, 5, 37, I955.

I 5. W. GrubHOFER \& L. SCHLEITH, Naturwissenschaften, 40, 508, I953.

16. M. JoHnson, The selective adsorption of the various types of aminoacids on several colloidal adsorbents. Diss., Washington, Catholic Univ. of Amer. Press, I938.

17. R. WILlStÄTtER, Ber. dtsch. chem. Ges., 37, 3758, I904.

I8. Cf. F. Amer. chem. Soc.s 4I, I264, I9I9; 44, 2930, I922; 45, I990, I923; 46, 2032, I924; 63, 923, I94I; f. chem. Soc., 127, I73I, I925; p. I568, I939; Nature, Lond., I41, 917, 1938; 142, I63, I938.

19. F. Kögl, J. G. Faber \& Z. C. DeBoer, Rec. Trav. chin. Pays-Bas, 69. 482, I950; Expos. ann. Biochim. med., IX, I9, 1950.

20. F. Karush, 7 . phys. Chem., 56, 70, I952.

21. F. KRIK (CRICK), Khimicheskaya Nauka i Promyshlennost, I (4), 472, I956; D. M. MatThews \& D. H. SMYth, F. Physiol., I16, 20 P, 1952.

22. H. MARTHIN \& W. KuHN, Z. Elektrochem., 47, 2I6, I94I.

23. W. Bradley \& G. C. EASTY, f. chem. Soc., p. 499, I95I; p. I5I3, I953; Nature, Lond., 173, 312, 1954; Disc. Faraday Soc., 16, I52, I954. Chem. E Ind., p. 574, I954.

24. G. M. Henderson \& H. G. Rule, F. chem. Soc., p. I 568, I939; Nature, Lond., I41, 917, I938; I42, 163, I938.

25. V. Prelog \& P. WIEland, Helv. chim. acta, 27, II27, I944; Referativnyi Zhurnal (Khimiya), 71826, 1956.

26. H. KREBS \& R. RASCHE, Naturwissenschaften, 4I, 63, I954; Z. anorg. chem., 276, 236, I954.

27. C. E. DENT, Biochem. F., 43, I69, I948; f. chem. Soc., p. I679, I948.

28. A. Santoro, Chem. Abstr., 48, 4448i, I954.

29. G. B. Bonino \& V. Carassiti, Nature, Lond., 167, 569, I951; R.C. Accad. Lincei, 9, 229, 1950.

30. S. Berlingozzi, G. Serchi \& G. Adembri, Sperimentale (Ser. Chim. biol.), 2, 89. I95I; Chem. Abstr., 46, 9070g, I952.

31. H. Kotake, T. Sakan, N. Nakamura \& S. Senoh, 7. Amer. chem. Soc., 73, 7973, I951; F. chem. Soc. Japan, 72, 795, I95I ; J. Inst. Polyt., Osaka, Ser. C, 2, 29, I95I; Chcm. Abstr., 7075, I953; E. I. KLABUnovskif̆, Priroda (2), 88, I955; S. K. YATKAR \& D. S. Sastry, F. Univ. Poona Sci. Technol., 4, 69, I953; Chem. Abstr., 78, I240i, I954.

32. P. Burma \& B. Banerjee, Sci. E Cult., I5, 363, r950; Chem. Abstr., 45, 3753, I95I; R. WEICHERT, Acta chem. scand., 8, I542, I954; 9, 547, I955; Z. Naturforsch., 7b, 677, I952; Ark. Kemi, 5, 523, 553, 1953; Hoppe-Seyl. Z., 279, 27, 1943; 281, I20, 1944; C. E. Dalgliesh, F. chem. Soc., p. 137, 3940, I952; Biochem. F., 52, 3, 1952; K. Closs, Chem. E Ind., p. I03, I953; Y. J. Fujisawa, Chem. Abstr., 48, I3550c, I954; M. Mason, F. biol. Chem., I95, 515, I952; J. P. LAMBooy, F. Amer. 
chem. Soc., 76, 133, I954; N. NAKAMURA, 7. chem. Soc. Japan, 72, 789, I95I; E. I. KlabunovskiĬ, Priroda, Ir, 86, I955; Chem. Abstr., 50, r r96Ig, I956.

33. F. Cramer, $Z$. angezv. Chem., 64, 136, r952; 68, I x 5, I956.

34. H. M. Powell, Nature, Lond., 170, 155, 1952; Endeavour, 15, 20, 1956; \}. chem. Soc., p. 3747, I952; W. BAKER \& J. F. MC OMIE, Chem. E Ind., p. 256, I955; f. chem. Soc., p. 6r, I948; p. I443, I952; Angew. Chem., 68, I I5, I956.

35. W. Schlenk, Experientia, 5, 200, I949; 8, 337, I952; Angew. Chem., 67, 762, I955; Svensk kem. Tidskr., 67, 435, I955.

36. L. HolzapFeL, Z. Elektrochem., 55, 577, I95 I.

37. H. SEIFERT, Naturwissenschaften, 42, I3, I955; Z. Elektrochem., 59, 409, I955.

38. E. I. Klabunovskil̆ \& V. V. Patrikeev, Dokl. Akad. Nauk S.S.S.R., 78 (3), 485, I95I; N. I. ShuǏkin, V. V. Patrikeev \& E. I. Klabunovskil̆, Avt. Svid., No. 95526, 30/Mai, I953.

39. R. Tsuchida \& M. Kobayashi, Bull. Chem. Soc. Japan, 6, 342, 1936.

40. G. K. Schweitzer \& C. K. TALbott, Chem. Abstr., 46, I IO04, I 952.

41. I. R. Kuebler \& J. C. Bailar, F. Amer. chem. Soc., 74, 3535, I952; 75, 4574, I 953 ; Nature, Lond., 142, I62, I938.

42. A. A. Balandin, Zhur. russ. fiz. Khim. Obshch., 6r, 900, 1929; Izv. Akad. Nauk S.S.S.R., 4, 624, I955.

43. E. I. Klabunovskil̆, Khimicheskaya Nauka i Promyshlennost', 2, No. 2, I97, I957.

44. R. WEgler, Leibigs Ann., 498, 62, I932.

45. H. L. Cohen \& G. F. Wright, F. org. Chem., 18, 432, I953.

46. D. L. Lipkin \& T. D. Stewart, F. Amer. chem. Soc., 6r, 3295, 3297, I939.

47. H. ERLenMeYer, Helv. chim. Acta, I3, 73 I, I930.

48. R. WEGLER, Liebigs Ann., 498, 62, I932; 506, 77, I933; 510, 72, I934.

49. H. Wurts, Bull. Soc. chim. Belg., 30, 30, I921.

50. P. Maitland \& W. H. Mills, F. chem. Soc., p. 987 , I936.

51. S. FUJISE \& H. SASAKI, Ber. dtsch. chem. Ges., 7I, 34I, I938; f. chem. Soc. Japan, 72, I073, I95I.

52. G. Bredig \& P. S. Fiske, Biochem. Z., 46, 7, I9I8; G. Bredig \& M. MinaefF, Biochem. Z., 249, 24I, I932.

53. V. Prelog \& M. Wilhelm, Helv. chim. Acta, 37, I634, I954.

54. G. Bredig \& F. Gerstner, Biochem. Z., 250, 4I4, I932.

55. S. AkaвorI, Nature, Lond., 178, 323, I956; Kagaku, 45 (2), 54, I955; Biokhiniya, 22 (I-2), I54, I957.

56. J. G. Grosh, F. Indian chem. Soc., I6, 51, 1939.

57. G. M. Schwab, F. Rost \& L. RudolPH, Kolloidzschr., 68, I57, I934; Naturwissenschaften, 12, 237, 1932.

58. A. StankJEWIEcz, Diss. Königsberg, I938.

59. A. P. Terent'Ev, E. I. KLABunovskil̆, Sbornik Statei po obshchei Khimii, Vol. 2, p. I52I, I598, I953; Uchen. Zapiski. Moskov. Gos. Univ., I5I, I45, I95I.

6o. A. A. Ponomarev \& V. V. Zelenkova, Zhur. obshch. Khim., 23, I543, I953; Dokl. Akad. Nauk S.S.S.R., 87, 423, I952.

6I. A. P. Terent'ev, E. I. KLABUnovskiǏ \& E. I. Budovskiř, Sbornik Statel po obshchei Khimii, Vol. 2, p. I612, 1953. 


\title{
On the Origin of the Fore-protein
}

\author{
SHIRO AKABORI \\ Institute for Protein Research, Osaka University, Osaka
}

IF PROTEIN is absolutely essential for all living things, the very beginning of life must have been a spontaneous formation of protein at a certain age of the Earth.

In 1936 Oparin [I] postulated that $\alpha$-amino acids could have been formed non-biologically from hydrocarbons, ammonia and hydrogen cyanide at the age of the Earth when the atmosphere contained these substances in high concentrations. Bernal [2] emphasized the role played by ultraviolet light in the formation of organic compounds at a certain stage of the evolution of the Earth. $\mathrm{He}$ also suggested that life might have originated on the surface of clay which accumulated large amounts of organic substances. Oparin's hypothesis has received strong experimental support from the recent work of Miller [3].

It has generally been believed that the first proteins or fore-proteins were non-biologically formed by the polycondensation of preformed free amino acids. This belief is solely based on the fact that proteins in present-day organisms are synthesized via free amino acids. Such non-biological formation of polypeptides and proteins, however, seems to be very difficult owing to the requirement of free energy, though Bresler [4] reported the reconversion of tryptic hydrolysates to the original proteins under an extremely high pressure.

In 1955 I proposed [5] a hypothesis concerning the origin of the fore-protein and speculated that it must have been produced through reactions consisting of the following three steps.

The first step is the formation of aminoacetonitrile from formaldehyde, ammonia and hydrogen cyanide.

$$
\mathrm{CH}_{2} \mathrm{O}+\mathrm{NH}_{3}+\mathrm{HCN} \longrightarrow \mathrm{H}_{2} \mathrm{~N}-\mathrm{CH}_{2}-\mathrm{CN}
$$

The second is the polymerization of aminoacetonitrile on a solid surface, probably in the state adsorbed on clay, followed by the hydrolysis of the polymer to polyglycine and ammonia.

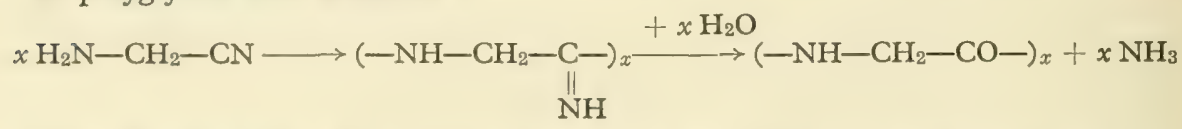

and the third step is the introduction of side chains into polyglycine by the reaction with aldehydes or with unsaturated hydrocarbons.

I have also pointed out that the formation of amino acid residues possessing the same configuration throughout one single peptide chain could be expected from this mechanism, assuming that the configuration adsorbed on the solid surface is the cis-form, as shown in Fig. I. 

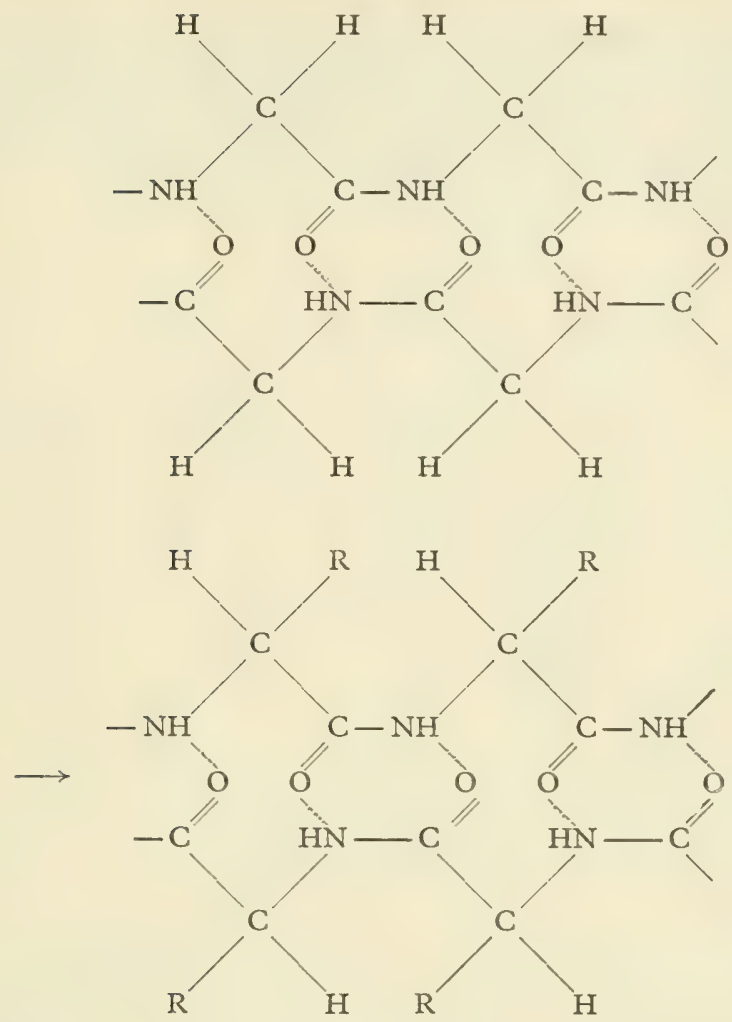

FIG. $\mathrm{I}$.

If polyglycine adsorbed on a solid surface had the configuration as indicated in the above figure, the plane including one carbon atom and two hydrogen atoms of the methylene group must be perpendicular to the solid surface. The reacting molecule must have come from outside, and, therefore, only one hydrogen atom directed to outside must have reacted, giving rise to amino acid residues of the same stereochemical configuration throughout one single peptide chain.

The validity of the second step in the above hypothesis was tested in the following model experiments, which were carried out by Hanafusa in my laboratory. Aminoacetonitrile was prepared by the condensation of formaldehyde, ammonia and hydrogen cyanide and was obtained in the form of its hydrogen sulphate. This was mixed with 20 parts of kaolinite and heated at $130-135^{\circ}$ for 5 hours. The product was extracted with dilute sodium hydroxide solution. The presence of glycylglycine and glycylglycylglycine in the extract was confirmed by paper and column chromatography.

The present paper deals mainly with experiments concerning the last step in the formation of the fore-protein, that is the introduction of side chains into polyglycine structure. Polyglycine used in the present work was prepared not from aminoacetonitrile but from glycine $N$-carboxylic anhydride or from glycine ester, by polycondensation with or without supporter. Polyglycine spread on 
the surface of kaolinite was suspended in water and treated with formaldehyde or acetaldehyde in the presence of a basic catalyst. The reaction product was washed with alcohol, dried and hydrolysed with $6 \mathrm{~N}$-hydrochloric acid. The hydrolysate was dinitrophenylated and analysed by silica gel chromatography. The results of these experiments are shown in Table I.

TABLE I

\begin{tabular}{|c|c|c|c|c|c|}
\hline \multirow[b]{2}{*}{ Sample } & \multirow[b]{2}{*}{ Aldehyde } & \multirow[b]{2}{*}{ Catalyst } & \multicolumn{2}{|c|}{ Reaction } & \multirow{2}{*}{$\frac{\text { Hydroxy-amino acid }}{\text { Glycine }}$} \\
\hline & & & $\begin{array}{c}\text { Temp. } \\
\left({ }^{\circ} \mathrm{C}\right)\end{array}$ & $\begin{array}{l}\text { Time } \\
(\mathrm{hr})\end{array}$ & \\
\hline \multirow{7}{*}{$\begin{array}{c}\text { PGK } \\
" \\
" \\
" \\
\text { PG } \\
y\end{array}$} & HCHO & \multirow{7}{*}{$\begin{array}{c}\mathrm{K}_{2} \mathrm{CO}_{3} \\
\mathrm{NaHCO}_{3} \\
\mathrm{TEA} \\
\mathrm{T}_{2} \mathrm{CO}_{3} \\
\mathrm{NaHCO}_{3} \\
\mathrm{TEA} \\
\mathrm{K}_{2} \mathrm{CO}_{3}\end{array}$} & 80 & 7 & 0.031 \\
\hline & , & & 80 & 7 & 0.030 \\
\hline & & & 100 & $2 \cdot 5$ & 0.004 \\
\hline & $\mathrm{CH}_{3} \mathrm{CHO}$ & & 60 & 50 & 0.015 \\
\hline & & & 60 & 50 & 0.014 \\
\hline & $\mathrm{HCHO}$ & & 100 & 3 & 0 \\
\hline & " & & 80 & 7 & ० \\
\hline
\end{tabular}

Abbreviations: PGK: Polyglycine-kaolinite.

PG: Polyglycine.

TEA: Triethylamine.

In the reaction with formaldehyde, $2-3 \%$ of glycyl residues of polyglycine were converted to seryl residues and in the case of acetaldehyde the rate of the conversion of glycyl to threonyl residues was about $1 \cdot 5 \%$. The degree of polymerization of polyglycine dispersed on kaolinite was from 140 to 170 . It is, therefore, clear that not only the $\mathrm{N}$-terminal residue but other glycyl residues reacted with the aldehydes. When polyglycine without supporter was used, practically no side chains were introduced into polyglycine under the same reaction conditions.

The conversion of seryl residue to cysteinyl or cystinyl residue in the foreprotein could have taken place as follows.

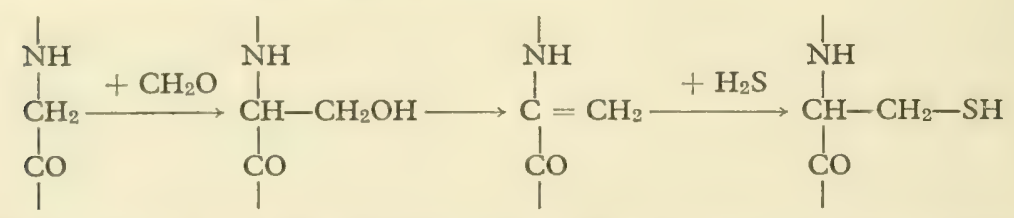

This hypothesis was then experimentally tested. For the purpose of experimental convenience we used polyserine synthesized by Okawa [6], one of my associates, according to the method shown in Fig. 2. The formation of cystinyl and cysteinyl residue has not yet definitely been confirmed, but when polyserine was treated with benzyl mercaptan in an alkaline solution, the presence of $S$-benzylcysteine in the hydrolysate of the reaction product was clearly demonstrated. 


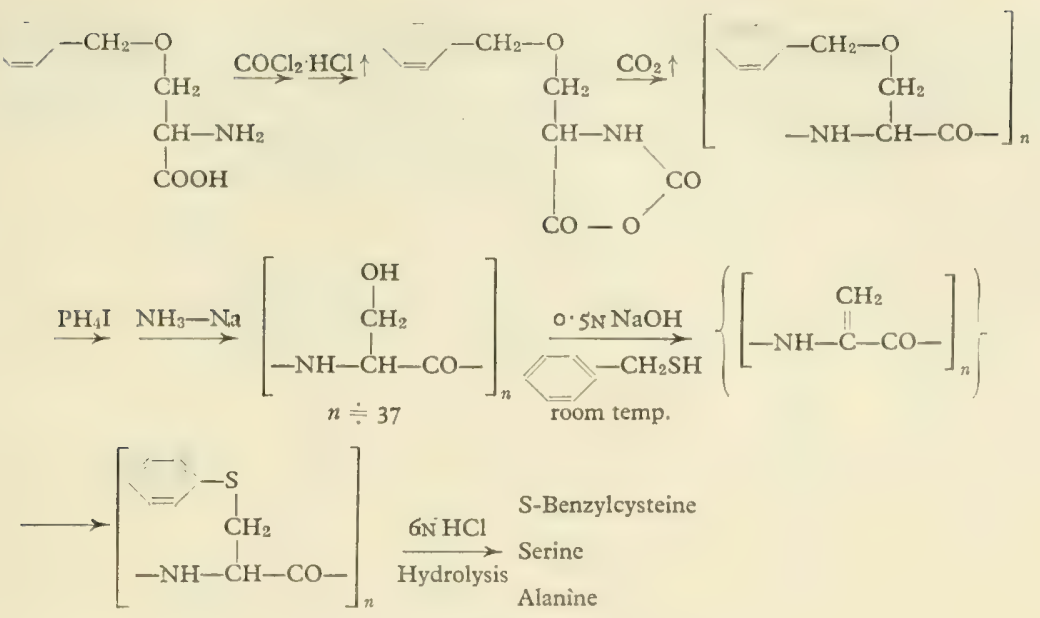

FIG. 2.

The formation of aspartyl residue in the fore-protein is also most likely to have occurred by a series of reactions shown in Fig. 3. The experiment to test this possibility was carried out by employing polydehydroalanine synthesized by Sakakibara from carbobenzoxy-dehydroalanine as shown in the figure.

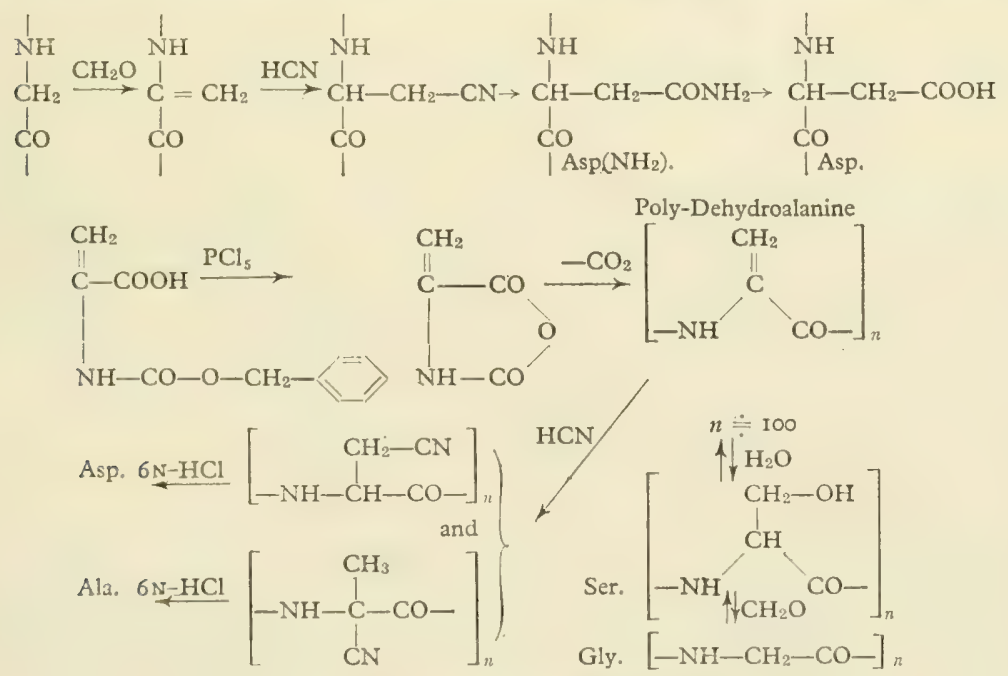

FIG. 3. Formation of aspartic acid.

olydehydroalanine is a light-brown, amorphous powder, which is soluble in water and formic acid but not in alcohols. This polymer was dissolved in water with potassium cyanide and kept at $20-25^{\circ}$ for 20 hours in a sealed tube and then hydrolysed by hydrochloric acid. The hydrolysate was chromatographed 


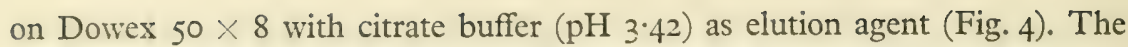
presence of aspartic acid, glycine and alanine was very clearly demonstrated. These amino acids were further identified by two-dimensional chromatography after they were converted to dinitrophenylamino acids (Fig. 5).

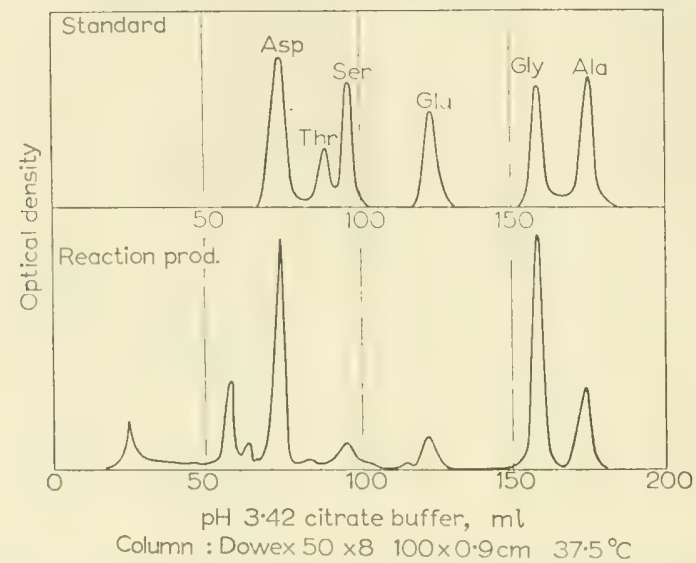

FIG. 4. Hydrolysate of reaction product of $\mathrm{HCN}$ with poly-dehydroalanine.

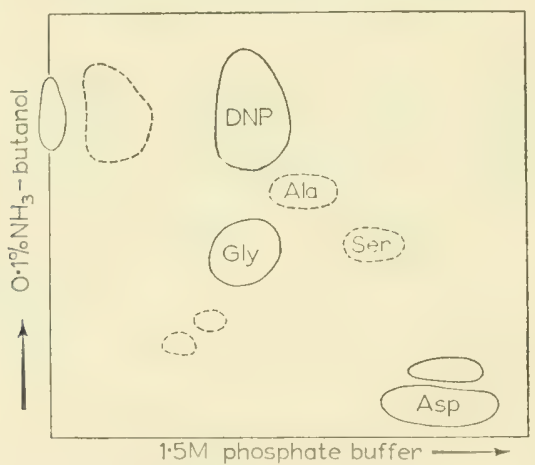

FIG. 5. Hydrolysate of reaction product of HCN with poly-dehydroalanine. Paper chromatogram of DNP-derivatives.

The formation of aromatic and heterocyclic amino acids in the fore-protein could have occurred by the condensation of methylene group of glycyl residue followed by hydrogenation (Fig. 6). The chemical structure of phenylalanine, tyrosine, tryptophan and histidine, in which one methylene group is situated between an aromatic or heterocyclic nucleus and a glycine group might support the above-mentioned mechanism of their formation in the fore-protein.

The formation of valine, leucine and isoleucine might have resulted from the direct addition of propylene, isobutene and but-2-ene respectively as shown in Fig. 6. Experimental evidence for such a mechanism is not yet sufficient. Every attempt to introduce a sec.-butyl group to polyglycine chain with basic catalysts has failed. When, however, polyglycine dispersed on Japanese acid clay was 
Formation of Aromatic Amino Acids<smiles>CNC(CCBr)C(C)C=O</smiles><smiles>BrCCc1ccc(Cc2ccc(OCCc3cc4cn(Cc5c[nH]cn5)cc4[nH]3)cc2)cc1</smiles>

Formation of Valine, Leucine, Isoleucine<smiles>C=CC(C)CC(NC(=O)C(CC(C)C)NC(C(=O)O)C(C)C)C(C)CC</smiles>

Fig. 6.

heated to $130^{\circ}$ for 5 hours with an excess of but-2-ene (probably containing a certain amount of isobutene) in the presence of $0.1 \%$ but-2-ene ozonide, the formation of a small quantity of leucine (or isoleucine) was observed by paper and column chromatography after hydrolysing the reaction product. Fig. 7 shows a column-chromatographic elution curve of the hydrolysate.

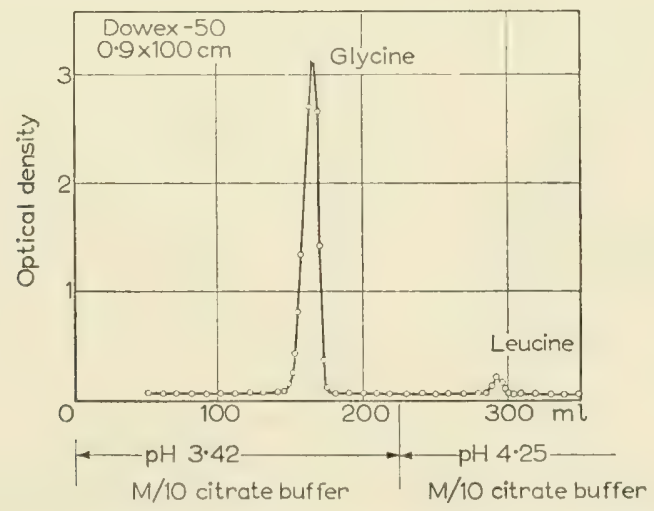

FIG. 7. Hydrolysate of reaction product of butene with polyglycine. 
We could not determine whether the amino acid corresponding to the small peak was leucine or isoleucine.

As is well known in synthetic organic chemistry, in the presence of a certain catalyst, acetylene readily reacts with hydrogen cyanide to form acrylonitrile; the presence of the latter substance in the fore-atmosphere is quite conceivable. The formation of glutamine, glutamic acid, ornithine and arginine could thus be formulated as shown in Fig. 8.

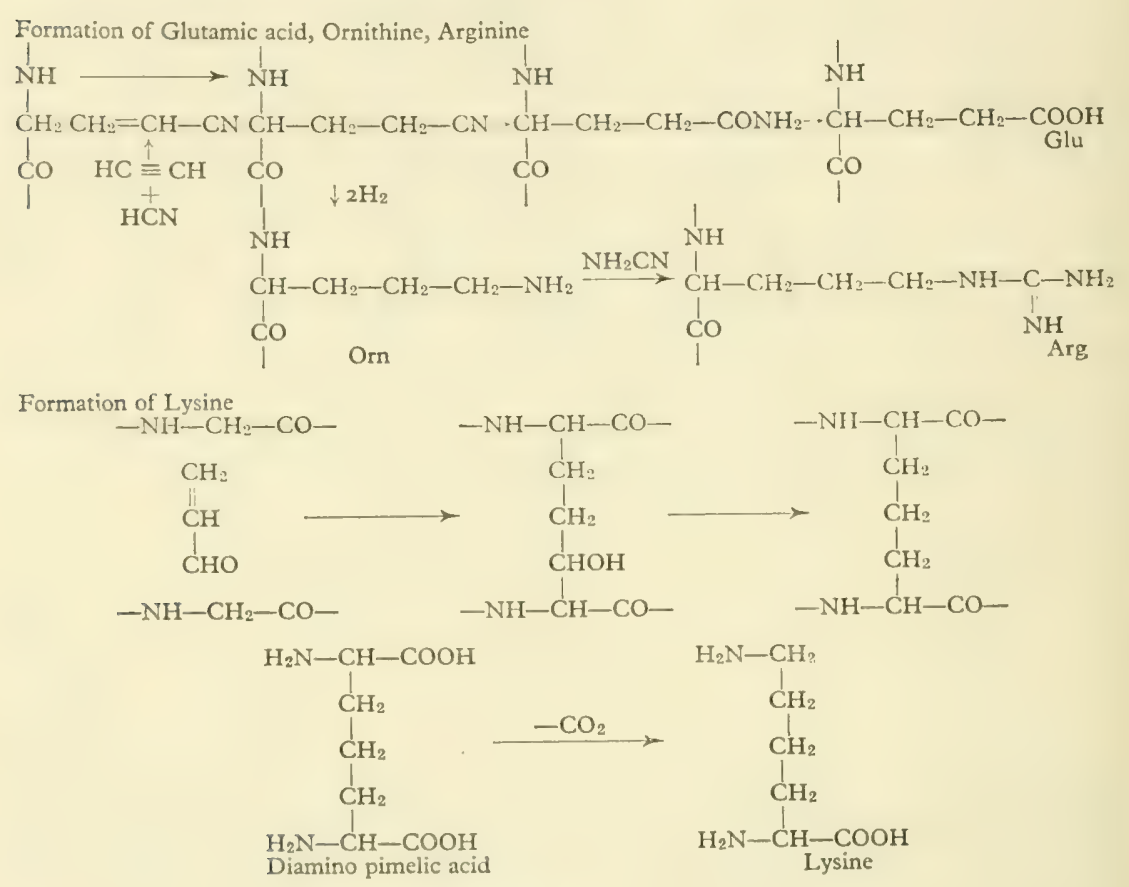

FIG. 8.

It 1 am allowed to make a more extended speculation, I could formulate the mechanism of the formation of lysine as shown in Fig. 8. The first step is a cross-linked condensation of one molecule of acrolein with two polyglycine chains, giving rise to a $\beta$-hydroxy- $\alpha \alpha^{\prime}$-diaminopimelic acid residue. This hydroxydiaminopimelic acid could have been reduced to diaminopimelic acid which was shown by Dewey \& Work [7] and also by B. D. Davis [8] to be the precursor of lysine in Escherichia coli. It is very important that, according to E. Work [9], diaminopimelic acid is widely distributed among various microorganisms. These findings might support the proposed mechanism on the formation of lysine.

Although I am afraid I went too far with my speculation, I would like to emphasize that it seems not too difficult to test the theory on experimental bases. Further work along this theory is now in progress in the Laboratory for Protein Research of Osaka University. 


\section{REFERENCES}

I. A. I. Oparin, The Origin of Life. Macmillan, New York, 1936.

2. J. D. Bernat, Physical Basis of Life. London, I95I.

3. S. L. Miller, Science, 177, 528, I953; f. Amer. chem. Soc., 77, 2351, I955; Biochim biophys. Acta, 23, 480, 1957.

4. E. S. BresLer et al., Izv. Akad. Nauk S.S.S.R., Ser. Biol., 13, 392, I949.

5. S. AKABORI, Kagaku (Science, in Japan), 25, 54, 1955.

6. K. OKaWA, f. chem. Soc. Fapan (in Japanese), 75, II99, I954.

7. D. L. DEWEY \& E. WORK, Nature, Lond., 169, 533, 1953.

8. B. D. Davis, Nature, Lond., 169, 534, I953.

9. E. Work, Biochem. F., 49, I7, I95 I; F. gen. Microbiol., 9, 394, 1953. 


\title{
Evolution of Enzymes and the Photosynthetic Apparatus
}

\author{
MELVIN CALVIN \\ Department of Chemistry, University of California, \\ Berkeley, California, U.S.A.
}

Mr Chatrman, members and guests, I would like to express my thanks to the Organizing Committee for the opportunity to be here, and to congratulate them on the thoroughness and care with which this Symposium has been arranged.

Time does not allow, nor does this audience require, a summary, or introduction to the present-day conception of various stages which must have occurred in the origin of life on Earth as we know it. The appearance of organic material on the surface of the Earth has already been adequately discussed, and the discussion on the development of cellular organisms will come later. It seemed wiser for me not to attempt even a summary of the paper which appears in the publication of the proceedings of this conference, but rather to select two particular points which I thought might add something to the basic pattern as it has been developed by Oparin. The first of these might be termed the development of catalysts, that is, enzymes and rudimentary synthetic sequences. The second will be a discussion of the possible mode of the development of what we now know as the photosynthetic apparatus.

With regard to the first point, the development of catalysts and rudimentary synthetic sequences: Even the most cursory examination of what is now known about the nature of present-day enzymatic mechanisms cannot fail to impress one with the apparent identity between the enzymatic reactions and the reactions as they are known to the organic chemist in the laboratory. For example, glyoxylase, by which methylglyoxal is converted to lactic acid, is nothing more or less than an internal Cannizzaro reaction which is catalysed by bases. Almost all of the hydrolytic enzyme reactions-esterases, proteases, phosphataseshave their non-enzymatic counterpart in the form of generalized acid or base catalysts, or more specialized catalysis by metal salts. For example, again in the case of the phosphatases, the freshly precipitated trivalent metal hydroxides are extremely effective, or manganese ion as a rudimentary phosphotransferase.

One particular group of catalysts which is widely dispersed in present-day biological systems is that centred around the element iron, particularly catalase, peroxidase and cytochrome. Here, a rather quantitative comparison can be made between the ability of the bare iron atom to perform some catalytic function and the ability of the iron atom to perform the same catalytic function as it has been developed in biological systems. Thus, in Fig. I one sees a comparison of the hydrated iron ion, the iron ion surrounded by a porphyrin as it is in haem, and 


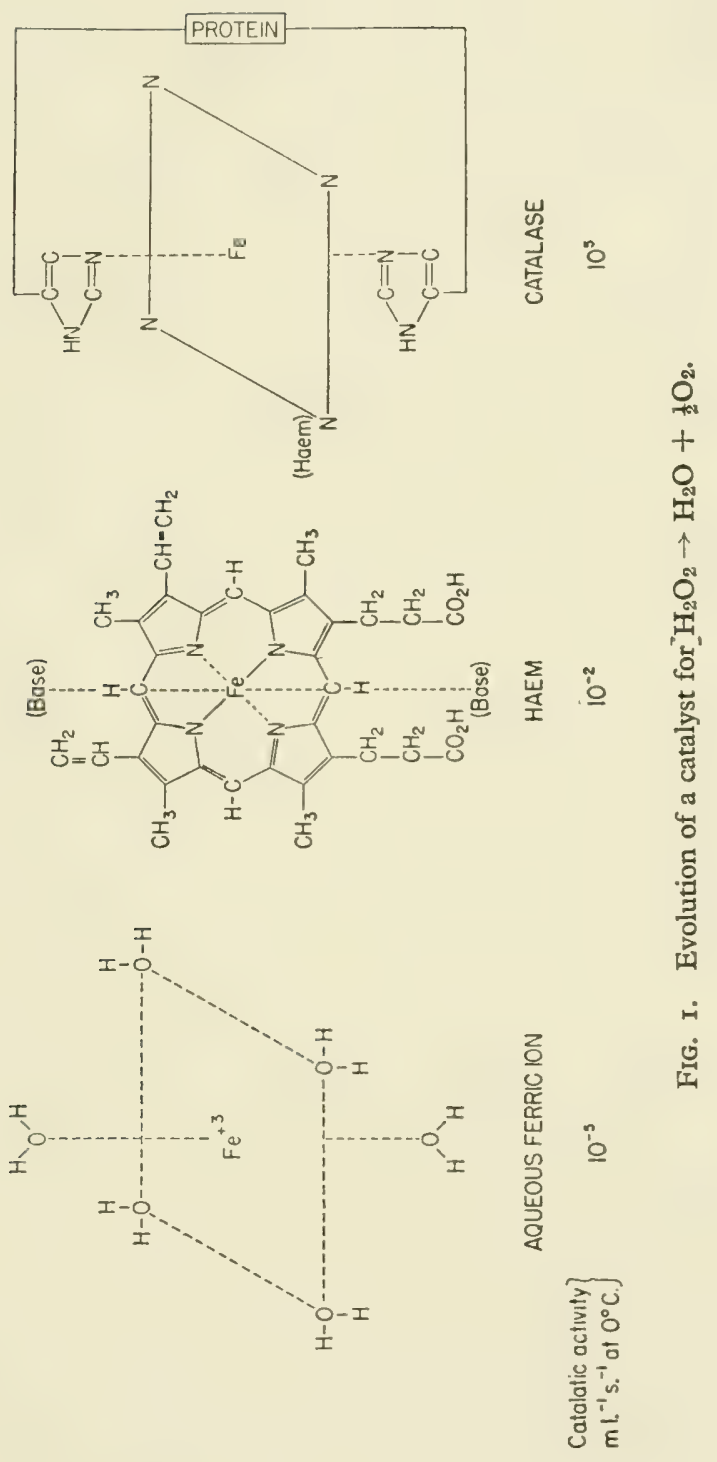


iron porphyrin, or haem, as it is incorporated into a protein, surrounded by two more co-ordinating groups of the protein to form catalase. The progressive increase in catalytic ability is from $10^{-5}$ for the aqueous ferric ion to $10^{-2}$ for the haem to $10^{5}$ for the complete enzyme. These are definitions of the catalytic function of the iron for the reaction involving the decomposition of hydrogen peroxide. However, we know that the iron has other functions, as well, most of which involve oxidation or reduction. For example, even catalase itself can function as a peroxidase, using hydrogen peroxide to oxidize organic substrates, provided the hydrogen peroxide is sufficiently dilute. Undoubtedly, the iron is also involved in what we now recognize as oxidative phosphorylation, that is, the conversion of the energy liberated upon the passage of an electron from a highly reducing potential to an oxidizing agent, such as oxygen or other material, with the concomitant storage of some of that energy in the form of unstable (pyrophosphate) linkages which may later be used for other purposes.

In order to convert the rudimentary catalytic functions which exist in all the elements and their simple compounds into the highly efficient ones that we now recognize as enzymes, we must introduce two additional ideas, one from the realm of chemistry and the other from the realm of genetics, both of which, however, could be considered as manifestations of exactly the same phenomenon. The first of these, from the realm of chemistry, is the idea of autocatalysis, that is, the basic notion that the product of a reaction may itself be a catalyst for the conversion of precursors into itself. This is a very common phenomenon in chemistry and perhaps is best illustrated in one of the simplest cases, namely, the reaction of molecular hydrogen with cupric ion. This reaction leads thermodynamically to the formation of cuprous ion and water. It so happens that the reaction of molecular hydrogen with cupric ion, although thermodynamically possible, is an extremely slow one without catalysis. However, the product of this reaction, that is, cuprous ion, is an extremely good catalyst for the reaction between hydrogen and cupric ion. Therefore, one can imagine, and indeed we have experimentally realized this long ago, a system consisting of molecular hydrogen and cupric ion which remain in this form for some period of time. However, should either a very slow noncatalytic reduction lead to cuprous ion, or should some random electron transfer lead to the formation of an appreciable number of cuprous ions in the mixture, then immediately the entire reaction mixture goes over to the more stable system consisting of cuprous ion.

The other notion which we would like to introduce is the one developed by the geneticist Horowitz. He suggested that the very complex series of reactions which we are now finding to be responsible for the synthesis of most of our existing biological material could have developed in a backward manner, beginning with the completely heterotrophic organism. He postulated that the first living things, complete heterotrophs, had available to them all possible precursors for their own duplication, and that their only function was to bring these together to produce themselves. One can then visualize a process in which at first one essential constituent of the mixture is depleted. Then, the particular organizational unit which found a way of manufacturing the depleted item from remaining molecules will, of course, survive, whereas those units which are unable to 
do so will disappear, since they can no longer reproduce themselves. Such a process of gradual depletion of available substrates with the evolution of continually longer and longer chains of synthesis would then constitute the origin of the synthetic sequences which we are now finding in present-day living orgaismns.

With these two ideas we can see how an enzyme, or, I should say, a highly efficient catalyst, could be built. It is worthwhile to trace such a development in a specific instance with which we might be familiar, for example the iron porphyrin. Fortunately, the essential steps in the present-day biosynthetic route to porphyrin have been unravelled for us. One could begin with succinic acid and glycine, two compounds which we already know can be made by the various random methods which have been discussed earlier, such as gaseous discharge or ionizing radiation or ultraviolet light. From these (succinic acid and glycine) an $\alpha$-amino- $\beta$-keto acid is formed, followed by decarboxylation to $\delta$-aminolaevulinic acid, two of which then condense to form a pyrrole nucleus, porphobilinogen. This molecule then passes through a series of steps, involving a number of oxidations, leading finally to protoporphyrin 9. The skeleton of this sequence is shown in Fig. 2.

With the introduction of iron into the protoporphyrin, or perhaps a better way to view it would be, the surrounding of iron by the protoporphyrin grouping, the iron becomes a better oxidation catalyst, and, as you can see, there are several oxidation steps along the biosynthetic route as we now know it. Thus, one has only to suppose that one or more of the sequences of steps leading to protoporphyrin is dependent upon an iron-catalysed oxidation, and this is almost certainly so, to arrive at the conclusion that once such an iron protoporphyrin is manufactured it will itself accelerate its own synthesis from such precursors as succinic acid and glycine and thus tend to build up the supply of the material and improve the iron catalyst that will be available for a variety of other functions as well.

The second point that I would like to make concerns how the development of the photosynthetic apparatus as we now know it might have occurred: In order to do this we review briefly what our present state of knowledge might appear to be with respect to the existing mechanism by which the photosynthetic apparatus in the green plants and in the lower organisms can convert electromagnetic energy into chemical potential as reduced carbon and molecular oxygen. One need hardly do more than point out the essential features of the process to recognize its present-day separation into several rather distinct parts. The reduction of carbon dioxide, we now have every reason to suppose, occurs in a series of reactions which can take place entirely in the dark. In fact, all of the enzyme systems which we now know to participate in the conversion of $\mathrm{CO}_{2}$ to carbohydrate have been found in a wide variety of organisms, many of which are not photosynthetic. For example, the Thiobacillus contains very nearly all of the necessary enzymes and Escherichia coli grown in xylose will contain not only 'carboxydismutase' but a number of other enzymes involved in the carbon reduction cycle. The final step was indeed taken when Racker was able to make a mixture of all the requisite enzymes and the energy-storing compounds [reduced triphosphopyridine nucleotide and adenosine triphosphate (ATP)] which produced hexose phosphate from carbon dioxide, all in the dark. 


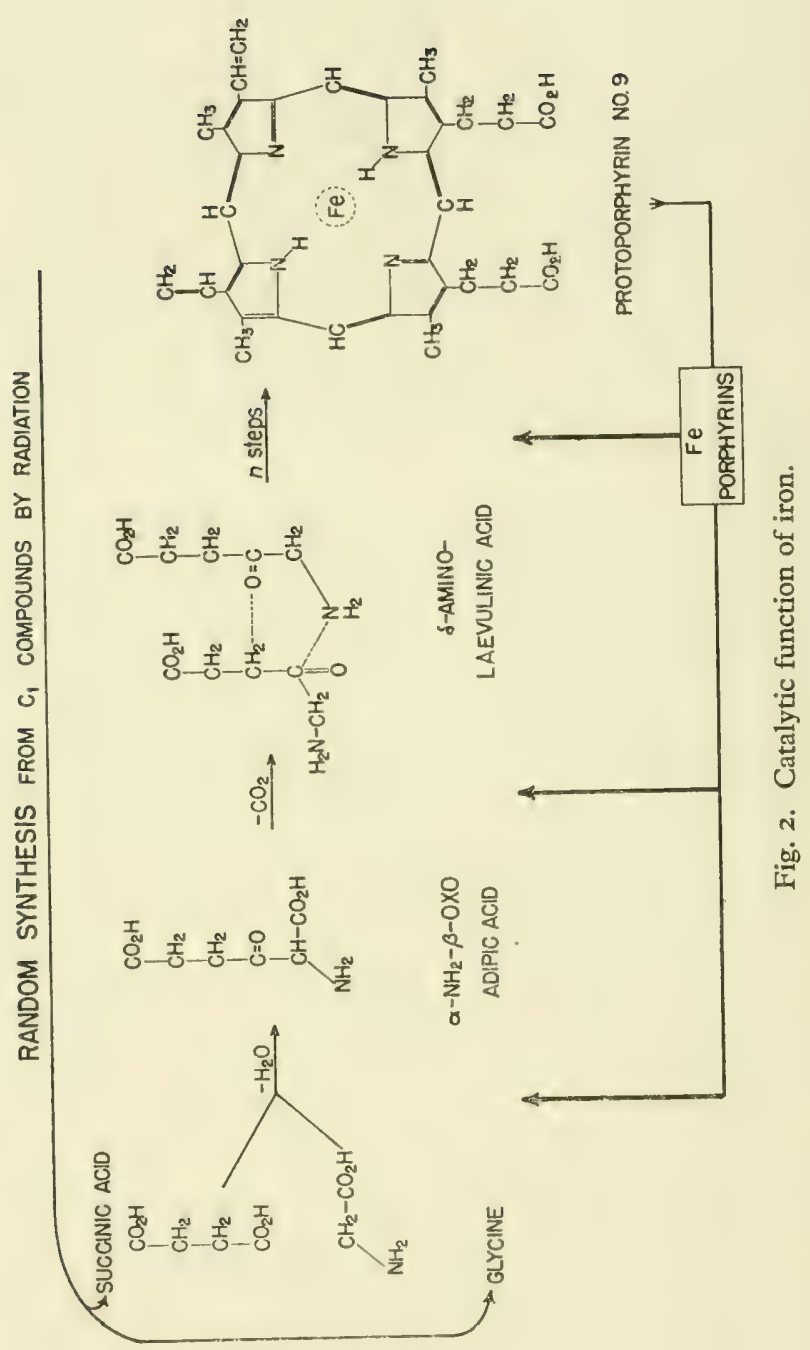



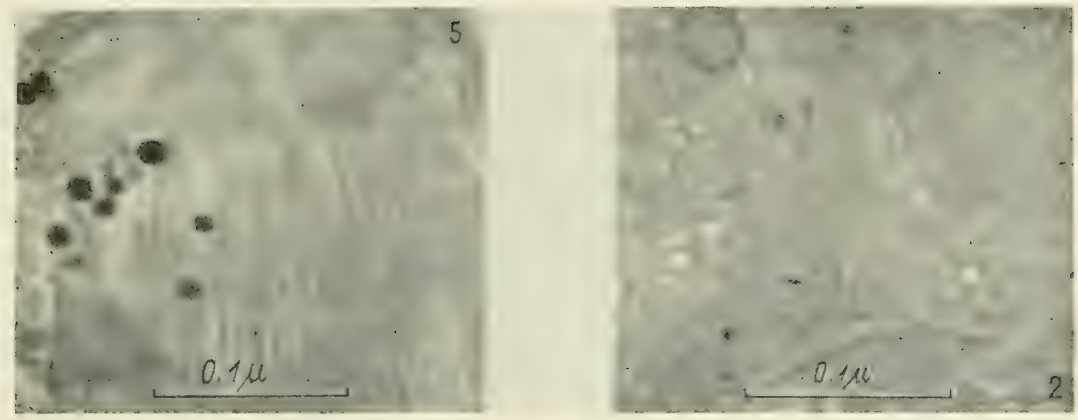

Fig. 4. Comparison of structure of mitochondria and chloroplasts (from 'Siöstrand'). 

We can therefore follow van Niel and reaffirm the suggestion that the photochemical apparatus in the green plants is primarily concerned with the splitting of the water molecule and the generation of reducing agent and intermediate oxidant. The latter (intermediate oxidant) will eventually find its way into molecular oxygen. The former (reducing agent) will be used to reduce the compounds formed by combination of carbon dioxide with suitable intermediates in the cell. From our knowledge of the nature of the carbon cycle it is already clear that ATP is also required for this latter process, and this ATP may either be generated by oxidative phosphorylation or by a recombination of the intermediate oxidant' with some 'intermediate reductant' that has been formed by direct photolysis. Thus, we can suppose that the reaction sequence which is now used by green plants for the reduction of carbon dioxide was developed independently of the photosynthetic apparatus, and presumably later coupled to the energy-capturing and transforming mechanism which the photosynthetic apparatus represents.

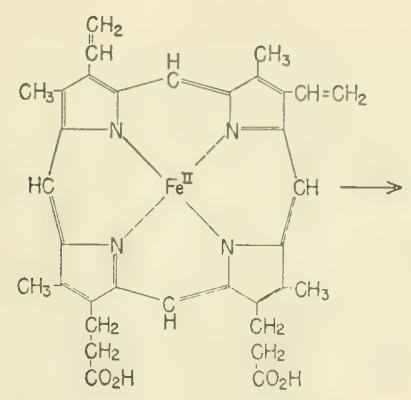

HAEM las in Haemoglobin and Cytochrom)

FE - PROTOPORPHYRIN NO.9

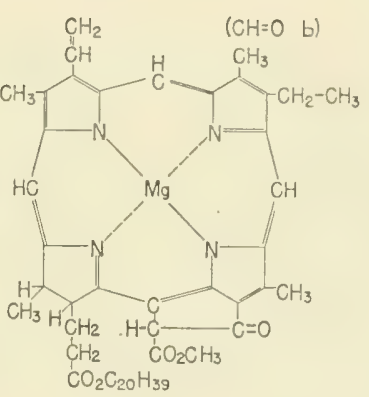

CHLOROPHYLL a

Fig. 3. Structural relationships between haem and chlorophyll $a$.

We must now examine the nature of the photochemical apparatus to see if we can discover something of its origin. The primary energy-trapping molecule is, of course, a porphyrin, chlorophyll. In recent years, the work of Granick has clearly indicated, if not conclusively demonstrated, that present-day synthesis of chlorophyll is a branch in the synthetic sequence leading also to the haems. This branch seems to occur just before the insertion of the iron into the porphyrin ring (Fig. 3).

We can thus see that the most likely course for the evolution of the photosynthetic apparatus involved the prior existence of the porphyrin type of catalytic structure. This catalytic structure was evolved not in response to the existence of sunlight, but rather in reponse to the other evolutionary driving force, which we have already seen operative in the development of the porphyrin nucleus, namely, the oxidative catalysis at which the iron compounds of the porphyrins are so efficient. This leads to the suggestion that the development of the porphyrin either was not directly dependent upon the existence of oxygen 
in the primordial atmosphere but occurred in response to its function in other oxidative dismutations not involving molecular oxygen, or that there was some molecular oxygen in the Earth's atmosphere prior to the advent of the photosynthetic apparatus which now produces it.

The development of such highly organized structures as are now found in the organelles of the cells, such as the chloroplasts and mitochondria, seems to be incompatible with the penetration of very much of the ultraviolet radiation from the sun in the wavelength around $2500 \AA$ which would have occurred had there been no oxygen in the atmosphere. To-day, of course, the oxygen in the upper atmosphere is photodissociated by this very ultraviolet light and is thus converted into quantities of ozone which, in turn, strongly absorbs in the region between $2200 \AA$ and $3000 \AA$. While it is possible to conceive of the development of heterotrophic organisms in the shelter of deep water and thus not exposed to the destructive ultraviolet, it is difficult to conceive of the evolution of a photosynthetic apparatus, even a primitive one, also in the same environment, since there would be little visible light available either for the evolutionary selective mechanism.

Thus we are constrained to believe not only was the evolution of higher organisms delayed until the appearance of appreciable amounts of oxygen in the atmosphere, but also the evolution of the porphyrin catalysis itself and some of the more complex structural elements in living cells had to await this protection. Presumably, it came aboui by virtue of the photodissociation of water into hydrogen and oxygen followed by the escape of the hydrogen from the gravitational field of the Earth, leaving behind an appreciable quantity of oxygen, even though it is now entirely photosynthetic in origin. We can thus envisage the development of the highly organized structural units which we see to-day in the form of mitochondria prior to the development of the chloroplasts and of the photochemical apparatus. The similarity in the structure of these two organelles is very striking, and it is not unreasonable to suppose that the latter had its origin in the former (Fig. 4).

Thus, the porphyrin molecule and the structural unit into which it is built had independent evolutions. Only at a much later time did the coupling of the optical properties of the porphyrin molecule to the energy demands of the carbonreduction cycle take place. This presumably occurred at a time when there may have already been a rudimentary photosynthetic energy-yielding apparatus in the near ultraviolet, perhaps using sulphur compounds as direct absorbers. The more efficient energy-capturing molecule, which the porphyrin is, could not be used in energy conversion until it was divested of the iron atom which was its principal reason for being. The reason for this is that the requirement for an efficient energy conversion carries with it the requirement for a long-lived excited state after the capture of the quantum. The iron porphyrin, although absorbing a good deal of visible light, cannot have a very long life in the excited state because of the presence of the magnetic iron atom in the molecule. The inhomogeneous magnetic field surrounding the iron atom breaks down the tripletsinglet selection prohibition and does not allow a long-lived triplet state of porphyrin. However, if the iron is replaced by magnesium, or some other dia- 
magnetic, bivalent cation such as zinc, then this molecule can have a long-lived triplet state, which is essential for the encrgy-migration and conversion with any high degree of efficiency.

I suspect that the rudimentary beginnings of a chlorophyll-type of photosynthesis may have occurred in the precellular period, in a period in which one had already scen the appearance of lipid-type coacervates and in which the disclike molecules of chlorophyll could assume a pseudo-crystalline arrangement, facilitating the energy transport and conversion. In all probability, it was at this point, or very near this point, that the cellular habit of life took shape. Finally, the generation of the oxygen-evolving mechanism, perhaps requiring the participation of the carotenoids and other such materials, occurred, leading to the higher plants, and to the whole potential of oxidative evolution. 


\title{
The Nature of the Forces Operating in the Process of the Duplication of Molecules in Living Organisms
}

\author{
LINUS PAULING \\ California Institute of Technology, Pasadena, Calif., U.S.A.
}

EACH FORM of life has the power of manufacturing molecules characteristic of that form. A human being manufactures kinds of molecules, including probably some tens of thousands of different kinds of proteins, which are characteristic of him. He passes on to his child the power of manufacturing many of the same molecules. A virus particle, with the collaboration of a suitable host, may have as immediate progeny hundreds or thousands of virus particles that are made in its own image.

It may be that life originated on Earth when, in the 'hot, thin soup' containing thousands and thousands of different kinds of molecules that had been formed by more or less random chemical reactions, there was, by chance, formed a molecule with the power of catalysing the synthesis of replicas of itself.

Whatever the details of the process of duplication are, it is characteristic of living organisms that they contain molecules with the power of manufacturing duplicates of themselves. A human being has molecules of haemoglobin in his red cells; his children have molecules of haemoglobin in their red cells, usually identical with those in the red cells of the parent. A human being has molecules of deoxyribonucleic acid in the nuclei of his cells; his children have molecules of deoxyribonucleic acid in the nuclei of their cells; and it is believed that many of these molecules are identical in structure with those of the parent.

In order to understand the nature of life and the origin of life we need to know what the process is by which molecules are able to duplicate themselves, what he forces are that are operating during the process.

It is my belief that the process of duplication of molecules and the other processes that show biological specificity involve not only the interatomic forces comprised under the name of chemical bonds but also the weak forces that operate between atoms - the forces of van der Waals attraction, electrostatic attraction between charged groups, and the formation of hydrogen bonds; and that in general biological specificity is the result of the especially strong interaction, involving collaboration of these weak forces, that can occur between molecules that are complementary in structure. It is this thesis that will be presented in the following paragraphs.

Let us ask how a molecule $A$, which we may call a gene, could produce a replica of itself. One conceivable way is that some special stabilizing force of interaction occurs between two identical molecules, $A$ and $A$, such that one 
molecule $\mathrm{A}$ is able to influence its environment so as to lead to the production directly of the second molecule A. This possibility is appealing because of its simplicity. The suggestion was made by Jordan [I] that the quantum-mechanical resonance phenomenon might lead to a special stability of an aggregate of two identical molecules, AA, relative to an aggregate of two similar but non-identical molecules, AB. A simple analogy is with a system of one electron and two identical nuclei, in which there is a strong interaction (formation of a one-clectron bond) as compared with a system of one electron and two non-identical nuclei, in which there is only a weak interaction, the electron remaining attached preferentially to one of the nuclei. It was pointed out by Pauling \& Delbrück [2], however, that the special quantum-mechanical interaction energy between large identical molecules, such as protein molecules, is negligible in comparison with the interaction energy of either identical or non-identical large molecules, and that this mechanism could not lead by a direct process to the synthesis of replicas of a molecule. Instead, Pauling \& Delbrück suggested that the process of duplication is a two-step process, involving the use of molecule $A$ as a template for the synthesis of the complementary molecule, $\mathrm{A}^{-1}$, and then the use of $\mathrm{A}^{-1}$ as a template for the synthesis of a molecule complementary to it, and identical with A.

The idea of complementariness in structure as the cause of biological specificity is an old one. The principal evidence for the theory comes from the field of immunochemistry, and the first, rather vague, suggestion of complementariness was contained in Ehrlich's lock-and-key explanation of immunological specificity. The idea that antigen molecules and the homologous antibody molecules have complementary molecular structures was suggested by Breinl \& Haurowitz [3], Alexander [4], and Mudd [5], in the period 1930 to I932, and a detailed theory of the structure and process of formation of antibodies based upon the principles of molecular structure was formulated in r940 [6].

Already in 1940 there was available a considerable amount of evidence in support of the theory of complementariness in structure of antigen and antibody, in the experimental results obtained by Landsteiner and collaborators through the study of the serological properties of azoproteins containing haptenic groups of known simple structure. A great amount of additional evidence in support of the theory was then gathered by the execution of experiments designed specifically to test the theory [7]. For example, it was found that the introduction of a methyl group in place of a meta hydrogen atom in the benzene ring of the benzoate ion decreases the combining power of the hapten with antibody molecules homologous to $p$-azobenzoic acid azoprotein to about one-fifth of the combining power of the benzoate ion itself. This fact is explained in a simple way as the result of a resistance to fitting the larger methyl group, which has an effective radius of about $2 \cdot 0 \AA$, into the region of the antibody which in the process of its synthesis was occupied by a hydrogen atom of the haptenic group of the immunizing azoprotein, this hydrogen atom having an effective radius of about $I \cdot 2 \AA$. The only conclusion that can be drawn from this experiment is that the antibody is closely complementary in structure to the haptenic group of the azoprotein, and that the fit between the complementary structures is a close one, 
to within less than $0.8 \AA$, a small fraction of an atomic diameter. It has also been shown that a negatively charged group is present in the antibody at very nearly the minimum distance of approach to a positively charged group in the haptenic group (the trimethylphenylammonium cationic group) of an azoprotein used in producing the antiserum. Many observed ratios of combining powers of different haptens could be explained only in terms of the formation of specific hydrogen bonds between antigen and antibody.

The theory that the process of duplication of the gene is a two-step process involving at each stage the formation of a structure complementary to that of the molecule acting as a template has been given strong support through the formulation of the Watson-Crick structure of deoxyribonucleic acid [8]. Evidence that genes are molecules of nucleic acid rather than molecules of protein has been gathered from several sources in recent years. The efforts to determine the molecular structure of fibres of deoxyribonucleic acid culminated in the formulation by Watson \& Crick of their structure, which involves two complementary molecules twisted about one another to form a double helix. At any level in one of the molecules there may be a nucleotide with any one of the four nitrogen bases adenine, thymine, guanine, or cytosine. The sequence of nitrogen bases in one of the polynucleotide chains may be, so far as we know now, completely arbitrary. However, according to the Watson-Crick structure the nature of the second polynucleotide chain is completely determined by that of the first; the second chain must be complementary to the first, with thymine wherever the first chain has adenine, adenine wherever the first chain has thymine, cytosine wherever the first chain has guanine, and guanine wherever the first chain has cytosine. This complementariness in structure is the result of the ability of adenine and thymine to form two hydrogen bonds with one another, and of guanine and cytosine to form three hydrogen bonds with one another. (Watson \& Crick proposed that guanine and cytosine form only two hydrogen bonds with one another, of a nature, however, somewhat different from those in the adenine-thymine pair; it was then pointed out by Pauling \& Corey [9] that there are three hydrogen bonds in the guanine-cytosine complex.) With Watson \& Crick [Io], we may accept as a reasonable molecular mechanism for the duplication of the double polynucleotide chain of deoxyribonucleic acid a process that involves the separation of the two chains, each of which then serves as the template for the synthesis of the other. In the nomenclature used above, we may describe the Watson-Crick double helix as $\mathrm{AA}^{-1}$; its process of duplication would involve the separation into $\mathrm{A}$ and $\mathrm{A}^{-1}$, each of which would then serve for the synthesis of a complementary structure, giving $\mathrm{AA}^{-1}$ and $\mathrm{A}^{-1} \mathrm{~A}$, two double molecules identical with the original one, and each containing onehalf of the original double molecule.

We may ask whether it might not be possible that the two chains $\mathrm{A}$ and $\mathrm{A}^{-1}$ of the Watson-Crick doublc helix are really a single chain, $\mathrm{A}$ and $\mathrm{A}^{-1}$ being attached to one another at one end. An argument has been presented to show that this suggestion is to be rejected [II]. If $\mathrm{A}$ and $\mathrm{A}^{-1}$ were separate chains, the process of duplication of $\mathrm{AA}^{-1}$ would be as described above. If they were the same chain, the process of duplication would consist in untwisting the double 
helix, to form the extended chain $\mathrm{A}-\mathrm{A}^{-1}$, with length twice as long. This would then serve to produce a compound helix

$$
\begin{aligned}
& A-A^{-1} \\
& A^{-1}-A
\end{aligned},
$$

with the same total length. This long double helix would then have to be untwined, and each of the halves $A-A^{-1}$ and $A^{-1}-A$ would coil to form the original complex and its duplicate. Therc would thus be two processes of untwining involved, rather than a single one. If the second process of untwining did not occur, we might be satisfied to accept the long double chain as a complex of a molecule $\mathrm{A}-\mathrm{A}^{-1}$ and its self-complementary duplicate, $\mathrm{A}^{-1}-\mathrm{A}$. This process cannot, however, be accepted, because there is no mechanism for ensuring the retention of complementariness of one end of the chain and the other end. Mutation might occur, changing the nature of one end or the other end, and if the chain in the process of duplication did not fold at some stage into the configuration of the short double helix, the lack of complementariness of the two ends of the chain would not interfere at all with the process of duplication, and this property of self-complementariness would be lost.

There is a significant difference between the manufacture of antibodies and the duplication of genes. The antiserum that is produced in response to the injection of an antigen is highly heterogeneous (the heterogeneity may correspond to the range of a factor of ten thousand in the equilibrium constant for combination of antibody and homologous antigen) [12], whereas the duplication of genes seems to be perfect, or nearly perfect. The manufacture of an antibody molecule is a process that occurs only once, so far as that molecule is concerned, and the molecule is not itself then used as a template. If the conditions within the cell in which the antibody molecule is being manufactured happen to favour the formation of a good molecule with large complementariness to the antigen molecule, the combining constant will have a large value, whereas if the conditions are unfavourable the combining constant for the antibody molecule that is formed will have a small value. There is no process of trial and error, such that the system can improve in the manufacture of antibodies against the injected antigen. The process of duplication of genes is different. A gene that had undergone mutation -for example, that has been damaged as the result of the absorption of a quantum of radiation-may serve as a template for the manufacture of a complementary molecule; we may call the mutated gene $A_{1}^{-1}$. The complementary molecule will then serve as a template, in the next cell division, for the manufacture of a molecule complementary to it, which we may call $\mathrm{A}_{2}$. In general we would not expect $A_{2}$ to be an exact duplicate of $A_{1}$. The process of two-stage duplication would then continue: $\mathrm{A}_{2}{ }^{-1}, \mathrm{~A}_{3}, \mathrm{~A}_{3}{ }^{-1}, \mathrm{~A}_{4}, \mathrm{~A}_{4}^{-1}, \ldots$ If after any number of duplications of this sort a molecule, $A_{n}$, happens to be formed that is especially well suited to serving as a template for the manufacture of a duplicate of itself, the process of duplication from then on would be a reliable one. The mechanism of heredity thus permits the ultimate discovery of a mutated gene that undergoes true duplication; but the mutated gene may, and in general will, not be the original gene that has been damaged by $\mathrm{X}$-radiation or produced in some other 
way by a primary process, but will be a product obtained after many steps of two-stage duplication.

The details of the process by means of which specific molecules of protein are manufactured by molecules of nucleic acid, which serve as the templates for their manufacture, are not yet known, but there is no reason to doubt that this process takes place. There are two aspects of the structure of proteins that may be differentiated. One is the ordering of amino acid residues into the proper sequence in the polypeptide chain, and the other is the folding of the polypeptide chain into the configuration characteristic of the native protein molecule. It is likely that the principal function of the gene in the process of manufacture of a protein molecule is to select the right amino acid molecules and to order their residues into the right sequence in the polypeptide chain. The experiments of Anson and Mirsky, showing that some proteins (hacmoglobin and trypsin) that have been subjected to alkali denaturation, causing some unfolding of the polypeptide chains, can, by proper treatment, be brought back to essentially the native configuration, suggest that the process of folding of the polypeptide chains into the correct configuration may occur automatically, without the help of a template, after the polypeptide chains have been synthesized.

We may ask whether or not it is possible for the genic template to function perfectly in ordering amino acid residues during the process of synthesis of polypeptide chains. An analysis of the forces operating between the amino acids and the genic template [13] has led to the prediction that the process must involve occasional errors, and that some protein molecules that are manufactured should have a sequence of amino acid residues slightly different from that in other molecules of the same protein. It is possible to make some predictions about the nature of the errors. For example, it may be predicted that it is highly unlikely that any amino acid residue other than a residue of glycine would occupy a glycine locus in the polypeptide chain; the selection of glycine by the template must involve the fitting of the hydrogen atom that serves as the side chain in glycine into a cavity in the template that is just large enough to accommodate a hydrogen atom, and is accordingly too small to accommodate the methyl group of alanine or any other side chain, and the van der Waals repulsion energy becomes so great when atoms are brought into contact at a distance even $0.5 \AA$ less than the normal van der Waals contact distance that the selectivity of this template for glycine can be expected to be essentially perfect. On the other hand, a part of the template that is complementary to alanine would have a cavity for the methyl group that would be small enough to reject all amino acids except alanine and the smaller one, glycine, and the selection of alanine rather than glycine would have to be made through the operation of the greater van der Waals attraction (London electronic dispersion energy) of the template for the methyl group than that for the hydrogen atom; the estimated magnitude of the energy difference leading to the selection of alanine rather than glycine has led to the prediction that the probability of an error involving the introduction of glycine in an alanine locus should be as much as $5 \%$. It may well be that the calculation of the energy difference has been made with too much caution, and that the predicted probability of an error of this sort is no more than $I \%$. 
The careful scarch for errors in the synthesis of protein molecules should lead to information that would either support or discredit the template theory of biological specificity. One careful study of this sort has already been made. D. Allen \& W. A. Schroeder [unpublished observation] have analysed haemoglobin from normal adult human beings and from patients with phenylpyruvic oligophrenia, who have in their plasma and cerebral-spinal fluid a concentration of phenylalanine 25 or 50 times greater than that in normal individuals. They found no difference in the phenylalanine content of the two haemoglobins, to within their experimental error, which was less than $3 \%$ (one residue per haemoglobin molecule-the molecule contains about 32 residues of phenylalanine). There are about twelve residues of tyrosine per molecule in that haemoglobin, and this result shows that the probability that a phenylalanine residue will be introduced in place of tyrosine (this is the most likely sort of error involving phenylalanine) as a result of the increased concentration of phenylalanine in the body fluids of the patients with phenylpyruvic oligophrenia is smaller than $8 \%$. at is possible, of course, that the introduction of the phenylalanine residue at I tyrosine locus would change the properties of the haemoglobin molecule enough to cause it to be rejected by the red cell.

The extent to which the properties of a molecule are determined by the folding of the polypeptide chains is suggested by the available information about the difference in structure of normal adult human haemoglobin (haemoglobin A) and sickle-cell-anaemia haemoglobin (haemoglobin S) [I4]. The difference in electrophoretic mobilities of these two forms of haemoglobin corresponds to a difference in electric charge per molecule of about three electronic units. The analyses that have been made of amino acid composition show no difference in composition within experimental error; in particular, there is no difference in acidic groups or basic groups great enough to explain the difference in charge of three electronic units. Moreover, the change in electrophoretic mobility of the globins obtained from these haemoglobins on slight denaturation, which causes the molecules to acquire essentially the same electrophoretic mobility shows clearly that the electric charge is determined in considerable part by the way in which the polypeptide chains are folded.

There is now available a great deal of information about possible configurations of polypeptide chains. Precise determinations of the structure of crystals of amino acids, simple peptides, and other substances closely related to proteins have been made by Professor Robert B. Corey, Dr E. W. Hughes, and their collaborators, as well as, in recent years, by other investigators. It has been found that the interatomic distances and bond angles are essentially constant in this group of substances. The distances found are $a \mathrm{C}-\mathrm{C}^{\prime}=\mathrm{I} \cdot 53 \AA, \alpha \mathrm{C}-\mathrm{N}=\mathrm{I} \cdot 47 \AA$, $\mathrm{C}^{\prime}-\mathrm{N}=\mathrm{I} \cdot 32 \AA, \mathrm{C}^{\prime}-\mathrm{O}=\mathrm{I} \cdot 24 \AA$, angles $\mathrm{N}-a \mathrm{C}-\mathrm{C}^{\prime}=\mathrm{II} 0^{\circ}, a \mathrm{C}-\mathrm{C}^{\prime}-\mathrm{N}$ $=\mathrm{II} 4^{\circ}, \mathrm{C}^{\prime}-\mathrm{N}-a \mathrm{C}=\mathrm{I} 23^{\circ}, \mathrm{O}-\mathrm{C}^{\prime}-\mathrm{N}=\mathrm{I} 25^{\circ}$. The principal degrees of freedom of the polypeptide chain, not determined by these parameters, are the azimuthal angles about the two single bonds $a \mathrm{C}-\mathrm{C}^{\prime}$ and $a \mathrm{C}-\mathrm{N}$. The stable configurations of polypeptide chains that have been reliably recognized so far (the a helix, the parallel-chain pleated sheet, the antiparallel-chain pleated sheet, and the polyglycine-II structure) all involve azimuthal orientations 
around these bonds such that $\mathrm{N}-\mathrm{H}$... O hydrogen bonds are formed, with the nitrogen-oxygen distance approximately $2 \cdot 79 \AA$.

In all of these configurations of polypeptide chains and in all of the structures for simple peptides and amides that have been reliably determined there is one structural feature that would not be predicted by the classical structure theory of organic chemistry. This is the planarity of the amide group. It is found by experiment that the planarity of the group consisting of the $\mathrm{C}^{\prime}$ atom, the $\mathrm{N}$ atom, and the four atoms bonded to them is preserved to within a mean deviation less than $0.05 \AA$ from the median plane. This structural feature was predicted in a straightforward way [ $\mathrm{I}_{5}$ ] by use of the theory of resonance, which is an extension of the classical chemical structure theory. According to the theory of resonance the structure of the amide group, as of other molecules for which a single distribution of chemical valence bonds does not provide a satisfactory representation, can be described in terms of two distributions (in some cases more) of the valence bonds. For the amide groups we write the two following electronic structures:

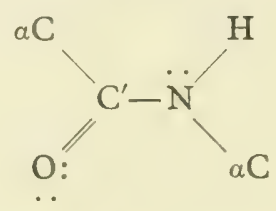

I

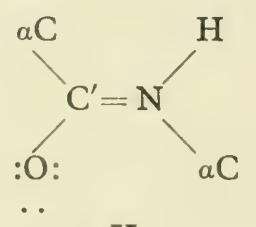

II

The group may be described as having a structure that represents the superposition of these two electronic structures: it may be described as a hybrid of these structures, with the $\mathrm{C}^{\prime}-\mathrm{N}$ bond a bond with partial double-bond character. The observed distance $\mathrm{C}^{\prime}-\mathrm{N}, \mathrm{I} \cdot 32 \AA$ ( $0.15 \AA$ less than the distance $\left.a \mathrm{C}-\mathrm{N}\right)$, indicates about $40 \%$ double-bond character for this bond, so that the two structures I and II shown above are described as contributing in the ratio about $60 \%$ to $40 \%$ to the structure of the amide group. With $40 \%$ double-bond character for the $\mathrm{C}^{\prime}-\mathrm{N}$ bond, the group can be expected to have the property of coplanarity to an extent that can be described quantitatively as about $40 \%$ of that of a molecule containing the carbon-carbon double bond.

The theory of resonance has been subjected to severe criticism; as I understand the criticism, it is based largely upon the fact that the theory involves the use of structures (such as the structures I and II given above for the amide group, or the two Kekule structures for benzene) that do not have independent existence in reality. It is true that these structures, use of which is made in the theory of resonance, are idealizations, and do not have existence in reality. However, if the argument were to be accepted as a valid argument against the theory of resonance and the theory were in consequence to be abandoned, it would be necessary also, for the sake of consistency, to abandon the whole structure theory of organic chemistry, because the structural elements that are used in classical structure theory-the carbon-carbon single bond, the carboncarbon double bond, etc.-also are idealizations, having no existence in reality $[I 6, I 7]$. There is no rigorous way of showing by experiment that two of the 
carbon atoms in the cyclohexene molecule, for example, are connected by a double bond. Every molecule has a structure, as was pointed out for the first time by Butlerow, and the properties of the substance consisting of these molecules are determined by their structure: we may say that the cyclohexene molecule is a system that can be shown experimentally to be resolvable into six carbon nuclei, ten hydrogen nuclei, and forty-six electrons, and that can be shown to have certain other structural properties, such as values $I \cdot 33 \AA$, I.54 $\AA$, etc., for the average distances between nuclei in the molecule in its normal state; but it is not resolvable by any experimental technique into one carbon-carbon double bond, five carbon-carbon single bonds, and ten carbon-hydrogen bonds-these bonds are theoretical constructs, idealizations, with the aid of which the chemist during the past one hundred years has developed a convenient and extremely valuable theory. The theory of resonance constitutes an extension of this classical structure theory of organic chemistry; it is based upon the same idealizations, the bonds between atoms, as classical structure theory, with the important extension that in describing the benzene molecule or the amide group two arrangements of these bonds are used, rather than only one. The theory of resonance in chemistry is an essentially qualitative theory, which, like the classical structure theory, depends for its successful application largely upon a chemical feeling that is developed through practice; the theory is a part of chemical structure theory, which has an essentially empirical (inductive) basis; it is not just a branch of quantum mechanics.

The pyrimidine and purine groups of nucleic acids provide another interesting application of the theory of resonance. The molecules of adenine, guanine, thymine and cytosine, and of other pyrimidines and purines, have their carbon, nitrogen and oxygen atoms in a single plane, as is predicted for molecules with structures that can be described as involving resonance among valence-bond structures in which the double bonds occupy a number of different positions, so that the property of planarity characteristic of the atoms adjacent to a double bond becomes associated with nearly all of the bonds in the molecule. The observed inter-atomic distances in these pyrimidines and purines [9] are also found to correspond not to $0 \%$ or $100 \%$ double-bond character, but to intermediate amounts of double-bond character.

I think that it is likely that, as further investigations of haemoglobins A and S are carried out, it will be found that the apparently very small difference in aminoacid composition of these two haemoglobins, amounting to perhaps a difference in only two residues per molecule, leads to a large difference in the way in which the polypeptide chains are folded, and that this difference in folding changes the properties of the molecules significantly, in particular the ionization constants of some acidic or basic groups.

The discovery of the abnormal varieties of human haemoglobin has led to some quantitative information about the rate of evolution of human beings. It was shown by Allison that the sickle-cell heterozygotes, with a mixture of haemoglobins $\mathrm{A}$ and $\mathrm{S}$ in their red cells, are protected against malaria. We may imagine that in a highly malarial region a mutation that converted the gene for A into the gene for $\mathrm{S}$ occurred, that after some generations there were a number 
of heterozygotes AS in the population, and that of the progeny of two heterozygotes the $25 \%$ of type AA would die of malaria, the $25 \%$ of type SS would die of sickle-cell anaemia, and the $50 \%$ of type AS would be protected against malaria and would not have the disease sickle-cell anaemia. Under these circumstances the heterozygotes would rapidly replace the original type AA. In some highly malarial regions in Africa the incidence of heterozygotes AS is as great as $50 \%$. If the assumption is made that all of the sickle-cell homozygotes SS die without progeny, we may calculate from this incidence of the heterozygotes that the advantage that the heterozygotes have over the normal individuals AA is $50 \%$-there will be an increase by the factor I 5 in the ration of heterozygotes to normal individuals in each generation. This is a very great increase, such that within one thousand or two thousand years the mutant type of human being, carrying a sickle-cell gene, would be found to have largely displaced the wild type, without the mutant gene. So far as I know, this is the only quantitative information that is available about the rate of evolution in man. The information shows that the process of evolution can, under favourable circumstances, be a very rapid one, and we may understand how it is that the process of selection of a pool of favourable genes, such as is now represented in the germ plasm of the human race, could have taken place so effectively during the period as short as $10^{9}$ years since the origin of life on Earth.

\section{REFERENCES}

I. P. Jordan, Phys. Z., 39, 7II, 1938; Z. Phys., II3, 431, I939; Fundam. radiol., 5, 43, 1939; Z. ImmunForsch., 97, 330, I940.

2. L. Pauling \& M. Delbrück, Science, 92, 77, 1940.

3. F. Breini \& F. HaUrowitz, Hoppe-Seyl.Z., 192, 45, I930.

4. J. AleXANDER, Protoplasma, 14, 296, I93I.

5. StUART MUdD, $f$. Immunol., 23, 423, 1932.

6. L. Pauling, f. Amer. chem. Soc., 62, 2643, I940.

7. L. Pauling, D. Pressman, D. H. Campbell, C. Ikeda \& M. Ikawa, F. Amer. chem. Soc., 64, 2994, 1942, and later papers.

8. J. D. Watson \& F. H. C. CRICK, Nature, Lond., I7I, 737, I953; F. H .C. CRICK \& J. D. Watson, Proc. Roy. Soc., 223A, 80, 1954.

9. L. Pauling \& R. B. Corey, Arch. Biochem. Biophys., 65, I64, I956.

IO. J. D. WATSON \& F. H. C. CRICK, Nature, Lond., I7I, 964, I953.

II. L. Pauling, in Aspects of Synthesis and Order in Growth. Princeton University Press, p. 3, 1955 .

12. L. Pauling, D. Pressman \& A. L. Grossberg, f. Amer. chem. Soc., 66, 784, 1944.

13. L. Pauling, Festschrift Prof. Dr. Arthur Stoll. Birkhaüser, Basel, p. 597, 1957.

I4. L. Pauling, H. A. Itano, S. J. Singer \& I. C. Wells, Science, II0, 543, I949.

15. L. Pauling, Proc. nat. Acad. Sci., Wash., 18, 293, 1932.

I6. L. Pauling, Les Prix Nobel en I954. Norstedt \& Söner, Stockholm, p. 91, 1955.

17. L. Pauling, in Perspectives in Organic Chemistry, p. I. Interscience, New York and London, 1956.

Contribution No. 2207 from the Gates and Crellin Laboratories of Chemistry, Califormia Institute of Technology, Pasadena, California, U.S.A. 


\title{
The Occurrence of Amino Acids in Nature
}

\author{
R. L. M. SYNGE
}

The Rowett Research Institute, Bucksburn, Aberdeenshire, Scotland

THESE ARE the first two sentences from The Specificity of Serological Reactions by Karl Landsteiner [I]. 'The morphological characteristics of plant and animal species form the chief subject of the descriptive natural sciences and are the criteria for their classification. But not until recently has it been recognized that in living organisms, as in the realm of crystals, chemical differences parallel the variation in structure.'

Since this was written, we have seen great advances in our understanding of proteins and amino acids, and especially in the range of the living organisms which have been studied chemically in this respect. My purpose is to try to extract from the mass of scattered observations, made with a variety of motives, such generalizations as appear relevant to the subject of the Symposium.

It is convenient to consider amino acids as occurring in living organisms: (a) chemically combined in proteins; $(b)$ chemically combined in peptides and other compounds of relatively low molecular weight; $(c)$ free.

The distinction between $(a)$ and $(b)$ is somewhat arbitrary. It has been convenient to draw the line at about mol. wt. 10,000, but the less well-defined materials have often been placed in one class or the other on the basis of solubility in hot water, in aqueous trichloroacetic acid or of some other easily observed property. Compounds having a specially simple amino acid composition have often been placed in class $(b)$ while having obviously high molecular weight.

Despite the arbitrary and empirical nature of this distinction, it is nevertheless possible to make a generalization about class $(a)$, the true proteins. These are often found to be 'conjugated' with 'prosthetic groups' varying very widely in chemical nature. However, the amino acid residues are nearly always the L-isomers of the following: glycine, alanine, valine, leucine, isoleucine, serine, threonine, cyst(e)ine, methionine, aspartic acid, asparagine, glutamic acid, glutamine, proline, phenylalanine, tyrosine, tryptophan, lysine, arginine and histidine. It is not twenty years since the last of these twenty amino acids, threonine, was proved to be a protein constituent. Since then, despite intensive search in proteins from a wide variety of living organisms, with use of methods of analysis much better than those previously available, no new amino acid has been found that is generally distributed and a number of the better-studied protein preparations have had all their components accounted for quantitatively from among these twenty common amino acids. Moreover, it is unusual to find more than 
one or two of these twenty amino acids to be absent from a protein preparation. These facts are the more striking when taken together with the fact that in classes (b) and (c) many new species of amino acid have been discovered, as is briefly discussed below.

Of course there are other amino acids which occur only in protein of a particular type, or only in proteins of a limited range of organisms or have some other peculiarity of distribution. Of these, the better-authenticated examples are so few that they may conveniently be mentioned here.

Derivatives resulting from substitution of tyrosine or thyronine with iodine occur in the proteins of the thyroid gland, and have been studied in considerable detail in recent years. Similar compounds, including bromine-substituted derivatives, occur in the proteins of a number of marine organisms, including seaweeds, sponges and corals.

L-Hydroxyproline, in animals, seems characteristically to be present only in connective-tissue proteins of the collagen and elastin groups. Some claims have been made for its occurrence in other proteins but these require verification by isolation, the more so because Radhakrishnan \& Giri [2] found by isolation that L-allohydroxyproline occurs free in sandal leaves (cf. [3]). These authors have listed some of the claims that chemically bound hydroxyproline occurs in nature other than in connective-tissue protein. Besides these, may be mentioned claims in respect of seaweeds [4], diatoms [5], sponges [6], fungi and bacteria [7-12], maple-sap peptides [13] and hydrolysates of soil [14-I5]. A dehydrogenated form of hydroxyproline, 'oxyminaline', was stated by Minagawa [16] to be a component of fungal pectases. The only proteins in which hydroxylysine has so far been found are connective-tissue proteins which also contain hydroxyproline [I7] $a$-Aminoadipic acid has been reported to occur in the seed proteins of maize [I8] and sarcosine in those of the groundnut [19]. Lanthionine was reported as a constituent of locust muscle by Stein [20]. Here there was no ground, as in other cases, for suspecting that it had arisen by degradation of cystine. a-Aminoisobutyric acid has been claimed as a constituent of casein hydrolysates by Oshima, Yoshihara \& Sakamoto [2I].

There is evidence that Se can take the place of $S$ in the proteins of plants grown on Se-rich soil and of animals feeding on these plants [22-24]. This is the only known natural example of incorporation of foreign amino acids into protein which parallels such observations as the incorporation of artificially administered ethionine.

$\alpha \epsilon-$ Diaminopimelic acid has particular interest since it appears to be confined to bacteria and bluc-green algae, among which it has a wide distribution, although it is absent from some groups [12]. (Fujiwara \& Akabori [25] claim to have detccted it in hydrolysates of Chlorella ellipsoidea.) As well as occurring in various non-protcin extracts of bacteria, diaminopimelic acid occurs in a combined form in the extraction residues. It now seems definitely established that it can be a constituent of the peculiar cell-wall material, which is further discussed below. What does not seem well established is whether or not diaminopimelic acid is a constituent of the 'true proteins' of bacteria (cf. [12, 26, 27]). The amino acid described as cystine from alkali-soluble proteins of Coryne- 
bacterium diphtheriae [28] seems more likely to be diaminopimelic acid. Likewise the unknown amino acid [17] found by Samarina et al. [29] in acid hydrolysates of Vibrio spp. which had been extracted with hot saline was probably diaminopimelic acid. Hoare \& Work [30] have described the distribution among bacteria of the different stereoisomers of diaminopimelic acid. The chemically related dipicolinic acid occurs in the spores of Bacillus spp., but it does not seem established whether or not it is chemically bound [3I, 32]. A diaminosuberic acid isomer has been isolated from Actinomycetales by Work [33].

The above seem to be all the less common amino acids which may at present be regarded as occurring in proteins. However, the occurrence of $\mathrm{D}$-forms of the common amino acids must also be considered. It is difficult to assess the significance of the occurrence of $\mathrm{D}$-forms in protein hydrolysates, since the hydrolysis itself may bring about racemization. The racemic phenylalanine found by Martin \& Synge [34] in hydrolysates of wool and by Galaev [28] in bacterial hydrolysates may exemplify this. Even actual inversion during hydrolysis may occur (cf. [35]). These possibilities have helped to complicate still further the long and inconclusive controversy that has raged around the alleged occurrence of D-amino acids in the proteins of cancerous tissues. Nevertheless, it is now clear that $\mathrm{D}$-amino acids occur in protein-like components of some bacteria. The classic instance is the capsular 'polypeptide' of Bacillus spp., whose chemical nature was discovered by Ivanovics \& Bruckner. This has in recent years been studied in great detail both by its discoverers and by many other workers. It seems generally agreed that this polymeric substance is the product of condensing together residues of $\mathrm{D}$-glutamic acid by peptide linkages involving almost exclusively the $\gamma$-carboxyl groups $[36,37]$. It seems also to be established that diaminopimelic acid most commonly occurs in the meso form, having the $\mathrm{D}$-configuration at one end of the molecule and the L-configuration at the other [30]. Such examples have led several workers to examine systematically the configuration of amino acids obtained by the hydrolysis of bacteria. In general L-amino acids predominate, as in other living organisms. D-Amino acids have, however, been found as follows. In Bac. brevis, Konikova \& Dobbert [38] found substantial amounts of D-amino acids. Somewhat smaller amounts were found by Stevens, Halpern \& Gigger [39], who showed that D-aspartic acid contributed substantially to the total. Later Stevens, Gigger \& Bowne [40] showed that the $\mathrm{D}$-amino acids were predominantly $\mathrm{D}$-aspartic acid and $\mathrm{D}$-phenylalanine, and were in a form which could largely be extracted from the bacteria by hot aqueous ethanol; this resembles more closely the antibiotic peptides produced by this organism than 'true protein'. In agreement with this, Vyshepan [4I] found very little D-amino acid in hydrolysates of cells of Bac. brevis or of Bac. mycoides which had been exhaustively extracted with ethanol. Jenkins \& Ciereszko [42] found L-glutamic acid to predominate in cells of Bac. subtilis despite the exclusive presence of $\mathrm{D}$-glutamic acid in the capsular substance. Lawrence \& Halvorson [43] found small amounts of D-amino acids, including D-glutamic acid, in vegetative cells and in spores of Bac. terminalis. Dunn et al. [44, 45] found D-glutamic acid in Lactobacillus spp. Holden \& Snell [46] found D-alanine in Lactobacillus, Leuconostoc, and Streptococcus. Camien [47, 48] found D- 
aspartic acid in organisms of the same genera. Stevens et al. [39] further found significant amounts of D-amino acids in Bacillus subtilis and Torulopsis utilis. The cell-wall material of Gram-positive bacteria has in recent years been shown to yield on hydrolysis sugars, hexosamines and characteristic mixtures of only a few amino acids; the mixtures found have proved of some value to the systematist. These amino acids belong chiefly to the group glycine, alanine, aspartic acid, glutamic acid, lysine and diaminopimelic acid (for references see [49, 50]). It is particularly interesting that the greater part of the D-alanine present in lactic acid bacteria was present in the cell wall [5I]. By adding $\mathrm{D}-\alpha$-aminobutyric acid to the media in which the bacteria were grown, it was to some extent incorporated in the cell-wall material. There is thus no reason as yet for supposing that $\mathrm{D}$-amino acid residues occur in the 'typical proteins' of bacteriathey have only so far been unequivocally demonstrated in 'peptide' fractions soluble in organic solvents and in capsular and cell-wall materials that are not in any sense 'typical proteins'.

Thus it seems that proteins, which are found in substantial amount in every living organism so far studied, form a remarkably compact chemical grouping. When this chemical uniformity is seen in relation to the diversity of important functions which are carried out by proteins in the living organism, it seems very reasonable to postulate a common evolutionary origin for all the organisms at present living on Earth. The observations at least cover a wide range of animals, higher plants, algae, fungi, heterotrophic bacteria and viruses. They are deficient in respect of autotrophic bacteria. Dr Howard Lees tells me that the only evidence of which he is aware relating to the amino acids present in such organisms is for Thiobacillus thio-oxidans [52] and for Nitrosomonas [53]. In both these instances most of the common amino acids and no unusual ones were observed. Fossils have in general proved unsuitable for amino acid analysis*, but it is of interest that a very incomplete amino acid analysis of haemoglobin from a Crossopterygian fish [54] did not give figures much outside the range already observed among Vertebrata.

I have elsewhere engaged in speculation $[55,56]$ as to why these particular twenty amino acids came to make up the proteins of living organisms, and at the Symposium itself no doubt further speculation will take place.

As concerns amino acid residues in substances of class $(b)$, it is important to remember how few substances belonging to this class have been known until recent years. Such substances tend to be thrown away when proteins are prepared by the traditional methods. Systematic searches for such substances have been few, although they are becoming more frequent. The great majority of the substances in this class have been found in the course of trying to purify materials possessing some striking biological activity. Substances in this class have been listed by Bricas \& Fromageot [36]; cf. [57, 58]. The number known is at present increasing very rapidly. It is striking that amino acid residues or related chemical groupings of novel structure or steric configuration occur in a large proportion of those substances possessing specific toxic activities which have been isolated from bacteria and fungi. Many of these amino acids have

* [Note added in proof.] But sec P. H. Abelson, Ann. N.Y. Acad. Sci, 69, 276, 1957. 
been listed by Bricas \& Fromageot. The conclusion seems inescapable that the toxic properties are directly related to the 'abnormal' features of chemical structure, and the student of evolution is tempted to see here a specialized adaptation which does not throw much light on the evolution of protein structure or of the common amino acids. All twenty of these last have been found in compounds of class (b), but of course their lower molecular weights preclude the simultaneous presence of such a wide variety of amino acid residues as is usually present in a protein.

As concerns group (c)-free amino acids-all the twenty common amino acids have been found free in all living organisms where thorough analysis has been made, although often the concentrations in the tissue juices may be very low. There is much evidence that free amino acids are directly involved in the anabolism and catabolism of proteins. However, the common amino acids seem to have many other biochemical functions. Increasingly many amino acids which do not occur in proteins have been found free in living organisms in recent years. The variety seems particularly abundant in higher plants, where a particular amino acid may characterize a particular genus or natural order. Lists have been given by Grobbelaar, Pollard \& Steward [59], Synge [58] and Virtanen [60] but the number increases almost weekly nowadays. It is particularly great for leguminous plants. The evolutionary problem seems somewhat similar to that presented by the alkaloids.

This survey of the natural occurrence of free and combined amino acids in nature serves to emphasize the chemical similarity of all living organisms on the Earth, and thus agrees on the whole with the results of chemical and biochemical studies of other classes of substance. The information will be of great interest when the biochemistry of Mars and of planets in other planetary systems becomes accessible. As concerns the terrestrial origin of life, it seems rather to block the progress of studies, suggesting that most of the chemical evolution of proteins occurred in a remote past from which have survived only organisms which had already arrived at a very standardized chemical structure.

However, the study of amino acids and amino acid composition is only the most elementary part of protein chemistry. Recent progress towards the understanding of the structure and function of proteins opens a fascinating prospect for comparative terrestrial biochemistry in the not too far distant future. The possibility of observing species differences in the structural chemistry of proteins was suggested by early serological work with animal and plant products [I], especially if this is considered together with Landsteiner's own work on the serological specificity of synthetic and natural peptides [6I]. Differences in Fe and $S$ contents of haemoglobins from different species have long been known. We now have a number of examples of species differences between proteins and peptides which have been verified in full chemical detail. Thus, Brown, Sanger \& Kitai [62] have shown that sheep insulin differs from bovine insulin at only one amino acid locus in the whole molecule, while pig insulin differs from both these at two, different loci. The vasopressin from the pituitary gland of the pig has a lysine residue where bovine vasopressin has an arginine residue [63]. Tyrocidines $\mathrm{A}$ and $\mathrm{B}$, produced by one strain of Bacillus brevis, are cyclic decapep- 
tides $[64,65]$ incorporating a pentapeptide sequence which also occurs, repeated twice, in the cyclic decapeptide gramicidin $S$ [66] which is produced by a different strain of Bacillus brevis. In all these cases there is variation in chemical structure without much change in biological activity. Thus study of the interplay of form and function in living organisms, which led up to Darwin's formulation of evolution, is now being extended, as chemical study, to the ultramicroscopic aspects of living organisms. It seems likely that this study, which is bound to be extremely laborious, will throw light on many of the problems of systematics which are still obscure, and particularly on the systematics of micro-organisms. It is likely also that, as we begin to understand something about mechanism as well as structure, we shall be able to deduce much that is relevant concerning the problem of the origin of life.

\section{REFERENCES}

I. K. LANDSTEINER, The Specificity of Serological Reactions. Thomas, Springfield, Ill., 1936.

2. A. N. RADHAKRISHNAN \& K. V. Giri, Biochem. f., 58, 57, I954.

3. A. S. Ramaswamy, F. Indian Inst. Sci., 38A, 62, I956; Chem. Abstr., 50, 8861, 1956.

4. A. Mazur \& H. T. Clarke, F. biol. Chem., 123, 729, 1938.

5. E. M. Low, f. Mar. Res., I4, 199, 1955.

6. S. Akabori, K. Satake \& H. Ono, Science (Japan), 20, I32, I950; Chem. Abstr., 45, I027I, I95I.

7. K. Felix \& I. Pendi, Hoppe-Seyl. Z., 283, I28, I948.

8. E. Work, Biochim. biophys. Acta, 3, 400, 1949.

9. E. Bourland, M. Rouyer \& J. Mathé, Congr. int. Biochin. Paris, Résumés, p. 384, I952; Chem. Abstr., 50, 8774, 1956.

IO. W. KeLLNER \& H. MARTIN, Naturwissenschaften, 4I, I64, I954.

II. D. K. RoY, Naturwissenschaften, 42, I8I, I955.

12. E. WORK \& D. L. DEWEY, f. gen. Microbiol., 9, 394, I953.

13. J. K. Pollard \& T. Sproston, Plant. Physiol., 29, 360, I954.

I4. J. M. BREMNER, Biochem. F., 47, 538, I950.

I5. D. I. Parker, F. J. Sowden \& H. J. Atkinson, Sci. Agric., 32, 163, 1952.

16. T. Minagawa, Proc. imp. Acad. Japan, 21, 33, 37, I945; Chem. Abstr., 47, 151, I953.

17. P. B. Hamilton \& R. A. Anderson, f. Amer. chem. Soc., 77, 2892, 1955.

18. E. WINDSOR, f. biol. Chem., I92, 595, I95I.

19. R. D. Haworth, R. MacGillivray \& D. H. Peacock, Nature, Lond., 167, 1068, I95I.

20. J. M. Stein, Chem. E Ind., p. 774, I955.

21. Y. Oshima, S. Yoshinara \& Y. SAKamoto, f. agric. chem. Soc. Japan, 27, 102, 1953; Chem. Abstr., 49, I4860, I955.

22. M. J. Horn \& D. B. JoNES, f. biol. Chem., 139, 649, I94I.

23. G. S. Weissman \& S. F. Trelease, Amer. F. Bot., 42, 489, 1955.

24. R. O. Leonard \& R. H. Burns, F. Anim. Sci., 14, 446, 1955.

25. T. Fujiwara \& S. Akabori, f. chem. Soc., fapan, Pure Chem. Sect., 75, 990, 1954; Chem. Abstr., 49, 3325, 1955.

26. E. S. Holdsworth, Biochim. biophys. Acta, 9, 19, 1952.

27. G. K. Shrpitsyna. Dokl. Akad. Nauk S.S.S.R., r05, 315, 1955; Chem. Abstr., 50, 7940, 1956.

28. Yu. V. Galaev, Biokhimiya, 20, 673, 1955.

29. O. P. Samarina, M. G. Kritsman, L. M. Yakobson \& A. S. Konikova, Biokhimiya, 15, 287, 1950.

30. D. S. HOARE \& E. WORK, Biochem. F., 61, 562, I955.

31. J. F. POWELl, Biochem. Э., 54, 210, I953.

32. J. J. Perry \& J. W. Foster, f. Bact., 69, 337, 1955.

33. E. WORK, f. gen. Microbiol., 9, ii, 1953. 
34. A. J. P. MARTin \& R. L. M. SYNGe, Biochem. F., 35, 9I, I94I.

35. A. Stoll, A. Hofmann \& 'T. Petrzilka, Helv. chim. Acta, 34, I544, I951.

36. E. Bricas \& C. Fromageot, Advanc. Protein Chem., 8, I, I953.

37. S. G. WALEY, F. chem. Soc., p. 517, 1955.

38. A. S. KoNikova \& N. N. DOBberT, Biokhimiya, I3, II5, 1948.

39. C. M. Stevens, P. E. Halpern \& R. P. Gigger, f. biol. Chem., 190, 705, I95I.

40. C. M. Stevens, R. P. Gigger \& S. W. Bowne, f. biol. Chem., 212, 46I, I955.

4r. E. D. Vyshepan, Biokhimiya, 19, 490, I954.

42. L. T. Jenkins \& L. S. CiereszKo, f. biol. Chem., I9I, 305, I95 r.

43. N. L. LAWrence \& H. O. Halvorson, F. Bact., 67, 585, 1954.

44. M. S. Dunn, M. N. Camien, S. Shankmian \& H. Block, f. biol. Chem., 168, 43. 1947.

45. M. N. Camien, A. J. Salle \& M. S. Dunn, Arch. Biochem., 8, 67, 1945.

46. J. T. Holden \& E. E. SNell, F. biol. Chem., 178, 799, 1949.

47. M. N. Camien, Proc. Soc. exp. Biol., N.Y., 77, 578, 195 I.

48. M. N. Camien, f. biol. Chem., 197, 687, 1952.

49. C. S. Cummins \& H. HaRris, f. gen. Microbiol., I4, 583, 1956.

50. S. Guex-Holzer \& J. TOMcsik, f. gen. Microbiol., I4, I4, 1956.

5I. E. E. SNeli, N. S. Radin \& M. IKaWa, 7. biol. Chem., 217, 803, 1955.

52. I. D. Frantz, H. Feigelmain, A. S. Werner \& M. P. Smythe, f. biol. Chem., I95, $423,1952$.

53. T. HOFMAN, Biochem. F., 54, 293, I953.

54. S. De Prailaune, C.R. Soc. Biol., Paris, I49, 655, I955.

55. R. L. M. SYNGE, Biokhimiya, 10, I79, I945.

56. R. L. M. SYNGE, Lect. Inst. Chem., I, I952.

57. R. L. M. Synge, The Chemical Structure of Proteins (Ed by G. E. W. Wolstenholme, \& M. P. CAMERoN), p. 43. Churchill, London, 1953.

58. R. L. M. SYNGE, in Moderne Methoden der Pflanzenanalyse, Vol. 4, p. I, Berlin, I955. 59. N. Grobbelaar, J. K. Pollard \& F. C. Steward, Nature, Lond., 175, 703, 1955.

60. A. I. Virtanen, Angew. Chem., 67, 381, 1955.

6I. K. LANDSTEINER, The Specificity of Serological Reactions, rev. ed. Harvard University Press, Cambridge, Mass., 1947.

62. H. Brown, F. SANGER \& R. Kitai, Biochem. F., 60, 556, I955.

63. V. Du Vigneaud, D. T. Gish \& P. G. Katsoyannis, f. Amer. chem. Soc., 76, 475 I, 1954.

64. A. Paladini \& L. C. Craig, f. Amer. chem. Soc., 76, 688, I954.

65. T. P. King \& L. C. Craig, F. Amer. chem. Soc., 77, 6624, 6627, 1955.

66. R. SchWYZER \& P. Sieber, Helv. chim. acta, 40, 624, 1957. 


\title{
A Chemical Theory of Spontaneous Generation*
}

\author{
SIDNEY W. FOX \\ Oceanographic Institute, Florida State University, Tallahassee, Florida, U.S.A.
}

SUGGESTIONS of how life originated by natural means were offered by the Greeks [I]. Charles Darwin added to these vague concepts in I87I [2] one paragraph of chemical prescription for the beginning of life. The details of Darwin's paragraph, although inadequate, are in agreement with the most advanced thinking today. The modern era of thought in this field received great stimulus from the book by Academician Oparin [I], whose pioneering contribution we are privileged to honour at this Symposium.

In so far as the speaker is aware, serious and informed experimentation in this field began in 1951 with studies of the effects of high-energy radiation on carbon dioxide and water by Calvin and co-workers [3]. Working with an atmosphere consisting of ammonia, methane, hydrogen and water, Miller was notably able to produce amino acids by electrical discharge [4]. Amino acids have now been synthesized in so many presumably primordial ways in different laboratories that the contention that such results are not intrinsically surprising [5] appears to be broadly supported. There is increasing evidence for the notion that no matter which simple reactants are studied, and no matter which physical conditions are tested, organic compounds in the same somewhat narrow range of possibilities will result.

The prebiochemical distance from such organic compounds as amino acids to the origin of life, however, must be quite large. Unless the first organism did not fit a Kluyverian pattern of biochemical unity [6], the amino acids and other intermediates must have yielded: proteins, nucleic acids and numerous other biochemical substances and reaction pathways, before life could emerge from its matrix. Other authors have pointed out the significance of the problem of formation of protein as a component of the problem with which we are concerned here $[1,7]$. The work to be described in this paper, however, began with an attempt to understand only the prebiochemical origin of protein. The experiments yielded a succession of unexpected results and stimuli for new experiments such that a unified theory of biochemical origins is emerging.

The embarkation point for the experiments to be described was the hypothesis that peptide bonds might be formed at temperatures elevated enough to

* Aided by Grants No. H-23I4 and RG-4666 of the National Institutes of Health, U.S.A., Public Health Service, and from the General Foods Corporation and the Rockefeller Foundation. Contribution No. 87 of the Oceanographic Institute of the Filorida State University. 
volatilize byproduct water. Huffman had shown in 1942 [8] that the production of dipeptides from amino acids at $298^{\circ} \mathrm{K}$ by any route, requires an input of 2000-4000 cal. per mole of dipeptide formed (Table I).

TABLE I

Free-energy change accompanying formation of dipeptides from amino acids

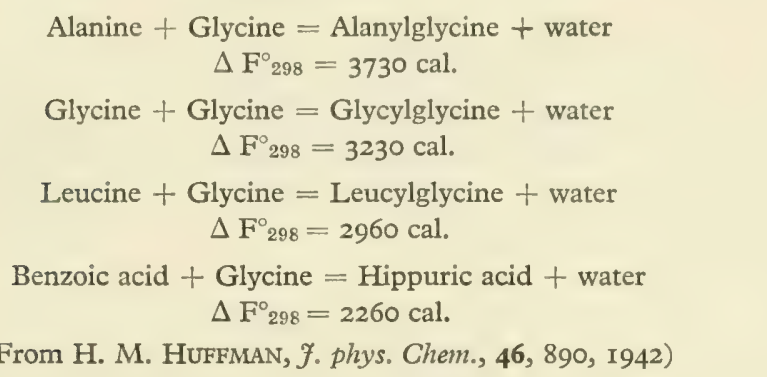

One can calculate that the $\Delta \mathrm{F}$ value is more favourable at higher temperatures for the dry reaction in the forward direction, but a destructively high temperature is nevertheless indicated for an energetically spontaneous reaction. One can visualize, however, an overcoming of the energetic barrier by the occurrence of a temperature sufficient to remove water in the gaseous state:

$\mathrm{H}_{2} \mathrm{~N} \cdot \mathrm{CHR} \cdot \mathrm{COOH}+\mathrm{H}_{2} \mathrm{~N} \cdot \mathrm{CHR}^{\prime} \cdot \mathrm{COOH}=\mathrm{H}_{2} \mathrm{~N} \cdot \mathrm{CHR} \cdot \mathrm{CONH} \cdot \mathrm{CHR}^{\prime} \cdot \mathrm{COOH}+\mathrm{H}_{2} \mathrm{O} \uparrow$

When experiments of this sort were first performed, unexpected indications of the production of more amino acids than those taken for the reactions were found. From this beginning, experimental results often paralleled by thermal experiments described in the early literature, led to a picture of thermal pathways.

Some of these results are depicted in Figs. I and 2.

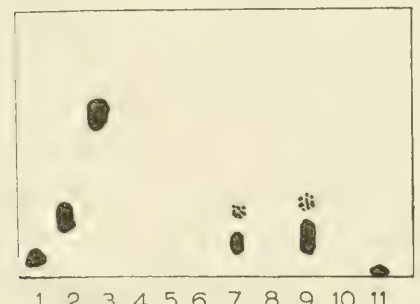

FIG. I. Tracing of chromatogram of products from ammonium salts of Krebs-cycle acids.

(1) 10 $\mu 1$. of aspartic acid standard; (2) ro $\mu \mathrm{l}$. of alanine standard; (3) ro $\mu \mathrm{l}$. of leucine standard, to permit comparisons of $R_{F}$; (4) Io $\mu$ l. of unheated monoammonium fumarate; (5) Io $\mu \mathrm{l}$. of unheated monoammonium malate; (6) Io $\mu \mathrm{l}$. of heated monoammonium fumarate: (7) $2 \mu \mathrm{l}$. of hydrolysed heated monoammonium fumarate $(2 \mu \mathrm{l}$.); (8) Io $\mu \mathrm{l}$. of heated monoammonium malate; (9) I $\mu \mathrm{l}$. of hydrolysed heated monoammonium malate showing faint spot with $R_{F}$ of alanine; (Io) Io $\mu \mathrm{l}$. of hydrolysed heated monoammonium succinate; (II) Io $\mu \mathrm{l}$. of hydrolysed heated ammonium citrate showing non-ninhydrin spot at origin. Solutions were from $\mathrm{I} \cdot \mathrm{O} \mathrm{g}$ of reactant made up to $\mathrm{I} 5 \mathrm{ml}$. with water. Standards contained I. o $\mathrm{mg}$ amino acid per $\mathrm{ml}$. Chromatogram coloured with ninhydrin. 


\section{$\therefore \therefore$ -}

$\begin{array}{llllllll}1 & 2 & 3 & 4 & 5 & 6 & 7 & 8\end{array}$

FIG. 2. Tracing of chromatogram of products from ammonium hydrogen malate.

(I) Io $\mu$ l. of aspartic acid; (2) Io $\mu$ l. of $\alpha$-alanine; (3) ro $\mu$ l. of $\beta$-alanine; (4) ro $\mu \mathrm{l}$. each of aspartic acid and $\alpha$-alanine; (5) ro $\mu \mathrm{l}$. each of aspartic acid and $\beta$-alanine; (6) Io $\mu \mathrm{l}$. each of aspartic acid, $\alpha$-alanine, and $\beta$-alanine; (7) $20 \mu \mathrm{l}$. of product from ammonium malate heated at $160^{\circ}$; (8) $20 \mu \mathrm{l}$. of product from ammonium malate heated at $200^{\circ}$. Chromatographic solvent was 7 pyridine $: 3$ water. Coloured with ninhydrin.

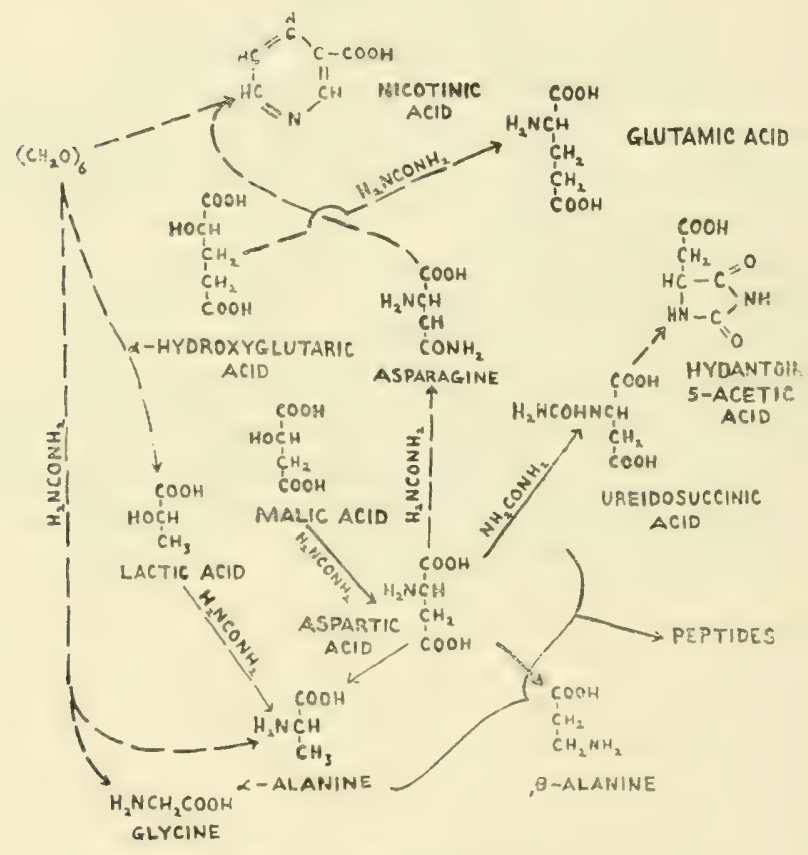

FIG. 3. Thermal pathways.

The reactions for which detailed supporting data have been published are depicted in Fig. 3 by solid arrows. Other reactions are indicated with broken arrows.

The obtaining of conclusive evidence for the production of peptides by thermal treatment of unsubstituted amino acids revealed some striking features. Early reports on heating of amino acids show that these tend to form diketopiperazines, amines, tars and other decomposition products $[9, \mathrm{I} 0]$ rather than linear peptides. Even the product from aspartic acid, which appeared to be an 
exception, has been questioned [9]. It is now clear that a critical detail in forming peptides by heating amino acids is not to heat them singly, as in the procedures reported in virtually all of the discouraging early literature, but to heat them in concert.

For these results, the dicarboxylic acids, glutamic acid and aspartic acid, are of particular significance. Glutamic acid heated alone yields the inner lactam:

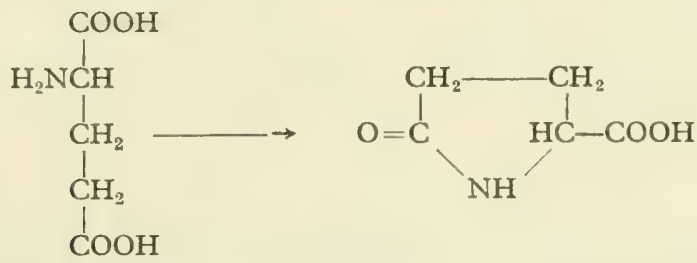

but when heated with glycine, which forms a linear polyglycine, it yields a polymer containing typically $20 \%$ of glutamic acid. The polymer gives rich infra-red indication of being a linear peptide and other evidence as well.

As Kovacs suggested earlier [II], polyaspartic acid is a polyimide which hydrolyses to a true peptide under alkaline conditions. This structural interpretation has been substantiated in our laboratory (A. Vegotsky, K. Harada \& S. W. Fox, unpublished experiments) with the aid of infra-red studies.

These experimental results with glutamic acid and aspartic acid are significant in that they designate principles whereby one can visualize how a variegated peptide such as a protein might form under primitive thermal conditions, despite the negative indications from the literature. In view of the concept of a yet highly limited evolution of protein molecules [12, I3] the fact that most proteins are composed of at least one-fifth dicarboxylic amino acid residues is more understandable. Another feature is that these reactions need not be solid reactions inasmuch as the lactam of glutamic acid, pyrrolidonecarboxylic acid, is liquid at the temperatures employed (in the range of $160-180^{\circ}$ ). A liquid state also results from phosphoric acid, inclusion of which has been found to facilitate many of the reactions studied (K. Harada \& S. W. Fox, unpublished experiments).

The thermal pathways of Fig. 3 are striking in their similarity to the sequences involved in the early stages of a generalized biosynthesis for all organisms. Obviously there are differences, but the compounds and their order of appearance in the thermal picture resemble closely the substances and sequences of anabolism. Another perspective for viewing this parallelism is provided by the biogenetic law. If one accepts the concept that the development of an organism reflects its evolutionary history, he should then expect that this principle would be reducible to the chemical level. In the depiction of Fig. 3, this requirement appears to be met.

Not only have the thermal pathways been found to imitate the anabolic pathways. It is now possible to point to features that were first uncovered by thermal studies, and then disclosed by more conventional biochemical experimentation. 
One of these is the imide structure for aspartic acid peptides, as first proposed by Kovacs \& Koenyves [II]:

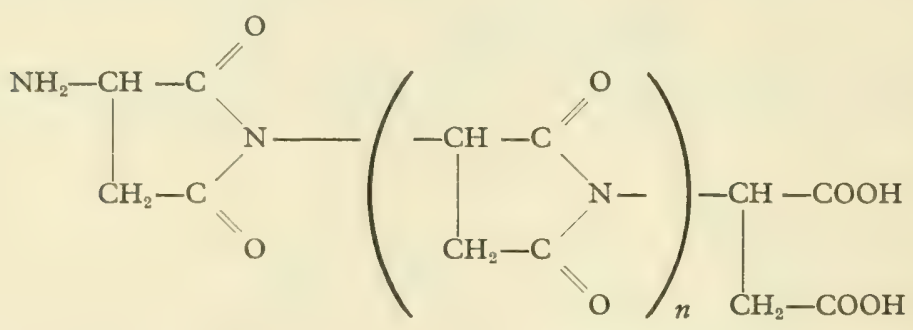

and confirmed in studies in our laboratory (A. Vegotsky et al., unpublished experiments). This structure has been found in bacitracin hydrolysate [I4] and is suggested for search in proteins (A. Vegotsky et al., unpublished experiments).

Another instance of pioneering by thermal experimentation is provided by the fact that it was possible to suggest in May of 1955 that anabolism involving the tricarboxylic acid cycle, the urea cycle, pyrimidine biosynthesis, amino acid biosynthesis, and protein biosynthesis was a joint phenomenon [12]. More recently, Reichard \& Hanshoff [15] have pointed out the joint relationship of the first three of these five pathways on the basis of results from experiments employing more traditional biochemical techniques.

The unified thermal theory provides an answer for the vexing problem of how such a profusion of biochemical intermediates and processes could have originated.

The answer stresses the effect of an exponentially increasing number of biochemical substances which can result when a sustained input of energy, such as the thermal, acts upon a few simple organic compounds of the appropriate selection. The recorded and unrecorded thermal experiments indicate that increase in number of chromogenic substances in chromatograms tends to accelerate as heating is maintained. Against this background, one can visualize how an organism may emerge from its biochemical matrix, which at that moment becomes environment, with a full complement of substances. This pathway to profusion of substances is compatible with the notion, derived from the loss nature of mutants [I6], that the first organism was quite fully equipped biochemically.

The biochemical inferences to this point are drawn essentially from experiments in our laboratories. If these inferences are correlated with other thinking a larger picture can be formulated. The origin of the first organism can be visualized as an extension of biochemical emergence, inasmuch as the thermal experiments suggest the appearance, in overlapping order, of reactions, protein, and nucleic acid. When translated into functional terms this sequence is anabolism-enzyme-gene and recalls the Beadle concept of control of anabolism though the hierarchy of gene-enzyme-metabolism [16]. This picture is presented in Fig. 4. The first step may be a long slow process, but once the second stage is reached the process is most easily understood as a rapid one. The first turn 


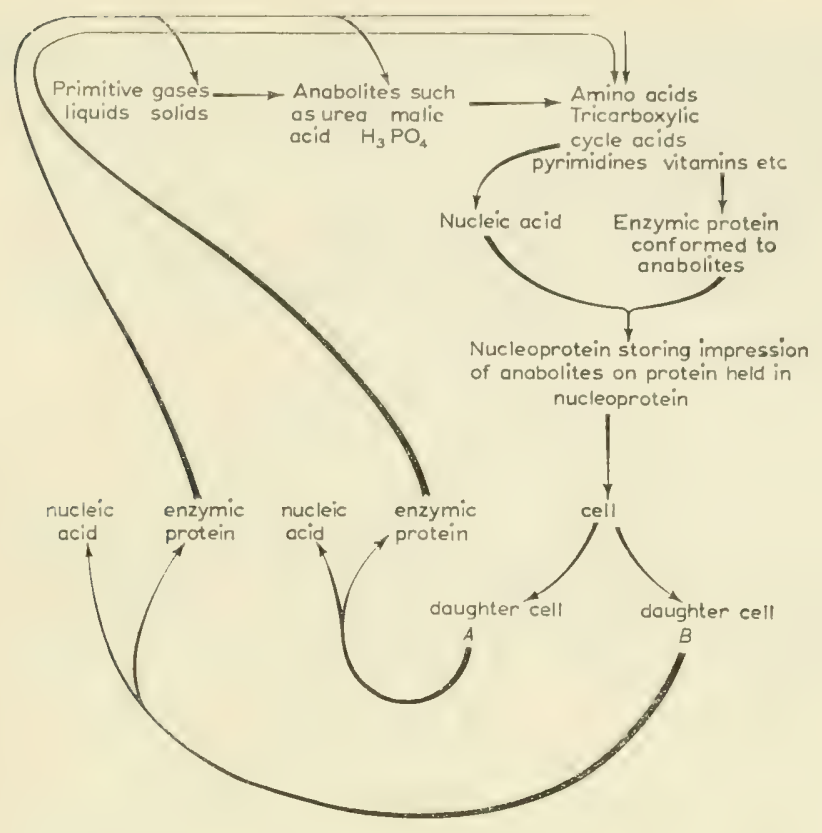

FIG. 4. Cyclical biosynthetic, enzymic, and genic process. This diagram pictures the first cell as having been formed in the first operation of the cycle.

of the cycle beginning with the appropriate intermediates is then the production of the first cell. Enzyme protein can thus be looked upon as an initiator of anabolic reactions in the life history of the new cell and nucleoprotein can be regarded as a device for memorizing the anabolic reactions. These devices can be seen to operate for the first cell in a way similar to that visualized by Beadle for current cells.

Although the entire picture presented in this paper integrates many levels and areas of biochemical activity, it is, of course, incomplete. Such problems as primordial fixation of nitrogen, origin of optical activity, membrane formation, and modulation to an aqueous state from an anhydrous one have been or will be treated elsewhere [12, I7]. Unique solutions for other component problems must also be found. As the essential validity of the main thesis is further tested, answers to the other component problems may, however, be expected to appear if the main thesis is correct. Life must have begun without the aid of such special apparatus as we can assemble or obtain today, and the thermal experiments and the interpretations of them continue to provide explanations which suggest answers to additional component problems. One may expect that a final theory will be a unified theory which will explain internally governed generation of the biochemical world, emergence of life, and the evolution of that memory mechanism of human mentality which we can reasonably anticipate will eventually solve in full the salient problems of man's curiosity about his origins. 


\section{REFERENCES}

I. A. I. Oparin, The Origin of Life, 2nd ed. (transl. by S. Morgulis). Dover Publications, New York, I953.

2. C. DARWIN, Quoted by G. HaRdin, Sci. Mon., N.Y., 70, I78, I950.

3. W. M. Garrison, D. C. Morrison, J. G. Hamilton, A. A. Benson \& M. Calvin, Science, II4, 4I6, I95I.

4. S. L. MILLER, Science, 117, 528, 1953.

5. S. W. Fox, Chem. Engng Newus, 35, (25), 10, 1957.

6. A. J. Kluyver \& C. B. VAN Niel, The Microbe's Contribution to Biology. Harvard University Publications, Cambridge, Mass., U.S.A., I956.

7. H. F. Blum, Amer. Scient., 43, 595, 1955.

8. H. M. HufFMan, $\mathcal{F}$. phys. Chem., 46, 885, 1942.

9. E. Katchalski, Advanc. Protein Chem., 6, I23, I95I.

10. A. B. MegGY, F. chem. Soc., p. I444, I956.

I1. J. Kovacs \& J. KoENYves, Naturwissenschaften, I4, 333, 1954.

I2. S. W. Fox, Amer. Scient., 44, 347, I956.

13. S. W. Fox \& P. G. HoMeyer, Amer. Nat., 89, I63, I955.

I4. D. L. Swallow \& E. P. AвRAHam, Biochem. F., 65, 39P, 1957.

I5. P. Reichard \& G. HANSHOFF, Acta chem. scand., 10, 548, 1956.

I6. G. W. BEADLE, Harvey Lect., 40, I79, I944-45.

17. S. W. Fox, J. E. Johnson \& A. Vegotsky, Science, 124, 923, 1956; S. W. Fox, f. chem. Educ., 34, 472, 1957. 


\title{
The Scale of Structural Units in Biopoesis
}

\author{
J. D. BERNAL \\ Birkbeck College, University of London
}

IN ALL discussions referring to the evolution of material systems, be they galaxies, organisms or societies, two aspects have to be kept in mind simultaneously at every stage in the discussion-the dynamic and the static-the processes and the structures. Living organisms are built from atoms and at the same time they react and change according to the laws of atomic combination. Systems of extraordinary complexity and variety are built up, maintained and modified but all repose on the same elements, that is on certain simple properties common to all actual or possible life. These provide the given data into which all schemes of biopoesis must be fitted. At the first stage of emergence from the inorganic world this corresponds to the considerations of the physical and chemical properties of the simple molecules of water, carbon dioxide and ammonia, discussed by Henderson in his Fitness of the Environment; later they include the colloidal properties of globular and fibrous polymers of the proteins, nucleic acids and of bimolecular lipid sheets, exemplified in terrestrial life by structures such as those of the proteins. We have learned of these properties largely through their occurrence in organic structures but once the structures are provided the properties have nothing specifically vital about them, as has been shown by their occurrence in synthetic plastics and fibres. My object here is to show that much of the apparent complexity and arbitrariness of living systems is due to just such physical conditioning and that the true biopoetic problems represent the residue after these have been allowed for.

One argument which has been used from the highest antiquity against any spontaneous evolution of life has been the apparent impossibility of such an arrangement coming together by chance. It was already urged against the early Greek atomists, of which we catch a seventeenth-century echo in John Hall's Epicurean Ode:

'Since that this thing we call the world

By chance on Atomes is begot,

Which though in dayly motions hurld,

Yet weary not,

How doth it prove

Thou art so fair and I in Love?'

Some have taken up the same theme less poetically in modern times and 
have claimed to demonstrate by mathematical arguments that even such a small part of organized nature as a molecule of ribonucleic acid would, if it had to come together by chance from a congeries of atoms, take almost infinitely more time than the presumed age of the universe. I know Professor Haldane [I] has argued that a very unlikely thing is not an impossible thing and that the chance origin of life cannot be altogether neglected, but most of those bringing forward such arguments use them in a purely negative sense. If life could not have come together by pure chance, they argue, then its presence is either an illusion or that life was created and guided at every step by an intelligent agent or at least by a teleological seeking for perfection. I do not want here to enter into these arguments, which are more philosophical than scientific, but I do want to make the point that the problem has been wrongly posed. There is no question, to anyone who has examined the evidence, of the need to explain the origin of life as consisting of one decisive step, because it plainly did not originate as such. Even

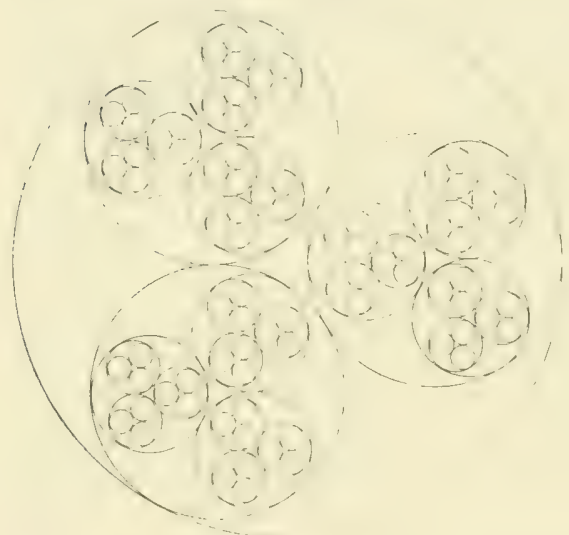

FIG. I. Formal scheme of five orders of a sequence of inscribed circles. Each unit contains three of the order beneath it.

if we cannot as yet precisely determine the stages of biopoesis, their general character is already apparent, as I have attempted to sketch in my other contribution. Over and above any hypothesis of stages in time, we have before us in biochemistry and ultra-cytology concrete evidence of a series of grades of structure of increasing complexity. The structures that we observe or study are not arranged in a continuous order but a discontinuous one.

Each type of structure seems to be composed of units of fairly definite sizes which come together to form another unit on the next level (Fig. I). Take for example a vertebrate striated-muscle cell or fibre, itself a member with thousands of others of a macroscopic muscle (Fig. 2). Leaving aside the ccll membrane, nucleus, mitochondria and other organelles, the functional element is the striated muscle fibril. This is composed of some hundred elements, the myomeres, each with its transverse $M$ and $Z$ membranes still of unknown composition and function. Each myomere contains a parallel arrangement of some thousand distinct myosin fibrils, interleaved with actomyosin fibrils. Both fibrils contain some hundred polypeptide chains [2,3]. The chains are made of specific sequences of amino acids which in turn are made of between ten and thirty atoms. Here 


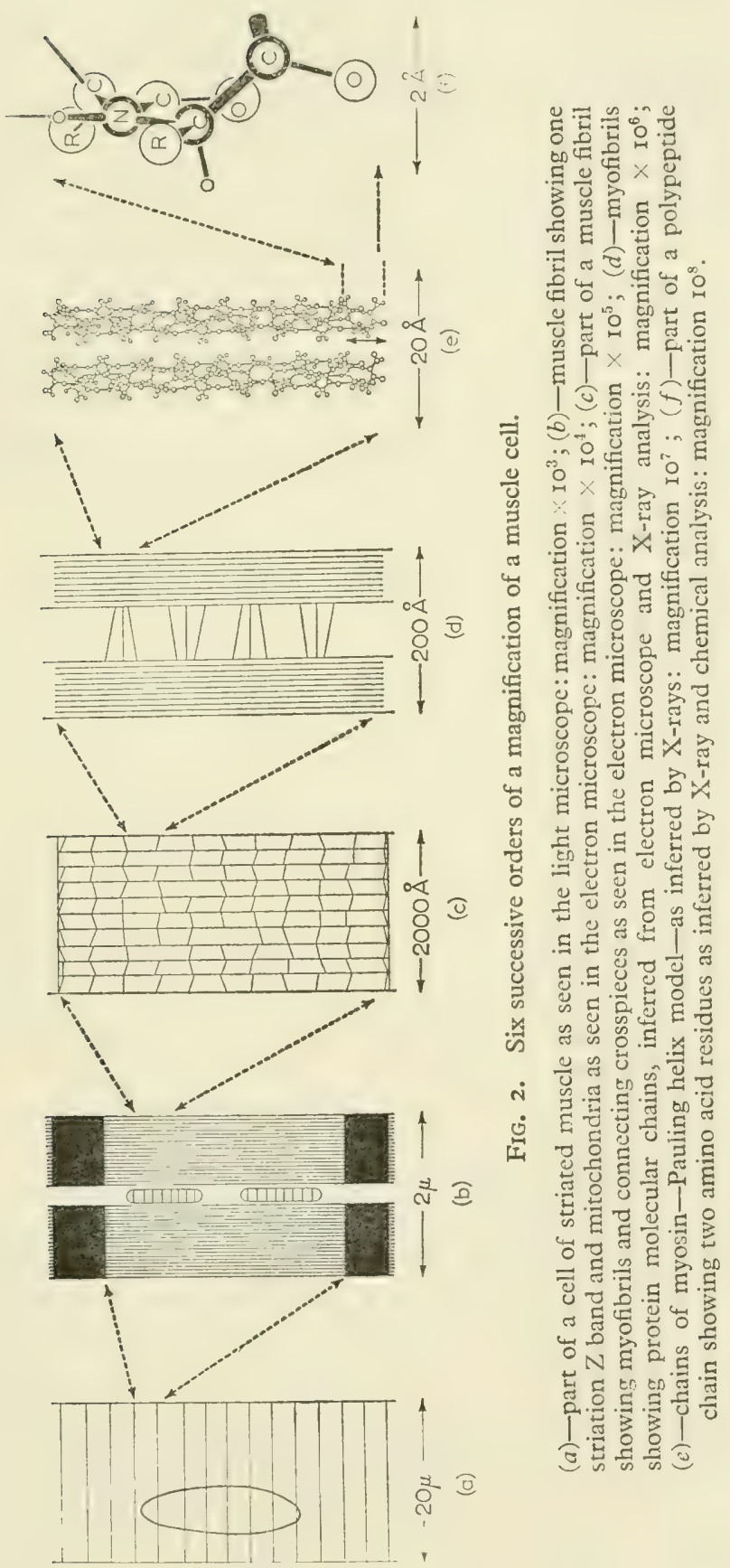


therefore are six objectively separate levels of organization, each one including all those beneath it.

This example brings out the main thesis of this paper, namely that: The probability of formation of a highly complex structure from its elements is increased, or the number of possible ways of doing it diminished, if the structure in question can be broken down into a finite series of successively inclusive sub-structures. I believe this theorem is capable of formal proof if it can be properly formulated, but I leave this task to the logicians. Here I am concerned primarily to demonstrate that such sub-structures can be formed from atoms related by the known laws of physics and chemistry. Further, I want to show that each kind of substructural unit corresponds to a definite and limited range of absolute sizes and shapes and that at each level the laws of association of the units are qualitatively different. None of this, in principle, depends on biological analysis; it would hold for all combinations consisting mainly of the four elements hydrogen, carbon, nitrogen and oxygen. As, however, only a few of these structures have been produced synthetically, examples, particularly of the most complicated forms, will be sought in the field of biological structures.

The size range, the shapes and the methods of mutual attachment of the units of every level depend on factors which are partly physical-that is in respect to the nature of the mutual potentials or attractive or repulsive forces between the particles-and partly geometrical, determined by their relative sizes and shapes. It will be convenient to deal with this geometrical or formal element first, as it is common to all sizes and natures of mutual potentials. Indeed formal analogies to microbiological structures can even be found from human technical experience which in fact provides them with their vocabulary such as piling, twisting, twining and pleating. A logical starting point is the quasi-spherical particle, for others of different shape can always be constructed from such particles. All that need be postulated of them is a more or less fixed radius and the capacity of joining to one or more similar particles. The number that it can join on to may be called its co-ordination number, analogous to the valency of atoms. The lower limit of the co-ordination number is not necessarily fixed; that is a particle can be linked to fewer than it can accommodate but the upper number is limited by close-packing considerations to $12-14$.

In the simpler cases we are concerned with the linking of similar particles or at least, as in proteins and nucleic acids, of particles with similar linkage systems though with different side groups. More complicated relations involving more than one type of co-ordination can occur with heterogeneous particles and some of these may be very important, such as those of the nucleoproteins, the lipoproteins and the mucoproteins, but the structure of these plainly depends on that of their homogencous components, which must be treated first.

The co-ordination number of a particle with similar particles is not merely an intrinsic property but also depends on external conditions and may be very sensitive to them in cases where the difference in the free energy of association of different kinds is small.

How this can occur can be illustrated in the following ideal case. In Fig. 3 ( $a$ and $c$ ) are shown two forms of the mutual potential surfaces of a pair of 
particles with respect to a third particle in its vicinity. In $(a)$ in the region of the potential minimum there is a shallow trough along the axis of the particle pair, in $(c)$ it lies along the equator. The addition of a third particle to the system will be collinear in the case of $(a)$ and triangular in that of (c) (Fig. $3 b$ and $d$ ). It is easy to see that this will lead, with further additions, to the formation of a fibre in the first case and a close-packed crystal in the other without there being much to choose between them in their mutual energies of association. This is borned out in practice by the very common occurrence of the so-called reversible fibrous-globular ( $\mathrm{f}-\mathrm{g}$ ) transition in many proteins of which that of insulin has been most studied [4]. The fibrous association may be, so to speak, vulcanized by primary valence formation as in the case of the physiologically important fibrinogen-fibrin transformation, so as to make reversibility difficult.

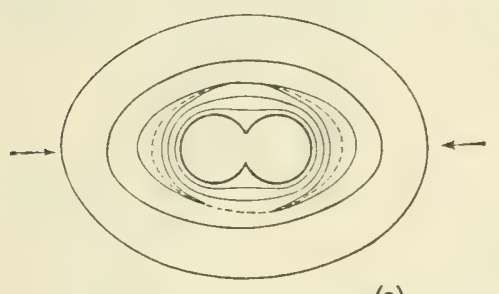

(a)

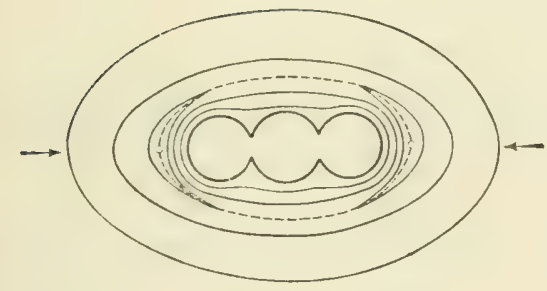

(b)

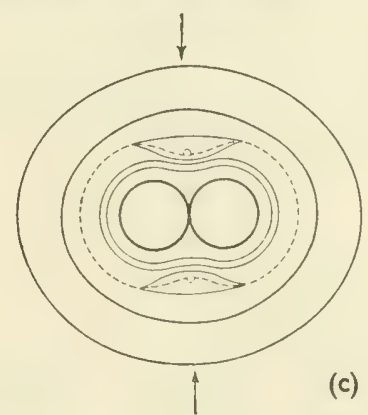

(c)

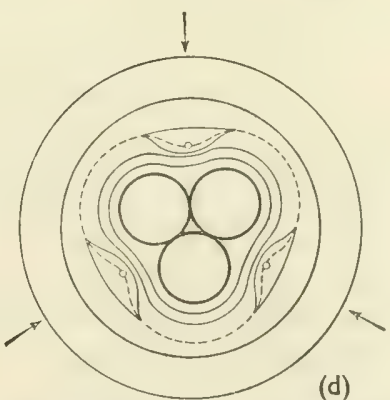

(d)

FIG. 3. Determination of type of co-ordination of particles in two dimensions by shape of mutual equipotential curves.

(a) and (b)-with troughs of potential along axis leading to linear co-ordination; $(c)$ and $(d)$-with troughs of potential at right angles to axis leading to close-packed agglomerations. 0 -potential minima; $\rightarrow$-direction of attachment of further particles.

A co-ordination number of one can only lead to a particle pair, but such pairs seem to be common among the proteins, notably in insulin where the chemical unit of 5500 molecular weight is nearly always found in solution as II,000 or some higher multiple, 33,000 or 44,000 . It also arises when a single metal atom is co-ordinated with protein molecules, as in the case of the mercury-albumin complexes. Here steric co-ordinations limit the association to two, which will be the general rule where the co-ordinating agent is small compared to the coordinated [30]. 
A co-ordination number of two leads to an unbranched linear association. If the two co-ordinating are nearly at $180^{\circ}$ the result is a nearly straight line polymer of indefinite length; if the angle is smaller it is a ring or close helix. Angles of $90^{\circ}$ or less will produce fourfold or triple aggregations without much waste space, as for instance in the $33,000 \mathrm{~mol}$. wt unit in zinc insulin. The helix will be the most probable form for larger angles owing to the stabilizing effect of secondary interactions between successive coils. This seems to be the explanation for the arrangement of the protein shell in the rod-like viruses such as tobacco mosaic virus, though we cannot be sure yet whether in this case there is one closely packed helix or an aggregation of several slightly coiled helices.

The simplest form of three co-ordinated pattern is that of a hexagonal plane net. This, however, unless stabilized, is likely to curl into a cylinder or spiral roll. At any rate no indisputable example of it has been analysed though it may account for the protein part of cellular or intracellular membranes. Another product of three co-ordination is the closed basket of cubic, often of isoctahedral, symmetry (532) which has been revealed as the shell of the globular viruses-

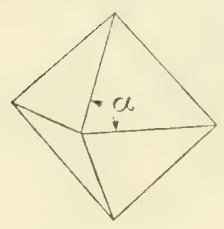

(a)

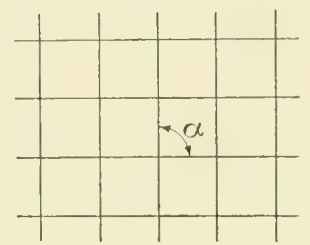

(b)

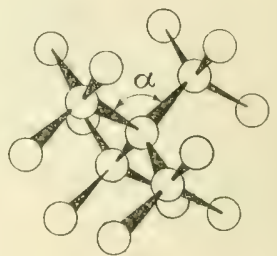

(c)

FIG. 4. Types of aggregate formed by 4 co-ordination when angle $\alpha$ between vectors joining neighbours is:

(a) -less than $90^{\circ}$ leading to closed octahedron; $(b)$-equal to $90^{\circ}$ leading to an indefinite plane square net; $(c)$ - greater than $90^{\circ}$ leading to a three-dimensional extended (diamond) structure.

tomato bushy stunt and turnip yellow $[5,6]$. Higher co-ordinations lead to clump-like aggregates or to indefinitely extending crystals. The former occur if the points of attachments are concentrated on one side of the particles. For instance, four attachments in the form of a pyramid would lead to a closed group of six in the form of an octahedron, while four in the form of a tetrahedron would lead to an indefinite arrangement of the type of a diamond crystal (Fig. 4).

If we consider the further aggregations, not of quasi-spherical particles, but of the kinds of structures which, as shown above, can be derived from them, there are further possibilities of complexity. In essence, however, these reduce to two: the packing of elongated particles, which may include twining; and the piling of platy ones, which may include rolling up. The simplest arrangement of straight or quasi-straight elongated particles is hexagonal packing (Fig. 5, $a$ and $b$ ). This will result in two kinds of structures according as to whether the elongated particles can be arranged with all their ends in parallel shells, nearly normal to their general direction, or not. In the latter case, which is the only one for particles of unequal length, a long aggregate with characteristic grain 
will be formed which, if the transverse direction is limited, will have the structure of a roving or thread according to the degree of twist.

The case of long particles of equal length occurs predominantly in organized nature for derivatives of long-carbon-chain compounds, fatty acids, phospholipids, lipoproteins. These seem to be the basis of the double layers found in almost all cells from which, by a spiral rolling up, are formed the myelin sheaths of nerves. With them are associated sterols and other morc complex elongated molecules of approximately the same length, $20 \AA-25 \AA$, as the predominant $\mathrm{C}_{16}-\mathrm{C}_{20}$ straight-chain hydrocarbons.

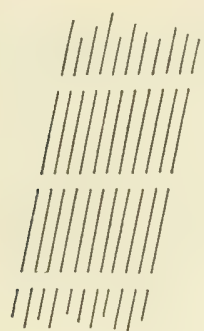

(a)

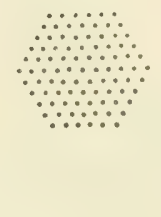

(c)

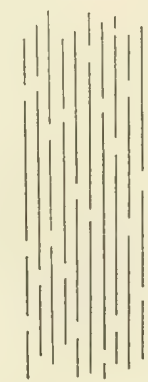

(b)

FIG. 5. Modes of regular packing of elongated particles.

(a)-when these are of equal length leading to multiple sheet structure; (b)-when these are of unequal length leading to tactoid or fibre structure; $(c)$-illustrates the hexagonal net packing common to $(a)$ and $(b)$.

The packing of helical particles offers more complexities. Close-coiled helices approximate to cylinders and pack accordingly in hexagonal close packing. If, however, the helices are of the same sense their coils may interlock as appears to be the case for tobacco mosaic virus [7] (Fig. 6). This process may go further still in more loosely coiled helices. Where the pitch is equal to twice or more of the diameter of the helical particle, more than one helix may share a common axis, leading to the two- or three-fold twined helices such as are found in dcoxyribosenucleic acid (DNA) and in collagen. Such compound helices may themselves be straight or may have an axis forming another helix of different pitch (coiled coil). This may lead in turn to further coiling and so to cable-like structures of almost indefinite complexity (Fig. 6).

These considerations are all of an extremely general kind, involving hardly more than the geometrical consequences of the arrangements of impenetrable solids whose shape can in turn be evolved from the aggregation of spherical particles. Such a phenomenon as crystallization, in the sense of indefinite regular aggregations, can be exemplified by structures on a variety of scales from atoms, viruses, and bacteria [8] up to matches and cannon balls. To correspond with an actual scale of structures other more physical conditions have to be invoked and filled in to the more abstract geometrical ones already described. If we confine ourselves to structures stable in water and ionic solutions, and this is 
sufficient to cover all terrestrial life, we can set out a sequence of five interparticulate forces or mutual interaction energies. In this sequence each of these corresponds to a longer range of action and a weaker interaction energy than those preceding it and, what is perhaps most important, the steps though broad are separated by wider gaps.

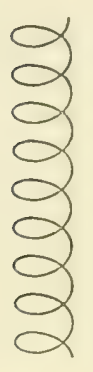

(a)

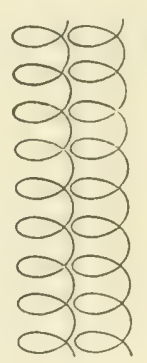

(b)

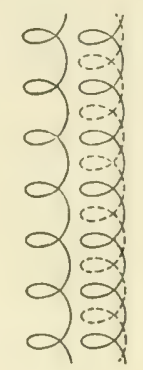

(c)

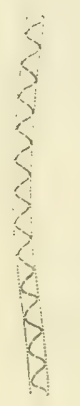

(d)

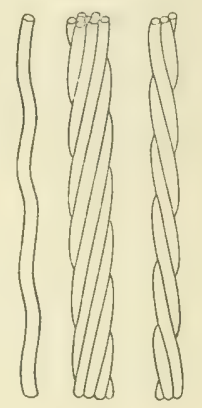

(e)

FIG. 6. Types of diagrammatic aggregation of helical molecules.

(a)-simple helix; (b) -interleaved helices on adjacent axes; $(c)$-interleaved helices sharing common axes (double helix); (d)-coiled coil helix (after Pauling); (e)-combination of coiled coil helices to form twined cables.

Only homopolar forces, the hydrogen bond and ionic forces are reasonably well understood and will not be further discussed here (see Table I). The mechanism of the remaining two, which I have called cryohydric and long-range forces, are still unexplained theoretically or are the subject of current controversy. There is, however, little doubt about the reality of these forces and of their range of action because these are revealed by determinate structures which so far can only be explained by postulating them. They are in my own view distinct. The cryohydric forces imply an ordered but not necessarily ice-like grouping of water molecules such as, for instance, occurs in the rare-gas hydrates. They are operative up to the range at which such structures can be maintained, itself a function of the temperature, at room temperature something of the order of $20 \AA$. They are also a function of the size of the particles they bind together, being greater the larger and flatter these are. In the case of montmorillonite clay, where these conditions are optimal, the range is at least up to $40 \AA$ [9].

The long-range forces on the other hand operate through a medium indistinguishable from water or ionic solution, incapable of showing rigidity. Whether they are due to simple Van der Waals' forces, demonstrated to exist between extended solids [IO, II], or, as Kirkwood has suggested [I2], due to virtual ionization, they seem to operate wherever there are particles of over $100 \AA$ in diameter containing ionizable groups. In terms of energy there seems to be a minimum which leads to a condition of equilibrium at a definite distance, provided that the thermal energy is not greater than that of the interaction minima. The position of the minimum is not notably sensitive to temperature but as old experiments on tobacco mosaic virus [13] have shown, it is much affected by $\mathrm{pH}$. 
The existence under certain circumstances of this equilibrium results in the division of the solution containing them into two parts whenever the overall concentration of particles is less than that which would ensure the equilibrium distance. In the more concentrated regions this critical concentration is maintained: in the rest there is in general a far more dilute solution.

TABLE I

Types of interparticulate forces

\begin{tabular}{|c|c|c|c|c|c|}
\hline Name & Mechanism & $\begin{array}{l}\text { Order of } \\
\text { magni- } \\
\text { tude } \\
\text { of inter- } \\
\text { action } \\
\text { energy } \\
\text { (kcal/ } \\
\text { mole) }\end{array}$ & $\begin{array}{l}\text { Range } \\
\text { of } \\
\text { action } \\
(\AA)\end{array}$ & $\begin{array}{l}\text { Kinds of unit } \\
\text { between } \\
\text { which such } \\
\text { forces act }\end{array}$ & Examples \\
\hline $\begin{array}{l}\text { Homo- } \\
\text { polar }\end{array}$ & Electron sharing & 500 & $\begin{array}{l}\text { I-2 } \\
\text { in } \\
\text { organic } \\
\text { com- } \\
\text { pounds }\end{array}$ & $\begin{array}{l}\text { Electron-deficient } \\
\text { atoms }\end{array}$ & $\begin{array}{l}\text { All organic com- } \\
\text { pounds } \\
\text { Long-chain poly- } \\
\text { mers }\end{array}$ \\
\hline $\begin{array}{l}\text { Hydro- } \\
\text { gen } \\
\text { bond }\end{array}$ & $\begin{array}{l}\text { Action of incom- } \\
\text { pletely screened } \\
\text { hydrogen atom } \\
\text { attached to one } \\
\text { atom or other } \\
\text { polarizable atoms }\end{array}$ & 15 & $\begin{array}{c}2 \cdot 4-3 \cdot 2 \\
\text { usually } \\
2 \cdot 7\end{array}$ & $\begin{array}{l}\mathrm{OH}-\text { and } \mathrm{NH}- \\
\text { groups in relation } \\
\text { to } \mathrm{OH} \text { and } \mathrm{CO}\end{array}$ & $\begin{array}{l}\text { Water. Acids. Su- } \\
\text { gars. Urea. Pu- } \\
\text { rines (Nucleic } \\
\text { acids). Proteins }\end{array}$ \\
\hline Ionic & $\begin{array}{l}\text { Coulomb attrac- } \\
\text { tion between ions } \\
\text { or charged atoms } \\
\text { of different sign }\end{array}$ & 20 & $2-3$ & $\begin{array}{l}\text { Basic } \mathrm{NH}_{2} \text { or } \mathrm{NH}_{3}+ \\
\text { groups and acid } \\
\mathrm{COO}-\text { g roups. } \\
\text { Halogens, etc. }\end{array}$ & $\begin{array}{l}\text { Soaps. } \\
\text { Basic hydrochlor- } \\
\text { ides. Zwitterions. } \\
\text { Glycine }\end{array}$ \\
\hline $\begin{array}{l}\text { Cryo- } \\
\text { hydric }\end{array}$ & $\begin{array}{l}\text { Linking of ions or } \\
\text { charged a to ms } \\
\text { of different signs } \\
\text { through layers } \\
\text { of water mole- } \\
\text { cules in fixed po- } \\
\text { sitions (ice-like) }\end{array}$ & 5 & $3-20$ & $\begin{array}{l}\text { Medium-sized } \\
\text { molecules Io } \AA \\
\text { or more in dia- } \\
\text { meter containing } \\
\mathrm{OH} \text { groups in } \\
\text { presence of limit- } \\
\text { ed amounts of } \\
\mathrm{H}_{2} \mathrm{O}\end{array}$ & $\begin{array}{l}\text { Bentonite clays. } \\
\text { Protein crystals }\end{array}$ \\
\hline $\begin{array}{l}\text { Long } \\
\text { range }\end{array}$ & $\begin{array}{l}\text { I mperfect } 1 \mathrm{y} \\
\text { known but may } \\
\text { depend on mu- } \\
\text { tually induced } \\
\text { ionization of } \\
\text { a mphoteric } \\
\text { molecules }\end{array}$ & $<\mathrm{r}$ & $20-3000$ & $\begin{array}{l}\text { Very large am- } \\
\text { photeric particles } \\
\text { roo } \AA \text { or more in } \\
\text { diameter in water } \\
\text { or ionic solutions }\end{array}$ & $\begin{array}{l}\text { Bentonite gels. } \\
\text { Iridescent hydr- } \\
\text { oxide gels. Tac- } \\
\text { toids (tobacco mo- } \\
\text { saic virus). Co- } \\
\text { acervates (Tipula } \\
\text { virus) }\end{array}$ \\
\hline
\end{tabular}

The long-range forces are undirected, but the shapes of mutual equipotential surfaces around flat or elongated particles ensure a tendency towards parallelism. This leads, in the case of identical particles such as viruses, to a liquid-crystal condition for equilibrium sols of such particles with one- or two-dimensional 
long-range order. For spherical particles only short-range order is maintained usually leading to a quasi-liquid arrangement of the particles.

In this last case we find the typical spherical coacervate droplets; in the two first, the parallelism ensures an anisotropic surface tension resulting in spindleshaped drops or tactoids [13], or, when the particles are extremely elongated, to swollen fibres with a regular hexagonal arrangement as in muscie [2].

It will be seen from this brief consideration of the nature of interparticulate forces that not only do they form a sequence of decreasing strength with increasing distance, but also that they operate between particles of increasing scale. It is as if each kind of particle had to be assembled by forces of a lower order until it reached the size at which the higher-order forces operate. It will be noticed that the largest order of magnitude referred to, the full range of the socalled long-range forces, is $1000 \AA$ or one-tenth of a micron, still less than the wavelength of visible light, so that there is still a large step between their range of action and the structures observable in the light microscope. Nevertheless, structures formed by means of them are responsible for the macroscopic appearances and mechanical properties of units of sub-cellular and cellular levels. Most of these ultimately depend on the tensile strength of membranes or fibres and the question is therefore resolvable into that of the weakest forces holding the particles of such fibres together. Owing, however, to the considerable elasticity of configurational or rubber-like character of most of these structures, stresses are so evenly distributed that considerable tensions and pressures can be sustained. By combining the knowledge, still very qualitative, of the interparticle forces with that of the geometrical conditions it is possible to provide some approximately rational classification of the different stages of aggregation occurring in biological structures (Table 2).

The first stage, that of aggregation of single atoms, is covered by the theories of organic chemistry. It ends with the formation of small molecular groups with open or cyclic chains, most of which are found again in higher associations and so may be referred to as monomers. It is noticeable that, apart from the lipids, there are few if any directly atomic polymers found in organisms. It would almost appear that the monomer formation and polymerization processes were intrinsically separate, or at any rate corresponded to different periods in the biopoetic process.

The second stage, the formation of polymers, is still in the field of organic chemistry though in a more recent part of it and its kinetic mechanism has still to be elucidated. For our purpose here it would seem that relatively few types of link are involved which may be put in some order of lability, beginning with the polymetaphosphate link, the sugar-phosphate link occurring in nucleic acids, the peptide link occurring in protein, the polysaccharide link, occurring in starches and celluloses, and the carbon-carbon link, occurring in lipids and rubber. These may also be, as I have indicated in my first paper (p. 38), the order of occurrence in biopoesis, though I would favour, for reasons given there, placing the peptide link before the sugar phosphate.

The nucleic acids and the proteins differ from the other natural polymers in that they are intrinsically heteropolymeric; they are made of a number of 
different monomers arranged for each type of protein or nucleic acid in a characteristic order. The order of amino acids and of nucleotides in related nucleic acids and proteins may be connected (this will certainly be discussed at the Symposium) but here we are concerned with the specific questions of order

TABLE 2

Stages of aggregation occurring in biological structures

\begin{tabular}{|c|c|c|c|c|}
\hline Name of particle & $\begin{array}{l}\text { Nature of last } \\
\text { stage binding }\end{array}$ & $\begin{array}{c}\text { Order of } \\
\text { magni- } \\
\text { tude of } \\
\text { mole- } \\
\text { cular } \\
\text { weight }\end{array}$ & \begin{tabular}{|} 
Order of \\
magni- \\
tude of \\
particle \\
dimen- \\
sions
\end{tabular} & Examples \\
\hline $\begin{array}{l}\text { Simple molecule } \\
\text { (monomer) }\end{array}$ & $\begin{array}{l}\text { Homopolar } \\
\text { bonds }\end{array}$ & $50-200$ & IO $\AA^{3}$ & $\begin{array}{l}\text { Amino acids. } \\
\text { Purines. Porphyrins. } \\
\text { Sugars. Lipids }\end{array}$ \\
\hline $\begin{array}{l}\text { Chain polymer } \\
\text { (Homo or hetero) }\end{array}$ & The same & $\begin{array}{l}1000- \\
100,000\end{array}$ & $\begin{array}{c}5 \times 10 \\
\times 1000 \AA\end{array}$ & $\begin{array}{l}\text { Silk fibroin, } \beta \text {-type. } \\
\text { Denatured proteins. } \\
\text { Cellulose. } \\
\text { Rubber }\end{array}$ \\
\hline Coiled polymers & $\begin{array}{l}\text { Hydrogen bonds } \\
\text { or S-S links }\end{array}$ & $\begin{array}{l}\text { The } \\
\text { same }\end{array}$ & $\begin{array}{l}10 \times 10 \\
\times 500 \AA\end{array}$ & $\begin{array}{l}\text { Coiled fibrous protein, } \\
\alpha \text {-type. } \\
\text { Deoxyribosenucleic acid }\end{array}$ \\
\hline $\begin{array}{l}\text { Folded or coiled-coil } \\
\text { polymers } \\
\text { Globular particles }\end{array}$ & The same & $\begin{array}{l}10,000- \\
100,000\end{array}$ & $(50 \AA)^{3}$ & $\begin{array}{l}\text { Smaller globular proteins. } \\
\text { Ribonuclease }\end{array}$ \\
\hline $\begin{array}{l}\text { Homogeneous agglo- } \\
\text { merated particles } \\
\text { Twined fibres }\end{array}$ & $\begin{array}{l}\text { Ionic or cryo- } \\
\text { hydric forces }\end{array}$ & $\begin{array}{r}50,000- \\
1,000,000\end{array}$ & $\begin{array}{c}(100 \AA)^{3} \\
20 \times 20 \\
\times 1000 \AA^{3}\end{array}$ & $\begin{array}{l}\text { Larger globular proteins. } \\
\text { Haemoglobin. Seed glo- } \\
\text { bulins. } \\
\text { Haemocyanin. } \\
\text { Fibrous insulin. } \\
\text { Collagen }\end{array}$ \\
\hline $\begin{array}{l}\text { Heterogeneous agglo- } \\
\text { merated particles or } \\
\text { fibre aggregates }\end{array}$ & The same & $10,000,000$ & $\begin{array}{c}(200 \AA)^{3} \\
100 \times 100 \\
\times 5000 \AA\end{array}$ & $\begin{array}{l}\text { Nucleoproteins. } \\
\text { Lipoproteins. } \\
\text { Mucoproteins, etc. } \\
\text { Smaller viruses }\end{array}$ \\
\hline
\end{tabular}

only in so far as they affect the configuration of the polymer. One aspect of the polymerization process, however, is relevant to this-its termination-which determines the size of the resulting polymer. In the case of polyamino acids we find in nature to-day a whole range of length from oligopeptides, with from 5 to 20 units like gramicidin S (10), oxytocin (9), adrenocorticotropin (50), through the smaller proteins like insulin (60) to ribonuclease (I28). Whether the number is ever much larger, except in the fibrous proteins like myosin and leratin, is not clear. It seems, however, that the molecules of the larger globular proteins are not constructed of one but several peptide chains.

With the nucleic acids we know less of the existence of oligomers beyond the 
dimers, but this may be simply because they cannot as yet be crystallized. Most of those isolated by centrifugation are certainly very high polymers. Even here, however, there seems to be some natural limit [I4, I5]. The size of polymers is of physico-chemical importance because it determines the nature of the forces, not only between similar particles of polymer as described above, but also between one particle and smaller molecules, offering, for instance, possibilities of oriented adsorption.

Nearly all linear polymers, and certainly those found in organisms, are not rigid structures and can exist in a number of configurations depending on such external circumstances as the temperature, $\mathrm{pH}$ and other properties of the medium in which they are placed. This is also a function of the shape and chemical activity of the monomers, particularly of the parts not immediately involved in the main polymer chains, namely the residues or side chains. Where these are neutral and small, as in the methyl residues of polyisoprene rubber, different chain arrangements have all approximately the same energy and the configuration is random. Where, on the other hand, the residues themselves contain, as in the proteins, polar groups such as $\mathrm{NH}_{4}{ }^{+}$or $\mathrm{COO}^{-}$or, as in the nucleic acids, the large aromatoid molecules of the pyrimidines and purines, stable, low-energy configurations are preferred and these for steric reasons tend to take on a helical form. Hence come the hydrogen-bonded Huggins-Pauling helices of the protein or the double Watson-Crick helices of the deoxyribosenucleic acids, stabilized by the piling of their purine and pyrimidine residues.

The major factor responsible for the configuration of the proteins is the possibility for hydrogen-bond formation. It would appear that in all such configurations every or nearly every available bond-forming hydrogen atom, that is all in $-\mathrm{OH},-\mathrm{NH}$ or $-\mathrm{NH}_{2}$ groups, normally form hydrogen bonds to suitable acceptors such as $-\mathrm{O}-\mathrm{OH}$ or $\mathrm{H}_{2} \mathrm{O}$. This naturally holds as much for side chains as for main-chain groups. Configurations which do not permit the maximum number of bonds will be of high energy and be unlikely to occur. To judge from the degree of order observed in protein crystals, entropy effects do not seem to be important. However, there will in general be a number of configurations of approximately the same maximal hydrogen-bond number and consequently of approximately the same energy, and therefore the actual configuration may depend on other factors-steric effects in the chain itself, relations to other chains or with molecules in the medium. As hydrogen bonds can be formed quite as easily between adjacent or distant portions of the same chain or its side groups or between different chains, the possibility of alternative quasi-stable structures is enormous.

The simple $\alpha$-helix form, internally hydrogen-bonded, though probably the most stable for polypeptides with medium or large side chains is not so for smallside-chain polypeptides, which favour the crosslinked $\beta$-form of silk. Nor is it that adopted by most of the natural crystalline or globular proteins. In the normal $\mathrm{pH}$ range and in the absence of strong hydrogen-bond-breaking substances such as urea, that is, in the undenatured state, such proteins have molecules approximating more to the spherical than to the thread-like shape. This may be simply a consequence of the large effective surface of the pattern. A quasi-spherical 
form implies a more complex folding or coiled coiling of the polypeptide chain than occurs in simple spirals. What precisely is this configuration has yet to be determined in any single case. This is the great object of protein crystal analysis but it must be admitted that so far this has led only to negative results: that is, we know that some of the simpler arrangements of parallel-packed spirals cannot account for the observed intensities of X-ray diffraction from globular protein crystals. We cannot really claim, though here success may be very close, that even the principle of packing of the chains in globular protein is yet understood. All that can be said is that there appears, from the study of the distribution of the shorter interatomic vectors in the analysis of their crystals, that more than one basic arrangement is possible. The configuration in ribonuclease $[\mathrm{I} 6, \mathrm{I} 7]$ differs from that in haemoglobin and related compounds [18, 19].

However, recent work by Kendrew [3r] on the structure of whale myoglobin, using multiple heavy-atom substitution to fix the complex phases of X-ray reflections, indicates an irregularly bent tangle, presumably of polypeptide helices surrounding the haem group.

The biological significance of the folding of protein chains to form globular molecules is not altogether clear. It would appear from studies on enzymic activity [20] that this is equally effective in the extended form produced in strong urea solutions. Further, from the amount of space available, about 10$20 \AA$, presumably, for enzyme protein molecules in the interstices of mitochondria, they can only be in the form of single or double extended peptide chains. Nevertheless, in solution in tissue fluids and possibly also in intracellular fluid, they are present as compact thicker molecules. Also, protein crystals, presumably formed of globular molecules, are occasionally found in cells while the outer shells of viruses and possibly of microsomes as well are also formed of them. We may provisionally, therefore, think of the globular form as one state, possibly only the equilibrium or resting state, of the protein molecules. The biological importance of the larger globular molecules may indeed be rather physico-chemical and colloidal. They would secure by their shape the maximum of easy diffusion and by their size a relative freedom from thermal disturbance. This would give them an importance in maintaining osmotic pressure and as a transport mechanism for amino acids.

Evidence is accumulating that the larger globular protein molecules of mol. wt above 14,000 and even less, as in the case of insulin, are formed of secondary agglomerations of identical or quasi-identical subunits of the minimal simple peptide of between 30 and 100 monomers. This can be proved only by reversible disaggregation, as in the case of haemoglobin with four units which can be split first into two and then into four subunits of the myoglobin type. The way this disaggregation is affected, by the use of extreme $\mathrm{pH}$ or strong ionic conditions, suggests that the links between the units are ionic and a similar explanation would account for the triple association of zinc insulin. With even bigger molecules such as haemocyanin, with a molecular weight of second or even third order, agglomeration of an even more labile character seems to occur and here the subunits are large enough to be seen in the electron microscope.

Another type of agglomeration of protein molecules seems to occur in crystal- 
lization, where the studies of Perutz [21] and his school have shown that linking through water molecules plays a predominant role. The amount of water can be very variable, but it would seem as if protein molecules are separated normally only by one or two layers of water molecules and that in the more hydrated cases the large lacunae between the molecules are filled with ordered water molecules as in ice or cryohydrates. Crystallization is not, however, a common biological phenomenon and aggregates of this sort are probably of very minor importance in biopoesis.

The forms of aggregation of nucleic acid do not at the moment seem to be as complex as those of proteins, but this may be simply on account of our smaller knowledge of them. The necessity of packing the purine pyrimidine groups in a quasi-parallel arrangement leads to a very open helix [22]. Indeed it is too wide for a double helix [23], but this seems to be stabilized in the case of DNA by the complementary purine-pyrimidine double hydrogen-bond linkage, as also is the poly-ribose-adenine, poly-ribose-uridine complex synthesized by Rich [24]. The width and rigidity of the DNA helix would indicate a molecule some I000 $\AA$ or more long and forming a parallel hexagonal arrangement [25] and this has also been shown in vivo in sperm heads [26-28]. However, this cannot always be the case, for in the DNA-containing bacteriophages the width of the head is not more than $200 \AA$, so that some kind of folding or alternative packing must be possible.

The most complex as well as the most interesting structures based on polymer association are the heterogeneous complexes of which the most studied have been the nucleoproteins, though to understand biological structures much will also have to be learned of the lipoproteins and mucoproteins. At the moment it would appear that there are two different kinds of nucleoprotein: one, occurring in sperm, where DNA is linked with small basic protamine molecules; and the other in viruses containing ribosenucleic acid molecules embedded in a protein shell consisting of large-molecule proteins [25, 28]. In the first case the nuclcic acid molecule seems to determine the structure, in the latter case the protein for an almost identical shell can be assembled without nucleic acid. In both cases, however, there can be no doubt that the synthesis of the protein is connected primarily with the nucleic acid, for, in the virus at least, the kind of protein produced in the cell of the infected plant is entirely determined by the kind of nucleic acid introduced.

It is between particles of the order of magnitude of viruses and microsomes (100-300 $\AA$ ) that the long-range forces discussed above can most effectively operate. However, it is difficult to follow out their operation in vivo on account of the number of other particles of approximately the same dimensions usually found in cells, and because of the presence of extensive lipid membranes. Theoretically, however, we would expect such forces to be responsible for the slow movements of internal parts of cells in, for instance, chromosome pairing and mitosis, though here there may also be the effect of the formation of fibres by the $(\mathrm{g}-\mathrm{f})$ transformation and their subsequent contraction in a way that I have speculated on elsewhere [29].

This sketch of the structure and mutual relations of the particles that are 
found in present-day biological structures is still tantalizingly vague in the more complex regions involving the largest particles. It should serve, however, to bring out the main thesis of this paper: that the existence of a whole series of such structures, each with characteristically different properties, goes a long way to help to explain how such an apparently almost infinitely complex organization such as the cell could have been produced step by step from simpler structures right back to the atomic layer, in such a way as I have described in my other paper or in any other based on the same geometrical and physical conditions. Although it would be a mistake to equate precisely the successively more complicated grades of organization described here with the hypothetical temporal stages of biopoesis, the two must have a rough parallelism. The formation of a structure of suitable complexity is a necessary, though not a sufficient, condition for certain physico-chemical functions. For example, the colloidal behaviour always found inside living systems, and probably absolutely necessary for them, must rest on coiled and folded polymers built inside the system itself. It is not my place here to try to trace out these relationships in detail; this will appear from many other contributions. It should be sufficient here to lay down an ordered description of the various types of building blocks and bonds available for biopoesis, as a guide to those who are concerned with other and more dynamic aspects of it.

\section{REFERENCES}

I. J. B. S. HALDANE, New Biol., I6, I2, I954.

2. H. E. HuxLEY, Biochim. biophys. Acta, 12, 387, 1953.

3. A. J. HodGE, F. biophys. biochem. Cytol., 2, I3I, 1954.

4. D. F. Waugh et al., f. Amer. chem. Soc., 75, 2591, 1953.

5. D. L. D. Caspar, Nature, Lond., 177,475 , I956.

6. A. Klug \& R. E. Franklin, Biochim. biophys. Acta, 23, I99, 1957.

7. R. E. Franklin, Biochim. biophys. Acta, 19, 403, 1956.

8. R. J. GOLDACRE, Nature, Lond., 174, 732, I954.

9. K. NorRISH, Discuss. Faraday Soc., 18, 120, 1954.

Io. J. Th. G. Overbeek \& M. J. SparnaAy, Discuss. Faraday Soc., 18, I2, I954.

II. B. V. Deryagin et al., Discuss. Faraday Soc., 18, 24, 1954.

12. J. G. Kirkwood, Proc. nat. Acad. Sci., Wash., 38, 863, 1952.

13. J. D. Bernal \& I. Fankuchen, f. gen. Physiol., 25, i i I, I94I.

I4. W. Frisch-NiggemeYER, Nature, Lond., 178, 307, 1956.

15. P. Y. CHENG, Nature, Lond., 179, 426, 1957.

16. C. H. Carlisle et al., Proc. Roy. Soc., B, I41, 85, 1953.

I7. F. H. C. Crick, Acta cryst., Camb., 9, 908, 1956.

18. Sir L. Bragg \& M. Perutz, Proc. Roy. Soc., A, 225, 315, I954.

19. J. C. Kendrew, Proc. Roy. Soc., A, 237, 255, II; 238, 305, III, I956.

20. C. B. Anfinsen et al. (including Linderstrom-LANG), Biochim. biophys. Acta, I7, I4I, 1955.

21. Sir L. Bragg \& M. Perutz, Proc. Roy. Soc., A, 213, 425, 1952.

22. S. Furberg, Acta chem. scand., 6, 634, 1952.

23. J. D. WATsON \& F. H. C. CRICK, Nature, Lond., 171, 964, I953.

24. A. Rich, f. Amer. chem. Soc., 78, 3548, 1956.

25. R. E. Franklin, Nature, Lond., 177, 930, I956.

26. F. RinNe, Nature, Lond., 126, 279, 1930.

27. M. H. Wilkins \& J. T. Randall, Biochim. biophys. Acta, 10, 192, I953.

28. M. Fevghelman et al. (including M. H. F. Wilkins), Nature, Lond., 175, 834, 1955.

29. J. D. Bernal, The Cell and Protoplasm (Ed. by F. R. Moulton). American Association for the Advancement of Science, Washington, 1940.

30. J. D. Bernal, Discuss. Faraday Soc., 25, 7, 1958.

3I. J. C. Kendrew, Proc. Roy. Soc., A, 246, 369, r958. 


\title{
Biochemical Processes in the Simplest Structures
}

\author{
A. I. OPARIN \\ A. N. Bakh Institute of Biochemistry, U.S.S.R. Academy of Sciences, Moscow
}

IN OUR view the type of organization peculiar to life could originate only as a result of the evolution of a multimolecular organic system, separated from its environment by a distinct boundary, but constantly interacting with this environment in the manner of 'open' systems. Since, as evidenced by a number of features, present-day protoplasm possesses a coacervate structure, the mentioned systems, which represent the starting point for the evolution leading to the origin of life, could have been coacervate drops. But in contrast to the coacervates artificially obtained by laboratory methods these drops had to possess a certain pattern of reactions interlinked in time as characteristic for open systems. Moreover, in the course of their evolution the initial systems must gradually have become more complex and elaborate both in space (in regard to their structure), and in time (i.e., in relation to the reaction pattern).

In a general form these concepts have been discussed in my book The Origin of Life on the Earth (3rd ed., Oliver \& Boyd, Edinburgh, 1957). In the present paper only single experimental data are presented obtained within recent time in my laboratory.

Since initial systems of this type were bound to be destroyed at early stages of the development of life owing to natural selection, and could not have persisted up to the present time under natural conditions, we can put the suggested processes of evolution to the test either by gradually increasing the complexity of artificially obtained systems, or by destroying to a certain extent natural protoplasmic structures and making a study of the fragments thus obtained. It is in these two directions that our experiments have been carried out. Of course they can only be regarded as preliminary ones.

To attain the former aim, we chose, in collaboration with T. Evreinova, T. A. Shubert, M. N. Nestyuk and G. Larionova artificially prepared coacervate drops.

To make their organization approach more closely the organization of protoplasm it was necessary, in the first place, to induce in these drops chemical transformations disturbing their static type of stability. This can most readily be achieved by incorporation, into the coacervate drops, of enzymes which catalyse transformations of substances forming part of these drops. Such incorporation, in principle, is quite possible, but it can only be realized if certain rules are observed. 


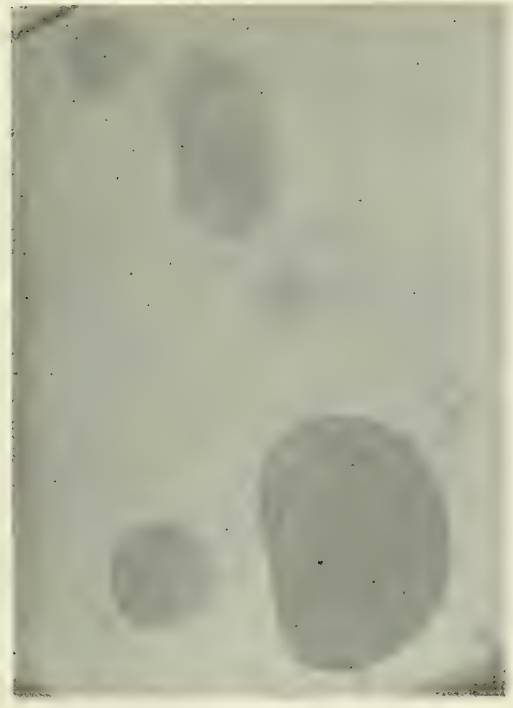

(

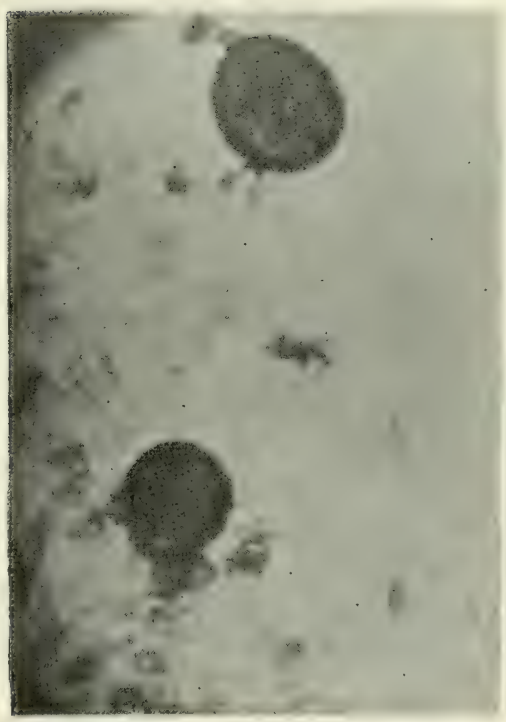

C

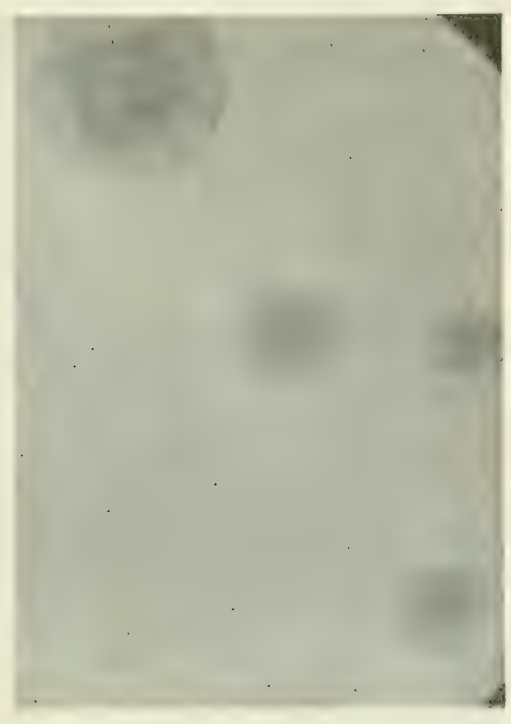

1,

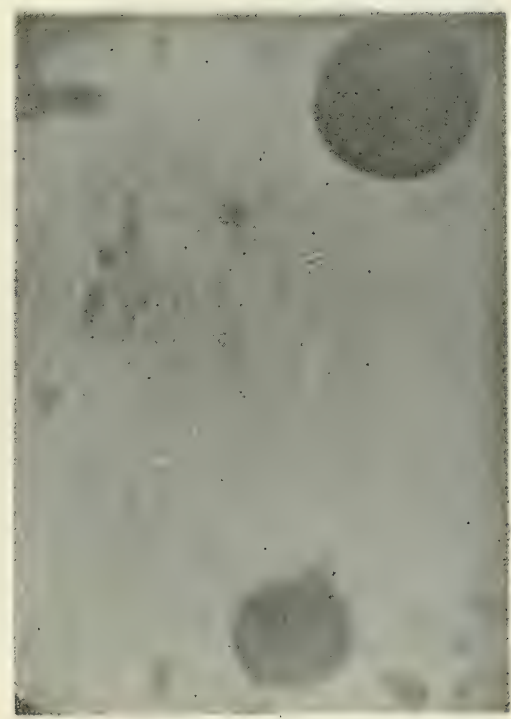

(1)

FIG. I. Effect of $a$-amylase in coacervates:

(a) - starch-containing coacervares; (b) - starch has been broken down to amylodextrins; $(c)$-starch has been broken down to erythrodextrins; $(d)$-starch has been broken down to achroodextrins. 

In such experiments it must, for one, be kept in mind that coacervates formed from certain components can exist only within relatively narrow limits of $\mathrm{pH}$, while the activity of the enzyme to be included into the system requires, in its turn, a definite optimal range of actual acidity. Therefore the success of the work can be assured only if the coacervate selected for observing enzymic activity can exist in the pH range optimal for the activity of the enzyme in point.

Let us consider some actual experimental examples of the inclusion of enzymes into coacervate drops. The condition common to all these experiments is that the coacervates should be prepared from diluted solutions $(0.0 \mathrm{I}-0 . \mathrm{I} \%)$, at a definite temperature. Thirty minutes after incorporation of the enzyme and substrate into the coacervate droplets, the latter are separated from the solution by centrifugation ( $1500-3000 \mathrm{rev} . / \mathrm{min}$ ), and in the sediment and supernatant thus obtained determinations are made of the products of action of the enzyme embodied in the coacervate drops.

To study the effect of $\alpha$-amylase [I] a coacervate was obtained which consisted of soluble starch, gelatin and of protamine sulphate prepared according to Kossel's [2] method from the spawn of Amur salmon. Coacervation was effected in the following way: $0.4 \mathrm{ml}$ of a $0.5 \%$ solution of protamine sulphate, $\mathrm{I} \cdot 2 \mathrm{ml}$ of $0.67 \%$ gelatin solution and $0.1 \mathrm{ml} \alpha$-amylase solution, containing $0.2 \mathrm{mg}$ enzyme, were added to $0.4 \mathrm{ml}$. of $0.1 \%$ soluble starch. The mixture was brought to $\mathrm{pH} 7.0$ with the temperature at $50^{\circ}$. At fixed intervals samples were taken, stained with iodine and photographed with an ultraviolet microscope and chromoscope on colour film.

Figure I $a$ shows coacervates containing starch; Fig. I $b$ coacervates in which the starch was broken down to amylodextrins; Fig. Ic to erythrodextrins; and in Fig. Id it is seen that the degradation of starch reached a stage approaching achroodextrin.

Further analysis showed that under the given conditions the activity of the enzyme in the coacervate was lower than in the aqueous solution of the constituents from which the coacervate was obtained. Evidently, in the coacervate drops possessing considerable viscosity due to their high content of protamine and gelatin, the rate of movement of the substances diminishes, while the adsorption capacity of the drops is increased. The experiment shows how marked an influence even a structure so primitive in the biological sense as are coacervate drops may have on the course of individual enzymic reactions.

A study of the degradation of starch to sugar in coacervate drops was made with the use of $\beta$-amylase [3]. To obtain coacervate drops, $2 \mathrm{ml}$ of $0.67 \%$ aqueous solutions of gelatin and gum arabic, taken in the ratio $5: 3$, were mixed with $0.5 \mathrm{ml}$ of a $\mathrm{I} \%$ solution of phosphorylated or soluble starch and $0.5 \mathrm{ml}$ of $0.05 \%$ amylase solution. The mixture was brought to $\mathrm{pH} 4.82-4.85$ with the temperature at $40-42^{\circ}$ and kept 15 minutes at this temperature. Preliminary sampling showed that the amount of starch of the coacervate drops was equal to $13.1 \%$ of the total starch present in the whole coacervate (drops and liquid phase).

Calculation for unit volume shows that the concentration of starch in the coacervate drops was 4.5 times higher than in the equilibrium fluid. The $\beta$ - 
amylase was determined in the drops with the indicated starch content. The results are given in Table $\mathrm{r}$.

\section{TABLE I}

The effect of $\beta$-amylase on starch in coacervate drops

\begin{tabular}{|c|c|c|c|c|c|}
\hline \multirow{4}{*}{$\begin{array}{l}\text { Substrate } \\
\text { preparation }\end{array}$} & \multirow[b]{4}{*}{ Sample } & \multicolumn{4}{|c|}{$0.0 \mathrm{I} \mathrm{N}-\mathrm{KMnO}_{4}(\mathrm{ml})$} \\
\hline & & \multirow{2}{*}{\multicolumn{2}{|c|}{$\begin{array}{c}\begin{array}{c}\text { Coacervate } \\
\text { drops }\end{array} \\
\text { (Sediment) }\end{array}$}} & \multirow{2}{*}{\multicolumn{2}{|c|}{$\begin{array}{c}\begin{array}{c}\text { Equilibrium } \\
\text { fluid }\end{array} \\
\text { (Supernatant) }\end{array}$}} \\
\hline & & & & & \\
\hline & & I & 2 & I & 2 \\
\hline Soluble starch & $\begin{array}{l}\text { Experimental } \\
\text { Control }\end{array}$ & $\begin{array}{l}0.65 \\
0.19\end{array}$ & $\begin{array}{l}0.75 \\
0.20\end{array}$ & $\begin{array}{l}3 \cdot 45 \\
0.20\end{array}$ & $\begin{array}{l}3 \cdot 70 \\
0 \cdot 20\end{array}$ \\
\hline Phosphorylated starch & $\begin{array}{l}\text { Experimental } \\
\text { Control }\end{array}$ & $\begin{array}{l}I \cdot 10 \\
0.62\end{array}$ & $\begin{array}{l}I \cdot 24 \\
0.57\end{array}$ & $\begin{array}{l}7 \cdot 46 \\
0 \cdot 33\end{array}$ & $\begin{array}{l}7 \cdot 42 \\
0 \cdot 33\end{array}$ \\
\hline
\end{tabular}

The figures in the table show that the concentration of reducing sugars, computed for unit volume, was four times greater in the coacervates than in the equilibrium fluid. Consequently, formation of the reaction products is concentrated in the coacervates due to the fact that they contain the enzyme. In this case also we can regard the coacervates as systems in which the morphological structure substantially influences the nature of the process.

In order to test the alternative possibility that the increased concentration of reaction products in the coacervate drops was due to absorbed sugar from the surrounding solution, control experiments were made with the addition of maltose to coacervate containing inactivated amylase; in this case all the added maltose was recovered in the equilibrium fluid, and not in the coacervate sediment. Evidently, we are justified in regarding the presence of maltose in the coacervate drops under the adopted experimental conditions as a result of the action of $\beta$-amylase in the coacervate drops on starch embodied in these drops.

A good illustration of the incorporation of enzymes into coacervates are our experiments on the coacervation of bacterial lysates. A solution (lysate) of Micrococcus lysodeikticus cclls with high catalase activity was obtained from N. Gel'man. The experiments were carried out in the following way: $0.2 \mathrm{ml}$ of O.OI $\mathrm{M}$ phosphate buffer with a fixed $\mathrm{pH}, \mathrm{O} . \mathrm{I} \mathrm{ml}$ of bacterial lysate diluted I : IOO, (the method of preparing the lysate is given in the following section) followed by $0.25 \mathrm{ml}$ of $0.67 \%$ aqueous solution of gum arabic were added to $0.5 \mathrm{ml}$ of $1.5 \%$ aqueous solution of protamine sulphate obtained from the spawn of sevruga sturgeon by Kossel's method. The complete mixture with $\mathrm{pH} 6.0$ was maintained in a water bath for 3 minutes at temperature of $+4 \mathrm{I}-$ $43^{\circ} \mathrm{C}$. The formation of coacervate drops was controlled with the microscope in all experiments. Then $0.2 \mathrm{ml}$ of $0.64 \% \mathrm{H}_{2} \mathrm{O}_{2}$ solution was added to the mixture. Incubation with hydrogen peroxide lasted from 2 to 5 minutes. After this the enzyme was inactivated by $0.4 \mathrm{ml}$ of $10 \%$ (w/v) $\mathrm{H}_{2} \mathrm{SO}_{4}$. The activity of the 
enzyme was expressed in terms of $\mathrm{ml} . \mathrm{O}^{\circ} \mathrm{Or} \mathrm{N}-\mathrm{KMnO}_{4}$ consumed for titration of the remaining hydrogen peroxide. Simultancous control determinations were made on samples with inactivated enzyme. The catalase of the lysate was inactivated in the autoclave at $\mathrm{I}$ atm. for 30 minutes.

In this way we determined the total catalase activity of the whole coacervate, consisting of coacervate drops and the surrounding equilibrium fluid.

To decide the question as to how the enzyme was distributed between the coacervate drops and the equilibrium fluid, we prepared two coacervates, 'A' and ' $B$ '. Coacervate ' $A$ ' contained the active enzyme, while coacervate ' $B$ ' contained inactivated enzyme. Both coacervates were kept without $\mathrm{H}_{2} \mathrm{O}_{2}$ for three minutes at a temperature of $+4 \mathrm{I}-43^{\circ} \mathrm{C}$ and then centrifuged in the cold. The supernatant of coacervate ' $B$ ' was added to the sediment of coacervate ' $A$ ', while the sediment of coacervate ' $B$ ' was added to the equilibrium fluid (supernatant) of coacervate ' $\mathrm{A}$ '.

Thus, the first system corresponded to the coacervate drops of the coacervate containing the active enzyme, and the second system to the equilibrium fluid of that same coacervate.

These mixtures were placed in a thermostat at $4 \mathrm{I}-43{ }^{\circ} \mathrm{C}$ for three minutes; then hydrogen peroxide was added to them and the activity of the enzyme was determined in the manner described above.

The results of the experiments are shown in Table 2.

TABLE 2

Determination of the activity of catalase in coacervates

\begin{tabular}{|c|c|c|c|}
\hline \multirow[b]{3}{*}{ System } & \multicolumn{3}{|c|}{$0.0 \mathrm{I} \mathrm{N}^{-\mathrm{KMnO}_{4}(\mathrm{ml} .)}$} \\
\hline & \multicolumn{3}{|c|}{ Time of incubation with $\mathrm{H}_{2} \mathrm{O}_{2}$} \\
\hline & $2 \mathrm{~min}$. & $3 \mathrm{~min}$. & $5 \mathrm{~min}$ \\
\hline Coacervate $\mathbf{A}$ (coac. drops + equil. fluid) & $2 \cdot 23-2 \cdot 55$ & $I \cdot 50$ & 0.73 \\
\hline Coacervate B (enzyme inactivated) & $7 \cdot 23-7 \cdot 30$ & $7 \cdot 0$ & $7 \cdot 25$ \\
\hline Coacervate drops A + equil. liquid B . & $2 \cdot 10-2 \cdot 20$ & $1 \cdot 70$ & $0 \cdot 70$ \\
\hline Equil. liquid $\mathrm{A}+$ coacervate drops $\mathrm{B}$. & $7 \cdot 05-7 \cdot 05$ & $7 \cdot 23$ & $7 \cdot 00$ \\
\hline
\end{tabular}

The figures given above show that the catalase activity of the bacterial lysate is concentrated entirely in the coacervate drops, while there is practically no enzyme in the equilibrium fluid.

The second method of investigation suggested by us was applied in studies carried out in collaboration with N. Gel'man and I. Zhukova. Methods recently developed for the isolation of separate structural clements of the cell have made possible the study of the connection between the structure of the cell and the processes taking place within it. In our experiments we made use of the fact that by treatment of the cells of Micrococcus lysodeikticus with lysozyme in the presence of different concentrations of sucrose, fragments of bacterial cellsprotoplasts-can be obtained with a greater or lesser degree of destruction of the 
cell structure. In the experiments we used cultures of Micrococcus lysodeikticus No. 2665, Fleming strain, grown for 24 hours on meat peptone agar. The lysozyme was obtained by the method of Alderton, Ward \& Fevold [4]. The mixture in which the lysis was conducted consisted of $3.53 \mathrm{mg} \mathrm{NaCl}, 12.84 \mathrm{mg}$ succinic acid neutralized with $0.1 \% \mathrm{NaOH}$ solution to $\mathrm{pH} 6.5,0.05 \mathrm{mg} \mathrm{MgSO}_{4}$, $0.4 \mathrm{mg}$ of lysozyme, and sucrose solution, the concentration of which varied according to the conditions of the experiment. The protoplasts were obtained at the following molar concentrations of sucrose: $0.84 ; 0.74 ; 0.64 ; 0.54 ; 0.44$; 0.34 and 0.24 . The total volume of the reaction mixture was $2 \mathrm{ml}$. The weight of bacterial mass for the experiments on incorporation of labelled amino acids was $54 \mathrm{mg}$; for experiments on the biosynthesis of protein and for the determination of phosphate fractions it amounted to $150 \mathrm{mg}$ per sample. Lysis lasted for 30 minutes at a temperature of $37^{\circ}$. Photographs taken in phase contrast and with dark-field illumination testify that the protoplasts obtained after lysis were completely homogenous structures, sharply distinct from intact cells, and contained no admixture of the latter (Fig. 2). The micrographs of the protoplasts illustrate the process of the gradual breakdown of the cell with varying concentrations of sucrose present in the medium during lysis (Fig. 3). Lysis of bacteria in different concentrations of sucrose led to the passage of intracellular substance into the surrounding solution; this can be estimated by measuring the absorption at $260 \mathrm{~m} \mu$. The breakdown of the structure greatly influences the course of various processes. We were interested primarily in the integrated multistage processes of respiration and protein synthesis in which particularly marked co-ordinating effects of cell structure could be expected. We succeeded [5] in finding the threshold of preservation of the 'structure' below which the mentioned processes are sharply inhibited. This threshold proved to be different for respiration and for the incorporation of labelled amino acids. As shown by the following graph lowering of the sucrose concentration in the medium to less than $0.64 \mathrm{M}$ results in a decrease of the uptake of oxygen by the protoplasts associated with alteration of the respiratory quotient $(0.85-0.50)$. The latter phenomenon provides evidence that there occurs not only a decrease in intensity of the process but also a failure of the co-ordination of its links (Fig. 4).

Experiments on the incorporation of labelled amino acids were carried on with $\left[{ }^{1 \cdot 4} \mathrm{C}\right]$ glycine, added at a level of 150,000 counts $/ \mathrm{min} / \mathrm{ml}$ of reaction mixture. After incubation the reaction was stopped with trichloroacetic acid. The precipitate was then washed in the centrifuge (25 times), dried and assayed for radioactivity. From the radiometric data given in Fig. 4, it can be seen that within the limits of 0.34 to $0.44 \mathrm{M}$-sucrose concentration the rates of incorporation are approximatcly equal (I200-1000 counts/min/IO $\mathrm{mg}$ of dry weight of the protoplasts). On lowering the sucrose concentration below the level indicated, the incorporation was abruptly inhibited. In the absence of sucrose there is practically no incorporation, in accordance with the findings of other authors. The incorporation of glycine in the protoplasts is completely suppressed by biomycin $(200 \mu \mathrm{g} / \mathrm{ml}$ of reaction mixture); considerable inhibition (of the order of 90$95 \%$ ) is caused by $2: 4$-dinitrophenol, potassium cyanide, sodium azide, or sodium fluoride. It may be concluded from these data that the incorporation 

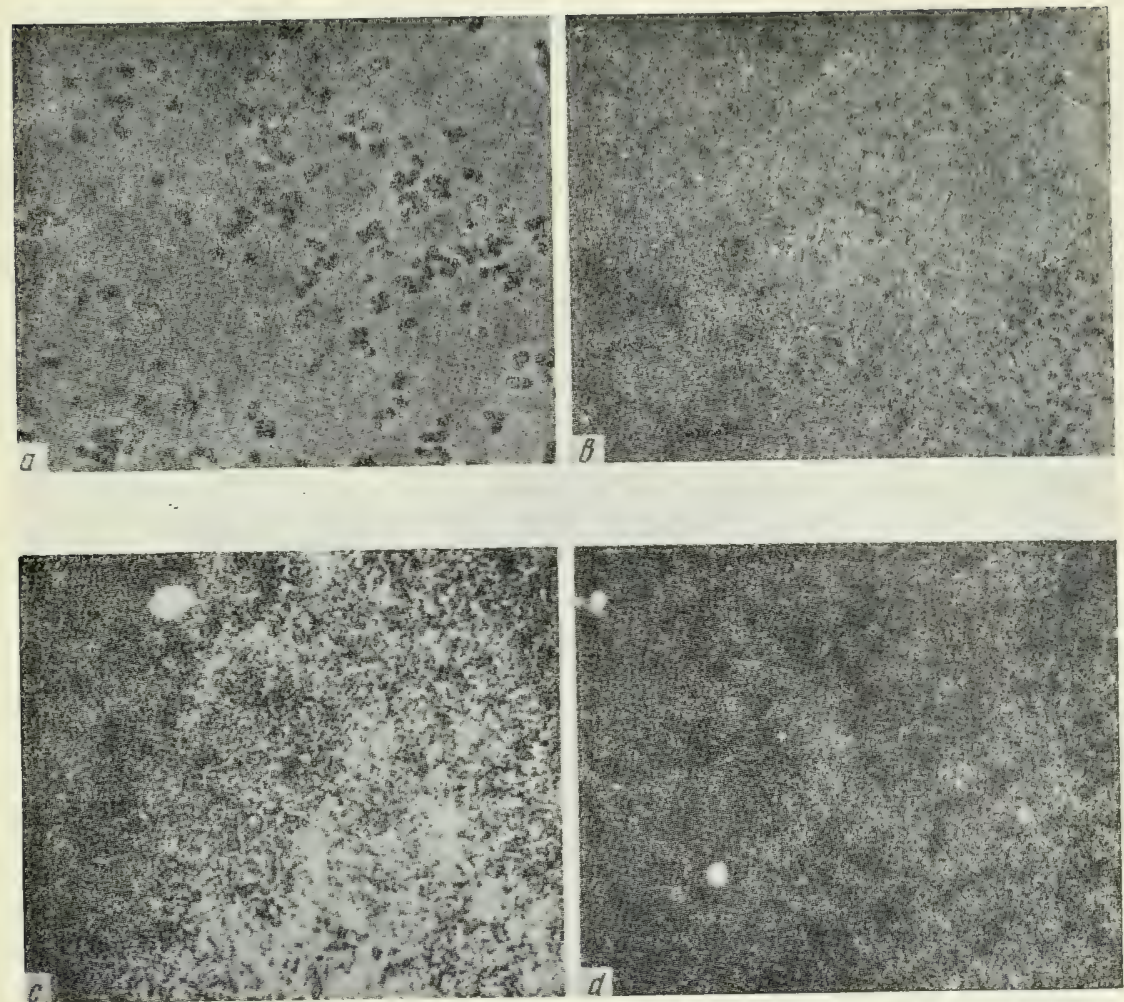

Fig. 2.

(a) -intact cells (phase-contrast $90 \times 7)$; (b) - same after lysis in $0.64 \mathrm{M}$-sucrose; $(c)$-intact cells (dark field $8 \times 7) ;(d)$-same after lysis in $0.44 \mathrm{M}$-sucrose. 
5
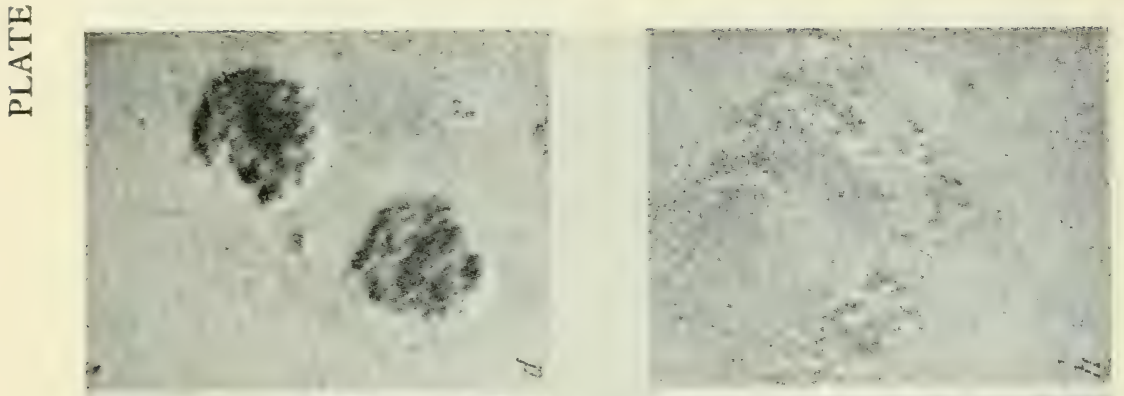

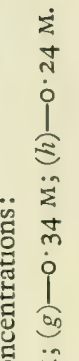
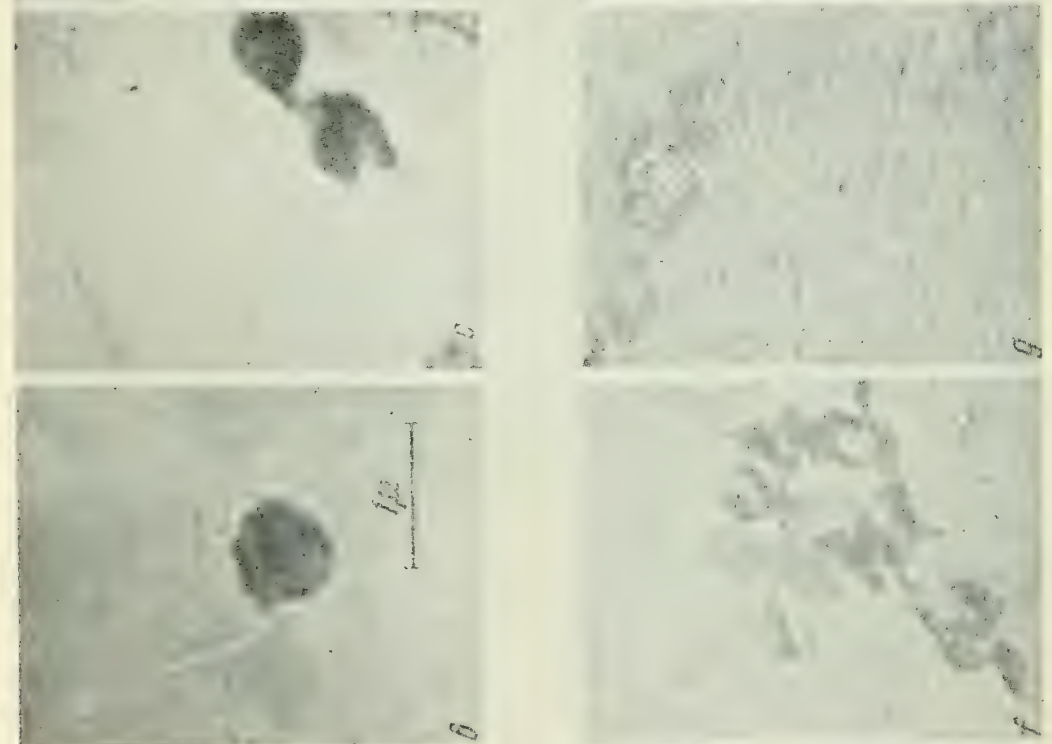

¿ี

莳宓

임

o s

远药

$>$ 过

पै

苟 1 总

응

品

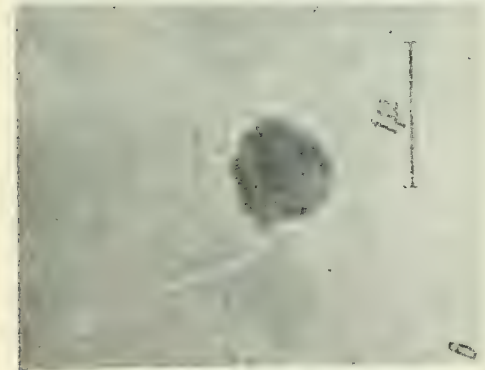

○े

(

을

o $\cdots$

之े

$\sum$

盛

¿

芯

क्षे के
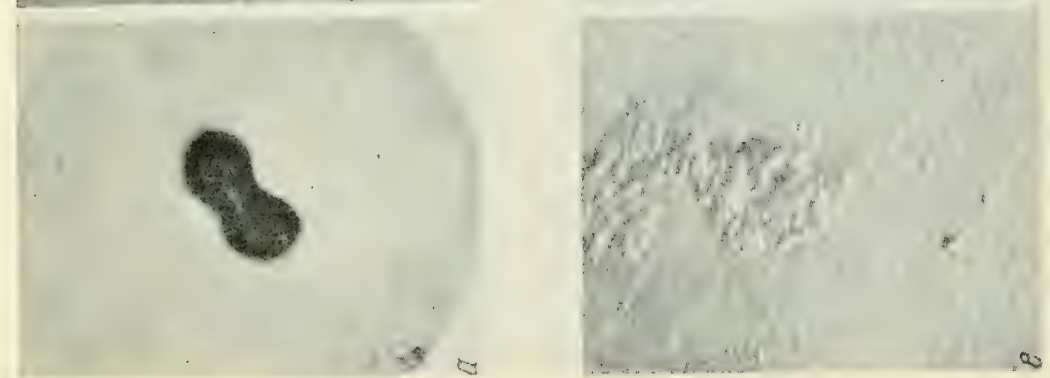

त 1

o

更

嵒

\begin{tabular}{l}
$z$ \\
$z$ \\
\multirow{4}{a}{} \\
0 \\
0
\end{tabular} 
of amino acids into the protein of the protoplasts under study is indeed one of the possible stages of the synthesis of protein, as suggested by Gale [6] and Borsook [7]. Energy is required for this reaction, as indicated by its suppression with 2 :4-dinitrophenol and sodium azide. However, the amount of energy needed is probably not great since incorporation still continues at those levels of destruction of the cell at which the protoplasts exhibit a low intensity of the respiratory process.

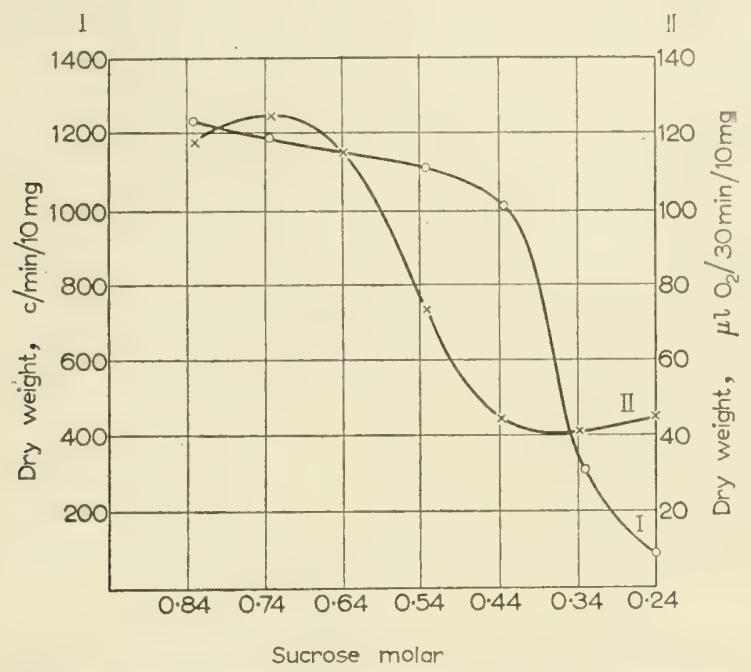

FIG. 4. Respiration of protoplasts (II) of M. lysodeikticus and incorporation of labelled glycine (I).

With the aim of ascertaining the sources of energy for the process of incorporation we determined some fractions of soluble phosphorus compounds in the filtrates obtained upon precipitation of the protoplasts with trichloroacetic acid. The mineral P (orthophosphate) and the ' 7 -minute P' (after hydrolysis for 7 minutes with $\mathrm{N}-\mathrm{HCl}$ ) were determined. The phosphorus was estimated by

\section{TABLE 3}

Assimilation of mineral phosphate during $\mathbf{2} 20$ minutes by protoplasts obtained at different sucrose concentrations

Results expressed as $\mu \mathrm{g} \mathrm{P}$ in the total volume of the reaction mixture (I ml)

\begin{tabular}{|c|c|c|c|c|}
\hline \multirow[b]{2}{*}{$\begin{array}{c}\text { Molarity of } \\
\text { sucrose }\end{array}$} & \multicolumn{2}{|c|}{ Mineral $\mathrm{P}$} & \multicolumn{2}{|c|}{ 7-minute $\mathrm{P}$} \\
\hline & Initial & $\begin{array}{c}\text { After } \\
120 \mathrm{~min} .\end{array}$ & Initial & $\begin{array}{l}\text { After } \\
\text { I20 min. }\end{array}$ \\
\hline 0.84 & 135 & 123 & 167 & 140 \\
\hline 0.64 & 140 & 127 & 169 & 140 \\
\hline 0.44 & 140 & $13 I$ & 165 & I 53 \\
\hline 0.24 & 149 & 132 & 176 & 145 \\
\hline Intact cells & I32 & 88 & 160 & 130 \\
\hline
\end{tabular}


the Lowry-Lopez method. I00 $\mu \mathrm{g}$ of orthophosphate per I $50 \mathrm{mg}$ of bacterial mixture were added to the reaction mixture. The total volume of the samples was I ml (Table 3).

The figures in the table show that mineral phosphorus from the experimental mixture is assimilated both by the intact cells and by the protoplasts obtained aiter lysis at different sucrose concentrations. According to the data given by Kane \& Umbreit [8], and recently by Rose \& Ochoa [9] the disappearing phosphate is recovered in the fraction of easily hydrolysed organic phosphorus compounds. According to our data the phosphorus of the mentioned fraction not only does not increase but even decreases, which may indicate an accumulation of organic phosphorus compounds of the type of polynucleotides. Such observations were made earlier by A. N. Belozerskil for actinomycetes [Io].

It should be noted that the nature of the process and its intensity are practically unaltered in protoplasts obtained at different concentrations of sucrose, as opposed to the processes of respiration and of incorporation of labelled amino acids. The process is, evidently, already impaired in the protoplasts from $0.84 \mathrm{M}$ sucrose solution, as compared with the intact cells; thus it is very sensitive and readily subject to 'uncoupling'.

The findings concerning the transformation of the fractions of phosphates in different preparations of protoplasts confirm our assumption that the incorporation of labelled amino acids requires but very small amounts of energy, as produced even in such disrupted systems as the protoplasts obtained under conditions of lysis in the presence of $0.44 \mathrm{M}$-sucrose. Obviously it is not the lack of energy which is the cause of suppression of the process of incorporation in protoplasts prepared under conditions of lysis at sucrose concentrations lower than $0.44 \mathrm{M}$. Here we are dealing with some kind of serious damage to the cell structure which completely inhibits the incorporation of labelled amino acid into the protoplasts.

Preliminary experiments were further carried out on the biosynthesis of protein in protoplasts prepared as described. To perform such experiments was of interest both with a view to investigating the process of protein biosyntheses as such, and for the purpose of elucidating the role of cell structure in this process. A number of studies, particularly those published recently, have been devoted to investigation of the process of protein biosynthesis in bacterial extracts, or cellular fragments. As an example of this we can cite the well-known experiments of Gale with fragments of the cell of Staphylococcus aureus and the work of the French scientists Nisman, Hirsch, Marmur \& Cousin [II]. In most of the studies on protein biosynthesis in different objects the process was measured by the increase in activity of some enzyme, selected by the investigator. Yet we bclicve that the increase in enzymic activity which takes place during incubation of cells, disrupted by one method or another, with amino acids and some other substances (particularly ATP) cannot in itself be considered as an cntirely reliable indication of the synthesis of protein.

The fact is that the enzymes, as shown by the author's earlier studies as well as those recently performed in his laboratory, can exist in the cell in a bound, inactive state, and can be liberated by the action of various factors. For example, 
the invertase of the yeast Saccharomyces globosus which is incapable of fermenting sucrose, is revealed upon treating the cells with ultrasonic waves, or after prolonged autolysis, these agents disrupting the complex of the enzyme with other high-molecular substances of the cell [12].

With these considerations in mind we undertook to measure the biosynthesis of proteins by determining the increase of protein nitrogen. In similar experiments, made with liver granules Khesin observed [13] a 10-20\% increase in protein nitrogen. In our experiments O. I $\mathrm{ml}$ of a solution of 19 amino acids, containing $40 \mathrm{mg}$ each amino acid $/ \mathrm{ml}$. was added to $2 \mathrm{ml}$. of the bacterial lysate representing a suspension of protoplasts in buffer solution with the selected concentration of sucrose. The experiments in which we determined the increase of protein nitrogen in the presence of the complete set of amino acids were conducted at $\mathrm{pH} \mathrm{8.7,} \mathrm{i.e.,} \mathrm{in} \mathrm{conditions} \mathrm{ensuring} \mathrm{solubility} \mathrm{of} \mathrm{all} \mathrm{amino} \mathrm{acids} \mathrm{in} \mathrm{the}$ reaction mixture. After incubation and precipitation with five volumes of trichloroacetic acid $(10 \%)$ the samples were centrifuged and the precipitates were quantitatively transferred to combustion flasks.

The data obtained are of a preliminary nature; they show that the maximum increase of protein nitrogen in the protoplasts can be observed when the latter are obtained by lysis in $0.84 \mathrm{M}$-sucrose solution. In these experiments bacteria lysed in the absence of sucrose and incubated with amino acids in the same conditions served as the control (Table 4).

\section{TABLE 4}

Protein nitrogen content of protoplasts after incubation with complete set of amino acids

\begin{tabular}{|c|c|c|c|}
\hline \multirow{3}{*}{$\begin{array}{l}\text { Molarity of } \\
\text { sucrose }\end{array}$} & \multicolumn{3}{|c|}{$\begin{array}{l}\text { Per cent increase of protein } \\
\text { nitrogen }\end{array}$} \\
\hline & \multicolumn{3}{|c|}{ Experiment } \\
\hline & No. I & No. 2 & No. 3 \\
\hline 0.84 & IO & II & I2 2 \\
\hline 0.64 & - & 6 & I2 \\
\hline 0.44 & - & 5 & 8 \\
\hline 0.24 & - & 0.00 & 0.00 \\
\hline
\end{tabular}

These figures show that the increase in protein nitrogen, which to a certain extent proves the biosynthesis of the protein, directly depends on the state of the structure of the protoplasts, to which this process is related in a similar manner as has been found for the incorporation of labelled amino acids. It should be emphasized however that these data are of a preliminary kind, since it is essential to investigate the effects on this process of drugs inhibiting respiration and biosynthesis, for example, dinitrophenol, potassium cyanide, sodium azide and others. Besides, another difficult problem still remains to be solved: the correlation which exists between the action of proteolytic enzymes and the con- 
centration of the products of disintegration in the medium, for we must keep in mind that the systems under investigation have active proteases, while the concentrations of added amino acids are quite high.

In the conditions of our experiments only the concentration of sucrose was varied, which altered the multimolecular structural elements, but had no effect on the number and structure of molecules constituting them.

The data reported above indicate that integrity of the multimolecular structure is a necessary condition for the complete synthesis of protein, as measured by the increase of protein nitrogen. It is, moreover, noteworthy that preservation of a constant amount of nucleic acids in the system is not yet a sufficient factor for the normal course of protein biosynthesis.

\section{REFERENCES}

I. A. I. Oparin, T. Evreinova, T. A. Shubert \& M. N. Nestyuk, Dokl. Akad. Nauk S.S.S.R., 104, 581, 1955.

2. H. Kossel, Hoppe-Seyl. Z., 22, I77, I896.

3. T. Evreinova, T. Shubert \& M. Nestyux, Dokl. Akad. Nauk S.S.S.R., 105, 137, 1955.

4. W. Alderton, H. WARD \& J. Fevold, f. biol. Chem., 157, 43, I945.

5. A. I. Oparin, N. Gel'man \& I. Zhukova, Dokl. Akad. Nauk S.S.S.R., 105, 1036, I955.

6. E. F. GaLE, Rapports et Conférences de 3-ème Congr. de Biochimie. Liège, 1956.

7. H. Borsook, Rapports et Conférences de 3-ème Congr. de Biochimie. Liège, 1956.

8. D. O'KANE \& W. UMBreit, F. biol. Chem., 142, 25, I942.

9. J. Rose \& S. OсHOA, f. biol. Chem., 220, 307, 1956.

IO. A. N. BELOzERSKIĬ, in press.

I I. B. Nisman, M. Hirsch, J. Marmur \& D. Cousin, C.R. Acad. Sci., Paris, 241, 1349, 1955.

I2. A. I. Oparin, N. Gel'Man \& I. Zhukova, Dokl. Akad. Nauk S.S.S.R., 97, 293, 1954.

I3. R. B. Khesin \& S. K. PetrashraǏte, Biokhimiya, 20, 597, 1955.

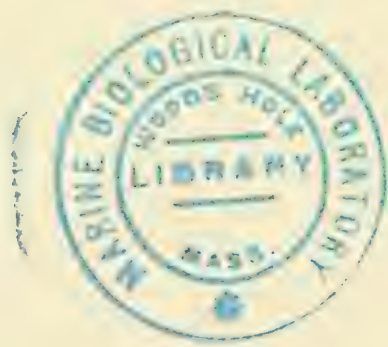




\title{
Protein Complexes as Biochemically Active Systems
}

\author{
G. A. DEBORIN
}

A. N. Bakh Institute of Biochemistry, U.S.S.R. Academy of Sciences, Moscow

SCIENCE TO-DAY is in possession of certain information about the possible paths of evolution of matter from inorganic compounds resulting in the appearance of organic substances, amino acids, polypeptides, etc. The least-studied stage in the development of matter towards the appearance of life seems to be the transition from relatively simple protein-like substances to biochemical systems of ever increasing complexity and then to complex protein systems displaying metabolism [I].

The data accumulated by biochemistry indicate that, owing to their high reactivity, proteins do not, as a rule, occur in contemporary living organisms in the free state, but are to be found in them in various complex formations with one another and with other substances. This appears to be one of the causes of what is known as the microheterogeneity of proteins. It is also characteristic that most enzymes are compounds of proteins with non-protein substances, which are largely responsible for the specificity and activity of enzymes.

These facts suggest that the first phase in the appearance of multimolecular protein systems might have been the formation of complexes of varying degrees of complexity, the components of which might have been primordial proteins and various groups of non-protein substances that, compounded with a corresponding protein, become capable of diverse transformations. The formation of such complexes may have been one of the stages in the appearance of conjugated proteins, including enzymes. In the process of their subsequent evolution these compounds acquired the specific functions in which they fundamentally differ from their constituents.

In connection with these concepts it appears highly interesting to elucidate the mechanism of formation and biochemical peculiarities of protein complexes, since the data obtained in this way would enable us to gain an insight into certain chemical processes underlying biological phenomena.

The information available concerning the interaction of proteins with other proteins [2] nucleic acids [3], polysaccharides [4], lipids [5], detergents [6], ions [7] etc., indicates that, depending on the chemical nature of the reactants, the character of the bonds arising between them may differ. Evidence is on hand pointing to the fact that the links between the components of such complexes may be based either on electrostatic interactions, or hydrogen bonds, or van der Waals' forces, or, finally, on covalent chemical bonds. It is natural to expect 
that the functions of both the protein and the non-protein components of the complex will depend on the type of bond, on the chemical groups affected by them and their influence on protein macrostructure. What appears particularly important is the alteration of the catalytic functions of the proteins in the process of complex formation, which, judging from all the available information, may play a certain controlling role in the creation of the multitude of enzymic processes which take place in a living organism. The discovery of such alterations would provide a basis for a deeper understanding of the mechanism of enzymic activity of the living cell and would help to establish certain notions concerning the possible paths of evolution of the primary proteins.

Owing to the importance of nucleic acids and lipids in the organism, investigators naturally gave their attention first to studying the influence of these types of compounds on the activity of certain proteolytic and hydrolytic enzymes. Slavik \& Smetana [8] demonstrated that yeast ribonucleic acid (RNA) and adenine in physiological concentrations inhibit the action of proteinases below their isoelectric point. Chepinoga \& Pavlovskii [9] established the reversible inhibition of the enzymic activity of aldolase and enolase on their combining with nucleic acids, especially with highly polymerized deoxyribonucleic acid. It was discovered by Šorm \& Grubesova [10] that pancreatic proteases are inactivated by pancreatic RNA. It is noteworthy that the inhibition of the protease activity of chymotrypsin does not involve alteration of its ability to participate in polypeptide synthesis. Robert \& Polonovsky [II] found that the destruction of lipoprotein complexes enhances the activity of milk xanthine oxidase, while Spiegelman [12] revealed that treatment of the protoplasts of Bacillus megaterium by trypsin and lipase totally suppresses the synthesis of enzymes in these protoplasts. There are a number of indications that protein substrates, when associated with nucleic acids, lipids or polysaccharides, are more stable to attack by a number of enzymes [13]. The study of the action of pharmacologic agents in the organism revealed that interaction with proteins reduces the physiological activity of a number of drugs. Thus, blood plasma lowers the activity of penicillin [14]; interaction with serum albumin reduces the antibacterial activity of oleic acid with regard to Mycobacterium tuberculosis [15] and the haemolytic activity of the fatty acids with respect to erythrocytes [I6], and so on. The limited data at our disposal at present thus definitely confirm the view that when proteins form complexes with other substances, this can appreciably alter the activity of both components.

Another trend in the study of lipoproteins aims at elucidating their rôle in the formation of coacervates, the surface layers of cellular organoids, protoplasmic membranes and other structural elements of living matter. Bungenberg de Yong [17] demonstrated, in a series of papers, that the first stage in protein and lipid coacervation is the formation of complexes between them, with surface phenomena at the interphase playing a substantial part. There is an extensive literature $[18-20]$ to confirm that protein and lipoprotein surface layers play an important part in the formation of cellular structures, determining not only the permeability of these structures, but also, largely, the metabolic processes in the protoplasm. It is natural to assume therefore, that great importance in 
establishing the rôle of morphological structures in biochemical processes in the cell attaches, among other problems, to the study of the whole series of problems relating to the interaction of proteins and lipids.

Model experiments were staged by the author of the present paper to study the interaction of certain proteins with hydrophobic substances of a lipid nature; their interaction, by virtue of the specific features in the chemical structure of the constituents, is due chiefly to van der Waals' forces, and does not cause substantial changes in the energy characteristics of the protein molecule. In earlier papers [2I] it was pointed out that egg albumin, when mixed with crystalline ergosterol at $37-40^{\circ} \mathrm{C}$, forms a complex containing one sterol molecule for every two protein molecules. Further investigations revealed that the protein-sterol complex is stable within a definite $\mathrm{pH}$ range (4-5) close to the isoelectric point of the protein. To ascertain what factors influence the formation and stability of protein-sterol complexes, we investigated the action of various denaturing agents. It was shown [22] that the addition of guanidine or urea to the initial protein solution inhibits its ability to form a complex with sterol, while their addition to the already formed complex does not lead to its decomposition in these same conditions, provided the optimal range of $\mathrm{pH}$ for complex formation is retained. It was also found [23] that the addition of $0.25 \%$ of cysteine to the solution stabilizes the complex to ultra-violet irradiation, which in the absence of cysteine decomposes the complex. From these experiments we drew the conclusion that the ability of the protein to form complexes with sterol depends on the preservation of its native structure, and that the complexes of egg albumin with ergosterol are more stable with respect to denaturing influences than the initial protein is.

In subsequent papers [24-25] we established, in conformity with the facts known concerning natural lipoproteins, that the lability of artificial proteinlipid complexes is not only determined by the state of the protein molecule, but also depends on the condition of the sterol molecule. More specifically, it was established that if a solution of the complex is kept in contact with air for several hours, it is split into its initial components. The decomposition of the complex in these conditions was found to be due to sterol oxidation, which can be catalysed by copper ions, just as in the case of natural lipoproteins. This pointed to a certain similarity between our artificial protein-lipid complexes and the lipoproteins isolated from organisms; the similarity is in composition and stability conditions, which helps to understand the factors controlling the transformations of these important compounds in the organism. It should be noted that we established formation of the above-mentioned protein-sterol complexes by means of two independent methods: by studying the isotherms of compressibility of the protein in a unimolecular layer on $5 \%$ ammonium sulphate solution and by the method of paper electrophoresis.

It was particularly interesting, in relation to the problem we are studying, to obtain complexes of lipid substances with enzyme proteins and to investigate the changes in enzyme activity resulting from complex formation. For this purpose we prepared complexes of trypsin with ergosterol according to the method described earlier. The formation of these complexes was determined on the basis 
of the isotherms of trypsin compressibility in a monolayer on $5 \%$ ammonium sulphate solution. Fig. I gives curves for the dependence of the surface pressure $F$ on the product $F A$ in a unimolecular layer for trypsin (curve I) and for the trypsin-ergosterol complex (curve II). These curves [26] indicate that the molecular weight of trypsin in the monolayer, as calculated according to the equation of ideal gases from the length of the section $\beta$ between the intersections of the curves with the $F A$ axis, equals 40,000 for trypsin and 80,000 for its complex with ergosterol. Thus just as in the case of egg albumin, trypsin, in forming a complex with ergosterol, produces associates detectable in the monolayer. Special experiments revealed that this complex is maintained during 48 hours at a $\mathrm{pH}$ of $7 \cdot 5-8 \cdot \mathrm{I}$.

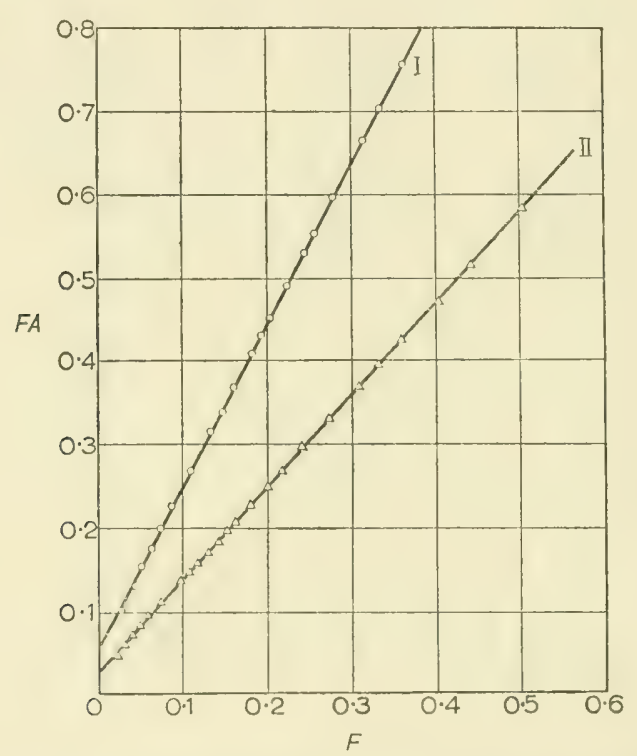

FIG. I. The dependence of the surface pressure $F$ on the product $F A$ in a monomolecular layer for trypsin (I) and for the trypsin-ergosterol complex (II).

The proteolytic activity of trypsin was determined spectrophotometrically according to the Kunitz method [27] at $280 \mathrm{~m} \mu$ and according to a modified Kunitz method at $400 \mathrm{~m} \mu$, as well as by determining the amino nitrogen in the incubated sample according to Van Slyke's method after precipitation by trichloroacetic acid.

Fig. 2 gives curves for the digestion of serum albumin by trypsin (curve I) and by the trypsin-ergosterol complex (curve II) as a function of the amount of enzyme. Here the extinction at $280 \mathrm{~m} \mu$ is plotted against the enzyme-substrate ratio. It follows from these curves that the complex has a higher proteolytic activity than pure trypsin, especially at enzyme/substrate ratios within the range I/200-I/50. Table $I$ lists the results of another experiment. In this case the optical densities ( $\Delta E_{1}$ for trypsin and $\Delta E_{2}$ for the complex) are obtained by subtracting the optical density after 90 minutes of proteolysis from the optical 


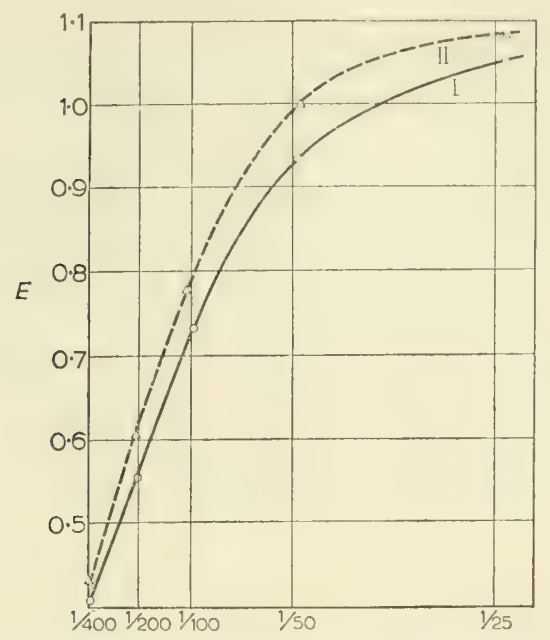

FIG. 2. The digestion of serum albumin by trypsin (I) and by the trypsin-ergosterol complex (II) as a function of the amount of enzyme (see text).

density at zero time. These data are in accord with the experimental results in Fig. 2. On the basis of these data we selected an enzyme/substrate ratio lying between I/50-I/IOO to study the kinetics of proteolysis of serum albumin by trypsin-ergosterol complex.

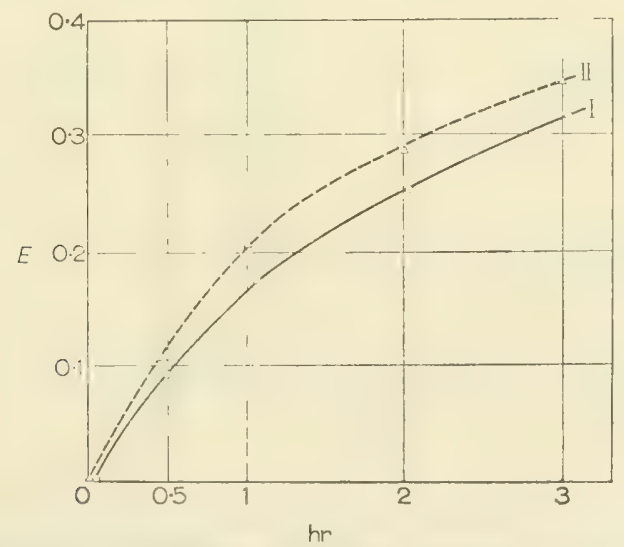

FIG. 3. The kinetic curves for serum albumin proteolysis by trypsin (I) and by its complex with ergosterol (II) obtained spectrophotometrically.

Fig. 3 gives the kinetic curves for serum albumin proteolysis by trypsin (curve I) and by its complex with ergosterol (curve II); the curves are obtained spectrophotometrically. Fig. 4 gives similar curves representing the rates of increase of amino $\mathrm{N}$, as determined by the method of Van Slyke.

Here the volumetric readings in $\mathrm{ml} \mathrm{N}_{2}$ are plotted against the time in hours. From the data of Fig. 3 and Fig. 4 it follows that the formation of the complex appreciably increases the proteolytic activity of the enzyme and the degree of 
substrate hydrolysis. Similar data were obtained by us for the proteolysis by trypsin and by its complex with ergosterol of heat-denatured egg albumin and of casein.

Special experiments have been carried out in order to study the changes in proteolysis of serum albumin by another proteolytic enzyme, viz. pepsin, as dependent on whether pepsin is free or forms a complex with ergosterol. The

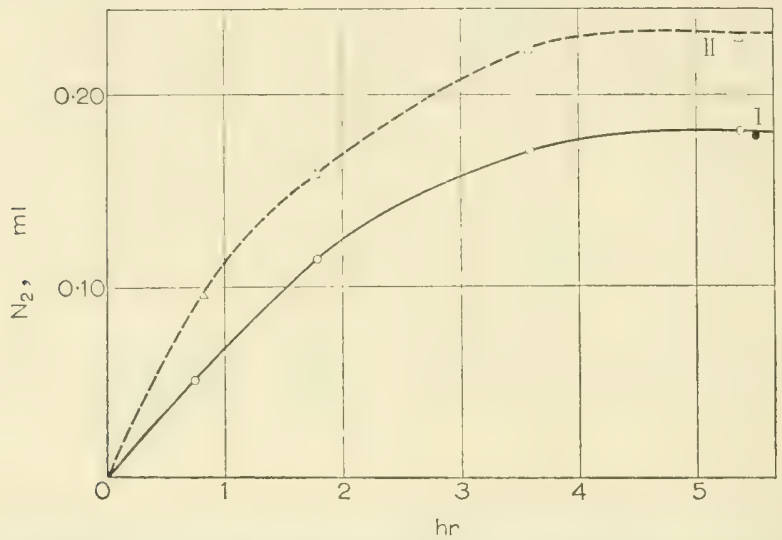

FIG. 4. The kinetic curves for serum albumin proteolysis by trypsin (I) and by its complex with ergosterol (II) determined by Van Slyke's method.

\section{TABLE I}

Activity of trypsin and trypsin-ergosterol complex as a function of enzyme amount

(Determined at $400 \mathrm{~m} \mu$-see text)

\begin{tabular}{c|c|c|c}
\hline $\begin{array}{c}\text { Enzyme/substrate } \\
\text { ratio }\end{array}$ & $\begin{array}{c}\Delta E_{1} \\
\text { for trypsin }\end{array}$ & $\begin{array}{c}\Delta E_{2} \\
\text { for complex }\end{array}$ & $\Delta E_{2}-\Delta E_{1}$ \\
\hline I/400 & 140 & 160 & 20 \\
I/200 & 200 & 230 & 30 \\
I/100 & 275 & 295 & 20 \\
I/50 & 307 & 330 & 23 \\
I/25 & 325 & 360 & 35 \\
\hline
\end{tabular}

results of the experiments, in which the same procedure was used as in trypsin experiments (enzyme/substrate ratio $\mathrm{I} / 500$ and $\mathrm{I} / \mathrm{I000}$ ), showed that with the pepsin-ergosterol complex proteolysis proceeds at a much higher rate than with pepsin alone).

It is concluded, therefore, that the course of proteolysis is changed by the interaction of the enzyme protein with lipid substances. In our view [28], these results indicate that the formation and breakdown of protein-lipid complexes is one of the possible tools for controlling enzymic processes going on within the organism. 
As pointed out above, there are a number of indications that the activity of certain enzymes is altered in the presence of nucleic acids. The study of these phenomena has in the main centred around the rôle of ribonucleic acid and has been carried out, for the most part, at $\mathrm{pH}$ values below the isoelectric point of the enzyme and the substrate. In these conditions, as is known, insoluble nucleoproteins are precipitated, this being the result of the formation of salt-like links between the acid and basic groups of the reactants. We thought that it might be preferable to study the effect of deoxyribonucleic acid (DNA) on the proteolytic process under conditions in which the interaction of DNA with the enzyme does not cause precipitation. Therefore we conducted our experiments at $\mathrm{pH}$ values above the isoelectric point of trypsin and serum albumin, i.e., at the optimum values for proteolysis (phosphate buffer, $\mathrm{pH} 8-8 \cdot 4$ ). The DNA used was obtained

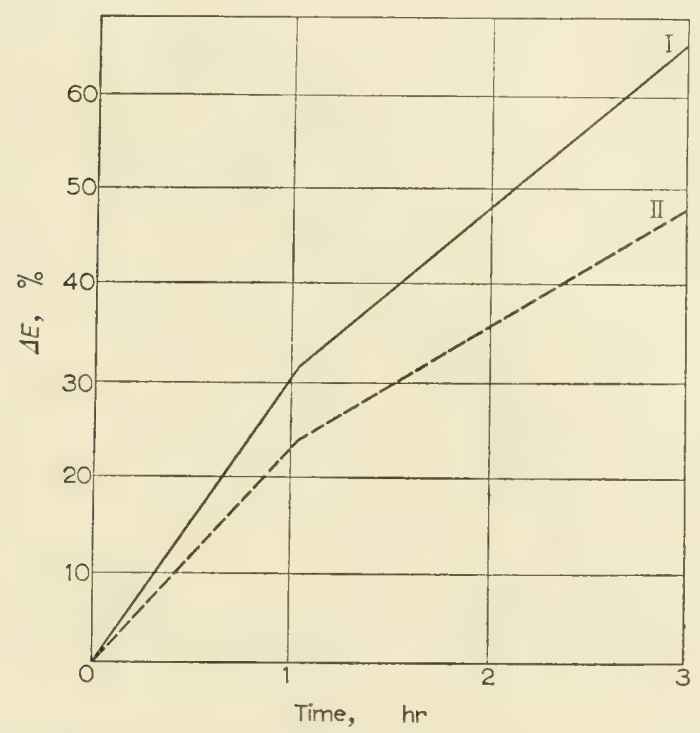

FIG. 5. The kinetic curves for the proteolysis of serum albumin by trypsin (I) and by trypsin with DNA (II).

from calf's thymus. The molecular weight of the DNA, determined viscosimetrically [29] was $0 \cdot 8-\mathrm{I} \cdot 5 \cdot 10^{6}$. The kinetics of proteolysis were determined by the modified spectrophotometric method of Kunitz at $400 \mathrm{~m} \mu$.

Fig. 5 gives the kinetic curves for the proteolysis of serum albumin by trypsin (curve I) and trypsin with DNA (curve II). Here the difference between the initial and subsequently measured value of extinction (the latter in percentages of the initial value) is plotted against the time in hours. It is apparent that in the presence of DNA the proteolytic process is retarded and the degree of hydrolysis decreased.

To gain an insight into the mode of inhibition of proteolysis by DNA we studied the effect of preliminary incubation of the enzyme or substrate with DNA. The curves obtained are shown in Fig. 6. Curve I is for serum albumin 
preincubated with $\mathrm{NaCl}$ for 45 minutes at $37^{\circ} \mathrm{C}$, after which the curve for proteolysis by trypsin (added after preincubation) was plotted. Curve II is for serum albumin preincubated with DNA, after which the course of proteolysis by trypsin was plotted.

Curve III is for trypsin preincubated with $\mathrm{NaCl}$, after which substrate was added and the proteolysis curve plotted then. In the case of curve IV the trypsin was preincubated with DNA, after which proteolysis was plotted for serum albumin. For curves II and IV the amount of DNA was the same and the DNA/ protein ratio was equal to $0 \cdot 066$; the enzyme/substrate ratio in these experiments was $I / 70$.

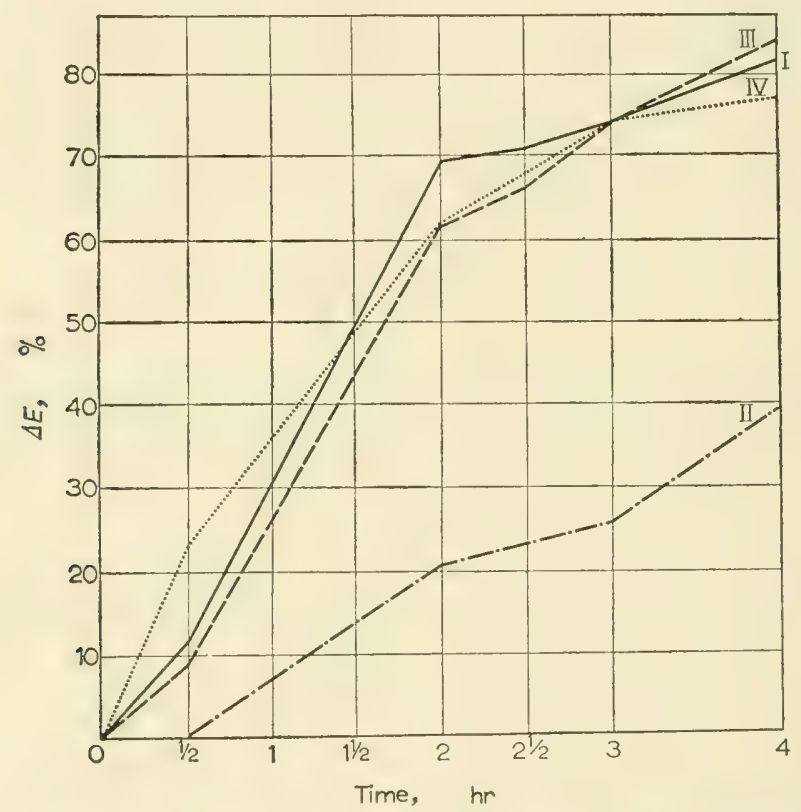

FIG. 6. The effect of preincubation of the enzyme or substrate with DNA on the proteolysis of serum albumin by trypsin (see text)

It follows from the experiment that marked inhibition of proteolysis occurred only if there was preliminary incubation of the substrate with DNA, whereas preliminary incubation of the enzyme with DNA had practically no effect on the kinetics of proteolysis. The conclusion to be drawn from these results is that DNA in the serum albumin-trypsin system affects not the enzyme, but the substrate, producing inhibition of the proteolytic process.

The author of the present paper also studied the influence of DNA on proteolysis at various DNA/substrate ratios. These findings are given in Fig. 7 , where the curve for the proteolysis of serum albumin by trypsin in the absence of DNA served as a control. The DNA/substrate ratio for curves I, II and III is equal to $0.33,0.66$ and 0.99 respectively. It was also found that at a DNA/ substrate ratio equal to $\mathrm{I} / \mathrm{I} 00$ proteolysis is likewise retarded appreciably. 
Inhibition of proteolysis in the presence of DNA was also observed when heat-denatured egg albumin or casein were used as substrates of tryptic hydrolysis.

The experimental results here reported show that enzymic processes in vitro can be affected by the presence in the reaction mixture of small quantities of substances such as lipids or nucleic acids, which are capable of interacting with the proteins taking part in the process. In the highly complex and multicomponent system of the living cell such effects are evidently much more pronounced, and they are made still more complicated by the influence of the numerous interfaces between cellular organoids.

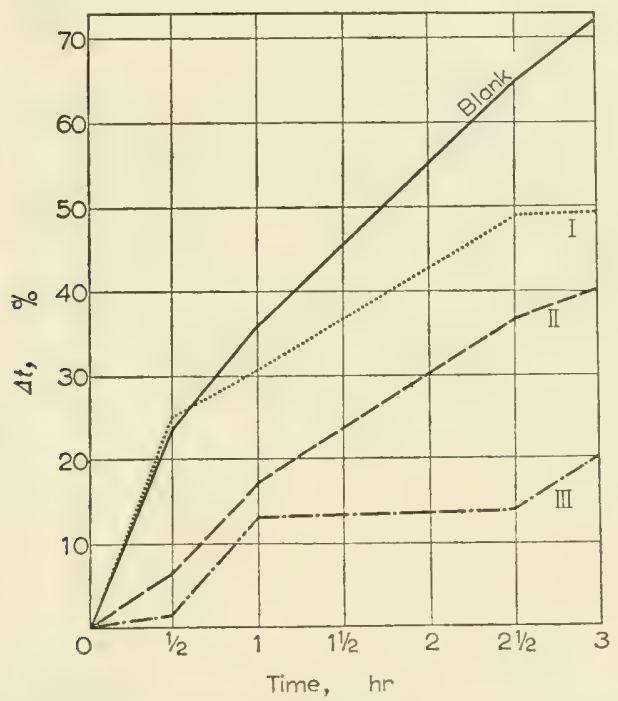

FIG. 7. The kinetic curves for the proteolysis of serum albumin by trypsin at various DNA/substrate ratios (see text).

The author is of the opinion that the formation of complexes by primordial proteins with one another and with other organic substances could have given rise to an enormous variety of compounds and chemical processes which, in the course of subsequent evolution, could have produced various conjugated proteins possessing specific biochemical functions, and could have engendered the whole set of enzymic processes essential to life.

The author wishes to acknowledge the participation of V. Z. Baranova, M. I. Bystrova and $\mathrm{G}$. F. Ivashchenko in the experimental work.

\section{REFERENCES}

I. A. I. Oparn, The Origin of Life on Earth. 3rd. ed. Izd. Akad. Nauk S.S.S.R., Moscow, 1957.

2. D. F. Waugh, Advanc. Protein Chem., 9, 326, 1954.

3. O. P. Chepinoga, Nucleic Acids and Their Biological Significance. Izd. Akad. Nauk Ukr.S.S.R., Kiev, 1956.

4. E. Chargaff, M. ZifF \& D. H. Moore, F. biol. Chem., 139, 383, I94I. 
5. D. F. Dervichian, Discuss. Faraday Soc., 6, 7, 1949.

6. F. Putnam, Advances in Protein Chemistry, 4, 80, 1948.

7. J. Klotz, The Proteins, vol. I. New York, I953.

8. K. Slavik \& R. Smetana, Chem. Listy, 47, 253, 953.

9. O. Chepinoga \& I. Pavlovskiı̆ $Z h$. Biokhem., 28, 308, 1956.

I0. F. Šorm \& M. GRUBEšova, Sborn. chechoslov. khim. Rabot, 20, 53I, 1955.

II. L. Robert \& J. Polonovsky, Discuss. Faraday Soc., 20, 54, I955.

12. S. Spiegelman, in Ionizing Radiations and Cell Metabolism (Ed. by G. Wolstenholme \& C. CopNor). Churchill, London, p. 185, 1956.

13. S. VON PRZYLECKI, Enzymologia, 8, I53, 1937.

I4. R. Tompsett, S. Schulz \& W. MCDermott, f. Bact., 53, 581, 1947.

15. B. Davis \& R. Dubos, f. exp. Med., 86, $215,1947$.

16. P. Bover, G. BAllou \& J. LuCK, f. biol. Chem., I67, 407, I947.

17. H. Bungenderg de Jong, Proc. Acad. Sci. Amst., 45, 601, 1942; 55, 317, 329, 338, $347,360,1952 ; 56,203$, 1953; 57, I, I3, 192, 204, 285, 1954 .

18. H. BooIJ, Discuss. Faraday Soc., 6, I43, 1949.

19. E. PONDER, Discuss. Faraday Soc., 6, I52, 1949.

20. T. Hayashi, Amer. Nat., 87, 209, I953.

21. G. Deborin \& L. Gorbacheva, Biokhimiya, 18, 618, 1953.

22. G. Deborin \& L. Gorbacheva, Dokl. Akad. Nauk S.S.S.R., 95, 317, 1954.

23. G. Deborin \& O. Shibanova, Dokl. Akad. Nauk S.S.S.R., 105, 526, 1955.

24. G. Deborin, M. Bystrova \& G. Ivashchenko, Izv. Akad. Nauk S.S.S.R., Ser. biol., 4, I16, 1956.

25. G. Deborin, Dokl. Akad. Nauk S.S.S.R., 108, 680, 1956.

26. Monomolecular Layers (ed. SовотKA). Washington, 1954.

27. D. Northrop, M. Kunitz \& R. Herriott, Crystalline Enzymes. New York, 1948.

28. A. Oparin, N. Gel'man \& G. Deborin, Arch. Biochem. Biophys., 69, 582, 1957.

29. D. SpITKovSKIĬ, Biofizika, I, 319, 1956. 


\title{
The Relation between Primitive and Present-day Photobiological Processes
}

\author{
C. REID
}

The University of British Columbia, Canada

THE PRIMITIVE photochemical processes which resulted in the syntheses of simple organic compounds on the Earth are not known. In view of the many possible routes it is unlikely that the pathway of molecular evolution, first random and later self-sustaining, that actually led to our present forms of life can ever be reproduced and we have no assurance that such a pathway is unique. However, the comparative ease with which an array of amino acids can be produced from the proposed primaeval atmospheric gases [I] makes it clear that we can follow the early stages of many such simple syntheses.

In setting up conditions for such experiments, the following postulates are fairly generally accepted [2]:

I. Little oxygen, and consequently no ozone layer was present in the atmosphere.

2. Solar energy extending to the neighbourhood of $2000 \AA$ was consequently available. Since such energy is ample for the breaking of almost all chemical bonds, it is in view of the very high flux of solar radiation a more likely choice than atmospheric discharges as the energy source for the chosen process.

3. In the initially reducing atmosphere $\mathrm{NH}_{3}, \mathrm{CH}_{4}$ and water vapour probably predominated, with $\mathrm{H}_{2}$ as a minor constituent; $\mathrm{CO}_{2}$, intermediate oxidation products of methane, and oxygen appeared only at a later stage.

4. In view of the continuous 'trial and error' encounters which must have been necessary, and the hydrated nature of the present-day key biological substances, most of the processes probably occurred in the sea, although the possibility of atmospherically formed and subsequently dissolved primary substances cannot be ruled out.

5. In view of the number of features common to life as we now know it, a common origin is indicated. Any forms of life in which some of these features are absent must be considered as possible representatives of very primitive forms. This points to certain sulphur bacteria, in which sugars found in all other organisms are absent, as the most likely candidates.

\section{GENERAL CONSIDERATION OF PHOTOPOLYMERIZATION}

The continuous making and breaking of bonds under the influence of highenergy radiation provides a perfectly reasonable process for the formation of 
polymeric material. What such a process does not provide in its simple form is a mechanism for the stabilization of any of these polymers. Bonds are being continuously broken as well as formed, and unless the breaking process can be stopped or radicals stable against dissociation are formed, the equilibrium molecular weight must be expected to be rather low.

The stabilization mechanism thus appears as the key step which may have determined the mode of subsequent evolution, determining what kind of molecule may be expected to 'grow'.

\section{Dissociation Prevented}

In polyatomic systems, energy in excess of that required for bond breaking may be present for a finite time before the dissociation actually occurs. This time increases rapidly as the number of vibrational modes in which the energy may be accommodated is increased. If no means of disposing of the excess energy is available, dissociation must ultimately occur, but if some means of energy dissipation within the dissociation time is available, disruption will be prevented. Probably speaking this dissipation may occur in two ways:

(I) The molecule is fluorescent, rapidly re-emitting absorbed light and thus surviving until attacked chemically and increasing its molecular weight. To continue to invoke this process, as the molecule grows larger, means that whereever in the molecule light is absorbed, the excitation energy must be transmitted to a luminescent group. Since we know that there are many more nonluminescent than luminescent groups among biologically important molecules, we arrive at the idea of a trap mechanism within the molecule, followed by a radiative process.

(2) The molecule is exceedingly well coupled to its environment, so that absorbed energy can be lost before dissociation. This is a well-known phenomenon in crystals-including molecular crystals-but again some molecule in the crystalline aggregate probably will be decomposed unless a 'trap' is provided. Dissipation as thermal energy within a crystal is also possible, though in molecular crystals this is usually too slow to prevent dissociation. A similar phenomenon may also occur for the case of a single molecule strongly absorbed on a suitable inorganic crystal, and such a heterogeneous system must be considered as a possibility.

\section{Decomposition Occurs, followed by Recombination}

This kind of mechanism is particularly suited to the condensed state and has been postulated to explain the results of many irradiation experiments. Two possibilities appear:

(a) Ions or radicals are formed, but are unable to move away from each other because of Coulomb attraction, strong absorption, or bulky neighbours (cage effect).

(b) Very long-living radicals are formed which can move apart, but which do not decompose into smaller fragments.

In both these cases excess energy may be dissipated at leisure as vibrational 
energy, and is followed by recombination in case (a) and either recombination or attack on some other molecule, resulting in increased molecular size, in case (b).

If we rule out the possibility of aromatic ions, since we suppose ourselves dealing with the pre-aromatic stage of synthesis, molecules containing - SH groups and $-S-S-$ bonds are the most plausible choices for ion and radical formation respectively. Sulphur compounds could also very reasonably provide the traps required for the nondissociative step mentioned previously. We therefore look very carefully at the role of sulphur in present-day biology.

\section{EVIDENCE FROM EXISTING BIOLOGICAL PROCESSES}

The great importance of such sulphur-containing molecules as coenzyme A, glutathione and SH-enzymes is well known. The problem that confronts us is how to distinguish a primitive process from one of later development. The most reasonable approach appears to be:

Look for common features in natural processes still intimately connected with a light absorption or emission step.

Observe how organisms react to excessive amounts of radiation.

The processes which have so far been examined are set down below.

\section{Photosynthesis}

The generality of the photosynthetic process makes it clear that whereas it is not a primary process (the photosynthetic pigments themselves being more complex than the molecules being considered here, and anyway unable to survive irradiation with $2000 \AA$ light), it does belong far back in the evolutionary sequence. It is therefore reassuring to find $6: 8$-dithio-octanoic acid postulated by Calvin and his co-workers [3] as the most likely electron-acceptor of the photoelectrons formed on irradiation of the chlorophyll grana.

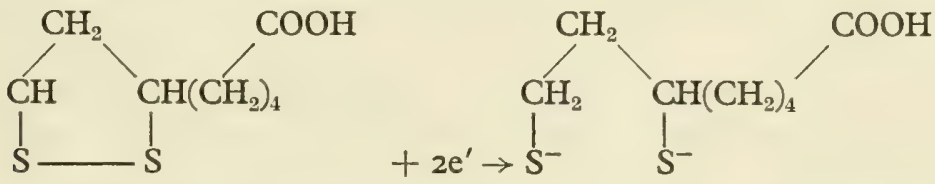

If Calvin's postulated mechanism is correct, the thioctic acid occupies a key position linking the photosynthesis with the Krebs cycle. This seems quite in keeping with the idea that sulphur occupied a key rôle in primitive bioenergetics.

The cytochrome system is not directly concerned with a photo-process, but in view of the structural similarity between the haem and chlorophyll molecules the confirmation of Theorell and his co-workers [4] that the haem is attached to its protein by two cysteine residues provides an interesting connection between the two systems.

\section{Vision}

Wald \& Brown [5] found that the photobleaching of rhodopsin (the proteinretinene compound responsible for rod vision) liberated free SH-groups and that the resynthesis of rhodopsin from retinene and opsin could be inhibited if 
the - $\mathrm{SH}$ group of the opsin were first blocked with $p$-chloromercuribenzoate. It seems very probable therefore that after light absorption, which occurs in the retinene part of the molecule, there is an excited electron in the immediate vicinity of an $\mathrm{SH}$ group or a sulphur bond to the retinene itself. On the exposure of the eye to strong light, changes in retinal $\mathrm{pH}$ have been observed which may well result from a shift in the equilibrium

$\mathrm{RSH} \longrightarrow \mathrm{RS}^{-}+\mathrm{H}^{+}$

which occurs when RSH is electronically excited. It seems clear that here again sulphur plays a key role at a point in the mechanism of vision very close to the photoabsorption step.

\section{Phototropism}

The struggle towards the light must have been one of the earliest survival mechanisms incorporated into living systems and phototropism is therefore relevant to our considerations.

The known 'auxins' are not sulphur-containing compounds. However, it has recently been shown [6] that the auxin naphthaleneacetic acid undergoes a specific reaction with the protein of an enzyme extract obtained from rapidly growing pea seedlings, but that the reaction is prevented if - $\mathrm{SH}$ groups in the enzyme are blocked. This work depends upon the interpretation of absorption spectrum changes of materials in vitro. If this intimate association between the auxin and - SH-containing molecules is confirmed, it provides more evidence that a general pattern of sulphur involvement in photoprocesses can be traced.

\section{Bioluminescence}

Only a very small proportion of living organisms show bioluminescence. In the cases so far investigated (bacteria such as Photobacterium, crustacea such as Cypridina, and the firefly, Photinus pyralis) the processes appear completely different from each other. These two facts suggest that bioluminescence is not part of the common evolutionary pattern, but has arisen accidentally in various quite unrclated species. If this view is correct, it is of much later origin than are the processes involving light absorption. This is consistent with the fact that no special rôle has yet been assigned to sulphur compounds in bioluminescence reactions, although in one case (firefly luciferin [7]) the presence of an - SH group has been suggested.

\section{RADIATION DAMAGE}

For several years it has been recognized that a number of substances can act as partial 'protectors' against radiation damage. Since radiation damage is usually of an oxidative nature, any added reducing material, and thus all organic matter, has some protective effect. Much the most efficient protectors are sulphur compounds [8]. It is of interest that free sulphur ranks with thiourea as one of the most efficient protective agents known. Protection measured in terms of retained activity of extracted enzymes, or of suspended living organisms show essentially the same results. 
In contrast to this finding it is also well established that enzymes, the functional groups of which are thiol groups, are much more readily inactivated by radiation than are nonthiol enzymes [9]. A combination of the two observations suggests that a large proportion of the radiation is trapped by sulphur compounds. If they are essential groups, their efficient trapping power results in severe damage to the system under consideration, but if they are non-essential, as is the case for added protectors, they, instead of more important groups, are ruptured.

A very interesting indication of the rôle of sulphur compounds has come from the work of Gordy et al. [Io]. Their technique was to subject various materials to $\mathrm{X}$-irradiation, and then examine the electron paramagnetic resonance spectra resulting from any electron unpairing brought about by the $\mathrm{X}$-irradiation.

They found the surprising result that all keratin-type proteins (present principally in outer 'protective' layers such as hair, feathers or scales and therefore subject to much radiation normally) showed a spectrum characteristic of only the cystine molecule, in spite of the fact that this amino acid represents only a few per cent of the total protein and therefore is responsible for only a few per cent of the total absorption of X-rays. Here is a clear case of trapping, this time probably via a 'hole' migration mechanism whereby electron loss from anywhere in the protein ends up as electron loss from the $S-S$ group of cystine.

From all of the above considerations it seems reasonable to draw the conclusion that, although many different radiation-absorbing and utilizing molecules have been developed as life evolved the close connection of each of these with the cystine molecule or other reactive sulphur-containing system points to the latter as a component of the primitive photochemical process.

\section{EXPERIMENTAL}

Experiments were carried out using a General Electric I000-w high-pressure arc (AH6 or BH6) as source of illumination. This arc emits about $5 \%$ of its energy as the (strongly self-reversed) $1849 \AA$ line of $\mathrm{Hg}$. Selection of a good arc is important because of absorption in the quartz capillary in some cases. For the same reason the $1849 \AA$ line intensity falls in old lamps faster than does the general intensity. New arcs were used after about 40 hours of operation.

Two systems were employed. If material absorbing at $2537 \AA$ or at longer wavelengths was present, a wide-angle grating monochromator was used with $2 \mathrm{~mm}$ slit width to isolate the $1849 \AA$ line. Using this system only about $0.0005 \mathrm{~W}$ of $1849 \AA$ light reached the sample. This was sufficient to detect, after 300 hours irradiation, amino acid formation from inorganic material, giving weak ninhydrin tests for alanine and glycine.

For most experiments there were no absorbers of $2537 \AA$ present. In these cases direct irradiation of the surface of the liquid with the full arc was employed with an aperture $f=\mathrm{I} \cdot 5$. This gave about $\mathrm{O} \cdot \mathrm{I} \mathrm{W}$ of $\mathrm{I} 849 \AA$ light absorbed by the sample itself. This system had the advantage of giving more products in shorter times, but the disadvantage that absorption of infrared light by the glass vessel used resulted in warming up of the solutions. In these essentially preliminary investigations no attempt was made to control this factor.

Experiments were carried out on two kinds of system. In the first inorganic materials, of the kind expected to be present in the sea in the pre-oxygen era were irradiated in aciueous solutions in the presence of various homogeneous and heterogeneous catalysts which it was expected might significantly affect the amino acid yield. The aqueous solutions were desalted in ion-exchange columns (using $A_{4}$ Duolite resin for anions and Amberlite IR I20 for cations), taken to dryness, the products dissolved in alcohol and chromatographed on Whatman No. I paper, using butanol, acetic acid and water $(4: I: 5)$ as the usual eluting agent. Phenol-water and pyridine-methanol were used for confirmation in some cases. 
In a second set of experiments the solutions were allowed to evaporate completely to dryness under irradiation, and irradiation continued for about I hour after liquid water had disappeared. This resulted in a considerable amount of polymeric material, which was estimated after dialysis in cellophan for 24 hours.

The substances investigated were methanol, formaldehyde, paraformaldehyde, ammonium carbonate, ammonium salts, free ammonia in basic solution, hydroxylamine, nitrites and nitrates. Many experiments were done both in air and in an atmosphere of $\mathrm{CO}_{2}$, with $\mathrm{CO}_{2}$ bubbling through the solution and filling the whole apparatus. Since the amino acid yields were always better under the latter conditions these are the ones reported. The concentrations of reactants were either $10 \%$ or, as in the case of paraformaldehyde, the maximum set by the solubility. Since the question of whether life began in concentrates of inorganic salts or in very dilute solution is unresolved, we saw no reason for working at very high dilutions.

\section{Products}

Apart from hexamethylenetetramine, which formed in large quantities at $\mathrm{pH}>7.5$ when formaldehyde and ammonia were present, and in smaller quantities when they were produced during the photoprocess, only glycine and formic acid were isolated (from the hydroxylamine-formaldehyde $\mathrm{CO}_{2}$, in presence of $\mathrm{Fe}^{+++}$system) in quantity large enough for positive identification ( $0.03 \%$ of $\mathrm{CH}_{2} \mathrm{O}$ was converted to glycine). All other identifications are from $R_{\mathrm{F}}$ values and co-chromatography. So far we have concentrated on amino acids although some spots not due to amino acids are also present. Table I shows the substances so far identified. Table 2 gives the efficiency of the various substances, based on the intensity of the glycine spot.

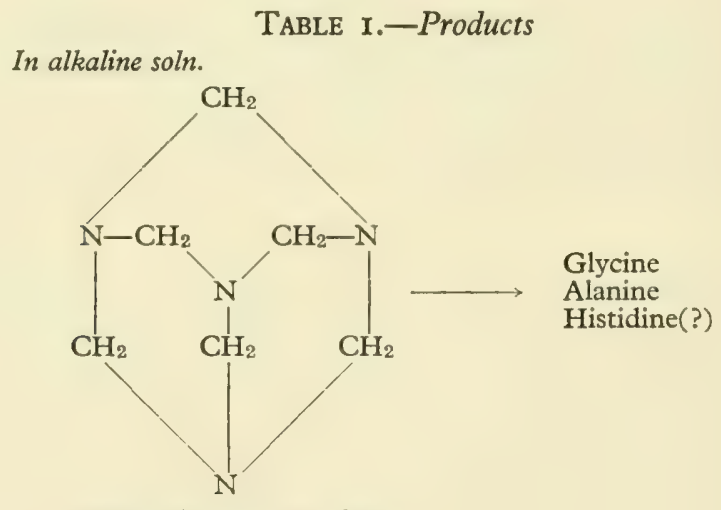

Hexamethylenetetramine

\section{At $\mathrm{pH} 6$}

Glycine

Alanine

Formic acid

Glutamic acid ?

Leucine?

\section{TABLE 2}

\section{Order of efficiency, based on glycine formation}

\section{Source of $\mathrm{N}$}

$$
\begin{aligned}
& \mathrm{H}_{2} \mathrm{CO}+\text { Basic Soln. } \mathrm{NH}_{2} \mathrm{OH}>\mathrm{NO}_{2}{ }^{\prime}>\mathrm{NH}_{3} \\
& \mathrm{H}_{2} \mathrm{CO}+\text { Acidic Soln. } \quad \mathrm{NH}_{2} \mathrm{OH}>\mathrm{NH}_{4}{ }^{+}>\mathrm{NO}_{2}{ }^{\prime}>\mathrm{NO}_{3}{ }^{\prime}
\end{aligned}
$$

\section{Source of C}

$$
\mathrm{HCOOH}>\left(\mathrm{H}_{2} \mathrm{CO}\right)_{n}>\mathrm{H}_{2} \mathrm{CO}>\mathrm{CO}_{2}>\mathrm{CO}_{3}{ }^{\prime \prime}
$$

(For polymer formation $\mathrm{H}_{2} \mathrm{CO}$ best) 
TABLE 3

Effect of catalysts

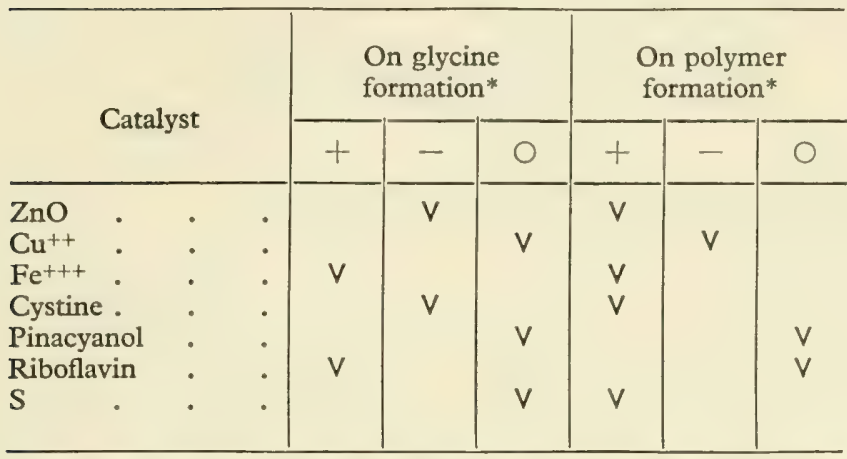

* Note $:+$ denotes quantity at least doubled; - denotes quantity at least halved; $O$ denotes no effect.

In our attempts to find a system in which the amino acid yield was higher we tried 7 catalytic systems, 2 heterogeneous and 5 homogeneous. Their effects are listed in Table 3. A positive effect is recorded where the glycine spot is a factor of 2 more intense than the standard.

In the second kind of experiment we started out with amino acids, and attempted to elucidate the effect of further irradiation on them. To a considerable extent the simple amino acids break down to smaller molecules, glycine and alanine both giving easily detectable amounts of ammonia and $\mathrm{CO}_{2}$.

However, glycine also gives one product in fairly large yield, moving with an $R_{\mathrm{F}}$ of about 0.37 in butanol-acetic acid which we first confused with alanine, but later showed by co-chromatography to be slightly slower. This substance still awaits final identification, but we suggest tentatively that it is glycylglycine. Its formation is increased in the presence of small amounts of riboflavin, but inhibited in the presence of cysteine.

The irradiation of cystine leads first to the formation of cysteine, and then to the formation of a great array of products. Among these some of the amino acids have been tentatively identified, but there are a great number of other types of chemical substance also present.

This result is interesting in view of the result reported by Fox recently of the thermal formation of a similar array of compounds from cystine.

This last result means that if there have been at any time conditions on the Earth under which comparatively large quantities of cysteine or cystine were formed, subsequent radiative or thermal transformations may have led to the production of a great array of small organic amino acids and other functional molecules close to each other. This is presumably the requirement if the very improbable association of a particular set of such molecules is to become significantly more probable.

\section{REFERENCES}

I. S. L. Miller, F. Amer. chem. Soc., 77, 235I, 1955.

2. A. I. Oparin. The Origin of Life, 2nd ed. Dover Publications, New York, 1953.

3. J. A. Barltrop, P. M. Mayes \& M. Calvin, f. Amer. chem. Soc., 76, 4348, 1954.

4. H. Theorel. Lurrents in Biochemical Research (Ed. D. E. GreEN). Interscience, New York, 1956, p. 275.

5. G. Wald \& P. K. Brown, f. gen. Physiol., 35, 797, 195I.

6. E. MARRE, R.C. Accad. Lincei, 18, 88, 1955.

7. B. L. Strehler, The Luminescence of Biological Systems. American Assoc. for the Advancement of Science, Washington, 1955, p. 199.

8. W. M. Dale, Discuss. Faraday Soc., 'Radiation Chemistry', 1952, p. 293.

9. E. S. G. BARRON, Symposium on Radiobiology. John Wiley, New York, I952, p. 216. IO. W. Gordy, W. B. ARd \& M. Shields, Proc. nat. Acad. Sci., Wash., 4I, 983, I955. 


\section{Subject Index}

Acetylene 122

Acids. (See also specific acids e.g. Lactic acid) hydroxy 90, 94, 108

Krebs-cycle 149

organic $87,89-94$

Acrylonitrile 122

Adenosine triphosphate I27, I29, I76

Adsorption, asymmetric 105-I08, III

Alanine. (See also Amino acids) 102, II9, I94

Albumin, serum. (See also Proteins) 182, I83

Aldehydes. (See also Formaldehyde) 89-94

Algae 26, 3I, I42, I44

Alkaloids 78, 79, I09, IIO, II 3

Amide group, planarity 138

Amino acids $35,43,75,87,89,90-94,96$, 98-104, I 16, I36, I49, I 50, I65, I74, I76, 195

aromatic, heterocyclic I2O

natural occurrence I4I-I46

Aminoacetonitrile II6, II 7

Aminonitriles 90

Ammonia 9, I0, 50, 87, 89, 90, 96, I I6, II 7

Ammonium compounds 22, 33, 77, 99, I00, I49, I94

$\alpha$-Amylase 170

$\beta$-Amylase 172

Anabolism 152, 153

Anaemia, sickle-cell I4O

Animals, morphological characteristics I4I

Anions, sources 23

Antibodies 133, 135

Antigens 133

Antipodes 77-79, 106

Archaean stage 25, 26, 28

Arginine. (See also Amino acids) $\mathbf{2 2}$

Aspartic acid II9

peptides 152

Asteroids 47, 49

Asymmetric resolution 81

Asymmetric syntheses $75-76,79-83$, 105II 3

Atmosphere, earth 2, 6, 19, 26, 43, 44, 52, $56,63,69,85,96$, ro2

Mars 13, 50

oxidizing 94

planetary 8-I4

primary $2 \mathrm{I}, 34$

Venus 12, 50

Atoms, aggregation I64
Autocatalysis I26

Auxins 192

Azoprotein I33

Bacteria. (See also Micro-organisms) 43, 64 I42, I43, I44, I72, I92

Basalts I6, 20, 28

Benzylcysteine II 9

Binary star 2

Biochemical processes $148-153,170-178$

Biogenic formations 24

Biological processes I9I

Biological structures 158-169

Biopoesis. (See also Life, origin) 30-45, I $55-$ I 69

Biosphere, origin $15-29$

Bitumens 7 I

Bonds $36,132,138,139,158,165,179,180$ cryohydric and long range forces $\mathrm{I}_{2}$ interparticulate forces, I33, I63

Calcium carbonate 23

Cambrian stage 28,29

Camphor 8I

Camphorsulphonic acid II

Carbamyl phosphate 36

Carboligase I09, II3

Carbon 56 syntheses from $\mathrm{C}_{1} \mathbf{1 2 8}$

Carbon cycle 129

Carbon monoxide 102

Carbon dioxide $21,33,43,50,52,56,63$, $95,127,148$

fixation 36, 129

Mars I3, 50

Venus II, I2, 50

Carbohydrates. (See also Sugars) 23, 26

Carbonates 23, 26

Carelozoon jatulica 26

Catalase 125,173

Catalysis, asymmetric 76, 105-113

Catalysts $35,37,44,124-127,195$

Cations, sources 23

Caustobiolites 7 I

Cells, first I 53 specialization $42,156,158$

Chemical diversity 55-62

Chemical structure I46, I56-I69 theory 139

Chlorine $5 \mathrm{I}$

Chloroplasts I28, I30 
Chlorophyll a $\mathbf{1 2 9}$

Chondrites I6, 20, 50

Clouds, preplanetary 47

Venus II, I2

Coacervates. (See also Eobionts) I70, I7I, $172,173,180$

Coal 66,71

Co-enzymes $35,36,43,44$, I9I

Co-Enzyme A I9I

Collenia walcotta 26

Comets 50

Complementariness I33, I34

Complexes, protein I79-187

Compounds, formation 6 , I8 optically active $74,79-83,105$ organic. (See Organic compounds)

Configurations $39,40,74-75$ polymer 166

Continents, formation 5, 25

Co-ordination number 158

Corycium 58

Cryohydric forces 162

Crypton I, 9

Crystallization I6I, I68 selective 77-79, 107

Cyclohexene I39

Cystine. (See also Amino acids) 193

Deamination 95

Decarboxylase II3

Deoxyribonucleic acid 40,42, 44, I34, I6I, I65, I 85, I 86

Deuterium II

Dipeptides. (See also Peptides, Polypeptides etc.) 149

Dissymmetry $74-83$

Dunites I6, 18, 20

Earth, atmosphere 2, 6, 8, 19, 2 I crust $15-21,66-68,69,71$ development I-6 formation 46-54 heat 16 primitive 86 thermal history 4-6

Earth-Moon system I-2

Electric discharges $86,88,95,98-104$

Electrons 133 acceptors 191

Elements 6, I8, 20, 58

Enantiomorphs 77-79

Energy, chemical potential 127, I75, 176 Earth's formation 4,5 electric discharge 86-92, 98-104 free $32,34,44$ gravitational 8 interparticulate forces 133,162 metabolic 8

migration $130-131$

radiation 37,189

ultra violet $86,95,98-104$
Environment 31, I55

Enzymes. (See also specific enzymes e.g. Esterases) $35,36,37,43,58,83,108-113$, I7I, I72, I76, I9I, I93 evolution 124-13I

Enzymic processes I53

Eobionts. (See also Coacervates) 39, 42, 44 Ergosterol 184

Erosion 6

Esterases IIO, II 3

Evolution 32, 46-48, 58, 60, I31, I39, I46, I55, I70, I90

Fibres 40, 165

Forces. (See also Energy) interparticulate, 133,163

Formaldehyde 34, 99, 100, 104, I16, I94

Fossils $7 \mathrm{I}$

Gases, atmospheric 23, 50

cosmic 18

deposits $65-68,7$ I

escape, from earth I, 9

from Mars 13

from Venus I2

inert 18,19

Gene-enzyme-metabolism I52, I53

Genes I34, I35, I40

Geosynclinals 25

Germanium 59

Glutamic acid 122

D-Glutamic acid I43

Glutamine. (See also Amino acids) 122

Glycine. (See also Amino acids) 87, I94

Granites 5, 16, 20, 25, 68

Haem 125, 129

Haemoglobins I37, I39, I45, I65, I67

Halogens 59

Haptens 134

Heat. (See also Temperature)

earth's 16

earth's formation 4,5

radioactive 4,27

thermal pathways 150

Helices 39, I34, I6I, I62, I66

Helium 2I, 66, 68, 69

Heterotrophs 126

Heterozygotes I39, I40

Hexamethylenetetramine $\times 94$

Hydrocarbons 33, 63, 65-68, 69, 7 I

Hydrogen $\mathrm{x}, 2,3,9,68,69,87,88,94,102$ escape, from earth IO, II, I2 from Mars 13 from Venus I2

Hydrogen bonds. (See also Bonds) I34, I63, I66

Hydrogen cyanide 89, 90-94, I16, II7, 122

Hydrosphere $33,44,52$

Hydroxyproline 142 
Immunochemistry 133

Inactis 26

Insulin $145,159,165,167$

Iodine 60

Ionic forces 163

Ions 125, I27, I90

Iron 5, II $, 26,49,88, I 25, I 27$

Isoleucine. (See also Amino acids) I2I

Isotopes 52, 6I

Jean's formula 9

Jupiter 2, 50

\section{Ketoaldomutase I09, II3}

Lactic acid $8 \mathrm{I}$

Laevulinic acid I 28

Leucine. (See also Amino acids) I2 I

Life, definition 32

geological conditions $63-72$

Mars I4

origin. (See also Biopoesis) 6, 8-14, 26, $46-54,55-62,74-83,85-97$, 156, 189

Venus II, I3

Light, asymmetric syntheses $79-83$

circularly prolarized $75,76,79-83$

photobiological processes I89-195

ultra violet $86,95,98-104,189$

Linkage systems. (See also Bonds) 158, 164

Lipids 4I, 44, I65, I8I

Lipoproteins I80, I8I

Lithosphere 33, 44

Lysine. (See also Amino acids) 122

Macromolecules. (See also Polymers, Proteins etc.) I64

Magnesium 130-13I

Malaria 140

Mandelic acid 106, 107

Margentin 3

Mars 3, I3-I4, 49

Membranes $4 \mathrm{I}$

Meteorites I6, 20, 50-52, 53, 68

Methane 9, 10, 22, 50, 52, 64, 65, 68, 69, 87,88

Methane petroleum 69

Micelles 4I

Mierococcus lysodeikticus 172, I74

Micro-organisms. (See also Bacteria, Organisms etc.) 89, IOI, 102

Mitochondria $43,128,130$

Molecular configurations $39,40,74-75$, I 66

Molecular duplication in living organisms I32-I4O

Molecular evolution 44

Molecular particles I58-169

Moon 2, 3, 49

Multiplet theory Iog
Muscle, fibril 156, I57

Mutants 140

Neptune 50

Nickel 5

Nitrogen 21, 22, 34, 66, 68, 69, 88 bases 134 protein 177

Nitromonas 144

Nucleic acids 39, I34, I36, I64, I65, I68, I85

Nucleoproteins 40,44, I65, I68

Nucleotides. (See also Polynucleotides) 36, 39,43

Oceans, formation $5,6,23$

Mars 13

primary 23

Venus 12

Oil. (See also Petroleum) 65, 71 composition 69 distribution 65-68

Oligomers 165

Opsin I9I

Optical activity $74,79-83,105$

Organelles 4I, 42

Organic compounds $28,33,43,46-54$

origin $85-97,98-104$

spontaneous generation $\mathrm{I}_{48} 8-\mathrm{I} 53$

structural units I56-I69

Organisms. (See also Micro-organisms) 44, $57,95,130$

evolution $28,42,46$, I44

molecular duplication I3I-I40

thermal pathways I5I

Ornithine. (See also Amino acids) $\mathbf{I 2 2}$

Oxidations I2, 34

Oxygen 6, 8, 10, 28, 34, 37, 94, 95, 130 escape, Mars I4

origin 56

Oxynitrilase 109, II3

Ozonizer 88

Particles, units in biopoesis $158-169$

Pasteur effect 75,82

Pepsin-ergosterol complex I84

Peptide chains 116-122

Peptides. (See also Amino acids, Dipeptides, Polypeptides, Proteins etc.) 145, I48, I50, I 52

Petroleum 53, 63-72, 76

Phenylalanine 137

Phosphates $36,39,57,60$, I75, I76

Phosphorylation, oxidative 126

Photobacteria I92

Photobiological processes $189-195$

Photochemical syntheses 127-I3I

Photosynthesis 29, 34, 36, 43, 44, 124-131, I9I

Phototropism 192 
Planets, origin $46-48$

Plants 29, 145

morphological characteristics I4I

Polyglycine II6-II8, I2I

Polymers 82, 160-169, 190

Polymerization $37,38,39,40,116,165,189$

Polynucleotide chains I34

Polynucleotides. (See also Nucleotides) 39, 40

Polypeptide chains $136,137,138$

Polypeptides. (See also Dipeptides, Peptides, Proteins etc.) 143, I66

Porphyrins 43, 69, I26, I27, I28, I30, 165

Potassium 16, 27

Proterozoic stage 25, 26, 29

Protein complexes $179-187$

Proteins. (See also Amino acids, Peptides, Polypeptides etc.) $35,37,39,43,57,74$, I36, I4I, I42, I44, I45, I48, I5I, I59, I64, I65, I66, I67, I75, I76, I77 configuration 167 origin $116-122$

Proteolysis $182,184,185$

Protoplasm 75

Protoporphyrin 127, I28, I29

Protoplasts $175,176,177$

Protozoa 44

Purines $88,139,165$

Pyrimidines 88, 139

Quartz, catalysts II2

Racemates $75,77-79,80$, 105-108, II 3

Radiation 6, Ir, 75, 76, 79-83, 86, 95, $98-$ 104, I 48,189 damage 192

Radicals $37,50,190$

Radioactive decay, earth $4,6,16,18,21$, 52,68

Radiogenic heat 27

Reactions 109, II3 exergonic 33

geochemical 4 prototype 64

Reductase 109, II 3

Reproduction 32, 44, 132

Resonance, theory 138-139

Retinene 192

Rhodopsin I9I

Ribonucleic acid $40,42,44, I 65,180,185$

Rocks 24, 66-68, 69

Rotational moment 2
Saturn 50

Seismology 4

Selection 58,59

Selenium 59

Serine. (See also Amino acids) II9

Sodium chlorate 78

Solar radiation. (See Radiation)

Staphylococcus aureus $\mathbf{1 7} 6$

Starch 172

Strecker synthesis 93, 94, 95

Succinic acid 128

Sugars. (See also Carbohydrates) 165, 172 formation 35, 43

Sulphur 10, 22, 34, 59

Sulphur compounds 24, I9I, I92

Tartaric acid 82

Tectonic processes 3,4

Tectonic structure 65

Temperature. (See also Heat)

earth 52

Mars I3

Venus I2

Thiobacillus thio-oxidans 144

Thioctic acid I9I

Thorium 16, 26

Toxicity 145

Trypsin $182-187$

Trypsin-ergosterol complex I82, I83

Ultraviolet light. (See under Light)

Uranium 16,27

Uranus 2,50

Valine. (See also Amino Acids) I2I

Van der Waal's forces $132,136,162$

Vanadium 59

Venus II-I3, 49

Viruses 4I, I6I, I63, I68

Vision I9I

Volcanic activity $5,19,25,28$

Volcanic gases 68

Vulcanism 3

Water, Earth's 5, 6

Mars I3

Venus I2

Water cycle 6

Water molecules 162

Water vapour 4

Xenon I, 9

X-irradiation 193 




